Andrews University

Digital Commons @ Andrews University

1994

\title{
Validation of Goals for Pre-Departure Missionary Orientation
}

Donna M. Worley

Andrews University

Follow this and additional works at: https://digitalcommons.andrews.edu/dissertations

Part of the Missions and World Christianity Commons, Other Languages, Societies, and Cultures Commons, and the Social and Cultural Anthropology Commons

\section{Recommended Citation}

Worley, Donna M., "Validation of Goals for Pre-Departure Missionary Orientation" (1994). Dissertations. 1561.

https://digitalcommons.andrews.edu/dissertations/1561

https://dx.doi.org/10.32597/dissertations/1561

This Dissertation is brought to you for free and open access by the Graduate Research at Digital Commons @ Andrews University. It has been accepted for inclusion in Dissertations by an authorized administrator of Digital Commons@ Andrews University. For more information, please contact repository@andrews.edu. 


\section{Andrews \$university}

Seek Knowledge. Affirm Faith. Change the World.

Thank you for your interest in the

\section{Andrews University Digital Library of Dissertations and Theses.}

Please honor the copyright of this document by not duplicating or distributing additional copies in any form without the author's express written permission. Thanks for your cooperation. 


\section{INFORMATION TO USERS}

This mamuscript has been reproduced from the microfilm master. UMI films the text directly from the original or copy submitted. Thus, some thesis and dissertation copies are in typewriter face, while others may be from any type of computer printer.

The quality of this reproduction is depeadent upon the quality of the cops submitted. Broken or indistinct print, colored or poor quality illustrations and photographs, print bleedthrough, substandard margins, and improper alignment can adversely affect reproduction.

In the unlikely. event that the author did not send UMI a complete mamuseript and there are missing pages, these will be noted. Also, if unauthorized copyright material had to be removed, a note will indicate the deletion

Oversize materials (e.go, maps, drawings, charts) are reproduced by sectioning the original, beginning at the upper left-hand corner and contiming from left to right in equal sections with small overlaps. Each original is also photographed in one exposure and is included in recuced form at the back of the book

Photographs included in the original mamuscript have been reproduced xerographically in this copy. Higher quality $6^{\prime \prime} \times 9^{\prime \prime}$ black and white photographic prints are available for any photographs or illustrations appearing in this copy for an additional charge. Contact UMI directly to order.

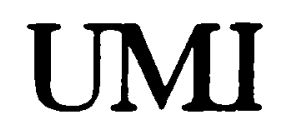

A Bell \& Howell Information Company 300 Nortn Zeeb Road. Ann Arbor. MI 48106-1346 USA

313:761.4700 800:521.0600 
Reproduced with permission of the copyright owner. Further reproduction prohibited without permission. 
Andrews University

School of Education

\title{
VALIDATION OF GOALS FOR PRE-DEPARTURE MISSIONARY ORIENTATION
}

\author{
A Dissertation \\ Presented in Partial Fulfillment \\ of the Requirements for the Degree \\ Doctor of Philosophy
}

by

Donna M. Worley

December 1994 
DMI Number: 9531163

Copyright 1995 by Worley. Donna Maurine

All rights reserved.

UMI Microform 9531163

Copyright 1995, by UuI Conpany. All rights reserved.

This nicroform edition is protected against unauthorized copying under Title 17, United States Code.

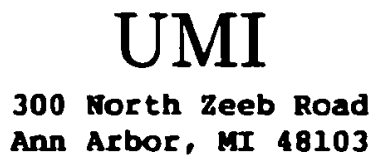

Reproduced with permission of the copyright owner. Further reproduction prohibited without permission. 
- Copyright by Donna M. Worley 1995

All Rights Reserved

Reproduced with permission of the copyright owner. Further reproduction prohibited without permission. 


\title{
VALIDATION OF GOALS FOR PRE-DEPARTURE \\ MISSIONARY ORIENTATION
}

\author{
A dissertation \\ presented in partial fulfillment \\ of the requirements for the degree \\ Doctor of Philosophy
}

by

Donna M. Worley

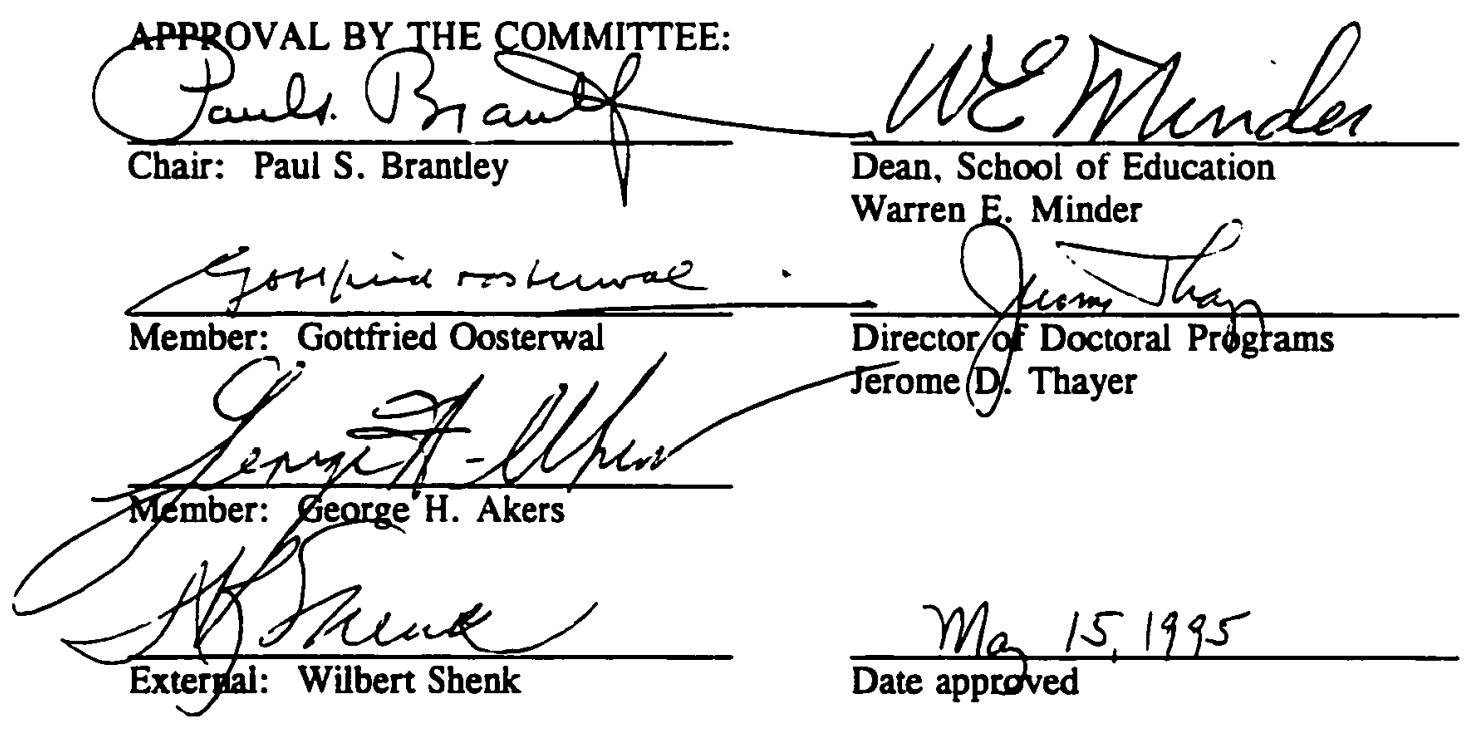




\section{ABSTRACT \\ VALIDATION OF GOALS FOR PRE-DEPARTURE MISSIONARY ORIENTATION}

by

Donna M. Worley

Chair: Paul S. Brantley

Reproduced with permission of the copyright owner. Further reproduction prohibited without permission. 


\title{
ABSTRACT OF GRADUATE STUDENT RESEARCH \\ Dissertation
}

\author{
Andrews University \\ School of Education
}

\section{Title: VALIDATION OF GOALS FOR PRE-DEPARTURE MISSIONARY ORIENTATION}

Name of researcher: Donna M. Worley

Name and degree of faculty chair: Paul S. Brantley, Ph.D.

Date completed: December 1994

\section{Problem}

Cross-cultural orientation programs facilitate missionary preparedness.

Orientation is more effective if driven by valid and suitable goals determined before methods are selected and programs implemented. This study attempted to identify valid goals for pre-departure programs and develop a framework for selecting them.

\section{Method}

The goals of the Seventh-day Adventist (SDA) Institute for World Mission (IWM) were selected for validation. IWM is a 4-6 week pre-departure orientation 
program that started in 1966 and had effectively prepared 2,500+ cross-cultural missionaries by 1993. Their goals are broad areas suitable for establishing sub-goals and objectives.

The validation process comprised four phases: identification and clarification of goals, collection of data from six validation sources, synthesis/analysis of data for cross-validation, and a reconceptualization of findings into a framework to guide determination/evaluation of suitable goals.

A combination of documentary, statistical, and analytical techniques was used to treat the data from six sources: three case study populations (staff/attendees, leaders, and current/retumed missionaries); and three external sources (missionary preparation literature and practice, cross-cultural literature, trends/issues).

\section{Results}

All IWM's goals were validated directly or indirectly by the six sources. Goals were considered appropriate (important, essential, and relevant) by $96 \%$ or more of the entiusiastic case populations. No essential goals are missing, although women's/children's preparation and leaming-to-leam skills need greater emphasis.

\section{Conclusions}

Orientation contributed to cross-cultural personnel preparation in 12 critical goal areas: cross-cultural awareness and skills/competencies, a sense of call/commitment, spiritual formation/growth, essential emotional/attitudinal growth, cultural understanding from area studies and mission issues, knowedges and practices important for new roles and psychological/physical health, familiarity with 
the sending organization information about philosophy/practices/policies, a paradigm shift for continuing growth through the rransformation of the mind/worldview, and fellowship which is a critical program goal for achieving an orientation purpose. Several other conclusions related to effective future preparation.

Although IWM is more effective than might be expected because of valid goals, focus on participant readiness, and orientation purpose, it could improve if goal implementation were expanded to before and after the orientation program. 
In loving dedication to my God and my family worldwide

for the completion of the task-revealing the lovely Christ

iii

Reproduced with permission of the copyright owner. Further reproduction prohibited without permission. 
TABLE OF CONTENTS

LIST OF FIGURES $\ldots \ldots \ldots \ldots \ldots \ldots \ldots \ldots \ldots \ldots \ldots \ldots \ldots$

LIST OF TABLES $\ldots \ldots \ldots \ldots \ldots \ldots \ldots \ldots \ldots \ldots \ldots \ldots \ldots$

A.CKNOWLEDGMENTS $\ldots \ldots \ldots \ldots \ldots \ldots \ldots \ldots$ xiii

Chapter

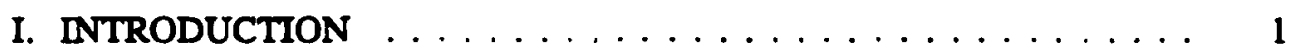

The Problem $\ldots \ldots \ldots \ldots \ldots \ldots \ldots \ldots \ldots \ldots$

Purpose of the Study ................. 9

Significance of the Study . . . . . . . . . . . . 9

Conceptual Foundations of the Study $\ldots \ldots \ldots \ldots \ldots \ldots 10$

Conceptual Foundations in the Literature . . . . . . . . . 23

Research Rationale for the Study . . . . . . . . . . . . 28

Definition of Terms . . . . . . . . . . . . . . 31

Delimitations ...................... 34

Limitations $\ldots \ldots \ldots \ldots \ldots \ldots \ldots \ldots \ldots \ldots \ldots$

Organization of the Study $\ldots \ldots \ldots \ldots \ldots \ldots \ldots \ldots$

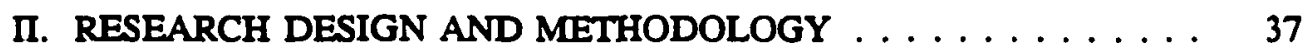

Case for Analysis: The Seventh-day Adventist

Institute of World Mission $\ldots \ldots \ldots \ldots \ldots \ldots \ldots, 41$

History of Seventh-day Adventist Mission . . . . . . . 43

History of the Institute of World Mission . . . . . . . 52

Phase One: Identification and Clarification of Program Goals . . . . 54

Phase Two: Validation From Several Sources .......... 59

Source 1: Observation of Program in Operation ........ 60

Sources 2 and 3: Survey of Administrative Stakeholders and Criterion Populations $\ldots \ldots \ldots \ldots \ldots \ldots \ldots$

Construction of the Instrument $\ldots \ldots \ldots \ldots \ldots \ldots 62$

Selection of the Populations . . . . . . . . . . 65

Collection and Evaluation of Data $\ldots \ldots \ldots \ldots \ldots 6$

iv 
Source 4: Review of Missionary Preparation . . . . . . . 67

Source 5: Summary of Cross-cultural Literature . . . . . . 69

Source 6: Discussion of Trends and Issues in Missionary

Preparation . . . . . . . . . . . . . 70

Phase Three: Synthesis of Sources for Cross-validation . . . . . 70

Phase Four: Reconceptualization of Program Goals . . . . . . $\quad 70$

Summary $\ldots \ldots \ldots \ldots \ldots \ldots \ldots \ldots \ldots \ldots \ldots \ldots$

III. PRESENTATION AND ANALYSIS OF FINDINGS FROM

VALIDATION SOURCES 1 TO 3:

CASE STUDY POPULATIONS $\ldots \ldots \ldots \ldots \ldots \ldots \ldots \ldots$

Source 1: Observation of the Program in Operation ........ 74

Development of Institute of World Mission's

Purpose and Goals . . . . . . . . . . . . . . 74

Orientation Program Purpose . . . . . . . . . . . 76

Historical Development of Institute Goals . . . . . . . . . 86

Summary of Development of IWM's Purpose and Goals . . 100

Summer Session, Institute of World Mission:

June 13-July $15,1989 \ldots \ldots \ldots \ldots \ldots \ldots 1$

Schedule and Goal Implementation . . . . . . . . . . 102

Goal Implementation Observation . . . . . . . . . . . . . 106

Attendee Evaluation Responses . . . . . . . . . . . 110

Evaluations of Summer, $1989 \ldots \ldots \ldots \ldots$. . . . . . 111

Evaluations of 17 Other Sessions . . . . . . . . . 114

Summary and Analysis of Findings From Source 1:

Staff/Attendee Views . . . . . . . . . . . 116

Sources 2 and 3: Survey of Administrative Stakeholders

and Criterion Populations . . . . . . . . . . . . . 120

Population Groups . . . . . . . . . . . . . . 121

Questionnaire Retum Rates . . . . . . . . . . . . 122

Population Demographics ... . . . . . . . . . . 125

Missionary Demographics . . . . . . . . . . . . . 126

Perceptions of IWM Goal Validity . . . . . . . . . . . 128

Goal Statements and Validation Categories . . . . . . . 128

Validation Category Number 1:

Are IWM Goals Appropriate? . . . . . . . . . . . 130

IWM goals are perceived to be important . . . . . 130

IWM goals are perceived to be essential . . . . . . 132

IWM goals are perceived to be relevant $\ldots \ldots \ldots \ldots \quad 135$

Summary: IWM goals are appropriate . . . . . . 135

Validation Category Number 2:

Are IWM Goals Possible? . . . . . . . . . . . . . 137 
Most IWM goals are perceived to be clear . . . . . . . .

Whether most IWM goals are measurable is unclear . .

Most IWM goals are perceived to be

feasible and attainable .............. 143

Summary: Most IWM goals are possible ... . . . . 143

Validation Category Number 3:

Were IWM Goals Attained? . . . . . . . . . . . 146

IWM goals attainment is observable . . . . . . . . . . 146

IWM goals are perceived achieved and applied . . . . 148

Nature of IWM goals attainment . . . . . . . . . 152

Validation Category Number 4:

Are the 12 Goals Comprehensive

Enough to Achieve the Aim? . . . . . . . . . . . 157

IWM goals are expected ................ 158

IWM goals are perceived to be comprehensive .... 159

Respondent Comments . . . . . . . . . . . . . . . . 159

Response Consistency .................... 163

Summary of Findings From Sources 2-3

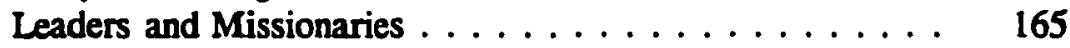

Validation Categories . . . . . . . . . . . . . . 166

Validation of Individual IWM Goals . . . . . . . . . . . 172

Relative Contribution of IWM Goals to Orientation . . . . . 174

Comparison of Leaders' and Missionaries' Views . . . . . . 176

\section{PRESENTATION AND ANALYSIS OF FINDINGS FROM}

VALIDATION SOURCES 4 to 6:

LTERATURE, PRACTICE, AND TRENDS . . . . . . . . . 178

Source 4: Review of Missionary Training . . . . . . . . . . . 178

Historical Development of Missionary Preparation Goals . . . . 179

Paul and Pre-Modem Preparation ............ 179

Rise of Planned Missionary Preparation . . . . . . . . . 181

Post-World War $\Pi$. . . . . . . . . . . . . . . . . 183

Post-war Trends Affecting Preparation .......... 186

Missionary Preparation Literature . . . . . . . . . . . . . 189

Literature Publication Overview ............ 190

Preparation and Personnel Retention ... . . . . . . . . 194

Effective Orientation Program Practices and Goals . . . . 196

Characteristics of Missionary Effectiveness

and Success $\ldots \ldots \ldots \ldots \ldots \ldots$

Goals of Missionary Orientation Programs ......... 203

Missionary Internship Orientation ... . . . . . . . 203

Missionary Agency Director Responses . . . . . . . 206 
Source 5: Summary of Cross-Cultural Literature . . . . . . . 210 Historical Overview of Cross-Cultural Programs and Goals . . 212 Cross-cultural Training Goals . . . . . . . . . . . 217

Cross-cultural Training Goal Categories . . . . . . . . . . 217

Source 6: A Discussion of World Trends and

Preparation Issues $\ldots \ldots \ldots \ldots \ldots \ldots \ldots \ldots \ldots \ldots$

World Trends and Preparation . . . . . . . . . . 223

A New Millennium . . . . . . . . . . . . 223

Changing Values . . . . . . . . . . . . . . . 227

Technology, Transportation, and Communication . . . . 227

Globalization . . . . . . . . . . . . . . . . . 229

Religion and Renewal . . . . . . . . . . . . . 230

Population and Poverty . . . . . . . . . . . . 231

Political Stability . . . . . . . . . . . . . . . . 232

Missionary Preparation Issues $\ldots \ldots \ldots \ldots \ldots \ldots \ldots . \ldots . \ldots 233$

Meeting Preparation Needs $\ldots \ldots \ldots \ldots \ldots \ldots .233$

Structures and Support . . . . . . . . . . . . 235

North American Personnel . . . . . . . . . . . . . 237

Complex Preparation Needs . . . . . . . . . . . 239

Selection vs. Preparation . . . . . . . . . . . . 242

Missionary Role . . . . . . . . . . . . . . . . . . 246

Design Issues . . . . . . . . . . . . . . . . . . . 248

Comparison of Extemal Sources: Sources 4 to $6 \ldots \ldots \ldots 250$

V. CROSS-VALIDATION AND RECONCEPTUALIZATION

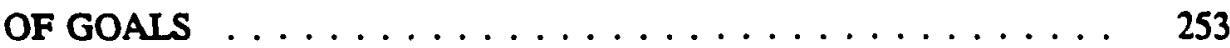

Phase Three: Cross-Validation of Goals From a

Synthesis of Six Sources $\ldots \ldots \ldots \ldots \ldots \ldots \ldots \ldots$

Overview of Findings . . . . . . . . . . . . . . . . 254

Synthesis and Analysis for Individual Goals . . . . . . . . 268

Validated List of Goals . . . . . . . . . . . . . . . . 279

Phase Four: Reconceptualization of Program Goals . . . . . . 286

VI. SUMMARY, CONCLUSIONS, AND RECOMMENDATIONS $\ldots 301$

Summary $\ldots \ldots \ldots \ldots \ldots \ldots \ldots \ldots \ldots \ldots \ldots \ldots$

Background and Problem . . . . . . . . . . . . 301

Research Procedures . . . . . . . . . . . . . . . . . 303

Research Findings $\ldots \ldots \ldots \ldots \ldots \ldots \ldots \ldots \ldots$

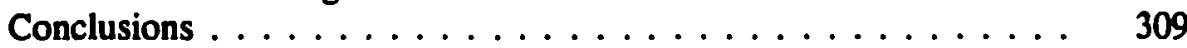

IWM Orientation . . . . . . . . . . . . . . . . 309

Conclusions Related to IWM Effectiveness . . . . . . . . 309

vii 
Conclusions Related to Suitability of Goals . . . . . . . . 311

Conclusions Related to the Research Study . . . . . . . . 313

Missionary Orientation Preparation .............. 314

Conclusions Related to Orientation Programs . . . . . . 315

Conclusions Related to Suitable Preparation Goal Areas . . 316

Conclusions Related to Planning Principles for

the Future $\ldots \ldots \ldots \ldots \ldots \ldots \ldots \ldots$

Recommendations ........................ 322

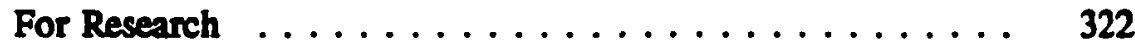

For Missionary Cross-Cultural Preparation . . . . . . . . 324

For Institute of World Mission . . . . . . . . . . . . 326

Appendix $\ldots \ldots \ldots \ldots \ldots \ldots \ldots \ldots \ldots \ldots \ldots \ldots \ldots \ldots$

A. QUESTIONNAIRES . . . . . . . . . . . . . . . . . . 329

B. IWM SESSION SCHEDULE, SUMMMER $1989 \ldots \ldots . \ldots \ldots$

C. ADDITIONAL TABLES ................ 346

D. LETTERS ............................. 360

BIBLIOGRAPHY $\ldots \ldots \ldots \ldots \ldots \ldots \ldots \ldots \ldots \ldots \ldots \ldots$

VITA $\ldots \ldots \ldots \ldots \ldots \ldots \ldots \ldots \ldots \ldots \ldots \ldots \ldots \ldots$

viii

Reproduced with permission of the copyright owner. Further reproduction prohibited without permission. 


\section{IIST OF FIGURES}

1. Goal Validation Process for Research Study $\ldots \ldots \ldots . \ldots \ldots$

2. A Comparison of North American IWM-prepared, Non-prepared, and Non-North American Missionaries . . . . . . . . . . . . . 49

3. Steps to Guide the Determination of Orientation Program Goals . . . . 292

4. Matrix for Determining Goals From General and Specific Preparation Needs . . . . . . . . . . . . . . . . . . . 294

5. Matrix for Assigning Goals to Preparation Phase . . . . . . . . . . 295

6. Matrix for Expanding Goals to Sub-goal/Objective Levels . . . . . . . . 297

7. Matrix for Determining Goal/Sub-goal Delivery Strategies . . . . . . 298

8. Matrix for Prioritization of Goals/Sub-goals . . . . . . . . . . 300 


\section{LIST OF TABLES}

1. Kohl's Delineation of Four Preparation Approaches

Examined in Five Aspects ..................

2. Comparison of Goals: Annual Council Recommendations and Early Institutes . . . . . . . . . . . . . . . . 89

3. Curriculum Categories and Time Distribution for Goal Implementation 103

4. Institute Program Schedule of Activities by Curriculum Category . . 104

5. A Comparison of Evaluation Questionnaire Objectives and IWM Clarified Goals . . . . . . . . . . . . . .

6. Numbers and Distribution of Respondent Questionnaires . . . . . . 121

7. Goal Statements With Corresponding Number and Key Word . . . . . 129

8. Relative Importance of the 12 IWM Goals as

Perceived by the Total Population ............... 131

9. Perceptions of How Essential IWM Goals Are . . . . . . . . . . . . . 134

10. Perceptions of How Relevant IWM Goals Are . . . . . . . . . . . 136

11. Ranked Means for How Appropriate IWM Goals Are . . . . . . . 138

12. Perceptions of How Clear IWM Goals Are . . . . . . . . . . . 140

13. Perceptions of How Measurable IWM Goals Are . . . . . . . . . 142

14. Perceptions of How Feasible IWM Goals Are ... . . . . . . . . 144

15. Perceptions of How Attainable IWM Goals Are ........... 145 
16. Number of Respondents Reporting Evidence of Attendees' Attainment of Each Goal . . . . . . . . . . . . 147

17. Perceived Achievement of Goals at IWM Orientation . . . . . . . . 149

18. Perceived Application of Goals in the Field . . . . . . . 150

19. Perceived Level of Mission Service Effectiveness (MSE) Reached and IWM Contribution to MSE . . . . . . . . . 152

20. Factors Contributing to Mission Service Effectiveness (MSE) Level . . 154

21. IWM Aspects Contributing to Training Effectiveness (MSE) Level . 156

22. IWM Goals That Respondents Did Not Expect or Would Not Have Expected . . . . . . . . . . . . 158

23. Perceptions of How Comprehensive IWM Goals Are . . . . . . . 159

24. Representative Respondent Suggestions for Improving IWM Missionary Preparation . . . . . . . . . . . . . 161

25. Means of Validation Characteristics for IWM Goals . . . . . . 173

26. Goals Ranked by Characteristics From Highest to Lowest Means . . 175

27. Responding Mission Agencies: Orientation Length and Goals Perceived Most Important . . . . . . . . . . . . 208

28. Overview of Findings From Six Validation Sources Pertinent to Goals Determination . . . . . . . . . . . . 255

29. Comparison of the Five Highest Goal or Goal Category Responses in Seven Questionnaire Analyses . . . . . . . . . 257

30. Relative Importance of Goal Categories Prioritized From Most/Least Important According to Five Data Sources . . . . . 260

31. Original Goal Statements and Findings From Research . . . . . . 280

32. Original and Modified Aim and Goal Statements $\ldots \ldots \ldots \ldots . . .282$ 
33. Illustration of IWM Goals Expansion to Sub-goal Level:

Important Skills Identified in Research . . . . . . . . . . . 284

34. Sample Scenario: Suggested Primary Delivery

Options for IWM Goals . . . . . . . . . . . . . . . 285

xii

Reproduced with permission of the copyright owner. Further reproduction prohibited without permission. 


\section{ACKNOWLEDGEMENTS}

Without the encouragement and support I have received from professors, family, and friends, I would likely not have completed a dissertation. To them all, I am most indebted. God never once failed to answer with the needed direction, support, and courage to hang on--though in the wisdom of His timing not mine.

Dr. Paul Brantley, my chairperson, deserves "the Gold" for the marathon patience and guidance he endured during the 26 miles. His contribution to the conceptual framework was invaluable. Dr. Oosterwal was not only a brilliant guide and mentor, but an inspiration par excellence. I have Dr. Akers to thank for even beginning a doctoral program. His contribution was always positive and encouraging with advice that was succinct and wise. Dr. Thayer was the smiling everything-all-thetime glue that kept the process together and headed in the right direction, and his confidence in my completion encouraged perseverance. Janelle McCoy was a gentle friend as she reminded me of deadlines in very caring and optimistic ways. And Dr. Chace is that giant who bridged the gap between stalemate and progress at a very critical time.

To my husband, Richard, I owe a debt I could not begin to repay. My only prayer is that his unselfish sacrifice will be repaid by the God Who enabled it. And a special thanks goes to each of our daughters, Celina, Clarissa, Darchelle, and Alicia who never failed to express "You can do it, Mom!" in numerous and creative ways.

xiii 


\section{CHAPTER I}

\section{INTRODUCTION}

"The world is shrinking at an incredible rate. . . . Isolation is unthinkable" (Singer, 1988, p. 3). American business acknowledges the trend toward globalization, recognizing the claim that the United States is "no longer economically self-sufficient or capable of commercial isolation. International commerce is vital to American prosperity" because it affects the economic health of "the entire nation" (Copeland \& Griggs, 1985, p. Xv). Yet, there is growing concem that the United States is becoming less able to effectively compete economically and politically in the world arena, and that American "success abroad is hindered by a failure to understand how cultures differ" (Weaver, 1988; Copeland \& Griggs, 1985, p. xxi).

Experts agree that Americans in particular appear to have difficulty understanding cultural differences, and they have acknowledged this failure in many fields (Hall \& Gudykunst, 1989). Bamum and Wolniansky (1989) stated that "nowhere do Americans pay so dearly for our cross-cultural ignorance as in our international negotiations. . . . We often gloat over our perceived victories without any idea of the mistakes we have made and the consequences we have yet to pay 
for" (p. 55). A study sponsored by the Southern Governors Association found American students "internationally illiterate." The Association criticized the educational system for failing to prepare students for today's realities. It "wamed that the United States is increasingly at a disadvantage . . . and that our nation has paid, and continues to pay, a high price for our international ignorance" (Weaver, 1988, p. 107).

Most theorists believe that cross-cultural understanding and functioning are not instinctive but must be learned (M. Bennett, 1986). It is possible to learn through on-field experience without training, but this laisse-faire approach has proven to be costly. Most persons need specific and well-planned information and leaming opportunities to enable and speed up satisfactory adjustment. Globalization has multiplied the need for more effective programs to improve intercultural communication and understanding, tolerance, and acceptance.

The importance of preparation for cross-cultural interaction is demonstrated by the identifiable and measurable losses when none exists. For instance, Copeland and Griggs (1985) estimated that 20-50\% of all multinational company employees sent overseas with no training or orientation return prematurely, a percentage that rises to as high as $70 \%$ for employees working in developing countries. "The cost of training is inconsequential compared to the risk of involving people who do not have the required skills and sensitivities" and fail to achieve their objectives (p. 1). 
The number of programs is multiplying to meet the demand for preparing intermational workers. In the rush to provide preparation, it is important that evaluation be used to determine what is cost effective. As in most other areas of endeavor, accountability is valued and expected. Wight and Boyle (1978) stated: "The rapid change, problems we face, and ambitious goals we have set have resulted in complex, costly programs competing for limited, and perhaps diminishing resources" (p. 1). They pointed out that we need to recognize "the need for sound evaluation to assist in selecting, developing, and improving those programs that accomplish the most with the most economical use of resources" (p. 1).

In the dramatic process of globalization, American ethnocentrism is a potentially serious roadblock to success. The need for training and its significant results affirm the importance of cross-cultural preparation. Effective global service results in successful task achievement, personal growth and satisfaction, host national acceptance, and a positive contribution to the foreign society. Mission organizations, along with business, government, and education, should continue to design and improve cross-cultural preparation programs to maximize success.

\section{The Problem}

Most North American missionaries receive some form of preparation before service. Such preparation may include both formal and non-formal opportunities. Formal preparation includes education, intemship, training, and orientation. Education may consist of a diploma, baccalaureate, or graduate degree 
in mission. Some prospective missionaries obtain a liberal arts undergraduate education with mission training that begins thereafter. Some take advantage of non-formal opportunities, such as correspondence courses, missions conferences, and seminars. One example is Urbana, a young adult missions conference that is held every 3 years and attracts up to 19,000 persons. Most missionaries receive at least some form of pre-departure orientation required by the sending organization, and perhaps additional orientation after entry into the field and/or in connection with reentry into North America. Many go on to obtain post-graduate preparation, and/or attend short seminars or institutes during furlough that focus on specific topics such as particular people groups.

However, most missionaries do not receive optimum preparation. One challenge for planners of missionary preparation is how to meet the needs of a diverse missionary population. The required time, cost, and opportunity for receiving all of the above kinds of preparation make it more suitable for career missionaries who are declining in number. Meanwhile, many short-term volunteers or intentional laypersons, whose numbers are increasing, have little preparation suitable for them. Every person who is interested in contributing to world evangelization should have at least a minimum preparation for the cross-cultural mission task appropriate for his/her level of involvement.

Another problem arises because many agencies provide only a limited portion of their own preparation or orientation and thus have difficulty designing and providing what their appointees need. Furthermore, some sending organizations 
have trouble finding suitable orientation programs. For example, some of the missionary training centers that provided quality pre-departure orientation in the past (such as Missionary Training Center, Stoney Point, NY) have closed within the last 10-20 years. Because there is often no clear recognition of a missionary's preparation needs, planning is at times haphazard, incomplete, or non-integrated; or it is not based on the real needs of those receiving the preparation or the context they will enter. Gaps or overlaps result (Peters, 1990). All Christians who serve across cultural boundaries should have as complete and appropriate a preparation as possible. Thus, much room for improvement exists despite the increasing number and types of preparation opportunities available.

Another difficulty facing planners and trainers is securing valid data with which to design missionary preparation. More than 15 years ago, Dowd (1978) lamented that "there seem to be quite a few models of training and case histories available but this knowledge is not being effectively shared" (p. 130). I discovered the truth of these words when I attempted to review missionary preparation literature. Dowd called for training model validation and program evaluation for missionary training (1978). Since then, a few studies have made their contribution, but challenges arising from the demands of both the immediate and long-range future urge another serious response.

A solid research-based approach to missionary preparation is needed. Even though missionaries have a longer history than any other group who has been prepared for cross-cultural service (Cleveland, Mangone, \& Adams, 1960, p. 264), 
there is a deficiency in formal research and theory building to improve the burgeoning practice. There has been little research in any missionary preparation aspects, and virtually none that has studied the development of the purposes and goals necessary to guide orientation.

Finally, cross-cultural preparation programs benefit from informationsharing. It is true that missionary work and its purposes differ substantially from that of business, government, or any other form of cross-cultural occupation. Missionaries are agents of change that ultimately impact the culture they enter. Furthermore, the sources for both personal and evangelistic change go beyond mere human endeavor; a major source centers in the supernatural. Yet, part of the need for a research-based response could be met by applying findings from general crosscultural preparation research and practice to the missionary context. Likewise, missionary preparation principles and practices could make a valuable contribution to the understanding of general cross-cultural effectiveness. However, missionary preparation has tended to be isolated from other types of cross-cultural preparation (Steffen, 1993). Much more should be done to tap this rapidly expanding resource even though its application is not directly related to nor adequate for missionary orientation needs.

Finding an answer to how to improve missionary preparation could be approached in many ways. This study is based on three assumptions that have shaped its focus. 
1. Valid goals should be identified prior to selecting strategic, flexible, and economical strategies to implement them, including those that use the technological advances of the 1990s and beyond.

2. Pre-departure orientation is critical to successful cross-cultural transition and ultimately to effective service. The preparation cycle of missionaries spans the entire time of their service, beginning with recruitment. Preparation's three phases include pre-departure, in-service, and re-entry. The particular focus of this study is the pre-departure phase. Because most formal educational preparation is obtained prior to recruitment and varies widely, this study centers on what preparation goals are suitable to prepare missionaries for entry into their field of service after appointment.

3. A goals focus and framework to guide the determination of goals for pre-departure orientation would make a contribution to both theory and practice.

In summary, the world is rapidly becoming a global community. This fact impacts many American organizational efforts, including those in ministry endeavors. Well-designed preparation for personnel who will work across cultural boundaries improves the communication, interrelations, and satisfaction of persons from both cultures. At the same time, it enhances technical success and reduces work-related failures and early withdrawals.

The preparation of missionaries could be improved. The diversity of prospective missionaries, their appointment needs, as well as the programs available to prepare them are orientation preparation problems that need to be addressed. The 
difficulty of securing research-based data to guide planning preparation presents a challenge. This research study was conducted because there is an undeveloped knowledge base for making missionary preparation decisions, and because current orientation programs must plan with a future perspective in mind. As previously indicated, effective yet creative preparation for Christians serving in cross-cultural contexts is critical at this time.

Pre-departure orientation for cross-cultural Christian ministry is an essential part of the preparation of personnel for world evangelization. The establishment of valid goals is an essential part of any planned leaming. Without valid goals, the effectiveness of the entire orientation program may be compromised.

Until recently, the process of goal-setting in general cross-cultural predeparture orientation has received little attention. In the 1970 s and 1980s, goal lists were not uncommon, but there was little correspondence among them. Individuals might think they were more similar to objectives without the behavioral dimension. Furthermore, most training models originated from particular strategies or groups of strategies. A lack of information on how to determine valid goals systematically also made planning difficult. A different view of cross-cultural preparation for ministry would give rise to altemative ways of planning preparation and orientation programs. Absence of formal research on goal-setting has inhibited the comprehensive understanding necessary for systematic program planning.

To capture the essence of the problem, this paper explores orientation program goal suitability and determination in light of practice and research. It also 
addresses the trends and issues arising from the milicu to help us understand how they impact missionary preparation. It is essential to keep current goals responsive to trends so that they will remain relevant.

\section{Purpose of the Study}

The purpose of this study was to identify suitable goals for preparing cross-cultural missionaries for departure, and consider how to determine them. A validation of the goals of a representative and comprehensive orientation program case was conducted to achieve this purpose. A four-phase process was designed for conducting this validation. This goals validation study will provide an opportunity for further development of normative, research-based strategies by which organizations may identify goals that are needed to orient personnel for crosscultural service.

\section{Significance of the Study}

The results of this research study will assist organizations responsible for missionary preparation to design their goals in such a way that they will meet the varying needs of cross-cultural workers today and tomorrow. The study will also make a contribution to the fields of both missionary and general cross-cultural preparation through its focus on goals and a research method that combines theoretical and empirical data for program planning.

An immediate result of the study will be the benefit to the General Conference of Seventh-day Adventists and Global Strategies Committee as they seek 
to address personnel preparation needs for the strategic initiatives being designed and implemented. It will also benefit the Seventh-day Adventist (SDA) Institute of World Mission (TWM), the comprehensive missionary orientation program selected as the case for study. Because formalized goals research has not been conducted for the Institute, findings will advance evaluation of the existing program and aid in the devising of future preparation strategies. The study could also help determine the degree of legitimacy the Institute's goals have from church leadership, missionaries, other missionary training programs, and literature. A final benefit will come from the evaluation of program effectiveness as indicated by the perceptions of Institute participants and observers in the field.

\section{Conceptual Foundations of the Study}

The challenge of preparing personnel for effective cross-cultural service is primarily an educational issue. It requires systematic planning, which necessitates viewing the entire preparation as a whole. Because cross-cultural functioning is a complex and sometimes difficult process, planning randomly on the basis of intuition, instinct, or experience is not responsible (Paige, 1986b, p. 4). Nor will planning based on tradition, profntype, pragmatics, imagination, or whim guarantee program success. Although there are numerous ways to acquire preparation, training and orientation programs are among the most important strategies for meeting the pre-departure preparation needs of cross-cultural workers. This section 
summarizes pertinent concepts relevant to missionary preparation, particulariy predeparture orientation.

Systematic planning is possible and effectual, but demands a consideration of numerous variables. Kohls (1987) suggests several: "composite profile of the participants," goals, use, degree of expected integration into the foreign culture, maximum amount of pre-departure time for preparation, how much of the preparation must occur before departure and what can be continued in-field, cultural similarity between native and target country, context for the leaming, overall flexibility of the learning population, resource constraints, and sponsor expectations and requirements (pp. 100-101).

The determination of goals for cross-cultural preparation is an essential step in the planning process, and is indispensable to effective preparation. The importance of goals in planning cross-cultural preparation is underscored in the literature (J. Bennett, 1986; Brislin \& Yoshida, 1994; Martin, 1986; McCaffery, 1986). Goals are believed indispensable to efficient and effective planned learning. In fact, the development of goals is not simply one of the chronological steps in the process of developing a plan for learning, but the step that prescribes the parameters for every other. Martin (1986) states that unintended and counterproductive outcomes may be the result of planning without explicit goals and objectives. Even though there are numerous causes for program failure besides faulty goals, there cannot be optimum program results without valid goals. If goals were the conceptual theme around which issues of content, methods, learning and delivery 
formats, scope and sequence, and individualization were organized, the field of cross-cultural preparation would have a more solid basis upon which to build theory. The term goal must be clearly conceived and defined in a technical sense because it is often used vaguely or casually (Nunes, 1987). A few examples illustrate the variety of uses in cross-cultural training literature. Goal is used to denote a category for content organization, a program approach, a leaming methodology, or the purpose of the preparation. An example of varied use in a single source is found in J. Bennett's insightful article on the importance of a multidimensional training approach (1986a). She uses "goal" loosely to describe its nature by referring to three learning dimensions of trainees: cognitive, affective, and behavioral or skill (p. 130). Actually, she believes goals should be classified in these three categories to ensure an integrated training approach. A page later in her article, she uses "goal" to express the dimensions collectively: a "multidimensional approach should be the stated goal" of cross-cultural programs so that there is no "accident of inconsistency" (p. 131).

The definition of goal given by Webster's Third New International Dictionary is an "end toward which effort or ambition is directed: aim, purpose . . . a condition or state to be brought about through a course of action" (Grove, 1986). For educational use, a typical definition of goal is "a broad or general statement reflecting the ultimate ends toward which the total educational program is directed" (Beane, Toepfer, \& Alissi, 1986, p. 116). 
A discussion of several characteristics of goals will contribute to a clarification of the concept. First, goals refer both to directions that guide the movements of learning toward points or outcomes, as well as those points or outcomes. Thus, a goal includes movement toward the accomplishment of an end even if the "end" is not reached. This point is important when considering goals pertaining to human growth and change, learning that is seldom concluded.

Goals should be understood in a curricular sense. Three major components of leaming programs are purposes/goals, methods/strategies, and evaluation; goals direct the strategies designed to achieve them, and evaluation determines the extent of that achievement. Goals are a part of the purpose component which includes aims, goals, and objectives. Purpose can be understood technically as a range of content from broad ideals to immediate objectives, and direction from real to ideal. The problem is that the term goal is often mistakeniy used interchangeably with aim and objective. All three terms are "statements of human intent, but they are written at quite different levels of specificity" (Davies, 1976, p. 22). Aim is the broadest and most long-ranged term. Objectives are the narrowest, and are often used to state the specific behavior expected and the level to be reached. In this way, objectives become the bridge uniting the goals and methods. Goals are an expansion of the aim into general parts that enable the aim to be operationalized by the objectives. As such, goals include both general and specific qualities, a fact that makes them difficult to conceptualize and operationalize. 
Planning is future-oriented by nature and requires this forward thrust through goals. Accelerating change suggests that planning is important to meet future needs, "to bring the context of the future into the present and make decisions about that future now" (Beane et al., 1986, p. 1). Davies (1976) pointed out that it would be difficult to have clear goals if the idea of the future and its demands were unclear. Toffler concluded that "all education springs from some image of the future. If we lack a clear vision of the future we seek, we lack both the goals and guidelines that help us to reach them" (cited in Shane, 1977, p. 14). Goals enable us "to command the future rather than be commanded by it" (Davies, 1976, p. 4).

Goals usually require implementation methods that utilize more than one learning domain, a fact especially true for the human growth learning required by successful cross-cultural functioning. Leaming domains include cognition, affect, skills, and other behavioral indices such as perception. The more learning domains utilized by an individual goal, the more effective the leaming, retention, and transfer will be.

All goals should be verified, modified, and kept relevant in order to keep the program on track. Of course there is no point in using goals that have not first been determined to be worthwhile for the program's purpose. Guidelines for validation are straightforward; goals should be kept relevant and appropriate, should satisfy the participants, and should be possible as well as challenging enough to maintain leamers' attention. They should be long term and semi-permanent. 
Further, if goals are determined by valid means, they will not need continual revision. Frequent revision should be made at the sub-goal and objectives levels.

Goals should be needs-based. Before designing the desired preparation, planners should know the needs of those for whom it is to be designed. These needs form the foundation for determining the goals that should guide a preparation process. One of the most versatile and useful procedures for determining valid goals is needs assessment. Technically, a need is defined as a "gap between the way things 'ought to be' and the way they 'are'" (Burton \& Merrill, 1991, p. 21). A gap implies a discrepancy, value judgment, and the possibility of error.

Needs assessment is defined as a "systematic process for determining goals," a "process for determining what should be taught" (Burton \& Merrill, 1991, p. 18), and "the process of determining goals, measuring needs, and establishing priorities" (p. 23). Needs analysis is considered the "first step in any systematic approach" because it is the process of understanding the problem (p. 18). A chapter entitled "Leam Before You Leap" portrays the role of needs assessment in planning training (Margolis \& Beil, 1989, p. 11).

Data for determining needs and then goals should come from valid sources. Davies stated that choosing sources is the most important question to consider (1976). Major sources for determining needs are either directly or indirectly from people. The needs analysis process must get the desired information by eliciting valid responses from all relevant groups. This analysis may include data from observations, task analyses, research, or theories about how a person interacts 
with others, the job/task, environment, circumstances, and experience. The most obvious persons to question are the program participants and those who have functioned as cross-cultural missionaries. Needs assessment can even be used to individualize the orientation program for the particular participants in attendance.

As many relevant sources and procedures as possible should be used for optimum understanding of what the needs are. Input should come from all aspects and persons that are in some way involved or affected by the training, such as the program, the trainer, the trainee, responsible organization, and the job/task and its context. Data from important groups and individuals may be obtained by means of interviews, work samples, questionnaires, group discussion, tests, observations, and records/reports. In fact, one advantage of assessing the needs of participants in a given program is providing them a "sense of personal investment" (Brislin \& Yoshida, 1994, p. 19). Other sources are the print media, work samples, key consultants, and records/reports. Needs assessment can be improved in several ways: making sure the sample size is large enough, the results are specific enough to design relevant programs, and the approach is suitable for the situation (Margolis \& Beil, 1989).

Goals may be stated from several points of view: the director/staff view (what they will teach), the participant (what participants will learn or achieve), and the program (what the program will accomplish). Program needs, perhaps the broadest, should also reflect the organization's philosophy and strategies for training. Program needs are modified or limited by the program purpose (the basic 
center around which the entire leaming experience is organized) which governs the goals to be included in the program. (The goal statements in this study are stated from the program perspective, which is centered on participant needs, and organized around an orientation purpose.)

Training and orientation are among the most important types of crosscultural preparation; in fact, they are essential for adequate preparation. They are not only valuable because they intensify and accelerate the learning process, or the unleaming process, but because they may determine whether some of the necessary changes will take place at all. They are more focussed, flexible, and can more easily accommodate methods for growth and experiential learning.

After all preparation needs have been clarified, but before making a final decision about which to select, the analyst should determine which needs are caused by a lack of trainee knowledge or skills and thus suitable for training. Some needs result in performance difficulties that may not be amenable to training (Margolis \& Beil, 1989). Planners should remember that a program is not necessarily the only or best form of intervention necessary (Silberman \& Auerbach, 1990). Neither should it be assumed "that all discrepancies in student performance can best be reduced by instruction" (Burton \& Merrill, 1991, p. 35). In some cases, extemal conditions inhibit or nullify even effective instruction, so preparation may require a solution that first removes these conditions (p. 35). Systematic planning requires that the selection of each goal for a program should take place only "when the trainer is 
convinced that training is the most appropriate way to overcome a current or anticipated shortfall in performance" (p. 26).

Cross-cultural preparation planning should proceed only after the needs that have been identified are formulated into goals essential for effective crosscultural functioning. When all data from the needs analyses have been collected, treated, and modified by limitations and constraints, the resulting needs thus identified are ready to be applied in the process of goal selection and program design.

The final step in systematic, comprehensive, and goals-based needs assessment is organizing the goals identified by the analysis process. This task requires three decisions: designation of each goal to the most appropriate phase(s) of the preparation cycle, assignment to the most appropriate delivery format within each phase, and selection of the program purpose.

The first decision designates each goal to its most appropriate preparation phase(s). Authorities believe cross-cultural preparation should be continuous and can be viewed as cyclical. In missionary preparation, there are three major phases in the cycle: pre-departure, in-service, and re-entry. The initial phase, predeparture preparation, begins with creating an awareness of mission among the people groups from which prospective candidates will be selected. It is continued by those who have a sense of call and may prepare themselves through formal education from a Bible college, liberal arts institution, specialized training, or advanced work in missiology. Recruitment, assessment, selection, appointment, 
training, and orientation follow. The next phase occurs after departure, in a designated location and/or in the country of appointment and includes post-arrival preparation and continuing education in the country and/or on furlough. The third and final phase prepares the cross-cultural worker to re-adjust to the home context. The second decision determines how the goals will be implemented, for they can be achieved in many ways. In addition to mission education and orientation, preparation may come from informal programs and independent or individualized opportunities. Many prospective missionaries have had experiences that contribute to their preparation. Perhaps the most significant is previous experience in a foreign context as a child of missionaries, traveler, student missionary, or former missionary. Other experiences include such activities as attending seminars and conferences, reading, watching/listening to video/audio cassettes, and visiting with those who have been or are cross-cultural workers and/or nationals. Only those goals that are best implemented in a program format, or have not been met otherwise, should be designated for the program. Finally, they should all fit the purpose of the particular program.

To complete this conceptual foundation, the terms training, orientation, and education are delineated. Clear terms and concepts are very important in the cross-cultural preparation field because their meanings vary, yet they are often used interchangeably, inconsistently, or inaccurately in a technical sense. This lack of precision is sometimes a cause of confusion that, along with the wide variety of 
models, approaches, and the contrasting assumptions that underlie them, inhibits conceptual clarity and theoretical development.

Training and orientation have a variety of meanings in the literature. They are used interchangeably by some cross-cultural and missionary trainers to refer to any type of cross-cultural preparation programs, or to refer to distinct but varying types of preparation. Martin (1986) and Paige (1986b) use training to refer to the entire process of preparation; they see no end to cross-cultural adjustment.

J. Bennett (1986), however, says that orientation deals with the "who, what, when, and where" of preparation, but training goes a step further by including the "how," and education is the broadest term because it includes the "why." Bennett cuts across conceptual distinctions, however, when she advises that all sojourner preparation should include some education, as well as training, and orientation that emphasizes "survival" information (p. 118).

Paige (1986b) refers to cross-cultural orientation as preparation, training, and support (p. v). He believes that cross-cultural orientation "has been viewed, with some justification, as an elementary form of cross-cultural training, organized around limited goals and objectives, implemented by quasi-professionals, and conducted with minimal time and minimal resources" (p. 1). He believes, however, that Bennett's view of orientation is too limited, and "the most sophisticated orientation programs could as easily be referred to as cross-cultural training or education" (p. 2). 
Another variation is the extent of preparation meant by the sender or receiver of the term. Even if used interchangeably, training and orientation do not usually refer to the same degree of preparation. For instance, training is often seen as longer and more specific in content than orientation, which is viewed as very short. A training or orientation program may last a couple of hours, weeks, or months, but it is seldom comprehensive in content even when it refers to the entire preparation. Cross-cultural preparation in general is comprised of content relating to cross-cultural functioning, although it may include survival and logistic information. Some preparation programs include moving details, and continue orientation in the country of assignment with mentors and other forms of planned transition guidance.

The term orientation often refers to preparation that occurs just prior to departure. This preparation is an attempt to get sojoumers in a state of readiness to enter the cross-cultural context. It may be limited to practical moving and transition information, may include preparation for dealing with culture shock, or may even include cross-cultural skills such as adjustment and communication. Its focus might be predominantly integrative. To the extent possible, the program should provide for all pre-departure preparation needs that have not yet been met.

In his useful article, Kohls (1987) provided a discussion of several experts' uses of these terms (Gudykunst \& Hammer, 1983; Harrison \& Hopkins, 1967), then clarified four major preparation terms on the basis of five descriptors that point out the differences. Table 1 is a modification of a chart prepared by Kohls to define these four primary terms. 
TABLE I

KOHLS' DELINEATION OF FOUR PREPARATION APPROACHES EXAMINED IN FIVE ASPECTS

\begin{tabular}{|c|c|c|c|c|c|}
\hline Type" & Application & Purpose & Methods & Time & Delivery \\
\hline Ed & $\begin{array}{l}\text { Knowledge content, } \\
\text { variety, quantity, and } \\
\text { in-depth mastery }\end{array}$ & $\begin{array}{l}\text { Develop mind, impart or } \\
\text { acquire knowledge to use } \\
\text { or just to learn }\end{array}$ & $\begin{array}{l}\text { Teacher passes info, } \\
\text { likely by lecture format, } \\
\text { with assignments, exams }\end{array}$ & $\begin{array}{l}\text { Longest: lifelong or } \\
\text { degreed, usually divided } \\
\text { into segments or units }\end{array}$ & $\begin{array}{l}\text { Educators, teachers, } \\
\text { professors, others, often } \\
\text { with advanced degrees }\end{array}$ \\
\hline $\mathrm{Tr}$ & $\begin{array}{l}\text { Specified objectives, } \\
\text { competency development, } \\
\text { cost-effective }\end{array}$ & $\begin{array}{l}\text { Achieve practical results: } \\
\text { objectives clearly stated, } \\
\text { predetermined, measured }\end{array}$ & $\begin{array}{l}\text { Participant-centered with } \\
\text { clear ends; experiential \& } \\
\text { practical methodologies }\end{array}$ & $\begin{array}{l}\text { Medium length: I day to } \\
2 \text { weeks, or several } \\
\text { courses in } 3.6 \text { months }\end{array}$ & $\begin{array}{l}\text { Trainers, facilitators, } \\
\text { trainees; developed by } \\
\text { subject matter experts }\end{array}$ \\
\hline Or & $\begin{array}{l}\text { Non-threatening prep for } \\
\text { shift to effective new- } \\
\text { environment functioning }\end{array}$ & $\begin{array}{l}\text { "Orient" for effective } \\
\text { functioning in new } \\
\text { situation or environment }\end{array}$ & $\begin{array}{l}\text { Begins where participants } \\
\text { are for orientation shift, } \\
\text { using various methods }\end{array}$ & $\begin{array}{l}\text { Short: usually from } 1 / 2 \\
\text { day to } 1 \text { week in length }\end{array}$ & $\begin{array}{l}\text { Designated by function: } \\
\text { "program coordinator", } \\
\text { or "session leader" }\end{array}$ \\
\hline Br & $\begin{array}{l}\text { Broad overview, or } \\
\text { particular program focus, } \\
\text { time-effective }\end{array}$ & $\begin{array}{l}\text { Provide background info, } \\
\text { a topic, or a situation } \\
\text { concisely, and with focus }\end{array}$ & $\begin{array}{l}\text { Systematic, organized, } \\
\text { simplified, sequenced, } \\
\text { presentation \& discussion }\end{array}$ & $\begin{array}{l}\text { Shortest: from } 10-15 \mathrm{~min} \text {, } \\
\text { up to } 1 \text { or } 11 / 2 \text { hours }\end{array}$ & $\begin{array}{l}\text { Experts who are usually } \\
\text { incumbents in in-house } \\
\text { positions }\end{array}$ \\
\hline
\end{tabular}

Note. Modified from a chart in "Four Traditional Approaches to Developing Cross-cultural Preparedness in Adults, " by L. Robert Kohls (1987) in

Intemational Journal of Intercultural Relations, II(1), pp. 89-106. $\quad$ Type: Ed = Education, $\mathrm{Tr}=$ Training, $\mathrm{Or}=\mathrm{Orientation,} \mathrm{Br}=\mathrm{Briefing}$. 
In the field of cross-cultural preparation for missionaries, the term education usually refers to formal training in colleges or universities. As terms, pre-departure training and orientation are often used interchangeably, but orientation will likely refer to that preparation occurring after appointment. Orientation is a more comprehensive form of preparation than is usually meant in general crosscultural preparation literature. The average depth of preparation, and time spent, is normally greater, and provided by more than a single program. Currently, preparation for missionaries likely includes some degree of formal missionary and cross-cultural education after which both training and pre-departure orientation follow. These may be continued even in the foreign field. Pre-departure orientation also often includes individualized leaming opportunities in the form of reading lists, handbooks or manuals constructed by the sending agency, introductions to the history and policies of the organization, and perhaps language learning.

\section{Conceptual Foundations in the Literature}

This validation study approaches preparation from the perspective of personnel needs, program purposes, and goals, rather than from methodologies. It assumes that each preparation need (goal) has cognitive, affective, and behavioral dimensions, even though the balance of these three dimensions within each goal is unique to that goal/need. The study also assumes that these dimensions should be reflected in the methods of implementation rather than be used to organize goals. Conceptually, this view contrasts with the frequent use of these three dimensions to 
categorize goals. Thus, this perspective provides a view of cross-cultural training that should contribute to an enlarged conceptual understanding of preparation.

There has not been much discussion in the literature about the definition, nature, or determination of goals for cross-cultural preparation. Wight and Boyle (1978) confirm the need for program goals to guide program planning, but alert the reader to several potential problems. For instance, the program should not be so narrowly goal-focussed that unanticipated outcomes or consequences arise, or worse, are not recognized. Goals should not be vague, as they believe many are, nor should they be unrealistic. Actual goals should be clearly stated; if developing a positive attitude is a direct goal, it should be stated and its achievement evaluated. Wight and Boyle (1978) suggest that some of the more nebulous goals should be looked upon as benefits or desired outcomes rather than as prescribed or actual outcomes (pp. 4-16).

Paige and Martin (1983) also criticize the misuse of goals. They believe many goals are ambiguous because they are defined in broad, vague terms, then used inappropriately as objectives. Furthermore, ambiguous goals are impossible to effectively evaluate. They also feel that program planners or trainers who set confusing goal statements are better off without them if they believe the desired learning is taking place as a result of having identified and stated them. Often goals are simply general themes, and are not developed beyond that form. These facts are a part of the reason Paige and Martin believe categorizing goals in the three domains mentioned above is useful and common; it is a safer solution to organize desired 
goals in the three-domain categories (cognitive, affective, behavioral) to aid decision making and encourage the conceptualization of cross-cultural leaming as a multifaceted phenomenon.

There are no clearly articulated comprehensive theories underlying current cross-cultural programs (Gudykunst \& Hammer, 1983, p. 121). Most attempts to bridge theory and practice have been in the form of classifications of design and other descriptive aspects of training. Such descriptive categories include program type (largely based on methodology used or training techniques), purposes and goals, training methods and activities, trainee and trainer characteristics, risk elements, behavioral requirements for participation, and/or the learning environment (Paige \& Martin, 1983).

Program types are often identified as traditional academic coursework, human relations training, Intercultural Communication Workshop, culture-general simulations, self-awareness model, area orientation briefings, language training, and cultural assimilator, among others. Each of these implies and functions on the basis of method which generates different purposes/aims, goals, and consequent objectives.

Program considerations (besides those of methodology) that affect goal selection and implementation include program content selection, the prioritization and sequencing of goals, as well as timing of the program. For example, if the trainee's departure date is over 6 months away, he/she is very interested in preparation for adjustment, communication, relationships, and understanding the 
contrasts between the home and host cultures. From 6 months until departure, trainee interest in these topics decreases. Instead, survival information becomes the priority (Gudykunst \& Hammer, 1983).

Intercultural effectiveness (ICE) is one category of cross-cultural research that informs preparation needs. It also represents part of the tension between personnel selection and preparation issues. If success could be accurately described or predicted, more permanent personal characteristics would guide selection, leaving those more appropriate for leaming goals more obvious. Personnel selection concerns are very important and arise from two facts: the critical role of the individual in success or failure, and the tremendous cost in time and money for preparation and failure or premature retum (Kealey \& Ruben, 1983). However, there is no clear distinction between trait and leaming aspects of cross-cultural preparation.

The field of intercultural effectiveness is not entirely without helpful information, however. Kealey and Ruben (1983) outline a "profile of the effective working individual overseas" as well as one for the nonworking spouse (pp. 158159). They begin with the assumption that the worker has the professional qualifications necessary, which include the education/training and experience to carry out the job, as well as commitment to the job and organization. (Preparation will add the cross-cultural dimensions of the specific job.)

Kealey and Ruben (1983) then describe the remaining factors in four categories. Two are related to observed behavior: (1) interpersonal skills 
(flexibility, respect, listening, relationship, control, and sensitivity), and (2) selfassertion/identity (flexibility, confidence, frankness). The other two categories include self-perception: (1) self-ratings (open/non-ethnocentric, open/flexible, family communication, frankness, self-confidence/initiative, harmony with others, outgoing), and (2) realistic pre-departure expectations (constraints and barriers to effective performance, optimism, some concems about overseas living, expectations of a rewarding experience). For an extensive update of research on intercultural communications competence/effectiveness, see volume 12, 1988, of International Journal of Intercultural Relations. More recent research approaches the concept less dogmatically, with greater diversity, and more complexity.

Another major area to examine for guidance in goal selection for crosscultural preparation is intercultural competence. Dinges (1983) discusses various approaches and models of intercultural competence for a conceptual understanding. An example he discusses is Brislin's six personal traits that arise from the person's "unique heredity and experience" and are "acquired without formal training" (p. 185). They are: a tolerant personality (multidimensional thinking, receptiveness to changing social perceptions, comfort in ambiguous situations, interpersonal patience, broad/flexible conceptual categories for social phenomena); personal strength (selfesteem, integrity, loyalty, courage); social relations skills (empathy, capacity for affiliation, ability to role-shift); intelligence (social problem-solving abilities, multidimensional intellectual ability, social judgment capacity); task orientation (identification with work, goal-oriented efforts, diligence, persistence, 
dependability); a potential for benefit (openness to change, ability to perceive and use feedback, motivation to leam).

A third area to study before planning preparation programs is crosscultural adjustment and adaptation. Because culture shock is a major hurdle to overseas success and satisfaction, adjustment issues generate much research. From this category come many of the developmental approaches to cross-cultural preparation, such as descriptions of "multicultural man," and processes of adjustment and adaptation, ethnocentrism to ethnorelativism, and multicultural identification.

\section{Research Rationale for the Study}

Because no straightforward research identifies what goals are needed for missionary pre-departure orientation, this study is exploratory. The methodology sought to identify valid preparation goals for cross-cultural ministry. To accomplish the purpose, I decided to begin with the goals of a representative and comprehensive missionary orientation program and validate them by generating data from an ample range of pertinent sources.

The case chosen was the SDA Institute of World Mission (IWM), the name given to the cross-cultural missionary orientation program for all missionaries sent out by the Seventh-day Adventist Church. Institutes are held in three regions of the world, but the American IWM is the parent organization and focus of this 
research. It is a 4-6 week program that has been in operation for 28 years and has trained over 2,500 persons.

A brief history of the Institute shows that it has attempted to be flexible and relevant to meet the needs of participants as well as the mission organization. Because denominational leaders believed that orientation would increase missionary satisfaction, effectiveness, and length of stay, they voted to begin this form of preparation. The orientations which began in 1966 appear to have accomplished their stated purposes: a marked decline in premature withdrawals from the field, a lessening of culture shock, improved effectiveness in cross-cultural ministries, an increase in missionary satisfaction along with greater acceptance by local administrators/nationals, and more frequent returns to service (Oosterwal, 1990).

After selecting the case for study, Phase One of the research effort was to identify and clarify its existing program goals. Relevant documents were examined for stated and implied goals and Institute schedules studied for implemented goals. A list of goal statements was constructed from these sources and went through a series of revisions in consultation with the Institute's director, associate director, and the chairperson of the curriculum deparment.

Phase Two was to select data from six sources considered pertinent and feasible for validating goals in an exploratory study. Sources 1-3 are related specifically to the case under study. The first source provided data from an observation of the program in operation over time to understand staff and attendee views of Institute goals. Data came from detailed session reports to the General 
Conference of Seventh-day Adventists, from participant-observation of an Institute I attended as a part of this research process, and evaluation forms from participants of 18 Institutes. The second and third validation sources comprised views of administrative stakeholders (church leaders) and criterion populations (current and retumed missionaries). Data were collected by means of a researcher-prepared questionnaire that elicited perceptions with regard to whether each goal was appropriate, possible, attained, and if the program was comprehensive enough. The last three validation sources drew data from sources external to the case. Source 4 was a review of missionary preparation goals from several views: A historical overview of missionary goal development, missionary preparation literature review, one current missionary orientation program, and 22 mission agency directors responsible for providing orientation programs. Source 5 was a summary of stated and implied goals gathered from cross-cultural training literature that also included an overview of the historical development of goals. Source 6 provided data from a discussion of world/mission trends and issues related to preparation that inform goal determination decisions.

Phase Three synthesized and analyzed the findings from the six data sources to complete the validation process. Phase Four provided a reconceptualization of missionary pre-departure orientation program goals that arose out of the entire research process. The framework that resulted can be used by organizations to guide the planning or evaluating of suitable orientation program goals. 
It should be mentioned that this study is an attempt to build on present theory and research more than to seek new discoveries. Several cross-cultural training authors suggest that, rather than performing original research, researchers should consider doing 'contextual' studies that are rooted in and built upon existing literature, theory, research, as well as program operation and practitioner experience (Martin, 1986). The methodology used for this study is particularly useful because. although it utilized a case study approach, the validation process included both contextual and empirical evidence from the case, as well as external measures of evaluation. External evidence came from history and future trends, literature, and program practice.

\section{Definition of Terms}

Terms used in this study that require clarification are defined as follows:

General Conference of Seventh-day Adventists is the legal name given to the worldwide church entity that directs the denomination for the purpose of teaching "all nations the everlasting gospel of our Lord and Savior Jesus Christ and the commandments of God" (Seventh-day Adventist Yearbook, 1990).

Divisions are the major geographic and administrative sections into which the world church and General Conference are divided. Each of the eleven divisions operates within a specified territory and is responsible for the operation of the worldwide organization within that region. They are: Africa-Indian Ocean, Eastern Africa, Euro-Africa, Far Eastem, Inter-American, North American, South 
American, South Pacific, Southem Asia, Euro-Asia, and Trans-European. The Inter-American Division was excluded from this study because it no longer has a sizeable number of missionaries from the North American Division. The Institute for the North American Division is the orientation on which this study is based. Unions are the geographic and administrative sections within each division. They may comprise a country, more than one country, or a portion of a country.

Institute of World Mission (IWM, or Institute) is the name given the Seventh-day Adventist missionary orientation programs which are held two or three times annually for a period of 4-6 weeks. As is seen in the questionnaire, participants often refer to the program as "Mission Institute." There are three such orientation programs held in the United States, Australia, and Europe. The parent orientation is in America.

Goals translate a learning purpose or aim into intended directions and outcomes. They determine the "what" of the education or training, rather than the "how," which are the methods. Objectives are those specific behavioral indices that place goals in operation so that they may be achieved and evaluated.

Validation refers to the process of justifying goals by determining their soundness and adequacy for meeting the intended program purpose and aim. This is the methodology used for this research study.

Cross-cultural and intercultural are two terms often used interchangeably, but that have slightly different connotations for many authorities. 
Both are used to denote the interaction of persons from two or more cultures. Although intercuitural seemed to be the term of preference for scholarly discourse, cross-cultural appears to be used more often in the literature. Cross-cultural is the term used in this study.

Cross-cultural ministry in this study refers to any form of service for the direct or indirect purpose of contributing to the spread of Christianity by persons working in a culture different from the one in which they were reared.

Orientation, training, and education are three terms used loosely, interchangeably, and often inaccurately in cross-cultural literature. Strictly speaking, each term indicates a different learning mode with different purposes and methods. Some authorities limit the concept of orientation to the provision of information about the particular cross-cultural context and/or preparing prospective sojoumers to deal with culture shock. Others expand it to refer to the entire process of preparation. For this study, orientation is used to refer to that preparation occurring after appointment and just prior to departure regardless of the extent of preparation coverage. It therefore is used to describe IWM's program, denoting a comprehensive, multi-dimensional, multiple-strategy, overview-type of preparation for persons about to leave for service in a cross-cultural context. It seeks to accommodate a variety of participant backgrounds and readiness while promoting those knowledges, understandings, attitudes, behaviors, and skills necessary for effective ministry and functioning in the appointed culture. Its purpose is centered around providing a non-threatening and nurturing environment in which to leam and 
prepare for entry into the new environment. The word preparation is used in a broad sense to denote any or all of these terms.

Pre-departure, pre-service, and pre-field are three terms used to refer to that part of missionary preparation prior to service in the field. There are subtle distinctions, however. Technically, pre-departure means before leaving the home country and pre-field means before arriving in the foreign context of appointment. (Pre-field orientation [PFO] is the more common term for missionary orientation.) Pre-service refers to any time prior to active service that could be defined by some as when remuneration begins (even before departure), or until the assumption of duties in the field, which might be months after arrival if language leaming takes place first. To avoid confusion, pre-departure is the main term used in this study. It refers to orientation that takes place prior to leaving the country.

\section{Delimitations}

The constraints of dissertation research made it necessary to select from among all possible relevant data sources those that were considered to be most feasible and appropriate to achieve the purpose of this study. Consequently, the biblical and task analysis sources were excluded. One people group was also excluded as a separate source of data--the recipients of missionaries, or host nationals--although data from national leadership respondents were identified and examined in the study. Although Institutes are held in three regions of the world, this study was delimited to those in North America. Other Christian mission 
agencies selected for stody have been delimited to the major North American Protestant agencies selected from the list in the 14th atition of Matsion Hardbook (1989). Catholic missionary endeavor, although wideapread, is dissimilar in several appects that make it leas relevant to this study. For insunce, mout Cutholic missionaries are single, have made a lifetime commitmeat to their mission, and allow more contextualization of the gospel than evangelieal Procesnnes. Also, their preparation is substantively differeat.

\section{Inimitations}

Several factors limit this study. The quality and quantity of dan are subject to the availability, accuracy, and/or completeness of available IWM information, evaluations, reports, and documents. Some questionanires might not have reached their destinations because of changes in the geographic location of persons selected to receive the questionnaire. Questionaaire return rates from overseas groups are subject to low retum rates characteristic of foreiga mail surveys. Finally, the study is limited by the external validity afforded by a case study approach. although three data sources seek to provide a measure of extemal validity.

\section{Organization of the Study}

This study is organized into six chapters as outlined. The usual review of literature chapter is incorporated into appropriate sections in chapters 1 and 4. 
Chapter 1 ineludes the introctuction and problem, purpose and significance of the study, its conceptanal foundations and recenrch rationale, definition of terms, delimintions and limintions, and organization.

Chapter 2 presents the case for study, outlines the four-phase validation process, and the methods that operationalized each phase.

Chapter 3 presents the findings of the dan gathered from the firs three of six sources that were used to determine the validity of the goeis of the selected orientation program. These sources generited dan from the case under soudy. Chapter 4 presents data from the final three of six sources for validation, a review of missionary preparation, a summary of cross-cultural literature, and 2 discussion of trends and issues.

Chapter 5 comprises a synthesis of the findings from the six sources for a cross-validation, and a roconceptualization of program goals for use as a tool to design or evaluate cross-cultural pre-departure preparation for miniscry.

Chapter 6 summarizes the study, presents the conelusions, and makes recommendacions. 


\section{CRAPIaR II}

\section{RESEARCI DEYTON AND MELHODOLOOY}

The purpose of this research study was to identify suithle gonls for predeparture orientation programs that prepare miscionaries for cross-cultural ministry. Ultimately, the study atteropted to sugsect a conceptinil finmeworit that crosscultural preparation programs can use in formulating their statemems of iment.

The methodology described in this chopter is a validation of the goils of a selected orientation program. The case stedied is the Sevemb-day Adventist (SDA) Institute of World Mission (WWM or Institute), the orgnimion establisted by the General Conference of Seventh-day Adventists to provide for the prepartion of its missionaries. This well-established comprehensive missionary orientation program was used to test the validation process to develop the conceptual framework for guiding goal selection.

Figure 1 depicts the validation process with its four phases. In Phase One, I identified and clarified the extant goals of the Institute; in Phase Two, I validated the adequacy of those 12 gonls by accumulating dan from six designated sources: observation of the program in action, survey data from church leaders and missionaries, review of missionary preparation, a summary of 


\section{Goal Validation Model}

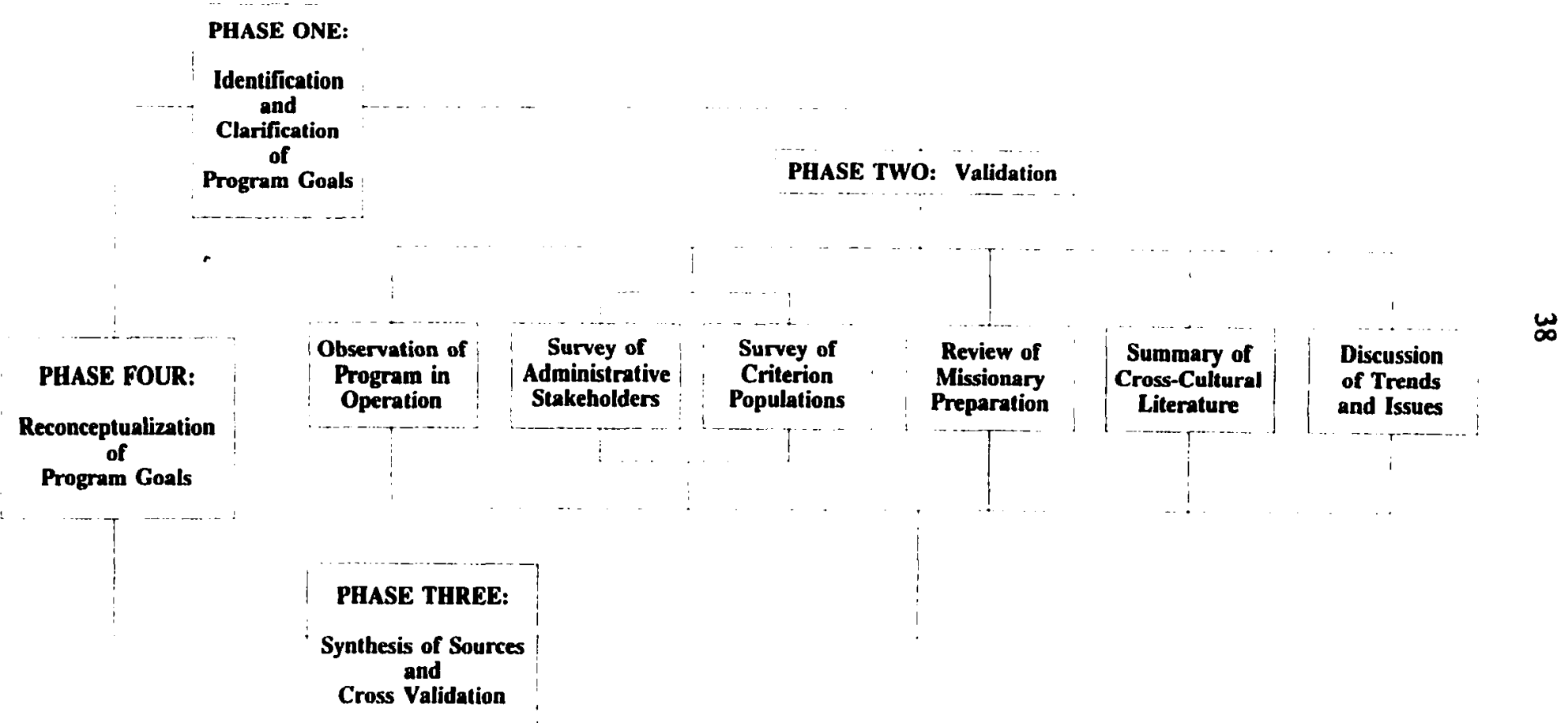

Figure 1. Four-phase validation process for the research study. 


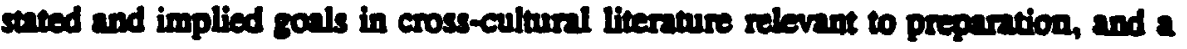
discussion of world trends and issues in miscionary prepantion. In Phase Three, information from all these sources whs andyred and syutheaized for a crosevalidution as a basis for Phase Four, the reconceptentiontion of initial progen gonls.

The six dath sources in Phase Two of the validation process do not represent data from all the possible categories that conil be used to identify and validute missionary pre-departure orientation gouls, of even the most impormm oses. At least seven categories would contribute importum don for determining crossculturnl preparation needs: the Scripures, treads and iseves related to the miscion context and preparation, perceptions of relevam populations, task amlysis, resenreh, theory, and progrem practice. The exploratory nature of this study prompted the selection of population perceptions as the primary source that were further validated by other selected data.

The first and most important source for guiding the preparation of missionaries is the biblical mandate. Guidelines from the Bible must direct decision making for the Christian. Mission is not possible without understanding the what, who, where, when, why, and how of the gospel commission. A second very important category, the global milieu and trends that shape the future, provides critical information peraining to the context of fulfilling the gospel commission. Data from this source helps to guarntee and maintain relevance. The third data source is provided by the perceptions of the persons who are in some way involved in mission and for whom the preparation is designed. Appropriate groups include 
program divectors/staff, participants, former and curreat missionaries, organizational leadership, and the host nationals who receive the miscionaries. A fourth category of dan comes from various types of task analysis, both for general cross-cultoural ministry and specific ministry roles. Categories throe and four are sometimes called "needs andysis" or "needs asceasment." Fifth is dath from relevant research, and sixth is from relevant theory. Datn from these categories are found mostly in literature and across sevenal disciplines such as the behavional and social sciences. A seventh category includes dat from cross-cultarnl and missionary prepartion progrnms in the form of case studies, evaluations, or other types of observation. If dat from all seven categories are combined, a fairly complete picture of preparation needs should emerge. A complete study of all seven categories, however, would be 100 broad and thus insppropriate for a dissertation. Because this study is explontory in nature and uses a case study method, it utilizes one primary category for an in-depth examination, and then checks the findings with a partial survey of four others for validation purposes. The major groups of persons were selected because their insights were accessible and valuable in evaluating IWM's orientation program goals: Source 1 explores the perceptions of program director/staff and amendees; Source 2 explores the perceptions of organization leadership from several levels; and Source 3 explores the perceptions of eurrentrenumed missionaries. These are the case study populations.

Research, theory, program practice, and trends/milieu are four categories of the seven that were also utilized in this study, but to a lesser degree. Data from 
these sources served as "reality checks" to complete the validation process. Research, theory, and program practice were combined for generating data for Sources 4 and 5 in Phase Two of the validation process, missionary preparation, and cross-cultural training/orientation literature. Trends and issues complete the data sources. (Because information from a review of literature is presented in these final three data sources, the usual chapter 2 review of the literature is eliminated.) An examination of the biblical mandate and task analysis was not directly dealt with because specific views and contexts vary widely, and this study is built on a broad, inclusive, and general understanding of mission that could accommodate the general goals presented.

Quantitative, documentary, and qualitative methods were employed in this study. After a discussion of the case for analysis and goal-clarification process, a description of the methodologies used for the three remaining phases follows.

\section{Case for Analysis: The Seventh-day Adventist Institute of World Mission}

The Institute of World Mission was the orientation program selected for this study. It prepares cross-cultural missionaries for the Seventh-day Adventist denomination. I was familiar with the program because I attended it in 1981 as a retumed missionary and in 1989 as a researcher. There are several other reasons why this program was selected:

1. It is comprehensive. The Institute of World Mission orientation program tries to meet all existing essential missionary preparation needs of its 
attendees. These needs are greater than might be the case for other missionaries because the majority of IWM's attendees will not have had diploma or degree education or training specifically for cross-cultural ministry, except for Bible knowledge or theology. Specialists, for example, may not be familiar with issues important to mission and ministry because their professional training did not include it. IWM is perhaps unique in the extent of its comprehensiveness.

2. It is representative. Although there are fewer comprehensive predeparture missionary orientations today, the Institute of World Mission is representative of those currently operating. One of the most well recognized is the Colorado-based Missionary Internship, which has trained individuals for crosscultural ministry since 1954 . Although it is an interdenominational orientation, IWM's orientation is similar to theirs in its approach.

3. It is effective. The Institute of World Mission is perceived to be successful in achieving its purposes. Reports show that the premature missionary withdrawal rate was significantly reduced by up to $72 \%$, and both leadership and missionaries attest to its importance in making cross-cultural service more satisfying and effective (undated IWM documents).

4. It is sizeable. To date, more than 2500 missionaries have been trained by North America's Institute, which is the particular orientation used for this study. This is around $70 \%$ of all North American Seventh-day Adventist missionaries sent out since the Institute began in 1966 (IWM documents). (SDA Institutes also orient missionaries at centers in Europe and Australia.) 
5. It is long-lived. The Institute of World Mission began in 1966 and has held to date (July 1994) 66 sessions of 4-6 weeks each, most at the rate of two or three annually. It is one of the longest, continuous missionary-orientation programs in operation today.

6. It is multidimensional. Even though most early missionary orientations were largely didactic in approach, the Institute has always recognized the need for a multidimensional approach. For example, the attitudinal dimension was present in the beginning, although there has been a growing emphasis on developing attitudes important for cross-cultural work.

7. It is responsive. Dr. Gottfried Oosterwal was the primary director of the Institute from its beginning until 1993. In 1989, he expressed a need for and interest in the study. The staff indicated a willingness to participate.

\section{History of Seventh-day Adventist Mission}

In order to understand the role of the Institute, it is useful to see it in the context of Adventist world mission history. The formative years of Seventh-day Adventist mission began around 1830 (Schantz, 1983), and were rooted in a belief that the world was on the brink of God's final evangelization harvest. This belief, championed in North America by William Miller, was visible in the rising global awareness of an imminent retum of Christ to earth. Around the middle of the first phase (1830-1860) of Adventist mission, around 100 persons who had expected Christ to come on October 22,1844, went through and beyond the "Great 
Disappointment." This particular event gave birth to the Adventist Movement which grew into the Seventh-day Adventist denomination around 20 years later (Schantz, 1983).

According to Oosterwal (1972), the first 10 years were spent in movement-identity formation and spiritual growth. The next 20 years provided time for organization and a shift toward a mission emphasis, albeit to individual Christians through a call to higher spiritual understanding. During these formative years, the embryonic structure that would "carry, promote, and oversee missions for the next forty years" was in place (Schantz, 1983, p. 431). Although the "message, manpower, money, and mechanism" were in place, the perception of a global mission was unclear (p. 43). By 1874, a third developmental phase, which lasted until the 1950s, was inaugurated by the sending of the first overseas missionaries to answer the Macedonian call from fledgling churches around the world (Oosterwal, 1983)

In 1889, the General Conference (GC) of Seventh-day Adventists set up the semi-autonomous Foreign Mission Board (FMB) to provide personnel to proclaim the message of a soon-coming Savior to the world. According to Bauer (1982), the Board was responsible over the next 14 years for all recruiting, screening, appointing, preparing, and supervising of personnel, in addition to fundraising, promoting, and strategizing for mission. As the FMB committee looked for personnel to implement its mission initiatives, it looked for evidence of such qualifications as mature judgment, leadership and administrative ability, 
experience, physical and emotional stability, determination, enthusiasm, energy, and practical skills.

Preparation for mission service came in many forms. Concerned leadership started a monthly Missionary Magazine a year before the mission board was formally organized. Leaders hoped to generate awareness of world evangelization needs among the membership, and to provide preparation for its missionaries. Each issue featured a major country and reported on its culture, religions, and needs, which were studied by individuals and "missionary reading circles" (Bauer, 1982, p. 121). Additional awareness and preparation came from independent church meetings and annual campmeeting presentations. For most missionaries, however, pre-departure preparation included personal study of books listed as important, and language training for the area of appointment, if it was possible. Medical personnel spent 6 months in training at the Battle Creek Sanitarium. General preparation continued on ship with a "library" on history, travel, and missionary biographies to make efficient use of the many weeks of travel. By 1907, preparation was upgraded by the establishment of Washington Foreign Mission Seminary. Prospective missionaries were expected to enroll for intensive area studies in the topics of geography, history, and culture (Bauer, 1982). Other opportunities early missionaries took advantage of were missionary literature and conferences held by prominent Christian missionary leaders and boards of that time. 
Around the turn of the century, in the context of a strong spiritual revival, "unprecedented growth of the denomination's mission program" provided a "major stimulus to the expansion of Adventist education" (Knight, 1984, p. 10). Knight pointed out that, similar to the mission and missionary training growth among American Protestant evangelicals of that time, both movements virtually exploded over the next 30 years. For instance, the number of mission stations grew from 8 to 270 between 1890 and 1930, and the number of missionaries from 42 to 8,479 . Largely to accommodate the need for workers, the number of schools beyond the elementary level grew from 7 in 1890 to 201 by 1930 . The earliest colleges reflected the reason for their founding in such names as Emmanual Missionary College (renamed of Andrews University for the first Adventist overseas missionary) and American Medical Missionary College. "The denomination looked to its schools to supply the ever increasing number of workers for its rapidly expanding worldwide work" (p. 11). In addition to training in the few particular professions and vocations in medical/health, education, business, and agriculture, curricula included a very strong emphasis in spiritual growth and knowledge of the Bible, Christian and SDA church history, and mission outreach.

Perhaps the strongest impetus for mission came from individuals whose spiritual strength and personal power directed the thrust of Adventist mission. From the 1840s until well into the 1900s, E. G. White contributed wisdom and enlargement to the worldwide vision of her reluctant contemporaries. From 1901 to 1930, two top General Conference administrators, A. G. Daniels and W. A. Spicer, 
encouraged the dramatic expansion in Adventist mission outreach that took place during the same period of spiritual renewal and educational expansion mentioned above. Their tools were a personal passion for mission, leadership style, worldwide mission travels, and organizational implementation strategies.

Ironically, however, the 1901 General Conference and subsequent organizational restructuring of the church during this same pregnant period of Adventist history, brought an end to the Foreign Mission Board. According to research conducted by Bauer (1982) and Schantz (1983), mission began to be viewed as an expression of general church administration rather than something "in addition" to it (Schantz, 1983, p. 43). As a result, the Board was replaced neither by a General Conference department nor a mission agency. In fact, leadership spoke of its function as a "mission board" that was "not apart" from the "central life" of the North American church (Bauer, 1982, p. 188).

The reorganization brought changes in the nature of mission outreach. No single entity was effectually responsible for mission expansion; no individual was responsible for mission as a leadership priority (p. 188). It may be that any effects of these organizational changes for mission were not initially discemed in the face of Daniel's and Spicer's zeal and powerful mission initiatives, but may have set the direction for a shift from frontier evangelization to infrastructural support through educational, medical, and publishing institutions and administrative organizations. Gradually, missionary roles shifted from evangelizing and church planting to specialist positions, and the result was a strong worldwide church with a 
diminishing work among the unreached. In fact, by 1980, more than $97 \%$ of all missionaries were serving an overseas infrastructure (Bauer, p. 233). To several mission experts, this appears to have been a tragedy. However, a transcendent God, who works within and through history to bring about His sovereign Will, challenges Adventist worldwide leadership to accept current challenges and to make the most of present realities and opportunities.

The 1950s opened a new era of mission when the church began to hear the call from a largely unevangelized world (Oosterwal, 1972). During this time, the student missionary movement in the church became more visible and structured. The first systematic research on Adventist outreach began (Schantz, 1983). The Institute of World Mission was organized in 1966 along with a department of mission in the Seventh-day Adventist Theological Seminary. Church headquarters inaugurated formal missionary preparation in the form of education and orientation to replace the loss of specific missionary courses in the colleges over the previous 20 years. Although not involved in recruitment, selection, and appointment, the Institute of World Mission was so successful in its preparation of missionaries that premature retum rates were dramatically reduced (IWM documents). By 1972 , nearly a century after their beginnings, Seventh-day Adventists had become the "most widespread single Protestant denomination, working in $84 \%$ of all countries" (Oosterwal, 1972, p. 43).

Since then, although the number of countries with an Adventist presence has continued to increase, there has been a decrease of over $50 \%$ in the number of 


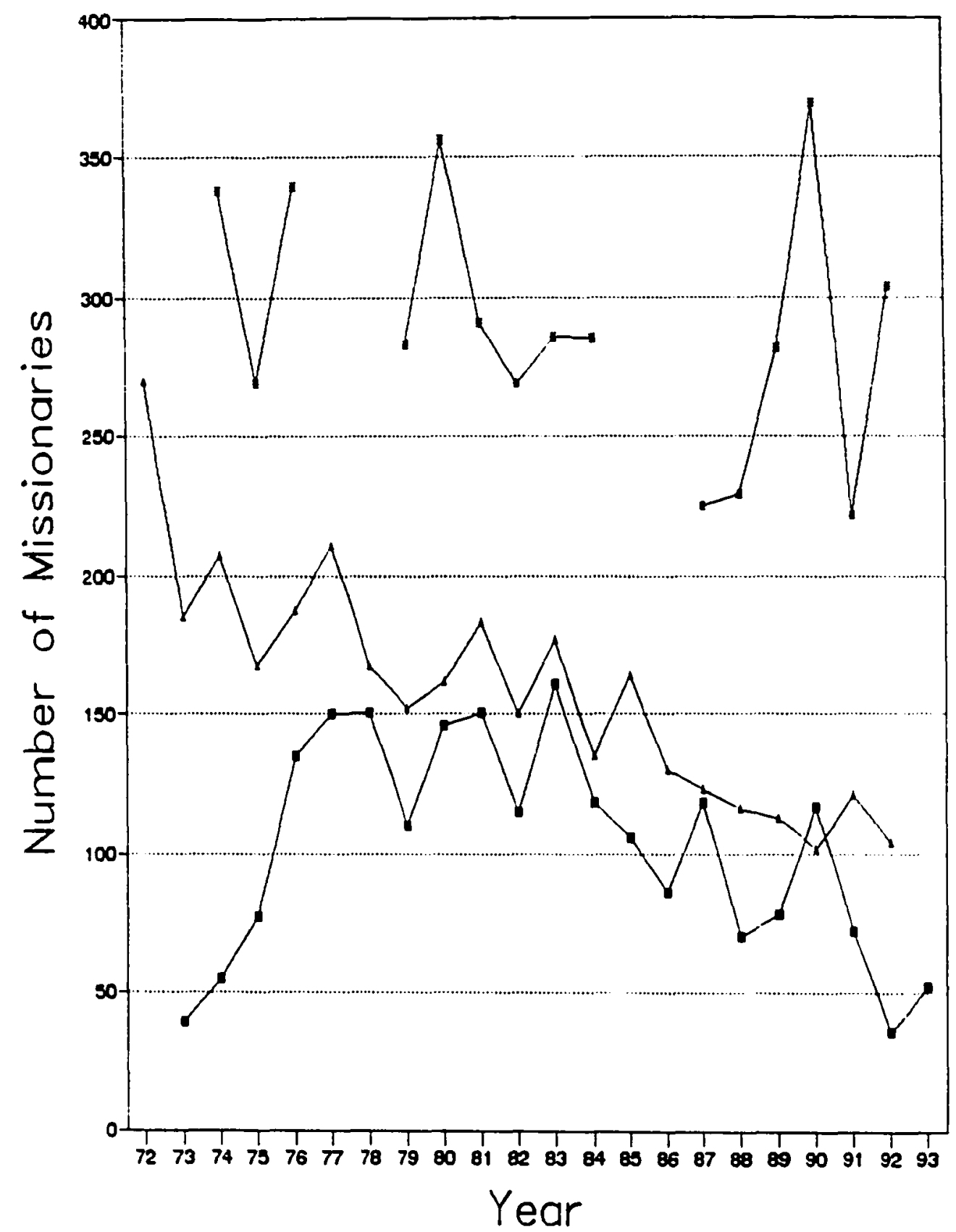

- Trained TAD Miss - - Non-NAD Miss

Figure 2. A comparison of North American IWM-prepared, non-prepared, and Non-North American missionaries. 
North American SDA missionaries. Figure 2 illustrates the decline of Seventh-day Adventist missionaries that took place between 1972 and 1993 . The decline has occurred in response to worldwide milieu, denominational trends, and changing mission structures. Because the nature of Christianity compels a sharing of the gospel with unbelievers, because a loss of mission means a loss of spiritual life (Dybdal, 1993), and because the church tends to reflect general world trends, the decline in real outreach opportunities prompted a rise of independent parachurch initiatives and accelerating volunteerism associated with short-term mission (such as Maranatha Flights International, MFI) and long-term projects through the recently organized independent mission board, Adventist Frontier Mission (AFM). There is currently a growing interest by the non-Western portion of the church family for participation in mission outreach that is directed more toward evangelizing the unreached. In most of these trends, the SDA church parallels evangelical Christian mission.

The General Conference has moved in some revolutionary directions within the last decade. The GC session (1990) elected a new president for the world field, Robert S. Folkenberg, who built upon and expanded the vision established by the outgoing president, Neal $\mathbf{C}$. Wilson. One of Folkenberg's four major thrusts is mission on a global level (1992). World leaders at the 1990 GC session formally established the Global Mission Commission (GMC). A third strategy coming from the General Conference session was the establishment of the Center for Intermational Relations (CIR) under Global Mission initiatives (Dysinger, 1992). One of CIR's 
purposes is to help "initiate, nurture, and support church members in cross-cultural witness" (p. 18), which includes the encouragement of "tentmaker" evangelism.

In June of 1994, a conference on the Global Mission Initiative generated a think tank to plan for the mobilization of volunteer personnel, predominantly from the non-Western church, to implement mission strategies. The organization of these strategies emanates from each of the world divisions and filters down through the lower level structures. Plans will be implemented within and through worldwide church structures, from the General Conference through the local church. It is critical for North Americans to continue sending personnel overseas if they are going to continue major funding for overseas work. The restriction of North American missionary budgets may ultimately jeopardize the financial base it has so long provided. If Global Mission strategies are going to achieve their goals, the grassroots church in North America will also need to be made more aware of the evangelization, relief, and development needs of our world, and each member's role in meeting them. In fact, a new office and director have been established to more strongly awaken the membership to challenging mission needs on the brink of Century 21.

The task of preparing personnel is gigantic, and is faced with numerous challenges. Issues involving holistic (some persons prefer to use "wholistic" to avoid confusion with the secular use of the term) preparation of this international group to be mobilized for reaching the unevangelized (including education, training, and orientation both prior to and during service) must still be considered and solid 
plans laid. The upcoming General Conference session scheduled for Utrecht, June 29 to July 8, 1995, is the next major opportunity to gain ratification and support for the next phase of global mission implementation. Undoubtedly, the Global Mission Initiative will present comprehensive proposals for preparing and orienting the new recruits so that effective outreach can accelerate.

The Institute of World Mission has been the organization charged with these challenges in the past; its role in the next phase of the preparation of the worldwide mission task force is being explored and designated.

History of the Institute of World Mission

The Institute of World Mission's history is striking. Recognizing the importance of specialized missionary orientation to prepare its missionaries, Seventhday Adventist church leadership called for a "Missionary Orientation Program" at its Annual Council in October 1956. Ideally, the program would orient all appointed missionaries prior to departure, although active missionaries without previous orientation have also attended.

The Council's action stated that a 6-week course should be available to all "newly appointed missionaries from the North American Division, missionaries furloughing in the North American Division, and overseas workers who have been sent to the United States for further study"; and the course should be held three times per year. Attendance was mandated for "all available missionaries from the North American Division" (General Conference of Seventh-day Adventists, 1956). 
The program was to be practical and responsive to worldwide developments and trends impacting mission. By setting up the new orientation, leadership hoped missionary satisfaction, effectiveness, and length-of-stay would increase.

Although missionary orientation did not begin until 1966, 10 years after the Council's action, the desired purposes seemed to be accomplished almost immediately. There was a marked decline in premature withdrawals from the field (33\% to 14\%), a lessening of culture shock severity, an improvement in missionary effectiveness and satisfaction along with greater acceptance by local administrators and nationals, and more frequent returns to mission service. Since its inception, however, dramatic changes in the world and missionary movement have kept the leadership reviewing the program for missionary preparation needs (Oosterwal, 1990). By 1975, three Institutes were being held per year. Institutes were 4-5 weeks long the first 7 years, then 6 weeks long until 1985 when they were reduced to 4 1/2 weeks. Institutes have also been established in Europe (1972) and the South Pacific (Australia, 1981).

Additional organizational modifications and changes have taken place (see Oosterwal, 1990). By the time the first 2 years of Institute operations were completed, a new department of world missions was created at the denomination's theological seminary which operated the "Mission Institutes." Ten years later, the orientation program was separated from the educational function of the department, and in 1981 was established as an organization of the General Conference linked to 
Andrews University in Berrien Springs, Michigan. It is currently located in its own building on the University campus.

The Institute of World Mission is charged with four responsibilities. The first is training and education. Besides conducting missionary orientation programs, the staff hold seminars on church growth and workshops on cross-cultural evangelism, present mission lectures, and provide missions counseling and management. The other three tasks include research and publications, missionary consultation, and missions promotion. The tasks beyond orientation programs are performed only to the extent that time and resources allow.

\section{Phase One: Identification and Clarification of Program Goals}

A study of goals rather than methods was chosen to find out what missionary preparation should include to prepare its attendees for effective service. The importance of determining goals before selecting methods to achieve them can hardly be argued (Beane et al., 1986; Davies, 1976; McNeil, 1981; Pentecost, 1973). There were neither research-based missionary orientation models in 1966 when the first IWM orientation was held, nor very little research data on what comprised effective missionary training (Dowd, 1978; Oosterwal, 1988). The Institute, however, has always been goal-directed even though its goals had not been validated by formal research before this study. The several-step process I conducted to determine Institute goals and to develop goal statements in consultation with its director spanned approximately 6 weeks. 
The goal identification and clarification process began with a search for stated or implied goals written in Institute documents over the years. The main documents used were the Annual Council guidelines, statements of program purposes/objectives by the director, and participant-evaluation questionnaires. Another source was the verbal presentation of goals at the opening meeting of the IWM session that I attended in 1989. Finally, I examined schedule topics and compared them with the actual activities as monitored during my attendance.

Although the 1956 Annual Council action did not dictate any particular goals or objectives for the new missionary orientation program, nine sudy areas were suggested:

a. A Bible course especially designed for missionaries.

b. Personal evangelism, with special emphasis on how to evangelize peoples of other religions and cultures.

c. Missions and the missionary task, using the lives of great missionaries as examples. Attention will also be given to the study of contemporary missionary problems through the maintenance of close contact with division leaders.

d. Importance of language study in the missionary's program, also methods of language study and phonetics.

e. Area studies. Each student will study the following items of the area to which he is assigned for missionary service:

(1) Geography and political history

(2) Current economic and cultural status of the country

(3) Indigenous religions and educational systems

(4) Missionary history and activities in the area

(a) of other denominations

(b) of Seventh-day Adventists

f. Healthful living for missionaries.

g. Denominational mission organization and policy, including denominational financial policies.

h. Human relations with fellow workers and with national peoples.

i. Personal finance. 
This list of topics was representative of the cognitive approach used by most missionary orientation programs of that day.

Although the Institute of World Mission was guided by the charter's recommendations, director Oosterwal, who is also trained as an anthropologist, recognized that the "powerful array of topics presented to the participants" did not effectively meet the missionaries' needs. Neither did they meet the practical needs the cross-cultural context demanded. He observed four unmet needs:

To become affirmed in their call to mission to which they had responded in faith; to be made aware of the missionaries' role as a learner (attitude training in humility); to be informed about their own as well as other people's values; and, to learn specific skills with regard to their assignment in mission in a cross-cultural context. (1988, p. 7)

The director sought to make the orientation more holistic and effective by formulating goals and selecting methods that would reflect the real needs of missionaries in a changing world. Consequently, four "objectives" were added: today;

to affirm the participants in their missionary call, and its meaning mission;

to help them in their spiritual growth as imitators of Christ in

to create a sensitivity towards other people's culture as well as an understanding of their own values;

to provide participants with basic skills in regard to their specific ministry, in the setting of the cultures in which they are called to live and work. $(1988$, p. 8$)$

Because the philosophy is geared toward "meeting the specific needs of the participants ... rather than learning a particular body of knowledge" (p. 8), the goals and methodologies were designed to emphasize attitudes, values, social interaction, and fellowship. Program content became centered on "four pillars": 
(1) principles and practices of world mission, (2) missionary anthropology, (3) area studies, and (4) issues in mission (p. 9). A glance at the program schedule shows these four modules as the core of the curriculum (Table 2). The experiential method was used to make program "leamer-oriented" rather than "topic-oriented."

As noted above, the Institute's goals have been redefined as they have undergone modification in an attempt to remain flexible and relevant to meet missionary, overseas context, and organizational needs. The challenge continued. By Oosterwal's 1988 report, a "steep increase in the number of premature missionary withdrawals" and "a sharp decline in the missionaries' satisfaction rate in cross-cultural service" had occurred (p. 8). These trends reflected a changing missionary movement in a rapidly changing world. They prompted the Institute to emphasize "missionary spirituality, in communication skills across cultural and racial boundaries, in genuine Christian social interaction, cultural sensitivity and fellowship" (p. 16).

In 1987, the staff revamped the IWM's evaluation questionnaire entitled "Missionary Orientation Session Evaluation" to be filled out by all participants at the close of each orientation session. Five goals are listed in question 1:

\section{INSTITUTE OBNECTIVES AND ORGANIZATION}

The Institute program has been developed with five major objectives in mind. These objectives include: 1. Emphasis on attitude development; 2. Preparation for cross-cultural ministry; 3 . Growth in spirituality; 4. The creation of awareness of current issues; 5. The development of Christian fellowship. [See Appendix A for a copy of this evaluation questionnaire.] (p. 1) 
The second step in the clarification process was to form prospective goal statements from the list of goals gleaned from these sources. All goals were integrated and compared with actual program activities. Two consecutive goal statement drafts were drawn up, the first a list of 8 and the second of 10. Each list was presented to the director for examination, modification, and confirmation. The tentative goal statement list was submitted to the vice-director who added an lith goal statement. This tentative statement list was then re-submitted to the director, who added a 12 th goal statement by dividing one of the goals. Throughout the process, goal statement wording was modified until it was considered satisfactory by the Institute director, Dr. G. Oosterwal, and curriculum department chaiperson, Dr. E. Stanley Chace.

The final list of goal statements was typed up in the form to be used in the questionnaires. Goal order was purposely designed to avoid any suggestion of prioritization, and this order was maintained throughout the use of the list in the questionnaires and dissertation analysis. The resulting 12 goal statements reflect the Institute's orientation program intents. In reality, these goals comprise the sum of cross-cultural preparation provided by the sending organization for Seventh-day Adventist missionaries appointed to cross-cultural service, except for transition details arranged for by the General Conference. At times, books or reading lists have been sent to appointees. When this plan worked, it was useful.

The 12 statements were designed to effectively meet the aim "to help missionary appointees be effective in cross-cultural ministry in general, and in their 
respective fields in particular" (questionnaire). These goals are listed in their final goal statement form:

1. To clarify church and agency policies and their application

2. To enlarge the understanding of current issues in world mission

3. To facilitate growth in the experience of faith

4. To create an awareness of the essential role of culture in ministry

5. To further the development of attitudes vital to effective ministry

6. To identify and foster essential cross-cultural competencies

7. To increase knowledge and understanding of role expectations

8. To nurture community, fellowship, and relational skills

9. To strengthen the sense of call and commitment to mission

10. To teach/encourage appropriate mental/physical health practices

11. To provide orientation to respective world areas of service

12. To equip for continuing growth by mindset transformation.

\section{Phase Two: Validation From Six Sources}

Data for validating the Institute of World Mission's goals came from six sources: the program in operation (staff and attendees), administrative stakeholders of the sponsoring organization (church leaders), the criterion population (current and retumed missionaries), a review of missionary preparation, a summary of crosscultural orientation goals, and a discussion of trends and issues. 
Source 1: Observation of Program in Operation

The program was "observed" through three activities. I attended a 4 1/2week Institute of World Mission orientation in 1989 as a participant-observer. Data came from attending all of the planned activities of the Institute, taping audio cassettes of all activities except recreation and programs, note-making, and interacting with participants and staff. Attending the Institute enabled me to view the goals and their implementation from both the attendee and staff perspectives. Institute documents, such as registration pre-session inventories and post-session evaluations to be filled out by the participants, added to my insights for additional confirmation or modification. A copy of the evaluation form currently used is included in Appendix A.

A second part of the observation source of information was an examination of the evaluation documents for 17 more Institute sessions. Finally, I studied reports made to the General Conference by the director/staff in order to understand their views and how the goals were developed and modified over time. (The results of this last activity are reported first in chapter 3.)

The purpose of the attendance and observation was twofold: To evaluate the goals by experiencing their implementation, and to provide staff and attendee perspectives. For this perspective, several questions were asked. Which felt needs were being met and which were not? What aspects of the orientation, if any, seemed superfluous? Was there consensus? What did these observations contribute 
to an understanding of the goals created for this study? After the Institute, these questions were "answered" by the data from these three observation activities.

\section{Sources 2 and 3: Survey of Administrative Stakeholders and Criterion Populations}

Data from church leadership and missionaries were collected by a questionnaire prepared for this study. These sources constitute the empirical portion of the validation process. Leadership and missionary perceptions about Institute goals are important because both groups are in a position to make informed value judgments.

Respondents indicated how strongly they felt about selected validation characteristics for each of the 12 goals. For analysis purposes, these characteristics were conceptually organized into validation categories: appropriate, possible, attainable, and comprehensive. Each category included two to four characteristics and was presented in the form of a question. The first asked: Are the goals perceived to be appropriate? This checks whether they are important, essential, and relevant. The second asks: Are the goals perceived to be possible? This checks whether they are clear, measurable, feasible, and attainable. The third asks: Were the goals attained? This refers to achievement during the Institute and the application of goals in the field. The fourth question is: Are all the goals together comprehensive enough to achieve the aim of orientation for cross-cultural ministry? It checks whether the goals are expected and comprehensive. 


\section{Construction of the Instrument}

The content of the questionnaire was organized into sections appropriate for the analysis planned. It proceeded through several drafts, each of which were discussed with the Institute's director and the chairperson of the curriculum department. The tentative, final rough-draft form was given to six returned missionaries as a field test control, and desired modifications were made before the questionnaires were printed. Because it was not important to know who the respondents were, there was no place in the questionnaire for identity to be indicated or extrapolated. No mention of anonymity was made in the questionnaire or accompanying letter because the nature of the required responses did not appear to be threatening. In fact, many returned the questionnaire with a letter containing further comments, suggestions, and a signature.

The questionnaire sent to leaders and missionaries appears in Appendix A. It is comprised of two sheets printed on both sides. The front page asks 14 multiple-choice questions to provide demographic and background information about the responding population. These are divided into two sections: questions 1-7 are to be answered by all respondents and questions 8-14 only by current or former missionaries. Section 1 asks the respondent to circle his/her response to indicate age, marital status, occupation at the time of response, national category, pre-adult background (urban/rural, denomination), highest level of schooling completed, and missionary-related course areas of college-level work. Section 2 asks for a response to indicate missionary status (former, current, or under appointment), appointment 
type, time spent in mission service, type of missionary orientation, children at home in the field, type of mission service, and reasons for return.

The second page asks the respondents to rank the 12 goal statements of the Institute of World Mission according to how important they believe each is to prepare missionaries for cross-cultural ministry. Respondents are asked to circle a number from 1-5 on a Likert-type scale that best expresses their view, based on the following criteria: 1 = not important, 2 = somewhat important, 3 = important, $4=$ very important, and $5=$ extremely important. From these perceptions, goals can be ranked by how important the respondents believe they are to prepare a person for mission service. Respondents are then asked to circle the numeral in front of any goal they did not or would not expect for a missionary orientation program. These responses show whether the Institute's goals corresponded to the respondents' perceptions of adequate and comprehensive orientation.

Page 3 asks the respondent to show the extent each goal is: Clear (goal is easily understood), Attainable (goal can be accomplished by participants), Feasible (training for goal can be carried out by the Institute), Measurable (achievement of goal discemable), Relevant (goal is appropriate and timely), and Essential (goal is necessary for effective preparation. Again respondents are asked to circle one of five items on a Likert-type scale: SD for strongly disagree, $D$ for disagree, $U$ for undecided, A for agree, and SA for strongly agree. Respondents are next asked to circle the numeral in front of each of the 12 goals they had observed achieved by missionaries who had attended the Institute. 
The final page asks five questions about goal attainment. The primary question instructs respondents to circle their choice (SD, D, U, A, and SA) to express their opinions about how well they believe they achieved each goal during the Institute, and how well they believe they were able to apply each goal in the field. Each of these opinions is elicited by expressing it in the form of a question constructed to illustrate achievement and application of the goal.

Responses to the other four questions provided information about how respondents perceived the nature of attainment. Respondents were asked to answer the first question by circling a number from $1-10(1=$ none, $5=$ average, $10=$ most) to indicate what level of effectiveness they felt they had reached in their mission service. A second question then allowed respondents to express to what extent they believed each of 15 factors contributed to the level of their mission service effectiveness. The third question asked respondents to rate how 13 different facets of IWM contributed to their orientation effectiveness. The last question to be answered was "On a scale of 1-100\%, what \% do you feel Mission Institute training contributed overall to the effectiveness of your mission service?" These questions were designed to facilitate the analysis of attainment to make analysis more meaningful.

Even though the instrument was not statistically validated, appropriate validation steps were taken. During the formative stages, the design and content were shaped by a validation rationale created from a study of literature discussing curriculum validation. From this rationale, validation characteristics and categories 
evolved. Expert guidance from several extended discussions with the chairperson of the curriculum department as well as the Institute's director (a missionary and/or trainer for over 37 years) contributed to formative validation. Finally, after the questionnaire was tentatively completed, it was given to six missionaries as a field test, after which slight modifications were made.

\section{Selection of the Populations}

This questionnaire was sent to 1393 individuals who comprised the available populations of the six delimited groups listed below. Names and addresses were obtained from the November 1990 list of current missionaries, the 1990 edition of Seventh-day Adventist Yearbook for leaders, and the 1992 edition for returned missionaries.

The six groups are as follows. First were the 1990 officers of the General Conference of Seventh-day Adventists at the world headquarters located in Silver Spring, MD (total =64). Second and third were the current officers of the nine world divisions (the North American Division was excluded) which had a significant number of North American missionaries serving in their region and the current officers of every union conference into which the nine world divisions are divided, (total $=173$ ). Fourth were the current heads of the major educational and health institutions within the jurisdiction of the nine world divisions (total $=101$ ). Fifth were all North American Division missionaries who were currently serving in a cross-cultural setting according to the November 1990 General Conference list, 
whether or not they had had IWM orientation (total $=519$ ). If the list included names for both husband and wife, two questionnaires were sent in the same envelope. Sixth and last were retumed missionaries, whether or not they had had Institute orientation, who were selected from General Conference lists of persons voted to return during the 10 years between 1981 and 1990 and whose current addresses were obtained (total $=536$ ).

\section{Collection and Evaluation of Data}

The questionnaires were mailed with a covering letter from Dr. Gottfried Oosterwal, director of the Institute of World Mission orientation program at that time. This letter explained the need for a study and requested prompt completion of the questionnaire. Included also were pre-addressed envelopes in which to return the questionnaires to the Institute offices. Stamps were put on all inserted envelopes that would be retumed within the United States, except for those going to the General Conference headquarters. Because of high overseas postage charges, reminders were sent only to returned missionaries living in the United States and Canada 3 weeks after the first mailing.

Data from completed questionnaires were entered into a computer and analyzed with SPSS.PC under the direction of Dr. Jerome D. Thayer, director of the Center of Statistical Services and Academic Advisement at Andrews University. Because this is an exploratory study, most of the data analysis from the questionnaires was descriptive in nature. Frequencies were tallied for the 
demographic portions of the questionnaire. Each of the other sections was analyzed by comparing frequencies, means, standard deviations, and a ranking of goal means according to characteristics. Correlations and factor analysis completed the descriptive treatment of the data.

The 12 characteristics variables were correlated with all the nondemographic variables to check for significant relationships among them. All variables representing the 12 characteristics were factor analyzed to determine whether they in fact clustered in the categories as conceptualized for the study (appropriate, possible, attained, comprehensive). Factor analysis provided statistical support for three categories: appropriate, possible, and attained. The fourth, comprehensive, involved only one major variable, which was not sufficient to form a cluster. In addition, one-way anova was used to check for any significant differences among the response comparisons of demographic and validation characteristics. Demographically consistent responses would enhance reliability. On the other hand, differences could contribute to a greater understanding of preparation needs.

Source 4: Review of Missionary Preparation

Several types of data were collected for the fourth validation source, a review of missionary preparation. The purpose for gathering these data was to find out what goals developed as missionary preparation evolved, what goals are found in a review of literature, and what goals are implemented in other missionary 
68

orientation programs. Data came from books, joumal articles, research studies, dissertations, theses, other programs in operation, telephone interviews, and a questionnaire sent to 65 mission agency directors who were responsible for providing orientation for their missionary appointees.

The purpose of the questionnaire for mission agency directors was to elicit an evaluation of the Institute's goals. The study desired to find out how they perceived the value of Institute goals to prepare for cross-cultural ministry. For this one-sheet questionnaire, two goal statements were added to the original 12 in an attempt to accommodate orientation programs whose goals may differ from those of the Institute of World Mission. One goal related to language training and the other to some form of integration of previous mission education. Respondents were asked to state whether they believe that each of the $14 \mathrm{goal}$ statements was expected, stated, intended, or not applicable for cross-cultural missionary orientation. The second section of the questionnaire asked several questions that sought to elicit descriptive information for analysis and comparative purposes, such as program size, type, and length; content, methods, and aids used; trainees' required qualifications, appointment location, and type of service.

Selection of mission agencies was made from three agency lists in the 14th Mission Handbook (Roberts \& Siewert, 1989) choosing those who send out the greatest number of missionaries and would be most likely to be informed about missionary orientation. The first list was entitled "Forty largest USA agencies ranked according to their overseas career personnel" (p. 54); the second "Twenty 
USA agencies with largest number of short-term personnel" (p. 56); and the third "Ten largest Canada agencies according to overseas career personnel" (p. 68). After duplications were removed, these names were integrated into one final list of 65 .

The questionnaire for each mission agency director was inserted into an addressed envelope along with a pre-addressed, stamped, retum envelope, and mailed. Retums from this second questionnaire were also analyzed by using the SPSS software program, and evaluated by frequencies.

\section{Source 5: Summary of Cross-cultural}

\section{Literature}

To continue validation, Institute goals needed to be compared with what general cross-cultural orientation literature (research, theory, and practice) indicates is necessary for cross-cultural pre-departure orientation. The methodology used to accomplish this was an analysis of stated and implied goals found in relevant literature. The major literature sources were selected for the value and extent of their potential contribution to this portion of the study, and are considered representative of available literature.

Several questions guided the search: What are the underlying assumptions guiding cross-cultural orientation? How did cross-cultural goals develop? What are the elements and dynamics of the cross-cultural encounter or experience? What is the role of the foreigner in that encounter or experience? What are the tasks, roles, skills, attitudes, knowledge, and information considered essential and appropriate for cross-cultural workers? What are the behaviors of those persons who are believed 
to be effective cross-cultural workers? What leaming is necessary for the foreigner to perform his role effectively? What characteristics are seen to be required, desired, or in need of modification or elimination for effective cross-cultural service? Which of the essential leaming is appropriate for pre-departure orientation programs? Into what goal categories can the necessary learning be organized?

\section{Source 6: Discussion of Trends and Issues in Missionary Preparation}

Source 6 provides a dimension to goal determination that makes goals and planning directed toward the future, and is responsive to it. Various books and articles that discussed world trends and issues for missionary preparation were consulted, and pertinent data synthesized and analyzed.

\section{Phase Three: Synthesis of Sources for Cross-Validation}

The goals that resulted from the six sources of data were analyzed and synthesized by an inductive cross-validation process. Data from the sources were compared, contrasted, and integrated into a final set of valid goals. The crossvalidation process indicated what the final set of goals should be. The findings were contrasted with the 12 goal statements of IWM and modifications were made.

\section{Phase Four: Reconceptualization of Program Goals}

The list of valid goals was reformulated into a conceptual framework that is useful for designing or evaluating cross-cultural orientation programs. For the 
broadest use, the framework's format is conducive to alerting the user to the range of real and potential pre-departure preparation needs of prospective cross-cultural workers. From it, an organization could plan how to provide for all recognized needs, whether through an orientation program only or a combination of methods and opportunities.

The framework can be used for several more specific purposes. The staff of a pre-departure orientation program may use it as an aid to determine their own goals, after which they can develop sub-goals and objectives based on the particular needs and resources of their participants and program, and select strategies that would best implement them. Or the staff may use it to guide goal evaluation and subsequent modification.

\section{Summary}

The purpose of this research study was to identify suitable goals for missionary cross-cultural orientation programs and to provide a framework for their determination. The methodology used was a validation of the goals of the Institute of World Mission, a representative, comprehensive, pre-departure missionary orientation program. Its 28 years and 66 orientations have made an invaluable contribution to over 2,500 Seventh-day Adventist missionaries, their mission work effectiveness, and satisfaction.

A four-phase process was developed to validate the Institute's goals. The first phase was the identification and clarification of program goals. The second 
was the collection of data from six sources for validation of the Institute's goals. The six sources comprised observation of the program in operation, a questionnaire sent to both administrative stakeholders (church leaders) and criterion populations (current and retumed missionaries), a review of missionary preparation, a summary of cross-cultural orientation literature, and a discussion of trends and issues. Sources 2 and 3 make up the empirical portion of the study. Questionnaires were constructed and sent to selected populations. Descriptive analysis was used to determine whether the Institute's goals are (1) appropriate (important, essential, relevant), (2) possible (clear, measurable, feasible, attainable), (3) attained (observed, achieved during IWM, applied in the field), and (4) comprehensive enough to achieve the aim of the orientation program (expected, comprehensive).

The third phase was a cross-validation of the goals by a synthesis and analysis of all six sources. Finally, from the research process emerged a reconceptualization of program goals. This conceptual framework is also a process suggested to guide similar cross-cultural orientation programs in determining their most appropriate set of goals. It can be used as a tool for planning orientations, or designing goal modifications when changes are made or felt needs arise. Organizations may use it to decide how they will provide for all the pre-departure preparation needs of their workers. 


\section{CHAPTER III}

\section{PRESENTATION AND ANALYSIS OF FINDINGS FROM VALIDATION SOURCES 1 TO 3 CASE STUDY POPULATIONS}

Phase Two of this study is the selection of data from six sources to validate IWM's pre-departure orientation goals. This chapter reports the findings of the first three of these sources which are comprised of the case study populations. These several groups were selected because their perceptions are critical to validate suitable pre-departure preparation for cross-cultural missionaries. They include IWM's staff and attendees, administrative stakeholders (three groups of leaders), and both current and retumed missionaries.

The Institute was designed to be comprehensive because it is the only cross-cultural preparation most of the attendees will have outside of occasional related undergraduate or graduate coursework. Attendees are generally well-trained and qualified in their particular profession or vocation, however, and have usually had extensive education in Bible knowledge. Because it is comprehensive, IWM is a useful model to use for determining goals for preparing missionaries before they depart for service, and from which to determine those suitable for orientation programs. 


\section{Source 1: Observation of the Program in Operation}

Data from staff and attendees were generated from observing the program over time. As a researcher, I studied the IWM program in operation in the following ways: development of IWM's purpose/goals, observation of one IWM session, and examination of IWM evaluation forms.

The first task was a study of the Institute's purpose and development of goals over its 28 years of operation. Detailed reports to the General Conference Secretariat from the director and/or staff provided most of the data for this section. The second task was an evaluation of one particular 4 1/2-week session I attended in 1989 as an participant-observer. I surveyed the Institute's schedule of activities and actual practice to determine whether all goal statements created by the identification and clarification process were represented.

After the Institute, I examined the evaluation forms participants had completed to get another view of how the attendees felt about the various activities designed to achieve the goals. A final check reviewed completed evaluations from 17 previous Institutes held between 1987 and 1993. Comparing the combined data comprising Source 1 increases the reliability of the data from this source.

\section{Development of Institute of World Mission's Purpose and Goals}

Over most of the history of the Institute of World Mission, all pertinent documents have been kept. In addition to registration and evaluation questionnaires 
filled out by participants, comprehensive reports were prepared by the director and/or staff after each Institute and sent to the Secretariat of the sponsoring organization, the General Conference. Until recent years, most of these reports are very detailed, often 20-25 double-spaced pages each, and provide information regarding most facets of the Institute experience. This section is based on information drawn primarily from these reports to the General Conference.

The Institute's cross-cultural preparation for Seventh-day Adventist missionaries has always been needs-based. The orientation program determined its content by recognizing the needs of its participants, the contexts they will minister in, and the program purpose. These three sources of information to determine needs provide the trainers/experts with the core of what a preparation program should include. In the case of IWM, its goals are planned around participant needs informed by all three sources.

The following discussion illustrates how the Institute utilized education, training, and briefing modes by organizing them around an orientation purpose rather than a training or education purpose. The organizing principle of orientation is to prepare participants for entry into the foreign context through a secure and warm environment to enable maximum readiness to leam in the program and to enter the new context. Security and support constitute major participant needs when departure is imminent. Thus, a needs-based model and orientation purpose are closely interrelated, and show the relationship between program goals and means. 
The following discussion illustrates this relationship, and shows how the determination of program objectives can be tied to both goals and methods.

\section{Orientation Program Purpose}

Preparation can be divided into pre-departure, in-country, and re-entry phases. Each of these phases can be further organized by one or more leaming modes such as the four defined by Kohls: education, training, orientation, and briefing (see Table 1). His delineation of various learning modes and their applications illustrates how the general purpose for each differs. This study concerns pre-departure orientation, which identifies a particular phase of the preparation cycle delimited by the purpose inherent in it. The needs that arise or remain from the purpose of this particular preparation phase are those that are to be put into operation, translated into goals, and further translated into objectives and methodologies at the appropriate time in the planning process. If the purpose is not deliberately and carefully established, the subsequent goal development process will not be as clear and directive as it could be, and will probably limit program effectiveness. If an overall preparation plan to meet all person and context needs is designed first, and then every need is organized into the specific preparation phase(s) suitable, all relevant preparation needs would more likely be accommodated. It is the overall purpose of each segment within those phases, however, that determines where each need should be designated and thus dictates the specific needs each segment should meet. 
The importance of one overarching purpose is enhanced rather than eliminated when multiple leaming modes and approaches are necessary in a single program, as in the case with Institute of World Mission. Instead of attempting a multi-faceted purpose, one overall purpose should be established to provide the organizing principle around which all goals are organized. For example, the Institute of World Mission is held for appointees who have had little if any formal cross-cultural education/training preparation, but who have already been appointed and who await departure as soon as transition details have been taken care of, usually within a few weeks. (Some have had informal preparation such as relevant college coursework, overseas travel, student short-term mission experience, or as children of missionary parents.) The overall purpose for the Institute, then, must be "orientation," to provide the necessary information and experience to enable leamers to reach a state of readiness to begin the cross-cultural experience, in a nonthreatening environment. It is obvious that this readiness would also require most other forms of learning during orientation. An "orientation" purpose must be experiential in approach but can also accommodate the "education," "training," and "briefing" that need inclusion. The reverse is not necessarily true.

In some ways, the Institute of World Mission's orientation program tries to accomplish the impossible with regard to the extent of preparation it attempts. The enthusiasm and apparent readiness expressed by its participants not only helps to validate IWM's success, but also the value and effectiveness of selecting one overall purpose. The Institute of World Mission has not had to make major 
structural changes in its more than 27 years of operation. I believe the reason is because it identified and understood its real purpose in its beginning, and organized and integrated its goals around it.

The preparation needed by missionaries was modestly conceived by the organization in the 1960 s. Persons who attended the Institute had been recruited, selected, and appointed, although there were occasions when an appointment was reconsidered by the prospective missionary or sending organization as a result of Institute attendance. The General Conference Secretariat had made sure the families had passed the required physical exams, had provided the most urgent appointment details, and would provide a 1-month pre-embarkation visitation period. By the time appointees were sent to the Institute of World Mission, most were probably well into the selling, packing, and perhaps final visitation stages of the pre-departure phase of the transition. The Institute recognized that its participants would likely have little if any formal missionary preparation prior to program attendance, except for a probable foundation in Bible knowledge and task qualifications, even if attendees were retuming missionaries. All types of preparation--education, training, orientation, and briefing--were necessary because no other entity would assume these responsibilities. The 4-6 weeks allowed for the preparation program would require an intensive and comprehensive approach.

Pre-departure orientation has an inherent urgency for participants. Their readiness to learn is assured once they recognize that the program will meet their real and felt needs. The personal psychological environment and learning climate 
are critical for the feeling of transition support, and if they are positive they will mediate the culture shock that begins during this transition period. Human need during a time of profound change impacts identity, security, values, beliefs, motives, and other psychological variables. When the cross-cultural dimension is added to preparation needs, the critical nature of effective orientation is evident.

The changes that cross-cultural success requires are especially difficult for Americans who tend to be individualistic, are often unsocial with host nationals, and may be either too aloof or too dependent upon fellow expatriates. The program director and staff must aim to create a non-threatening and nurturing environment in which to arouse awareness of necessary cross-cultural learning that will enable psychological change to take place with minimum resistance. Participants have real and felt needs that are also represented by this purpose. The participants perceive a need to prepare for the transition by finding out as much as possible about the new context and how to function in it, little knowing the psychological trauma such preparation may bring. Some of the need for management of transition details elicits a caregiving function for the Institute staff and General Conference representatives. The real and potential loss of their social support system compels participants to seek replacement.

Thus, how could participant needs and types of program modes (education, training, orientation, briefing) with their differing purposes be organized into one program that would provide the greatest preparation possible? The Institute's solution to all these "orientation" needs was to focus on the orientation 
purpose and to deliberately create a "family." From the earliest moments of Institute activity until the finale, the reality of family was nurtured by the director and staff, and planned for in the schedule. The family approach is stated in the goal statement list as "To nurture community, fellowship and relational skills," and is designed to create a non-threatening environment, the hallmark of orientation, in which cross-cultural understanding and possible trauma could occur with minimum discouragement and damage. Several facts and incidents illustrate how implementing the program purpose through the nurture of family achieved a nonthreatening environment in which to view one's limitations (such as ethnocentrism), change attitudes, grasp knowledge of issues, encourage responsible risk-taking, and enable incorporation of required behaviors and skills into mind and choice patterns.

Almost without exception, the collection of appointed individuals that came together for each particular Institute had become a corporate group with its own unique and identifiable personality by the end of the first week. A person might argue that mere association as a group which spent most hours of the day together would be sufficient to provide this identity. Of course, a common purpose, shared vision, and shared time and space did contribute to family formation. However, these commonalities are not sufficient to explain the phenomenon. For example, several times when latecomers to the Institute arrived after the first week, they had difficulty becoming integrated into the family to the same degree as the rest of the group. They usually remained somewhat outside the "inner circle." 
Institute staff nurtured the shaping of community attitudes, confirmation of call, and growth of faith and commitment. The first step in corporate identity formation often came through some form of social occasion for getting acquainted. This party, together with one or two more recreation events in the form of volleyball or some other active games, and worships of praise and challenge, completed the first week's events that helped form the group's esprit de corps. The developing camaraderie contributed to further strengthening and clarifying a family identity during the remaining 3-5 weeks. As one person noted, "Participants came as strangers; they left as friends and as brothers and sisters."

Culture shock often begins before or during orientation, hence the need for a supportive and nurturing environment. In fact, the orientation experience may help inoculate against overwhelming future culture shock. When the indistinct and euphoric dreams of many appointees become filled in by a more realistic picture, the contrast is often disappointing. In this sense, all goals contribute to necessary orientation preparation and require an environment that provides reassurance while the realistic picture is being painted.

The staff was challenged in its attempt to form and maintain this family identity. Some groups were highly mono-cultural. The greatest challenge came when the group was culturally diverse: the greater the ethnic, educational, or personality diversity, the more difficult to form the corporate identity. Although the Institute is primarily set up for North Americans, it includes persons from varied ethnic backgrounds. In addition, returning nationals were a secondary population 
who were provided the opportunity to attend IWM. These, together with others who were in the United States and desired the preparation opportunity, interracial married couples and various ethnically diverse North American couples would during some Institutes create a multi-cultural group. This type of group would take longer to develop a corporate personality, but tended to be more bonded once the formation did take place.

Educational diversity challenged the sense of family, but the higher the mean educational level, the easier the task. The inclusion of extreme or very distinct personalities also made group cohesion more difficult. Again, when the group experienced difficult times for any of these or other reasons, they often became more bonded by the end of the Institute. In contrast, size did not necessarily inhibit the level of corporate intimacy reached. When the number of participants for a few Institutes reached more than 100 , fears of ineffective group dynamics and an inability to succeed in building community were dispelled by the end of the first week. Also, when the group included returning or furloughing missionaries, as was often the case, developing a sense of family was easier than normal. In general, the greater the number of returnees, the greater their value for corporate formation.

Even though all other goals were requisite in their own right, the spiritual goals of Faith and Call/Commitment particularly contributed to the implementation of the fellowship goal as individuals and couples shared their hopes and dreams and sense of special calling from the Father of the group, God. These goals were 
implemented through corporate worship, praise, and prayer. The content of such experiences also contributed explicitly to building a sense of family. For instance, the first worship period for several Institutes found the participants standing in a circle holding a red ribbon. The worship director described the custom of a particular tribe in a Far Eastem village. Whenever a member of that community had to leave the village, the community got together and brought out a long rope tied in a large circle. After each member of the group made a verbal wish, the person leaving was given a piece of the rope to take with him to show that the circle would not be complete until he retumed. Each Institute participant then had his or her ribbon portion cut while recounting the special vision hoped for.

Particularly important were times of shared testimonies or prayer burdens for personal struggles arising from the life transition about to take place: leaving children or aging family members behind, selling a home or car, or facing fears and/or reticence germane to the appointment. Long after the Institute, the Communion and dedication services during the final weekend are among the most remembered occasions. Both events are symbolic of family dimensions: the footwashing ceremony reflected the mutual acceptance and forgiveness found in family; the bread and wine ceremony highlighted the unity found with our heavenly Parent/Brother; the dedication service provided public recognition and affirmation of accepting the call to join the "great missionary family." One unofficial goal of the Institute, spiritual re-conversion, was confirmed by a large number of the 
participants. Research indicates that sharing on the spiritual level may provide the deepest form of human bonding.

The Institute planned for the creation of a sense of family beyond the classroom. Besides the group mode of presentation in which participants attended classes, presentations, worships, social events, and recreation together, living in dormitories or motels naturally brought about a venue that encouraged informal interaction. During the first week, participants selected membership in one of several committees organized for recreation, social events, worships, evaluation, and the Communion and dedication services. Committee work took place under the direction of the participant leader and encouragement of assigned staff. Group pictures were taken to give each family and family pictures were taken and placed on a large wall map of the world near each family's destination. In addition, the staff spent hours in counseling.

However, there was a concerted effort by Institute staff to enlarge the parameters of the family group beyond Institute participants. One of the primary means was through the personnel from the General Conference Secretariat who visited the Institute, gave presentations, and aiso spent much time in counseling. These individuals were like "parents" who provided advice and encouragement for the new venture. Another opportunity to build the new family genre was the "matching program" which was designed to enable each appointee family to build a relationship with a local community family from the same country as that of the appointment. Both locations for the Institutes are university campuses, Andrews 
University in Michigan and Loma Linda University in California, which have multinational populations and provide a rich environment for these types of opportunities.

Evidence of successful family formation was visible in numerous ways. Talk of the benefits of fellowship was open and frequent among participants, and showed up in their written evaluations. Each Institute's corporate identity was unique and dependent upon the sum total of its participants and resultant interaction. Some groups developed stronger Institute identities than others; some groups organized themselves spontaneously for helping others. One such Institute collected money from among themselves to give to a family who had experienced a fire, to make a sizeable donation to a new mission, and to help support a needy fellow missionary family.

It was also common for Institute groups to organize spontaneous and informal opportunities to expand the family association during the Institute. These took the form of prayer bands, testimony meetings, shared meals, social events, or trips. Numerous groups urged the Institute to publish a newsletter or journal to enable continued communication and education in the field. Among these were groups that did not wait for the Institute to do something, but attempted their own "family" communication system by starting their own newsletter. It was characteristic for some groups to request more participant involvement in Institute aspects such as worships, and others to complain when they felt too many invited guest speakers threatened the sense of family they were experiencing. Association with nationals during the Institute could work both ways. On the one hand, 
participants wanted more association with them when they were viewed as important to start the "new" family structure they would soon need in the field. However, if the nationals were too open in their expression of the problems missionaries needed to overcome, that particular group felt emotional rejection.

Finally, the importance of the comprehensive approach organized around the orientation purpose is underscored by the very positive response of participants who had already served overseas without preparation. These participants generally felt that the Institute was extremely beneficial to them even though they wished they had had the opportunity to attend prior to their first overseas experience.

\section{Historical Development of Institute Goals}

Almost 40 years ago, when the decision was made to establish a missionary preparation program, cross-cultural preparation principles were not as clearly perceived as they are today. A person may argue that preparation needs of yesteryear were as great as they are today, but the fact remains that today's expectations are higher because the scientific and technological advances of recent years have made us more knowledgeable and there is a greater diversity of cultures. This review of the development of goals for Institute of World Mission illustrates changing perceptions and expectations of staff and participants. Of the three needs that serve as sources to inform program goals, the orientation purpose need of the Institute has already been discussed. The following deliberation combines the personal and contextual sources of needs to be addressed by preparation programs. 
Personal factors are a primary concem because they are at the "first level" in importance. Without meeting the real and felt needs of the individuals to be prepared, they might not be ready to learn or depart. Personal needs focus on the dynamics brought into the picture through personal integration of physical, psychological, social, cultural, and spiritual aspects arising from the state of being. Among these are (1) personality and temperament traits along with psychological aspects such as identity, self-esteem, learning style preference, attitudes, motivation, and growth; (2) cultural and background factors such as cultural diversity and socioeconomic status; (3) spiritual dimensions embracing faith and meaning; and (4) experience. Personal factors involve the readiness of the person for crosscultural learning and functioning. It is the "trainee" that determines these needs. The composite of individuals determines the corporate preparation needs. The challenge is to provide for the corporate needs without neglecting the unique needs of specific individuals.

Needs for cross-cultural preparation include more than personal needs, however. There are very real needs of which participants are unaware that are indicated by the context in which they will find themselves, a culture foreign to them. Contextual considerations include those challenges directed by successful performance of the appointed task within that foreign culture, as well as daily functioning therein. The degree of contrast between the person's home culture and the foreign one, the nature of the appointed task, and the length of time necessary to complete the appointment all contribute to the nature of the need which must be 
reflected in the goals. One of the "trainer's" tasks is to identify these needs. Goal development and modification emerge from the interaction of these needs sources.

From its beginning in 1966, the Institute of World Mission designed its program to be more relevant to missionary needs than outlined by the action of Autumn Council 10 years earlier (General Conference, 1956). The genius of the Institute and its effectiveness has been the staff/director's recognition of the real and felt needs of missionaries who are nearing the time of departure, and the establishment of the "orientation" approach. The key to program success is found in the Institute's organization and integration of all goais, learning modes, and activities around these needs. Table 2 illustrates the contrast between the goals as suggested by Autumn Council and the goals that were in operation the first few years of the Institute.

First of all, and in contrast to the recommendation, the early Institutes operated on the assumption that effective preparation was more than cognitive information. In fact, despite the term "orientation" used in the Council's minutes, the purpose as outlined by the recommended goals was more befitting "education" according to today's usage of the terms. This view of preparation as education is not surprising because prospective Seventh-day Adventist missionaries had no special missionary education. At this time, preparation for missionaries from other organizations often included diplomas in mission from Bible colleges, an educational mode, prior to their "orientation" preparation. Many of these education 
TABLE 2

COMPARISON OF GOALS: ANNUAL COUNCIL RECOMMENDATIONS AND EARLY INSTITUTES

\begin{tabular}{lc}
\hline \multicolumn{1}{c}{ Autumn Council. 1956} & \multicolumn{1}{c}{ IWM. 1966-1972 } \\
\hline Personal Needs: & Personal Needs: \\
Physical Health & Physical Health \\
& Family Issues \\
& Spiritual Nurture \\
& Fellowship \\
Professional Needs: & Professional Needs: \\
Mission, Missionary Task & Mission. Missionary Task \\
Evangelism--Other Religions & Evangelism-Other Religions \\
Language Study Methods & Language Methods. Communication \\
Human Relations & Human Relations \\
Bible for Missionaries & \\
Area Studies & \\
& \\
Practical Needs: & Missionary Anthropology \\
Personul Finance & Practical Needs: \\
Organization Policies & Personal Finance \\
\hline
\end{tabular}


programs included cross-cultural preparation as well. The Annual Council delegates may have assumed that education was the first priority. (The word "training" so commonly used when discussing missionary preparation usually refers to this type of education rather than skills development which "training" usually means in general cross-cultural literature.) The dilemma facing the Institute was how to accommodate both educational and orientation preparation needs. The Institute's initial emphasis to provide for personal pre-embarkation needs indicates that the Institute of World Mission established itself firmly as "orientation" in its overall purpose to create an environment within which cognitive information could take root in emotional and skill aspects of preparation.

In its early years, the Institute was geared more towards an educational mode than it is today. For example, the Institute, because it is connected to a university, has always strongly urged participants to take the main courses (Missionary Anthropology, Science and Principles--later Principles and Practices, World Religions, Area Studies) for graduate or undergraduate credit. Requirements included textbooks and reading materials, a research paper on the particular country of appointment, and up to 4 hours of examinations. The policy has had obvious side benefits. It did not, however, appear to affect goal achievement. Little difference was seen in the motivation or participation among persons who received credit and those who did not. This fact is another illustration of the transcendence of the "orientation" purpose from which participant motivation was driven. Recent Institutes have moved even more towards the affective than cognitive approach by 
eliminating the research paper, and using a case studies approach to "examinations," but the motivation remains.

Because the focus was "needs," flexibility to allow for changing trends, different IWM groups, and individual participant needs had to be built in. As the needs of participants or contexts changed, the goais and their contents required change. The registration questionnaires alerted the staff to corporate and individual needs. The intermingling and counseling by staff members provided data to supervise and adapt to emerging needs. One device employed to maintain flexibility and relevance from one Institute to the next was the evaluation committee whose members became group "monitors" of the particular needs and trends within the group that could be met by modification of current or future programs. The minutes of their weekly meetings became a type of formative evaluation. A final opportunity for feedback came with post-Institute evaluation questionnaires. At the end of each Institute, as the staff studied these data and wrote the report for the General Conference, unmet needs became evident and recommendations or plans were made to fill them. A final opportunity for planned flexibility came with the addition of a fourth "pillar," the goal of Issues in 1984. Even though there was a planned core, this goal was designed to provide for individual and corporate needs on an Instituteto-Institute basis if necessary.

Other changes were generated by needs arising from crisis situations. One such watershed year was 1974, when the number of participants was significantly larger and more diverse; participants included 11 single women, 10 persons from 
outside the United States, 16 full-time students, with approximately half of the participants being new appointees. Fortunately, for the first time, there was a second full-time staff member and full-time secretary who facilitated experimentation with innovations. Several permanent goal changes were initiated during this Institute. Area Studies was recommended by the official action, but the first eight Institutes did not provide information about the particular countries to which the participants were assigned except indirectly through general discussions. The Institute had been designed as a culture-general approach because it believed that the group format and limited time frame would not allow appointee preparation in both general and specific cultural issues.

The staff soon recognized the lack, and participants became more insistent. Although minor from the point of time spent, the first attempt in Area Studies divided the group into three major cultural regions for discussions relative to participant appointment locations. Response was enthusiastic. Most reports since 1974 have recorded participants' expressed desire for more Area Studies information. Participants became even more adamant after the Institute was reduced from 6 to 4 weeks. The amount of time for implementing Area Studies was reduced directly. The tension between providing enough country-specific information to satisfy the participants yet covering all the other real needs recognized by the staff within the time frame remains. This is a common problem for orientation programs. 
Another innovation begun in 1974 was voluntary psychological evaluation through inventories such as MMPI (Minnesota Multiphasic Personality Inventory). A professional in the field joined the Institute for the implementation of the emotional health goal. During that Institute, there was a consensus that the goal met a real need. Two years later, the 16PF test (16 Personality Factors) along with MAT (Motivation Analysis Test) and CAQ (Clinical Analytical Questionnaire) subtests were used. Children were soon included in the testing program. An attempt was made to have the tests administered to appointees and analyzed before the Institute began so there would be more time for individual counseling and subsequent participant change.

Both staff and participants found that the value of the mental/emotional health goal could hardly be overemphasized. The occasional participant would become defensive and resentful if the members of staff became too closely involved with the testing; they feared the tests would jeopardize their appointment. Use of psychological testing along with professional counseling has made participants aware of their strengths, needs, and weaknesses. Testing created a readiness to seek counsel and get needed help. It also strengthened the emphasis on spiritual goals by enlightening participants of their critical influence. The consulting and counseling services reduced missionary failures, premature retums, and brought more job satisfaction and effective ministry. A new unofficial screening function did, however, became apparent by the addition of this goal, which then became a threat to marginal and unfit candidates. The Institute's opportunity to project missionary 
success or to provide evidence of danger and potential failure has been occasionally used as a side benefit to the recruitment and selection methods of the sending organization. However, the inclusion of this goal has enabled many borderline cases to get the help needed to function normally in the cross-cultural context.

A third innovation coming out of the summer of 1974 was the discussion of issues relevant to the rapidly changing worid of mission. Several challenges from participant appointments demanded attention. One was the significant number of single women. Another was the changing nature of personnel, from front-line evangelists and church planters to specialists in education, development, and administration who, as laymen, were not sufficiently literate in the message and meaning of mission, and often did not fully identify with the organization and its structure. A final challenge was personnel who were not well-matched with their appointments. Tension that results from incongruity between the appointment and the person to fulfill it increases in a cross-cultural environment. This third problem required heavy counseling, sometimes different content and methods, but also a request to the sending organization to provide participants who were more carefully recruited, selected, and appointed. The program needed to be more responsive to individual requirements. The result was an increase in discussion of unique issues which prompted a new goal. Ten years later, Issues became the fourth pillar in the Institute's program.

This 1974 Institute also conducted the first program specifically planned for children. Throughout the life of the Institute, whenever the Institute has been 
able to provide programs for children, they have been received with gratitude and satisfaction. Whenever they have not, the lack was noticed by both participants and staff. Planning difficuities arise when numbers and ages of participant children (from none to over 70 per Institute, and ranging in age from birth to 20) fluctuate widely.

Two years later, 1976, another crisis of numbers and diverse needs occurred. This summer Institute had over 100 participants and more than 50 children. Again, reforms were initiated that became permanent. This time the changes brought new organizational forms, structuring, emphases, and schedules. The two main pillars of missionary principles and anthropology were formally joined by the now full-fledged third pillar of Area Studies, conducted by area specialists with regularly scheduled meetings. Thus, 10 years after the first Institute was held, goals included an emphasis on Awareness, Attitudes, Area Studies, both physical and emotional Health, as well as general areas of fellowship and spiritual growth. In 1979, spiritual goals were established in their own right. Prior to this time, spiritual nurture was primarily implemented through fellowship in worship, praise, and prayer. Praise and prayer were continued, but worship time was used to accomplish two more tasks: specific and intentional spiritual formation, and the advancement of a theological basis for the missionary enterprise. To the "what" was added the "how" and the "why."

During the 1970s, two practices relevant to goals had been installed. The intuitive prioritization of goals according to participant needs and time constraints 
became well established. The flexibility required in a crisis served the more minor needs and goals well, but revealed the primacy of fellowship and spiritual, attitudinal, and cross-cultural ministry goals. The importance of sequencing goals was also practiced. Awareness, a readiness goal, was the first goal implemented. The goals mentioned above were implemented throughout the Institute, but there was experimentation with the sequencing of other goals. Participants were found to be most receptive to the goal of mental and physical Health during the first week or two of the Institute, so that they had plenty of time to get individual counseling and necessary shots. Information concerning Policies was also best provided early so that the content could inform urgent transition decisions.

By 1982, the number of participants had decreased because there were fewer appointments and more early withdrawals. Participant answers on registration applications had predicted these trends. As fewer front-line and more specialist missionaries were sent, the vigor of the missionary identity and enterprise weakened. The missionary identity of specialists became blurred or almost nonexistent for many, replaced by that of their specialty. Specialists tended to look at themselves as performing their particular job in a foreign setting rather than missionaries utilizing their job opportunity to share the good news about Jesus Christ. Part of the reason for this was the growing numbers of appointees new to Christianity and/or the Seventh-day Adventist Church. One consequence of the lack of pioneer work and subsequent specialist identity was an "intra-church" mentality with its corresponding decline in the number interested in cross-cultural ministry and 
shift in motivation for overseas service evidenced in the registration questionnaires. This mentality was believed to be at the heart of premature withdrawal.

These trends presented a new orientation challenge for the Institute. Goals relating to spiritual factors, conversion, identity, and commitment needed stronger emphasis. The issue of goal prioritization became critical. If IWM could instill within participants a new or renewed missionary identity, sense of call and commitment, perhaps the "new" missionaries would renew the strength of the worldwide work through their example and confession. Additional personnel might be encouraged to join the missionary movement to help reverse the trends. There were indications that this tactic, implemented through the formalization of the goals Call/Commitment and Issues, had begun to regain lost support. Fortunately for the overall work, but unfortunately for this trend, there was an increasing and urgent reduction in expatriate missionaries in favor of national replacements.

By 1983, the plan to begin creating "new missionaries" was formed. Five basic elements were in place: attitude development, fellowship nurturing, issues awareness, spirituality and sense-of-call growth, and cross-cultural ministry preparation. Incorporated into the normal classes were topics in personal witnessing and Bible study, church-growth principles, the biblical role of the laity, and spiritual gifts. Worships were geared toward a "Week of Prayer" purpose. The staff requested the General Conference to add a pastor to the staff to conduct these, as well as be a spiritual counselor to the group; it was not granted. The need for personal reflection required designated time. 
Issues became a goal for the following Institute. Among pertinent issues participants wanted to discuss was the trend toward a more holistic view of mission, one that included relief and development work as well as evangelism. Some participants were appointed to such "social evangelism" tasks. Accompanying the recognition of these needs was an increased interest to expand the Institute session from 4 to 5 weeks, but this has not been effected.

The last 10 years reflect few and only minor changes. Participants tend to be highly qualified professionally, receptive to Institute training, and more likely to have had some cross-cultural experience and/or be new Seventh-day Adventists. It has become evident that recruitment policies must add financial screening to that of physical and psychological clearance before appointing personnel. Participants have begun to mention their appreciation for the "comprehensiveness" of the Institute. They express their preference for relevant and up-to-date information, and have a more urgent desire to know the way things really are. The expressed need for more transition-information details predominated the recurring request for more Area Studies information. Some participants want a "do's and don'ts" list approach. Discussions include topics such as what to do if faced with terrorism, how and to what degree the missionary should identify with the nationals, what the missionary spouse's role is--especially if he/she is leaving a career behind, what kind of legal arrangements to make (such as writing a will), and how to provide the best parenting and children's education in the cross-cultural context. The pillar of "Issues" still accommodates current concerns. 
Throughout much of IWM's history, the fellowship goal and main pillars were complemented by several specific courses that were designed or modified according to perceived need and staff availability. For instance, in 1973, these lectures included missionary task issues, such as "Language and Communications," "World Religions," "Islam," "Buddhism," "Hinduism," "Primal Religions," "Latin American Religions," "Marxism;" personal and family issues such as "What Missionary Children Ought to Know," "The Role of the Missionary Wife," "Health \& Hygiene," "Sex \& Marriage;" and lifestyle issues such as "Temperance \& Mission," "Practical Dimensions of Homelife," "Missionary Personal Finances," "Foods," and "Dress." Twenty years later, the Institute's schedule includes four pillars plus Health, Policies, and Roles. These curriculum units incorporate whatever the perceived needs are so that individual course titles are no longer needed. Participants generally considered these presentations important but of lesser importance.

In conclusion, over the 28 years of the Institute's history, several felt and real needs have been noted by staff/attendees and recorded in IWM documents. One of these needs is more pertinent information about the country of destination, especially details about living arrangements. A second necessity is that of preparation for the whole family, especially the spouses and children of appointees. Third is the strong appeal for additional orientation after arrival in the country and during the period of service. A fourth emphatic request has been the publication of 
a newsletter, journal, or some other form of communication that encourages continued support and leaming during foreign service.

In light of trends in the world and in mission, however, today's challenges are greater than at any previous time. Questions that must be answered include Who is to be prepared? By whom? At whose expense? In what manner? The diversity of participant needs, because of differences in individual backgrounds and appointment types, requires more flexibility in missionary preparation than has yet been designed. In 1994, the number of participants appointed by the General Conference and sent to the Institute is continuing to dwindle, while the global mission plans of the Church are expanding. In addition, new grassroots movements for short-term, "tent-maker," international, volunteer, and frontier missionaries are growing rapidly. It is unclear at this time just how the cross-cultural preparation needs of persons in these movements will be accommodated since they have not come directly under the auspices of the General Conference. What part the Institute of World Mission will play also remains to be seen. Perhaps the greatest organizational restructuring in the history of the Institute is yet ahead.

Summary of Development of IWM's Purpose and Goals

The Institute of World Mission is a needs-based comprehensive program that has organized its learning modes of education, training, and briefing around an orientation purpose. To create a nurturing environment, IWM intentionally creates a "family," a corporate group identity that is unique to each Institute session. 
101

Since beginning in 1966, the Institute has always included fellowship and spiritual, attitudinal, and cross-cultural ministry goals. The Institute began with two major goal areas called pillars listed in its schedule (missionary principles and anthropology), along with numerous other class titles to cover the topics needed. Minor goal areas were added for physical Health, then mental Health, Policies, and Roles. A third pillar, Area Studies, was added in 1976 when the Institute decided to try to provide for both culture-general and culture-specific needs. In 1984, a fourth pillar was added, Issues. This pillar has a content core, but provides a flexible format to meet individual and corporate goal needs. The challenges of cross-cultural ministry preparation facing the Seventh-day Adventist Church in the 1990s will likely induce some form of major restructuring.

Although there is no replacement for orientation-type preparation, the Institute may find itself facing the challenge of contributing in new and creative ways to the diverse preparation needs of short-term, independent professional, frontier, and other volunteer or self-supporting missionaries, as well as to regular appointees.

\section{Summer Session, Institute of World Mission June 13-July 15, 1989}

On the evening of June 13, 40 missionary appointees and their 23 children came from 11 states, Canada, Hong Kong, and Singapore for the first meeting of their orientation. The mood was generally one of expectancy, whether eager anticipation or slight apprehension. Those who had come were in varying stages of 
102

pre-embarkation readiness; some were due in their new fields right after orientation, others not for several weeks or months. The task that first evening was to settle logistic details involving children, accommodation, and details of the Institute schedule that was to begin at 8:15 the next moming. Few realized how differently they would see the world 32 days later after immersion in 110 hours of planned group learning, informal socialization, and integration into the new "family."

\section{Schedule and Goal Implementation}

Institutes are normally held three times per year for $41 / 2$ weeks each to prepare missionary appointees for cross-cultural service, preferably prior to departure. Because sessions have not changed substantially over the last 8-10 years, observing one institute in depth was a useful background for understanding IWM's goals.

Table 3 shows a summary of planned program activities organized into seven curriculum categories, along with the total approximate program time spent in each category. It also shows the contribution each category makes to the 12 goals clarified for this study. To understand how the activities shown on the program schedule (see Appendix B) were categorized, see Table 4. An examination of the schedule shows that all goals, as defined later by the goal statements created for this research, were planned for in the curriculum. In fact, the schedule was consulted during the goal-clarification phase of this study. 
TABLE 3

CURRICULUM CATEGORIES AND TIME DISTRIBUTION FOR GOAL IMPLEMENTATION

\begin{tabular}{|c|c|c|c|c|c|c|c|c|}
\hline & \multirow[b]{2}{*}{ Goals } & \multirow[b]{2}{*}{$\begin{array}{l}\text { Program } \\
\text { Logistics }\end{array}$} & \multicolumn{6}{|c|}{ Curriculum Categories } \\
\hline & & & Spiritual & Cross-cultural & $\begin{array}{c}\text { Missionary } \\
\text { Role }\end{array}$ & Area Studies & $\begin{array}{c}\text { Personal }+ \\
\text { Social }\end{array}$ & $\begin{array}{l}\text { Denomination } \\
+ \text { Policies }\end{array}$ \\
\hline 1. & Policies & & & & $x$ & & $x$ & $x$ \\
\hline 2. & Issues & & & $x$ & $x$ & $\mathrm{x}$ & & $x$ \\
\hline 3. & Faith & & $x$ & $x$ & $x$ & & $x$ & $x$ \\
\hline 4. & Awareness & & $x$ & $\mathbf{x}$ & $x$ & $x$ & $x$ & $x$ \\
\hline 5. & Attitudes & $x$ & $x$ & $x$ & $\mathbf{x}$ & $x$ & $x$ & $x$ \\
\hline 6. & Competencies & & $x$ & $x$ & $x$ & $x$ & $x$ & $x$ \\
\hline 7. & Roles & & $x$ & $x$ & $x$ & $x$ & $x$ & $x$ \\
\hline 8. & Fellowship & & $x$ & $x$ & $x$ & $x$ & $x$ & $x$ \\
\hline 9. & Call/Commitment & & $\mathbf{x}$ & $x$ & $x$ & $x$ & $x$ & $x$ \\
\hline 10. & Health & & $x$ & $x$ & $x$ & $x$ & $x$ & $\mathrm{x}$ \\
\hline 11. & Area Studies & & & $x$ & $x$ & $x$ & $x$ & \\
\hline 12. & Transformation & & $\mathbf{x}$ & $x$ & $\mathrm{x}$ & $x$ & $x$ & $x$ \\
\hline & Hours $(T=110)$ & 8 & 20 & 19 & 21 & 9 & $10+13$ & 10 \\
\hline
\end{tabular}

Note. Total scheduled counseling time available is 11 1/4 hrs., or about $15 \mathrm{~min}$. per individual. Non-scheduled time added significantly more counseling time. Time for personal counseling is not included. 
TABLE 4

INSTITUTE PROGRAM SCHEDULE OF ACTIVITIES BY CURRICULUM CATEGORY

\begin{tabular}{ll}
\hline \hline Curriculum Category & \multicolumn{1}{c}{ Institute Activities } \\
\hline Program Logistics & Parents' meeting, announcements, registration, library tour, exam (case study), evaluation, closing, dedication practice \\
Spiritual & Praise and prayer meetings, worships, communion (Lord's supper), dedication (on Saturday, July 15) \\
Cross-cultural & Missionary anthropology, half the film/discussion time, simulation (Bafa-Bafa), language learning, panel \\
Missionary Role & Principles and practices, professional meetings, mission issues, special interest groups (gender issues), half the film time \\
Area Studies & Area studies \\
Personal/Social & $\begin{array}{l}\text { Personal: health and hygiene, personality testing, mental health } \\
\text { Social: }\end{array}$ \\
Antroductions, getting acquainted, recreation, dinner/talent night \\
ADRA (Adventist Development/Relief Agency), church in mission, missionary finance, AWPS (Adventist World Purchasing \\
Service), insurance
\end{tabular}


The goals were implemented by a variety of cognitive, affective, and behavioral methodologies that included lectures, discussions, guests, personal counseling, films, a panel, a simulation, recreation, singing, prayer, recreational games, a talent program, an optional field trip, and community living in a dormitory. The various activities in the program schedule were organized into blocks of $15,30,50,90$, or 105 minutes each. The implementation of 10 goals made up the majority of these time blocks. Attitude development and mindset Transformation, the other two, were designed to result from the impact of the whole orientation through the knowledge and the way it was communicated or experienced. For example, films and other strongly emotive techniques were used, in addition to lectures, stories, and discussions.

According to Table 3, the majority of group time was spent in the three categories of spiritual, cross-cultural, and role issues, each taking around 20 hours. Three other categories (area studies, personal and social, and denominational) took around 10 hours each. Personal counseling time scheduled in the Institute program was around 11 hours, or an average of approximately. 15 minutes per attendee, but many additional hours were spent outside of the time scheduled. Eight hours were spent in caring for logistic details of the Institute.

Goal statements for growth in Faith and Call/Commitment represented the spiritual category and were largely nurtured through the daily devotionals, worships, communion, and dedication services. The "presence" of these goals was felt 
throughout the Institute, however, in the Institute climate, verbal and non-verbal expression, and expectations.

Several strategies were used to improve relational skills. There was an strong emphasis on fellowship and the development of a sense of family throughout the orientation. There were also planned opportunities for social interaction. For instance, every participant became a part of one of the four committees set up to plan for spiritual life, social activities, communion and dedication services, or Institute evaluation.

\section{Goal Implementation Observation}

I attended an Institute of World Mission orientation as a participantobserver at the very beginning of the research process to evaluate the verbal/nonverbal responses and social interaction dynamics. It was important to evaluate how attendees perceived goal implementation and their own goal achievement in order to understand the validity of those goals. Most attendees were unaware of how they would spend the next month. By the end of the first day, as the new world of crosscultural understanding began to open up to them, their surprise and awe were evident. For the majority, those early experiences brought an eagerness that was maintained or deepened except for times of physical, mental, or emotional overload

or stress. For most attendees, appreciation did not diminish, even if energy did.

Two factors regarding achievement must be taken into account, however. First, the program must cover the foundations of missionary education/training as 
well as provide "orientation" for the new cross-cultural assignment, because few participants have had any formal education in cross-cultural or missionary issues prior to the Institute. Moreover, a variety of non-goal factors impact attendee responses and goal achievement: particular staff presentations and emphases, staffparticipant interaction, individual participant needs, orientation climate, distractions, and other variables. Yet, the themes that emerge from the study of one Institute session, which are later compared with evaluations of several other sessions, provide a measure of reliability. The following discussion highlights attendee attitudes, impressions, and concerns that were unique to the 1989 session, but were important indicators of participant needs, achievement, and how well the Institute was implementing their goals.

As a participant-observer, I noted a decided interest in more specific information in Area Studies than was given. As might be expected, there were always more questions about material needs and resources of the new environment than could be answered. In fact, appointees were generally dissatisfied with the amount of practical information they were given about their particular area of service, transition details, and living arrangements. It would be difficult to imagine what attendees would want eliminated to allow more time for Area Studies, because most attendees were enthusiastic about all aspects of the program (with the exception of Policies for some). There is not enough time to cover both general and particular cross-cultural needs to the level everyone (or even the majority) desired. 
Another observation involves gender issues. Even though women often appeared more responsive to the presentations, they at times seemed to feel their needs were not well addressed. At the center of the problem is the female identity and roles. Most did not feel that issues relating to family and their roles as wife and mother were given sufficient attention, especially those women who had children, had not been appointed work in the overseas field, and/or were leaving a career behind. Inadequate preparation was not the only reason for women's dissatisfaction. The supporting role of women in mission is more diverse, complex, demanding, and less defined than that of men, and becoming prepared outside of orientation would be more difficult. Because women's issues were dealt with in only one 105-minute session, this distress appeared to be justified. Furthermore, except for the secretary, the Institute staff were men. Men are unable to fully identify with womens' needs, and there are certain issues women would not feel comfortable discussing with them.

Spiritual and social dimensions were among the most desired. Spiritual activities were felt to be critical. In fact, nurturing the sense of call and commitment appeared to elicit the strongest positive response. Some participants felt a need for more informal time spent in spiritual support, such as prayer groups. The Institute welcomed informal activities such as this, but understandably hesitated to plan it around an already tight schedule. On the social side, by the last week of the Institute, people had become relaxed around one another and began to feel the 
kind of social support that they would have liked from the beginning. Perhaps more could have been done to speed up the process of feeling at ease earlier on.

During the orientation, participant non-verbal behavior indicated a greater interest in some goals than others. Policies elicited a divergence of interest. Some believed the time spent could have been more profitably used otherwise, whereas others felt they needed more. Some of the differences could be explained by needs of particular individuals or presentations by particular persons. Issues in mission also generated a variety of responses, partly because of diverse and strongly held opinions. Awareness of the role of culture in mission began almost immediately and was the goal most consistently achieved by all. Interest was generally strong in presentations concerning the development of Attitudes and Competencies, but there seemed to be a naivete about how well participants thought they had achieved these goals. Because most participants were convinced these goals were important, they assumed more achievement than appeared to occur.

Most participants were interested in and challenged by the personality testing and mental health presentations. Some were hesitant. The few who felt threatened appeared to feel more comfortable when it was all over. Most participants strongly appreciated the information that contributed to selfunderstanding and coping skills. Although there was general interest in health practices, the level of interest varied with individual need.

Whereas interest was very high, participant achievement of the goals during the orientation was varied. Not everyone achieved mindset Transformation 
during the orientation, nor sensed the need for developing skills to continue culture learning in the field. Many of those who had monocultural backgrounds did not appear to grasp the variety and necessity of the cross-cultural skills they would need in the field. Neither did they seem to realize that specific skills can be achieved through practice. The length of time for meeting all preparation needs does not allow much time for skill practice.

Overail, however, participant appreciation was profuse, strongly felt, and appeared genuine.

\section{Attendee Evaluation Responses}

The third step was an examination of the evaluation forms from 18 sessions. The first examination surveyed responses from evaluation forms filled out by those who attended the summer 1989 institute. The second surveyed evaluation forms from 17 other sessions that had been held between 1987 and 1993. This examination provided another view of how the attendees felt about the goals and various activities that were designed to achieve them. The evaluation forms were designed by the Institute staff and given out to attendees on the day before the dedication service that closed the Institute. The questionnaire was designed to take one class period and asked attendees to respond to questions about the program's goals, its organization, individual presentations and presenters, methods and materials of presentation, social activities, accommodations, children's care, other facets of the Institute. It allowed for additional comments and/or suggestions. 
Evaluations of Summer, 1989

Twenty-seven of the $\mathbf{4 0}$ attendees completed the questionnaire. The first question on the evaluation asked whether the Institute had achieved its five stated objectives. These were listed as (1) emphasis on attitude development, (2) preparation for cross-cultural ministry, (3) growth in spirituality, (4) creation of awareness of current issues, and (5) development of Christian fellowship. Table 5 compares these with IWM's clarified goal statements.

\section{TABLE 5}

\section{A COMPARISON OF EVALUATION QUESTIONNAIRE OBJECTIVES AND IWM CLARIFIED GOALS}

\begin{tabular}{|c|c|}
\hline IWM Evaluation Objectiven & IWM Clarified Goal Stutement Keywords \\
\hline 1. Attitude development & S. Attitudes \\
\hline $\begin{array}{l}\text { 2. Preparation for crow- } \\
\text { cultural ministry }\end{array}$ & 4. Awareneas; 6. Competencies; 7. Roles; \\
\hline 3. Growth in spirituality & 3. Faith: 9. Call/Commitment \\
\hline 4. Awareseas of current isoues & 2. Inoves \\
\hline \multirow[t]{2}{*}{$\begin{array}{l}\text { 5. Christien fellowship } \\
\text { development }\end{array}$} & 8. Fellowship \\
\hline & Other goaln: 1. Policiea; 10. Health; 12. Transformation \\
\hline
\end{tabular}

Note. Numbers preceding objectivea/goal stntements are those asaigned them in the questionnairea.

Only one person disagreed that the Institute had accomplished their five goals by answering "no." The reason given was not related to the goals, however. Five qualified their "yes" by suggesting a stronger emphasis in one or two goals, particularly in awareness of cross-cultural issues. When asked which of the five 
objectives listed in the evaluation (attitude development, cross-cultural ministry preparation, spiritual growth, issues awareness, fellowship development) were most important to them, more than half said preparation for cross-cultural ministry. Participants believed attitude development was next in importance. Spirituality came next with 5 mentions out of 27.

Three questions in the evaluation asked whether attendees had any unmet concern or if anything was left out by the program. Around three-fourths said no or asked for a greater emphasis in one or more goals. The most common request was for more time for Area Studies. In fact, the minutes of the three evaluation committee meetings always included mention of the need for more area studies information. The other strongly mentioned request was for more time for women's issues and concems. Others asked for more help for single missionaries, or for help with transition details. When asked whether anything should be left out, participants said no on all accounts except two. The three hours of language-leaming strategies were thought to be excessive or unnecessary. Language leaming is not always included in the Institute program. In addition, a few suggested that some of the material could be condensed and repetition by different presenters avoided.

Some of the same items were listed as most and least meaningful activities, depending on the respondent. For the majority, the most meaningful activities were decidedly those relating to fellowship and social activities. More than half mentioned these, and spoke intensely of their importance. Although participants did not mention spiritual activities as much, I do not believe that they 
felt the fellowship was more important than spiritual goals. I believe they recognized that fellowship was in a different category than spiritual goals. Also, many spiritual activities were largely social.

The question asking which activities were least meaningful was left blank by the majority of respondents. Some activities were considered least meaningful to some, but most meaningful to others (e.g., the simulation game, Bafa-Bafa and specific types of recreation). For policies, comments throughout the questionnaire also revealed diversity of opinion. Some believed there was too much minutiae, or too few specifics, too much time spent or more time needed, either a waste of time or "very helpful."

Space was left for additional comments. A few spoke frankly but gratefully of the pain growth brings. The consensus was that they would never be the same. Additional suggestions made it clear that different attendees had different needs because their backgrounds, personalities, or circumstances varied. More than half volunteered a special thank-you at the end of the questionnaire to show their appreciation for the opportunity to attend the Institute.

Finally, attendee perceptions of the importance of the goals and how well they achieved them were influenced by non-goal factors, such as the quality of individual presentations, charisma of particular presenters, unexpected interruptions, and schedule changes. For instance, an unexpected interruption during the Institute came when the associate director became sick with malaria for several days. Participant factors also contributed. Some participants were distracted by 
exhaustion, illness, problems with children, concerns regarding relatives and/or appointment details, and various other stressors. In fact, it became evident that the Institute was fulfilling a larger role than the goals indicated. For many appointees, the timing of the orientation meant the Institute and its staff were called upon to be primary caregivers at this crucial transition period during which appointees felt vulnerable and without adequate coping skills. Knowing how to handle the transition is in itself one of the most important preparation needs of prospective missionaries.

\section{Evaluations of 17 Other Sessions}

A final check came from a review of completed evaluations from 17 more Institutes. Responses from these evaluation questionnaires were examined so that the findings could be compared with those of the orientation program I attended. Each Institute is unique because each has its own identity/personality, climate, and staff-attendee interaction. If similar perceptual themes emerge when comparing the evaluations from several Institute groups, reliability increases.

The evaluation forms for the 17 other sessions were the same as the one used for the 1989 summer session, so the first question of the evaluation was the same. It listed the five goals and asked the respondent whether (and how well) he/she felt the Institute program had achieved them (attitude development, crosscultural preparation, spiritual growth, issues awareness, and fellowship). No respondent said "no" to any goal for the 17 sets of program evaluations. All those 
who answered the question strongly in the affirmative agreed the goals had been achieved. Only $14 \%$ qualified their agreement with suggestions that usually took the form of advising a stronger emphasis in one or more goals. Several advised a stronger emphasis in issues awareness and some in spiritual growth. More emphasis in attitude development and fellowship were suggested by a few. One person suggested the Institute include "policies" as a goal since so much time was spent on policy issues. (It is a goal in the expanded list of 12.)

A second question asked attendees which of the five goals they felt had been most important for their training. Many respondents had difficulty choosing and wrote that by choosing one they did not intend to negate the importance of the others. Fourteen of the 17 Institutes chose preparation for cross-cultural ministry as the most important goal for them. When individual selections for all 17 are tallied, almost half selected cross-cultural preparation (47\%). Attitude development was selected by $25 \%$, spiritual growth by $18 \%$, and only $5 \%$ chose issues and $5 \%$ fellowship. In addition, it appears that participants believed the Institute had adequately prepared them for cross-cultural ministry since it was not usually mentioned as a goal needing stronger emphasis in tallied responses to the first question.

When questioned whether they had concerns that were unmet by the Institute, most attendees indicated they had none, but a few added qualifications. Concerns that were mentioned appeared to be a matter of emphasis rather than absence. For instance, many stressed the need for more Area Studies information. 
Several stated they needed information to help with transition decisions, something the Institute was not really qualified to provide, except as personal advice. Some attendees wished for a stronger emphasis in spiritual experience and/or fellowship opportunities. There were two unmet concerns listed that appeared to be more a result of absence than inadequate emphasis, however. These surfaced in 12 and 13 of the 17 Institutes. The most frequently mentioned need was for dealing with womens' and family issues. Almost as often, there were requests for some form of preparation and orientation for children. Except for the usual one to three class periods per Institute that discussed women's needs, Mission Institute did not appear to plan for either of these strongly felt needs in a significant way. Lack of time, finance, and priority are among the probable reasons. Finally, single attendees noted that the Institute did not sufficiently address their special needs.

When asked what activities they found most meaningful, attendees mentioned fellowship and social activities most often, and the simulation game BafaBafa next. Minor mention was made of spiritual activities or films. Again, the question asking what was least meaningful was usually left blank, but the few who answered mentioned films, the simulation game, or certain types of recreation (i.e., wished for table games rather than volleyball).

\section{Summary and Analysis of Findings From Source 1 Staff/Attendee Views}

Documents and participant-observation provided the data for determining the views of the staff and attendees. Three research activities make up Source 1: 
(1) a study of Institute staff reports to the sponsoring organization to determine goal development and prioritization; (2) an in-depth study of one Institute, its curriculum, schedule, staff-participant interaction; and (3) an examination of 18 sets of Institute evaluation forms filled out by attendees at the close of the session.

From the beginning, the needs approach was recognized as most useful by the director and staff, and this approach prompted an orientation purpose for missionary cross-cultural preparation that integrated the goals and organized all the leaming modes. The creation of "family" was the method used to implement an orientation purpose. Data from staff/attendees documents and observation show that the Institute's effectiveness and resulting participant success is largely due to its (1) orientation purpose and emphasis on fellowship; (2) spiritual and attitudinal dimensions; (3) applications made to the cross-cultural context for mission; (4) emphasis on psychological testing and counseling; (5) the addition of Area Studies; and (6) built-in flexibility that has been able to be responsive to the needs of individual Institutes as well as move with the trends.

The major emphases according to time spent were spiritual, cross-cultural, and missionary role issues, although fellowship overrides all other considerations in its pervasiveness. All goals have been implemented, although in varying degrees and by means of different methods. No major curriculum changes have taken place in the last few years of Institutes.

Despite variation, attendee verbal perceptions and written responses on IWM's evaluation forms are remarkably consistent. Perhaps most notable is the 
heartfelt thanks that permeated all forms of participant expression. Attendees believe the Institute meets its goals. For around half the attendees, preparation for cross-cultural ministry was believed to be the most important goal of the five listed on the evaluation form for the Institute to meet, and they believe it was met. They see attitude development as next most important, followed by spiritual growth. Awareness of issues in cross-cultural mission was mentioned most often as the one goal that could have had more emphasis when attendees were asked if all goals were met, but was selected fourth of the five stated in importance. Fellowship was ranked least important of the five, but was mentioned as the most meaningful activity in another part of the evaluation questionnaire. These observations were reflected in the staff reports to the General Conference.

"Unmet concerns" revealed individual needs that were a matter of emphasis rather than absence of goals. For example, increased emphasis in Area Studies and transition details was desired most. Although the Institute program is seen as comprehensive enough to most, there is a persistent perception that the Institute does not adequately meet concerns in issues relating to women, family, children, and singles. These inadequacies were also consistently mentioned by the staff in the closing reports to the General Conference.

A question may be raised why the staff views attitude development and fellowship as more important, when the participants generally select cross-cultural preparation for ministry as primary. Differences in the perspectives of the expert and recipient may be responsible for this phenomenon. Those responsible for goal 
implementation are "teachers" and would easily recognize the magnitude of readiness issues, such as attitudes, spiritual strength, and social support needs prior to and during the learning process. In contrast, the participant probably does not recognize these needs to the same extent as the expert because of limited understanding, view, and experience. Even if the participant does not easily recognize the primary role of affect, or takes it for granted, the participant is nonetheless freed to focus on the purpose for preparation and particular content of the learning.

Another reason participants may not perceive attitudes and fellowship to be as critical as the staff relates to how each group prioritizes needs. The goal "preparation for cross-cultural ministry," as it is listed in the evaluation questionnaire, is so basic and inclusive (representing more than half the 12 goals) that its perceived preeminence would be expected. In fact, it could be seen as the aim of the entire program. Subconsciously, participants may cognitively separate these three "stated objectives" of the evaluation form into primary and secondary levels (readiness and content) and, believing their attitudes are acceptable, see the actual content of learning as the core of preparation.

Evaluation form responses, including voluntary comments and suggestions for the Institute, revealed an intriguing theme. Although participants recognize their core need as cross-cultural preparation, many of the comments could be seen as a need for support, whether spiritual, social, training, or logistic. The strong desire for meeting spiritual needs has already been noted. References to fellowship 
pervaded the questionnaires, and it was stated as the most meaningful activity of the Institute. But participant suggestions also demonstrated the need for support. There were frequent references to a need for more time for personal counseling.

Comments focused on building a sense of family in practical ways, such as a desire for more missionary participation in non-social activities of the Institute, and greater opportunities to interact with non-participant missionaries and nationals during the Institute. There were also ideas for various forms of contact/communication between the Institute and missionaries in the field, and requests for continued orientation in the field. The felt need for more information in Area Studies and the diversity of opinion regarding Policies could also be seen as support issues.

These examples demonstrate in several ways that support appears to be the most strongly felt need during the time of the Institute, a fact that validates the orientation purpose used by the director and staff to organize the entire Institute preparation experience.

\section{Sources 2 and 3: Survey of Administrative Stakeholders and Criterion Populations}

Perceptions of two major groups make up the empirical part of this study: stakeholders (leadership) of the sponsoring organization, the Seventh-day Adventist denomination; and criterion populations--current and returned missionaries appointed and sent out by the sponsoring organization. All groups received the same questionnaire. 


\section{Population Groups}

Church leaders comprised four administrative groups: General

Conference administrators, overseas Division officers, overseas Union officers, and leaders of major overseas institutions. Division and Union officers were combined into one group for analysis to make a total of three. Missionaries comprised two groups: those currently serving at the time the questionnaires were sent out, and those who had returned from the field during the 10 years between 1981-1990, whose addresses were available in the Seventh-day Adventist Yearbook, 1992.

Approximately one-third of the questionnaires sent went to church leaders who make up a little over one-fourth of all respondents. The two-thirds sent to missionaries were nearly equaily divided between current and former, but the return rate of former missionaries was higher. Table 6 describes the population.

TABLE 6

NUMBERS AND DISTRIBUTION OF RESPONDENT QUESTIONNAIRES

\begin{tabular}{lcccccc}
\hline & Sent & Unret'd & Ret'd & Usable & \% Ret'd & \% Usable \\
\hline Church Leaders & 338 & 225 & 113 & 112 & 33 & 33 \\
General Conference & 64 & 28 & 36 & 35 & 56 & 55 \\
Divisions/Unions & 173 & 124 & 49 & 49 & 28 & 28 \\
Institutions & 101 & 89 & 28 & 28 & 28 & 28 \\
\hline Missionaries & 1056 & 534 & 534 & 483 & 51 & 46 \\
Current & 519 & 296 & 223 & 211 & 43 & 41 \\
Returned & 536 & 225 & 311 & 272 & 58 & 51 \\
\hline Group Totals & 1393 & 758 & 647 & 595 & 46 & 43 \\
\hline
\end{tabular}




\section{Questionnaire Return Rates}

Of the 1,393 questionnaires sent out, 647 (46\%) were returned, but only $595(43 \%)$ were filled in adequately for use in this study. Although the overall response rate of $43 \%$ is less than desired, it is considered sufficient for this study for two reasons. First, it is believed representative of the total population. Second, motivational and logistical factors help explain the low response rate.

Several factors illustrate how the respondent population is representative of the total population. The group proportions of questionnaires sent and returned are similar, as mentioned above. Tables that describe the population show that several of the subgroup percentages of respondents, such as gender, are also similar to the percentages of questionnaires sent to that group. Every demographic subcategory (except the age group 15-24) is represented by respondents. There is a range of response to the questions even though the overall perceptions are remarkably consistent. When responses were evaluated for demographic differences to check for reliability, only a few significant differences were found and these could be explained by expectable variation in felt needs. Furthermore, because the whole population was surveyed, the number of respondents does not need to be as large as a sampling technique would require. Finally, it is unlikely that such a large number of questionnaires sent out would elicit responses from only those who appreciated and benefited from IWM's orientation, and no single questionnaire differed dramatically from the overall response range of the majority. 
Based on observations, letters, and questionnaire comments, several motivational and logistical factors also help explain the relatively low response rate. One contributing factor is the length and detail of the questionnaire, and both church leaders and current missionaries are extremely busy people. Many are often away from home for extended periods of time; perhaps they never received the questionnaire or thought it was too late to retum it by the time they did arrive home. For the majority of missionaries, two questionnaires were included in the envelope for both husband and wife to fill out, but it is likely that some felt that only one completed return was necessary.

Logistically, it was difficult to obtain current addresses and to mail to foreign addresses. A study of Table 6 reveals a return pattern that illustrates the difficulty of sending mail to or receiving it from overseas locations. The retum rates of those groups based in the United States (General Conference leaders and retumed missionaries) are higher than of those overseas (Division, Union, institutional leaders, and current missionaries). For instance, there were twice as many returns from leaders working at the church headquarters in Silver Spring, Maryland, as from leaders in any of the overseas leadership groups. A similar pattern is reflected by the two missionary groups; the return rate for current missionaries is only $80 \%$ of the former-missionary group.

Overall, a higher proportion of missionaries $(51 \%)$ than church leaders (33\%) retumed questionnaires but, with only one exception, leaders returned usable questionnaires, whereas 49 missionary retums $(5 \%)$ were unusable. The very low 
response rate for leaders again illustrates the problem with foreign responses; the overseas subgroup had a $28 \%$ return rate even though the number of questionnaires sent was over four times the size of the Stateside leader group whose return rate was $56 \%$. One advantage to having received more overseas leadership retums would have been a larger number of non-North American responses. (The large percentage of non-North American leadership may also help explain the contrast between overseas and Stateside leadership retum rates.) Would responses from persons who did not respond have been substantially different from those who did retum a questionnaire? This is not known. What can be stated, however, is that the views of the non-North American group who did return questionnaires did not differ substantially from the range of North American responses.

A global population is not easy to survey. In fact, lower retum rates are generally expected for studies involving international populations. Besides the challenge of reaching a population through a foreign postal service, it is sometimes difficult to reach the named persons because they may no longer be at the address listed, and there is no practical way to pursue these problems. Furthermore, some of the techniques commonly used to improve response rates for survey methodologies were considered impractical for most of the population groups. Where these incentives were used for this study, they may have contributed to a higher response rate. For instance, stamped retum envelopes were included for the retumed missionary group, and reminders were mailed 3 weeks after the 
questionnaires. Their rate of return was $58 \%$, with half of the questionnaires coming in after the postcard reminder.

\section{Population Demographics}

The 595 respondents selected for sources 2 and 3 of the study are divided into church leaders (19\% of $\mathrm{N}$ ) and missionaries ( $81 \%$ of $\mathrm{N})$. The missionary group is further divided into current missionaries who make up $35 \%$ of the total population, and retumed missionaries, $46 \%$. This general population is described by age, gender, marital status, national background, current occupation, and educational level and background. Detailed statistical data descriptions for all the demographic information can be found in tables in Appendix $\mathbf{C}$.

Eighty-three percent of the population was between the ages of 35 and 64 , with one-third between $45-54$, and $11 \%$ aged $65+$. This age pattern is fairly consistent for gender, marital status, and ethnic origin. The highest proportion for each group--current missionaries, returned missionaries, and leaders--was found in ascending age spans, 35-44, 45-54, and 55-64, respectively. The vast majority of respondents are married (96\%); only three respondents stated they are divorced.

Eighty-five percent of respondents are North Americans. The remaining 15\% who returned questionnaires are originally from Central and South America, Australia, Europe, Asia, Africa, and the Middle East. Ten percent of North Americans are leaders, and $90 \%$ are missionaries, but $66 \%$ of non-North Americans are leaders and $34 \%$, missionaries. Of the population, one-fourth were educators at 
the time they filled out the questionnaire, $19 \%$ were administrators, $16 \%$ were in the medical/health field, $9 \%$ were doing pastoral/evangelistic work, and only $7 \%$ were homemakers.

Almost all of the respondent population (98\%) have been educated in institutions of higher leaming. Only six persons have not had any college work, and three of these have had vocational training. Thirty-eight percent hold a master's degree and 22\% a doctorate. Around one-fourth had coursework in eight areas: Bible/religion, missions, church growth, communications, anthropology, crosscultural studies, world history, and current world affairs. Over $90 \%$ of the respondents have had coursework in Bible/religion, $46 \%$ in communications, $40 \%$ in missions, and $22 \%$ in cross-cultural studies.

\section{Missionary Demographics}

When the total population is divided into missionaries and nonmissionaries, it is found that only $3.5 \%$ of the 595 respondents have had no crosscultural missionary experience. The missionary background of so many church leaders (81\%) should enable them to make an even more informed evaluation of preparation needs. Only 7 of 570 missionary respondents were not classified as regular appointment personnel. (Currently, a regular appointment is typically a 6year term with one or two furloughs, and provision for extending the contract 2 or 3 years at a time.) A majority of regular appointees was expected because most shortterm and other types of missionaries are self-supporting rather than financially 
connected to the sending structure of the denomination. The proportions of individuals according to missionary service type are similar to those of the general population: education, 33\%; administration, $24 \%$; and medical/health, $14 \%$.

The total number of years spent in cross-cultural service by the missionary respondents would span between 5,756 and 6,614 years, yielding an approximate average of between 10 and 11.6 years per missionary. It is impressive to note that $24 \%$ of all missionaries (133 persons) served around half $(3,145$ years) of the total number of years accumulated by the total group. There is evidence that career missionaries are decreasing in number. Missionaries gave two main reasons for retuming to the homeland: children's educational needs (23\%) and accomplishment of assignment (14\%). There was a small representation for each of the other reasons (see Table 47 in Appendix C). Retirement was the most common "other" reason given. Handwritten comments indicated overwork/bumout, a common problem prompting retum. Comments that revealed reasons not listed included conviction of God's leading, financial challenges such as debt, disadvantages of overseas living, organizational requests for resignation or release, family growth needs, or poor language abilities.

Only $62 \%$ of missionary respondents attended Institute of World Mission orientation, three-fourths of them current missionaries, but only $59 \%$ of the returned group. Interestingly, only 37\% of leaders with missionary experience have had IWM orientation. Age categories indicate that the older the missionary, the more likely he or she did not have IWM orientation (11\%-53\%). Reasons for this 
phenomenon include the increasing demand by the organization for missionaries to attend IWM and the increasing recognition of its value by appointees. Those who stated they had other training reported a variety of experiences such as growing up as an "MK" (missionary kid) or serving as a student missionary.

\section{Perceptions of IWM Goal Validity}

After the demographic section of the questionnaire, a list was presented of the 12 goal statements clarified for IWM's orientation program. The remainder of the questionnaire asked respondents, in a variety of ways, to indicate how important, essential, relevant, clear, measurable, feasible, attainable, attained, and comprehensive they perceived those 12 goals to be. Only those who had attended the Institute of World Mission were required to fill out the section relating to achievement.

\section{Goal Statements and Validation Categories}

The 12 goal statements are listed in Table 7. The numbering is used to make identification easier. The key word is the topic word selected from the goal statement for easy reference, and is used in the tables throughout the surveys, as well as in this dissertation. The entire goal statement follows the key word. Four validation questions were constructed to validate Institute goals and to allow respondents to express their perceptions of them. These reflect the types of validation considered appropriate for this study. Three of the four were supported by factor analysis. The four questions include Are these goals appropriate? Are 
these goals possible? Were these goals attained? and Are all 12 goals

comprehensive enough to achieve the aim? Validity is further strengthened by a concluding discussion of the consistency of the perceptions across demographic lines.

TABLE 7

GOAL STATEMENTS WITH CORRESPONDING NUMBER AND KEY WORD

\begin{tabular}{lll}
\hline & \multicolumn{1}{c}{ Key Word } & \multicolumn{1}{c}{ Goal Statements } \\
\hline 1. & Policies & To clarify church and agency policies and their application \\
2. & Issues & To enlarge the understanding of curreat issues in world mission \\
3. & Faith & To facilitate growth in the experience of faith \\
4. Awareness & To create an awareness of the essential role of culture in ministry \\
5. Attitudes & To further the development of attitudes vital to effective ministry \\
6. & Competencies & To identify and foster essential cross-cultural competencies \\
7. & Roles & To increase knowledge and understanding of role expectations \\
8. & Fellowship & To nurture community, fellowship, and relational skills \\
9. & Call/Commitment & To strengthen the sense of call and commitment to mission \\
10. Health & To teach and encourage appropriate mental/physical health \\
11. Area Studies & To provide orientation to respective world areas of service \\
12. & Transformation & To equip for continuing growth by mindset transformation \\
\hline
\end{tabular}

All response data for the 12 goals was factor analyzed to determine whether there was support for the way in which the variables were organized into the constructs represented by the validation questions. The data fell into three factors whose eigenvalues were greater than 1.00 corresponding to three questions. 
The fourth characteristic, comprehensiveness, was not expected to cluster in the factor analysis because there were far fewer data to determine it, and the methodology to determine comprehensiveness was necessarily more qualitative.

\section{Validation Category Number 1}

Are IWM Goals Appropriate?

For an IWM goal to be valid for cross-cultural orientation for ministry, it should be considered appropriate for and by the population. This first question examines the relationship of the goals to external requirements. In other words, are they considered important, essential, and relevant enough to meet the needs of the participants who will function in a cross-cultural context?

IWM goals are perceived to be important

Page 2 of the major questionnaire asks the respondents to rate IWM goals by indicating how important they felt each one was in preparing missionaries for cross-cultural ministry. This enabled me to rank the goals according to their means. The following scale was used: 1 = not important, 2 = somewhat important, $3=$ important, $4=$ very important, and $5=$ extremely important. Table 8 shows the relative importance of the 12 goals as perceived by the total general population.

Every goal is considered important by $96 \%$ or more of the population. In fact, every goal except one (Policies) has the largest number of responses in the "4" or " 5" category (very or extremely important). Three of the four goals, with $40 \%$ 
TABLE 8

RELATIVE IMPORTANCE OF THE 12 IWM GOALS AS PERCEIVED BY THE TOTAL POPULATION

\begin{tabular}{|c|c|c|c|c|c|c|c|c|c|c|}
\hline & \multirow{2}{*}{ Goals } & \multirow{2}{*}{$\mathbf{N}$} & \multicolumn{5}{|c|}{ Frequencies by $x$} & \multirow{2}{*}{$\mathbf{x}$} & \multirow{2}{*}{$\mathbf{s}$} & \multirow{2}{*}{ Rank } \\
\hline & & & 1 & 2 & 3 & 4 & 5 & & & \\
\hline 1. & Policies & 589 & 4 & 14 & 41 & 25 & 16 & 3.34 & 1.04 & 12 \\
\hline 2. & Issues & 591 & 1 & 5 & 27 & 38 & 29 & 3.91 & .91 & 6 \\
\hline 3. & Faith & 592 & 2 & 8 & 26 & 33 & 31 & 3.84 & 1.02 & 7 \\
\hline 4. & Awareness & 592 & 1 & 2 & 17 & 33 & 47 & 4.24 & .85 & 1 \\
\hline 5. & Attitudes & 592 & 0 & 3 & 15 & 38 & 44 & 4.22 & .83 & 2 \\
\hline 6. & Competencies & 590 & 1 & 3 & 15 & 41 & 40 & 4.17 & .84 & 3 \\
\hline 7. & Roles & 591 & 1 & 5 & 27 & 42 & 25 & 3.84 & .90 & 8 \\
\hline 8. & Fellowship & 590 & 1 & 6 & 31 & 37 & 25 & 3.81 & .90 & 9 \\
\hline 9. & Call/Commitment & 593 & 1 & 7 & 22 & 27 & 43 & 4.05 & 1.00 & 4 \\
\hline 10. & Health & 592 & 2 & 9 & 28 & 37 & 24 & 3.71 & 1.01 & 10 \\
\hline 11. & Area Studies & 591 & 1 & 5 & 21 & 37 & 36 & 4.02 & .90 & 5 \\
\hline \multirow[t]{2}{*}{12.} & Transformation & 564 & 4 & 10 & 32 & 33 & 21 & 3.56 & 1.05 & 11 \\
\hline & Average Tolals & 589 & 2 & 7 & 30 & 42 & 38 & & & \\
\hline
\end{tabular}

Note. $1=$ not important, $2=$ somewhat important, $3=$ important, $4=$ very important, $5=$ extremely important. 
or more of the responses in the "extremely important" (5) category, are those most related to cross-cultural issues: awareness, attitudes, and competencies. These also make up first, second, and third place in the ranking of goals, with only .069 difference in their means. The standard deviation is also the smallest for these three, which indicates that the range of these responses is narrowest and the overall response for these strongest. The next two most important goals are Call/Commitment and Area Studies. These first five goals have the highest number of responses in the fourth or fifth category. Goals ranked 6, 7,8 and 9 (Issues, Faith, Roles, Fellowship) tend to cluster together in perceived importance.

The two goals that are considered least important, although still perceived important, are Policies and Transformation; and, the diversity of response range is greatest. Based on the voluntary comments by individual respondents, policies were not seen as necessarily imporant for the orientation program to address.

Transformation appears to have been misunderstood or not understood at all by a large number of respondents. In fact, $4 \%$ did not even respond to the question. Yet, Transformation was considered an important goal by those who answered and appeared to understand the concept; over half selected the very or extremely categories.

IWM goals are perceived to be essential

The third page of the primary questionnaire asks the respondents to evaluate each goal on six characteristics. Two of these, essential and relevant, 
contribute to the perception of appropriateness of goals. At first glance, little difference may be seen between the concepts of importance and essential, but there are two reasons both were used. First, each concept was presented from a different perspective in the questionnaire: important was for ranking purposes, essential for a goal characteristic. Second, essential represents the degree of importance attached. A goal may be perceived to be important but not as necessary for achieving the aim.

Table 9 shows how essential the population perceived each goal to be.

The 5-point scale provided for participant response covers a negative to positive range: $S D=$ strongly disagree (1), $D=$ disagree (2), $U=$ undecided (3), $A=$ agree (4), and SA = strongly agree (5).

All 12 goals are perceived essential by the population, with only $1 \%$ to 4\% who disagree on 10 of 12 goals. Again, however, Policies and Transformation rank 11th or 12th and are the only goals whose means drop below 4.00 and whose standard deviations are larger than the others. Yet, only about $10 \%$ of the population disagrees that these goals are essential, whereas $12 \%$ and $31 \%$, respectively, are undecided. Awareness and Call/Commitment are considered the most essential goals. They are also the two goals that have the greatest number of responses in the "strongly agree" category. It is interesting to note that both goals have only $8 \%$ who are undecided or disagree that they are essential, with only $1 \%$ disagreeing that Call/Commitment is essential. The next two "essential" goals are Area Studies and cross-cultural Competencies. The next three goals cluster and are very closely ranked: Attitudes, Faith, and Health. 
TABLE 9

PERCEPTIONS OF HOW ESSENTIAL IWM GOALS ARE

\begin{tabular}{|c|c|c|c|c|c|c|c|c|c|c|}
\hline & \multirow{2}{*}{ Goals } & \multirow{2}{*}{$\mathbf{N}$} & \multicolumn{5}{|c|}{ Frequencies by $\%$} & \multirow{2}{*}{$\mathbf{x}$} & \multirow{2}{*}{$\mathbf{s}$} & \multirow{2}{*}{ Rank } \\
\hline & & & SD & D & $\mathbf{U}$ & $\mathbf{A}$ & SA & & & \\
\hline 1. & Policies & 540 & 2 & 7 & 12 & 53 & 26 & 3.922 & .94 & 11 \\
\hline 2. & Issues & 542 & 1 & 3 & 11 & 51 & 34 & 4.151 & .78 & 8 \\
\hline 3. & Faith & 545 & 1 & 3 & 10 & 47 & 39 & 4.200 & .82 & 6 \\
\hline 4. & Awareness & 545 & 1 & 2 & 5 & 43 & 49 & 4.383 & .72 & 1 \\
\hline 5. & Altitudes & 546 & 0 & 3 & 10 & 50 & 37 & 4.207 & .76 & 5 \\
\hline 6. & Competencies & 543 & 0 & 2 & 9 & 50 & 39 & 4.247 & .73 & 4 \\
\hline 7. & Roles & 542 & 1 & 3 & 13 & 56 & 27 & 4.052 & .77 & 10 \\
\hline 8. & Fellowship & 541 & 0 & 3 & 13 & 54 & 30 & 4.107 & .74 & 9 \\
\hline 9. & Call/Commitment & 545 & 0 & 1 & 7 & 45 & 47 & 4.365 & .68 & 2 \\
\hline 10. & Health & 550 & 0 & 4 & 8 & 51 & 37 & 4.195 & .77 & 7 \\
\hline 11. & Area Studies & 548 & 0 & 2 & 7 & 49 & 42 & 4.299 & .71 & 3 \\
\hline \multirow[t]{2}{*}{12.} & Transformation & 531 & 3 & 7 & 31 & 44 & 15 & 3.618 & .94 & 12 \\
\hline & Avernge Totals & 543 & 1 & 3 & 11 & 50 & 35 & & & \\
\hline
\end{tabular}

Note. $S D=$ strongly disagree, $D=$ disagree, $U=$ undecided, $A=$ agree, $S A=$ strongly agree. 
IWM goals are perceived to be relevant

Relevancy is the third validation characteristic contributing to appropriateness and is also measured on a "strongly disagree" to "strongly agree" scale (Table 10). Again, the population agrees that every goal is relevant. Again, Awareness is the goal ranked first. Again, Policies and Transformation are ranked 11th and 12 th and are the only two goals whose means fall below 4.00. Again, Area Studies, CallCommitment and Competencies rank in the top four, although Area Studies is second rather than third as for "essential."

\section{Summary: IWM goals are appropriate}

In summary, the means of each goal evaluated for the three characteristics show that the population agrees that all of IWM's goals are appropriate. The greatest divergence of opinion is found in responses for Policies and Transformation, the two goals consistently ranked lowest. Three factors that may have affected the divergence in Policies and/or Transformation pertain to participant groups as evidenced by response patterns (not significant differences). The mean for the group who did not attend IWM was higher than those with IWM orientation; as a group, non-prepared missionaries tended to view Policies as more important. Also, and only for the goals of Policies and Transformation, retumed missionaries as a group had a higher mean in each of the three characteristics for "appropriate" than current missionaries. Retumed missionaries may appear to view both goals as more 
TABLE 10

PERCEPTIONS OF HOW RELEVANT IWM GOALS ARE

\begin{tabular}{|c|c|c|c|c|c|c|c|c|c|c|}
\hline & \multirow{2}{*}{ Goals } & \multirow{2}{*}{$\mathbf{N}$} & \multicolumn{5}{|c|}{ Frequencies by $\%$} & \multirow{2}{*}{$\mathbf{x}$} & \multirow{2}{*}{ s } & \multirow{2}{*}{ Rank } \\
\hline & & & SD & D & $\mathbf{U}$ & $\mathbf{A}$ & SA & & & \\
\hline 1. & Policies & 541 & 2 & 5 & 8 & 65 & 20 & 3.963 & .80 & 11 \\
\hline 2. & Issues & 540 & 0 & 3 & 7 & 58 & 32 & 4.187 & .70 & 6 \\
\hline 3. & Faith & 541 & 0 & 4 & 8 & 56 & 32 & 4.157 & .75 & 8 \\
\hline 4. & Awareness & 542 & 0 & 1 & 4 & 52 & 43 & 4.373 & .60 & 1 \\
\hline 5. & Attitudes & 542 & 0 & 2 & 9 & 61 & 28 & 4.159 & .66 & 7 \\
\hline 6. & Competencies & 542 & 0 & 2 & 8 & 58 & 33 & 4.212 & .66 & 4 \\
\hline 7. & Roles & 537 & 0 & 2 & 10 & 64 & 24 & 4.086 & .67 & 10 \\
\hline 8. & Fellowship & 537 & 0 & 2 & 8 & 66 & 24 & 4.110 & .63 & 9 \\
\hline 9. & Call/Commitment & 539 & 0 & 1 & 5 & 54 & 40 & 4.323 & .64 & 3 \\
\hline 10. & Health & 545 & 0 & 3 & 6 & 59 & 32 & 4.196 & .69 & 5 \\
\hline 11. & Area Studies & 544 & 0 & 1 & 4 & 54 & 41 & 4.338 & .63 & 2 \\
\hline \multirow[t]{2}{*}{12.} & Transformation & 524 & 3 & 6 & 28 & so & 13 & 3.656 & .88 & 12 \\
\hline & Average Totals & 540 & 0 & 3 & 9 & 58 & 30 & & & \\
\hline
\end{tabular}

Note. $S D=$ strongly disagree, $D=$ disagree, $U=$ undecided, $A=$ agree, $S A=$ strongly agree. 
appropriate because a larger share of them did not have preparation. In addition,the finding may show the hindsight that comes from the experience of returned missionaries.

A final thought is that the proximity of the Institute experience to departure for IWM attendees may have affected the responses. If attendees had been appointed just prior to the Institute, attendees would not have had time enough to understand policies, so policy questions would seem more urgent. Comments indicate that Policies, even though believed important, could be "learned" in a context other than IWM orientation. Transformation appeared to be a goal not well understood. It is interesting that non-prepared missionaries also valued fellowship more highly in all three characteristics, and believed Area Studies was more important than those who attended IWM.

Table 11 shows the rank of each of the three characteristics that make up the "appropriate" category, and the rank of the goals when the three are combined. Awareness and Fellowship have the same rank for all three characteristics. Health and Attitudes are the two goals with the greatest contrast in ranking. Attitudes are perceived as highly essential, but apparently are not seen as relevant as other goals. The remaining eight goals are very similar in their ranking.

\section{Validation Category Number 2}

Are IWM Goals Possible?

Whereas the first validation category related to external aspects that determine the importance, necessity, and relevance of goals, the second examines 
TABLE 11

RANKED MEANS FOR HOW APPROPRIATE IWM GOALS ARE

\begin{tabular}{llcccc}
\hline & Goals & Important & Essential & Relevant & X Rank \\
\hline 1. & Policies & 11 & 12 & 11 & 11.3 \\
2. & Issues & 8 & 6 & 6 & 6.6 \\
3. & Faith & 6 & 8 & 8 & 7.3 \\
4. & Awareness & 1 & 1 & 1 & 1.0 \\
5. & Attitudes & 5 & 2 & 7 & 4.6 \\
6. Competencies & 4 & 3 & 4 & 3.6 \\
7. & Roles & 10 & 7 & 10 & 9.0 \\
8. Fellowship & 9 & 9 & 9 & 9.0 \\
9. Call/Commitment & 2 & 4 & 3 & 3.0 \\
10. Health & 7 & 10 & 5 & 7.3 \\
11. Area Studies & 3 & 5 & 2 & 3.3 \\
12. Trunsformation & 12 & 11 & 12 & 11.6 \\
\hline
\end{tabular}


four characteristics related to the goals themselves. This category asks whether each is clear, measurable, feasible, and attainable. Feasibility and attainability obviously relate directly to whether the goal is perceived to be possible, whereas clarity and measurability are indirectly related. For instance, if a goal is unclear, its attainment will be unclear, and may even be compromised. Yet it may be attained. If it is not measurable, its achievement is not provable even if it exists, but it may exist very strongly. Most cross-cultural learning is difficult to measure directly, but participant perceptions of attainment are one indication.

Most IWM goals are perceived to be clear

Based on the means listed in Table 12, the population perceives 11 of the goals to be clear. For the goal Transformation, $26 \%$ of the population disagrees that it is clear and $30 \%$ are undecided. This fact is likely one of the underlying causes for the lower means for this goal throughout the analysis. The clearest goals appear to be those that might be considered straightforward and those a person would expect a missionary population to understand. These include Call/Commitment, Area Studies, Health, Awareness, and Issues. Policies and Roles, along with Transformation, rank lowest for clarity. The lack of clarity may reflect the ambiguous nature of these facets of the mission experience, but it may also indicate a lack of understanding of what constitutes the goal content. For Policies, the responses might show confusion over what the policies really were; for Roles, the response may reveal multiple roles without clear lines of demarcation. 
TABLE 12

PERCEPTIONS OF HOW CLEAR IWM GOALS ARE

\begin{tabular}{|c|c|c|c|c|c|c|c|c|c|c|}
\hline & \multirow{2}{*}{ Goals } & \multirow{2}{*}{$\mathbf{N}$} & \multicolumn{5}{|c|}{ Frequencies by $\%$} & \multirow{2}{*}{$\mathbf{x}$} & \multirow{2}{*}{ s } & \multirow{2}{*}{ Rank } \\
\hline & & & SD & D & $\mathbf{U}$ & $\mathbf{A}$ & SA & & & \\
\hline 1. & Policies & 558 & 1 & 1 & 9 & 65 & 15 & 3.806 & .87 & 11 \\
\hline 2. & Issues & 551 & 1 & 6 & 7 & 66 & 20 & 3.996 & .75 & 5 \\
\hline 3. & Faith & 548 & 2 & 8 & 14 & 55 & 21 & 3.856 & .89 & 8 \\
\hline 4. & Awareness & 548 & 1 & 5 & 8 & 56 & 30 & 4.104 & .79 & 4 \\
\hline 5. & Attitudes & 546 & 2 & 7 & 16 & 55 & 20 & 3.830 & .90 & 9 \\
\hline 6. & Competencies & 542 & 2 & 9 & 11 & 55 & 23 & 3.887 & .93 & 7 \\
\hline 7. & Roles & 545 & 2 & 9 & 13 & 59 & 17 & 3.809 & .88 & 10 \\
\hline 8. & Fellowship & 542 & 1 & 6 & 9 & 63 & 21 & 3.954 & .81 & 6 \\
\hline 9. & Call/Commitment & 547 & 1 & 2 & 6 & 53 & 38 & 4.285 & .70 & 1 \\
\hline 10. & Health & 547 & 0 & 3 & 7 & 61 & 29 & 4.133 & .73 & 3 \\
\hline 11. & Area Studies & 548 & 0 & 3 & 5 & 59 & 33 & 4.212 & .69 & 2 \\
\hline \multirow[t]{2}{*}{12.} & Transformation & 536 & 8 & 18 & 30 & 34 & 10 & 3.188 & 1.10 & 12 \\
\hline & Average Totals & 547 & 2 & 7 & 11 & 57 & 23 & & & \\
\hline
\end{tabular}

Note. $S D=$ strongly disagree, $D=$ disagree, $U=$ undecided, $A=$ agree, $S A=$ strongly agree. 
Whether most IWM goals are measurable is unclear

An examination of the frequencies in Table 13 reveals that the majority of the population is undecided about or in disagreement with the measurability of 10 of the goals. Only the means for Area Studies and Health are closer to agreement than indecision, whereas the goals of Transformation and Faith even fall below 3, "undecided" (means $=2.842,2.736$ ). For a person familiar with the implementation challenges of these goals, it appears that the ranking of goals' measurability moves from those whose presentations are more cognitive, and outcomes are more easily visible to those which are not; and from those methodologies that are more fact oriented to those more experiential and abstract. The multi-dimensional nature of behavioral changes required for "crosscultural leaming" as well as cross-cultural service makes the achievement of these goals difficult to measure. A goal can be essential and very relevant yet difficult to measure. Indirect measurement may come in the form of personal perception and/or satisfaction, host affirmation, theoretical alignment, or in other ways. However, the challenge to develop new strategies for measuring such complex phenomena is being explored. An example is the measurement of Faith, ranked the least measurable by the population. The measurement of this construct has recently been seriously attempted in formal research. For this study, one reason for examining goals by eliciting the perceptions of groups is the difficulty in evaluating them by more concrete and scientific means. 
TABLE 13

PERCEPTIONS OF HOW MEASURABLE IWM GOALS ARE

\begin{tabular}{|c|c|c|c|c|c|c|c|c|c|c|}
\hline & \multirow{2}{*}{ Goals } & \multirow{2}{*}{$\mathbf{N}$} & \multicolumn{5}{|c|}{ Frequencies by $\%$} & \multirow{2}{*}{$\overline{\mathbf{x}}$} & \multirow{2}{*}{$s$} & \multirow{2}{*}{ Rank } \\
\hline & & & SD & D & $\mathbf{U}$ & $\mathbf{A}$ & SA & & & \\
\hline I. & Policies & 546 & 2 & 17 & 34 & 43 & 4 & 3.311 & .86 & 4 \\
\hline 2. & Issues & 542 & 1 & 17 & 36 & 41 & 5 & 3.314 & .86 & 3 \\
\hline 3. & Fuith & 543 & 7 & 35 & 39 & 16 & 3 & 2.736 & .92 & 12 \\
\hline 4. & Awareness & 545 & 2 & 14 & 41 & 37 & 6 & 3.301 & .85 & 5 \\
\hline 5. & Attitudes & 540 & 4 & 21 & 47 & 25 & 3 & 3.030 & .85 & 10 \\
\hline 6. & Competencies & 543 & 1 & 13 & 45 & 37 & 4 & 3.281 & .80 & 6 \\
\hline 7. & Roles & 537 & 3 & 14 & 40 & 39 & 4 & 3.273 & .86 & 7 \\
\hline 8. & Fellowship & 536 & 2 & 17 & 45 & 31 & 5 & 3.188 & .84 & 9 \\
\hline 9. & Call/Commitment & 540 & 2 & 17 & 45 & 29 & 7 & 3.200 & .87 & 8 \\
\hline 10. & Health & 542 & 1 & 6 & 34 & 50 & 9 & 3.586 & .79 & 2 \\
\hline 11. & Area Studies & 545 & 1 & 7 & 26 & 53 & 13 & 3.703 & .83 & 1 \\
\hline \multirow[t]{2}{*}{12.} & Transformation & 525 & 7 & 21 & 53 & 16 & 3 & 2.842 & .86 & 11 \\
\hline & Average Totals & 540 & 3 & 17 & 40 & 35 & 5 & & & \\
\hline
\end{tabular}

Note. $S D=$ strongly disagree, $D=$ disagree, $U=$ undecided, $A=$ agree, $S A=$ strongly agree. 
Most IWM goals are perceived to be feasible and attainable

Tables 14 and 15 describe population perceptions of feasible and attainable characteristics. Feasible was defined to mean that IWM can carry out the training for goal achievement, whereas attainable refers to the ability of the participants to reach an acceptable level of the desired goals. The population agrees that 11 IWM goals are feasible and attainable, but almost half are undecided about the goal Transformation (although the means are 3.299 and 3.297, respectively). The nearly identical ranking of feasible and attainable (except for two goal pairs reversed, 6-7 and 10-11) may indicate the complementary nature of these characteristics, or that respondents did not bother to differentiate carefully between them. Of interest is how the five goals seen most feasible and attainable are also those perceived to be clearest: Area Studies, Health, Awareness, Call/Commitment, and Issues. These are goals that IWM specifically addresses and that appear less ambiguous, four of which are implemented primarily through knowledge presentation.

\section{Summany: Most IWM goals are possible}

To summarize, 11 IWM goals are perceived possible as indicated by three of the four characteristics: clarity, feasibility, and attainability. The 12th goal, Transformation, is questioned in all three. The population questions the fourth characteristic, measurability, for 10 goals. Only 2 of the 12, Health and Area Studies, are considered marginally measurable. Another 2, Faith and Transformation, have means that fall below 3.00 (undecided), showing that most of 
TABLE 14

PERCEPTIONS OF HOW FEASIBLE IWM GOALS ARE

\begin{tabular}{|c|c|c|c|c|c|c|c|c|c|c|}
\hline & \multirow{2}{*}{ Goals } & \multirow{2}{*}{$\mathbf{N}$} & \multicolumn{5}{|c|}{ Frequencies by $\%$} & \multirow{2}{*}{$\mathbf{x}$} & \multirow{2}{*}{ s } & \multirow{2}{*}{ Rank } \\
\hline & & & SD & D & $\mathbf{U}$ & $\mathbf{A}$ & SA & & & \\
\hline 1. & Policies & 536 & 0 & 8 & 15 & 68 & 9 & 3.769 & .74 & 7 \\
\hline 2. & Issues & 541 & 0 & 3 & 15 & 70 & 12 & 3.895 & .63 & 5 \\
\hline 3. & Faith & 537 & 1 & 6 & 22 & 60 & 11 & 3.754 & .75 & 8 \\
\hline 4. & Awareness & 544 & 0 & 3 & 14 & 70 & 13 & 3.930 & .63 & 3 \\
\hline 5. & Attitudes & 537 & 0 & 4 & 27 & 60 & 9 & 3.715 & .70 & 10 \\
\hline 6. & Competencies & 538 & 0 & 4 & 24 & 63 & 9 & 3.773 & .68 & 9 \\
\hline 7. & Roles & 539 & 1 & 5 & 21 & 66 & 7 & 3.709 & .73 & 11 \\
\hline 8. & Fellowship & 533 & 0 & 4 & 21 & 67 & 8 & 3.792 & .64 & 6 \\
\hline 9. & Call/Commitment & 536 & 0 & 2 & 19 & 62 & 17 & 3.929 & .67 & 4 \\
\hline 10. & Health & 543 & 0 & 3 & 13 & 69 & 15 & 3.941 & .66 & 2 \\
\hline 11. & Area Studies & 545 & 1 & 3 & 12 & 64 & 20 & 3.985 & .74 & 1 \\
\hline \multirow[t]{2}{*}{12.} & Transformation & 522 & 3 & 9 & 47 & 37 & 4 & 3.299 & .82 & 12 \\
\hline & Average Totals & 538 & 0 & 5 & 21 & 63 & 11 & & & \\
\hline
\end{tabular}

Note. $S D=$ strongly disagree, $D=$ disagree, $U=$ undecided, $A=$ agree, $S A=$ strongly agree. 
TABLE 15

PERCEPTIONS OF HOW ATTAINABLE IWM GOALS ARE

\begin{tabular}{|c|c|c|c|c|c|c|c|c|c|c|}
\hline & \multirow{2}{*}{ Gosls } & \multirow{2}{*}{$\mathbf{N}$} & \multicolumn{5}{|c|}{ Frequencies by $\%$} & \multirow{2}{*}{$\mathbf{x}$} & \multirow{2}{*}{$\mathbf{s}$} & \multirow{2}{*}{ Rank } \\
\hline & & & SD & D & $\mathbf{U}$ & $\mathbf{A}$ & SA & & & \\
\hline 1. & Policies & 546 & 1 & 8 & 14 & 67 & 10 & 3.780 & .77 & 6 \\
\hline 2. & Issues & 542 & 0 & 4 & 13 & 71 & 12 & 3.893 & .66 & 5 \\
\hline 3. & Faith & 543 & 0 & 6 & 26 & 57 & 11 & 3.727 & .75 & 8 \\
\hline 4. & Awareness & 545 & 0 & 2 & 14 & 70 & 14 & 3.949 & .61 & 3 \\
\hline 5. & Attitudes & 540 & 0 & 5 & 32 & 54 & 9 & 3.674 & .72 & 11 \\
\hline 6. & Competencies & 543 & 1 & 5 & 26 & 59 & 9 & 3.713 & .73 & 9 \\
\hline 7. & Roles & 537 & 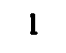 & 6 & 24 & 60 & 9 & 3.693 & .77 & 10 \\
\hline 8. & Fellowship & 536 & 0 & 4 & 23 & 64 & 9 & 3.780 & .67 & 7 \\
\hline 9. & CallCommitment & 540 & 0 & 2 & 20 & 60 & 18 & 3.926 & .70 & 4 \\
\hline 10. & Health & 542 & 0 & 3 & 13 & 68 & 16 & 3.969 & .66 & 2 \\
\hline 11. & Area Studies & 545 & 1 & 3 & 11 & 63 & 22 & 4.015 & .74 & I \\
\hline \multirow[t]{2}{*}{12.} & Transformation & 525 & 3 & 9 & 48 & 35 & 5 & 3.297 & .83 & 12 \\
\hline & Avernge Totals & 540 & $\mathbf{0}$ & 5 & 22 & 61 & 12 & & & \\
\hline
\end{tabular}

Note. $S D=$ strongly disagree, $D=$ disagree, $U=$ undecided, $A=$ agree, $S A=$ strongly agree. 
the population is in some form of doubt and non-agreement regarding their measurability. To the degree a goal is non-measurable, its attainability and attainment may not be verified; yet, non-measurability does not deny appropriateness or achievement.

\section{Validation Category Number 3}

Were IWM Goals Attained?

A third type of validation determines the extent to which the respondents perceive they achieved each goal during orientation and were able to apply each in the field. It should be noted that IWM goals attainment is not an "end" but a direction. Even though the pezceptions of the participants do not guarantee the reality of attainment, they are a strong indicator of some measure of that reality being present.

Attainment relates to attainability, although logic and the statistics of this study indicate that participants' perceptions of their attainment of goals may not correspond to whether they considered them attainable. Factors such as methods, materials, staff, and participant readiness also influence the degree of attainment achieved. Thus, a goal may be considered attainable, yet not be attained. A valid goal should be attained by the majority, however.

IWM goals attainment is observable

Page 3 of the questionnaire asked respondents if they had evidence that any of the 12 IWM goals were effectively attained by those who had attended IWM. 
Although not everyone would know who had attended IWM, nor would they know whether IWM training was what had enabled effective cross-cultural practice, still $36 \%$ of the population indicated that they had seen evidence of effective attainment of one or more goals. Table 16 shows that cross-cultural Awareness was observed by $30 \%$ of those persons who answered this question, and three goals (Issues, Call/Commitment, and Health) were observed by $24 \%$. Transformation and Faith were the least observed. These two goals are abstract and internalized, which may make their recognition more difficult. Respondents may have been wary to judge another's faith. Furthermore, Transformation was the least clearly understood goal statement. It is interesting to note the contrast between the observations of IWMtrained missionaries and those without IWM training.

TABLE 16

NUMBER OF RESPONDENTS REPORTING EVIDENCE OF ATTENDEES' ATTAINMENT OF EACH GOAL

\begin{tabular}{lccccccccccccc}
\hline N $=595$ & 1 & 2 & 3 & 4 & 5 & 6 & 7 & 8 & 9 & 10 & 11 & 12 & $T$ \\
\hline Leader & 13 & 18 & 6 & 19 & 10 & 11 & 10 & 10 & 17 & 12 & 15 & 6 & 147 \\
Miscionaries & 56 & 111 & 47 & 133 & 64 & 85 & 56 & 78 & 110 & 77 & 100 & 32 & 949 \\
Currex & 30 & 59 & 25 & 68 & 28 & 52 & 31 & 44 & 58 & 39 & 55 & 21 & 510 \\
Remurned & 26 & 52 & 22 & 65 & 36 & 33 & 25 & 34 & 52 & 38 & 45 & 11 & 439 \\
IMM-prep'd & 58 & 116 & 50 & 140 & 68 & 98 & 58 & 79 & 116 & 82 & 112 & 36 & 1013 \\
No IWM prop & 5 & 9 & 13 & 16 & 3 & 6 & 4 & 7 & 7 & 3 & 12 & 1 & 86 \\
\hline $\begin{array}{l}\text { Gol Selection f } \\
\text { (T = 1189) }\end{array}$ & 74 & 139 & 58 & 168 & 77 & 113 & 66 & 91 & 137 & 91 & 136 & 39 & 1189 \\
$\begin{array}{l}\text { \% f of T for } \\
\text { Eech Goal }\end{array}$ & 13 & 24 & 10 & 30 & 14 & 20 & 12 & 16 & 24 & 16 & 24 & 7 & 100 \\
\hline
\end{tabular}


IWM goals are perceived

achieved and applied

Attainment involves not only achievement during the Institute, but application in the cross-cultural context as well. Although program participants do not disagree that all 12 goals were achieved during IWM, they are unsure about 4 of the goals: Area Studies, Awareness, Policies, and Roles. There are logical explanations for this uncertainty. Because Area Studies, Policies, and Roles appear more relevant when the missionary actually reaches the field, they cannot be "met" with strong satisfaction during pre-departure orientation. For instance, before arrival, many do not really know what roles are expected of them, nor could they have a sense of knowing all the policies governing their specific appointment. In the case of Awareness, the pre/post-arrival perspectives may explain the difference. It may be that the more participants are exposed to the unfamiliar, the less they may feel they know. Table 17 indicates their responses.

Goals that participants feel more certain they achieved are goals that have a strongly motivational or emotional dimension (Faith, Attitudes, Fellowship, Call/Commitment, Transformation), or are goals in which demonstrable progress is inescapable (Issues, Competencies, and Health).

Participants agree they applied nine goals in their cross-cultural work, although not strongly, but question their application of the Fellowship goal. Does this indicate they saw Fellowship as a program goal? They are less sure whether they applied Policies or Area Studies in the field. (See Table 18.) 
TABLE 17

PERCEIVED ACHIEVEMENT OF GOALS AT IWM ORIENTATION

\begin{tabular}{|c|c|c|c|c|c|c|c|c|c|c|}
\hline & \multirow{2}{*}{ Goals } & \multirow{2}{*}{$\mathbf{N}$} & \multicolumn{5}{|c|}{ Frequencies by $\%$} & \multirow{2}{*}{$\mathbf{x}$} & \multirow{2}{*}{ s } & \multirow{2}{*}{ Rank } \\
\hline & & & SD & D & $\mathbf{U}$ & $\mathbf{A}$ & SA & & & \\
\hline 1. & Policies & 352 & 6 & 21 & 17 & 49 & 7 & 3.310 & 1.07 & 10 \\
\hline 2. & Issues & 358 & 1 & 7 & 5 & 64 & 23 & 4.014 & .80 & 1 \\
\hline 3. & Faith & 358 & 1 & 10 & 17 & 58 & 15 & 3.754 & .85 & 5 \\
\hline 4. & Awareness & 356 & 9 & 31 & 8 & 38 & 15 & 3.188 & 1.27 & 11 \\
\hline 5. & Attitudes & 357 & 1 & 4 & 14 & 65 & 17 & 3.933 & .73 & 3 \\
\hline 6. & Competencies & 355 & 1 & 7 & 27 & 53 & 12 & 3.668 & .84 & 7 \\
\hline 7. & Roles & 353 & 3 & 16 & 24 & 51 & 6 & 3.394 & .95 & 9 \\
\hline 8. & Fellowship & 355 & 1 & 14 & 16 & 48 & 21 & 3.746 & .98 & 6 \\
\hline 9. & Call/Commitment & 356 & 2 & 8 & 15 & 57 & 18 & 3.809 & .89 & 4 \\
\hline 10. & Health & 355 & 2 & 10 & 17 & 61 & 10 & 3.656 & .86 & 8 \\
\hline 11. & Aren Studies & 355 & 7 & 25 & 19 & 42 & 7 & 3.186 & 1.10 & 12 \\
\hline \multirow[t]{2}{*}{12.} & Transformation & 357 & 1 & 2 & 13 & 68 & 16 & 3.950 & .71 & 2 \\
\hline & Average Totals & 356 & 3 & 13 & 16 & 54 & 14 & 3.63 & & \\
\hline
\end{tabular}

Nole. $S D=$ strongly disagree, $D=$ disagree, $U=$ undecided, $A=$ agree, $S A=$ strongly agree. 
TABLE 18

PERCEIVED APPLICATION OF GOALS IN THE FIELD

\begin{tabular}{|c|c|c|c|c|c|c|c|c|c|c|}
\hline & \multirow{2}{*}{ Goals } & \multirow{2}{*}{$\mathbf{N}$} & \multicolumn{5}{|c|}{ Frequencies by $\mathscr{x}$} & \multirow{2}{*}{$\mathbf{x}$} & \multirow{2}{*}{$\mathbf{s}$} & \multirow{2}{*}{ Rank } \\
\hline & & & SD & D & $\mathbf{U}$ & $\mathbf{A}$ & SA & & & \\
\hline 1. & Policies & 353 & 5 & 23 & 26 & 41 & 5 & 3.167 & 1.00 & 12 \\
\hline 2. & Issues & 359 & 2 & 7 & 15 & 64 & 13 & 3.786 & .82 & 5 \\
\hline 3. & Faith & 355 & 2 & 13 & 25 & 48 & 13 & 3.580 & .93 & 9 \\
\hline 4. & Awareness & 354 & 1 & 5 & 13 & 65 & 16 & 3.915 & .74 & 2 \\
\hline 5. & Attitudes & 357 & 1 & 6 & 16 & 62 & 14 & 3.804 & .80 & 4 \\
\hline 6. & Competencies & 353 & 1 & 10 & 27 & 50 & 12 & 3.615 & .87 & 8 \\
\hline 7. & Roles & 355 & 1 & 2 & 7 & 80 & 10 & 3.975 & .55 & 1 \\
\hline 8. & Fellowship & 356 & 2 & 15 & 26 & 48 & 10 & 3.478 & .92 & 10 \\
\hline 9. & Call/Commitment & 356 & 2 & 6 & 15 & 59 & 18 & 3.848 & .84 & 3 \\
\hline 10. & Health & 352 & 1 & 10 & 19 & 62 & 9 & 3.662 & .82 & 7 \\
\hline 11. & Area Studies & 355 & 6 & 20 & 30 & 37 & 7 & 3.189 & 1.02 & 11 \\
\hline \multirow[t]{2}{*}{12.} & Transformation & 356 & 3 & 9 & 20 & 51 & 17 & 3.711 & .94 & 6 \\
\hline & Average Totals & 355 & 2 & 10 & 20 & 56 & 12 & 3.65 & & \\
\hline
\end{tabular}

Note. $S D=$ strongly disagree, $D=$ disagree, $U=$ undecided, $A=$ agree, $S A=$ strongly agree. 
Tables 17 and 18 describe participants' perceptions of goals achievement at IWM or application in the field. A comparison shows that most respondents showed a stronger agreement for achievement during IWM than application in the field except for two goals, Awareness and Roles. It is reasonable to assume that the awareness of cross-cultural issues and understanding of roles would be stronger in the field than at the Institute. Three goals, Area Studies, Health, and Call/Commitment, show equivalent participant agreement for both types of attainment. Five goals are very closely ranked for both types of attainment. Roles, however, is perceived as the goal most strongly applied in the field, whereas this goal ranks ninth in achievement during the institute. This goal would probably not be thought well-achieved before being on the job in the field, because participants do not know what to expect.

If attainment and attainability are compared, the $350+$ attendees were more cautious about whether they achieved and applied the goals than they were in affirming their attainability for more than half the goals. For the other half, participants believed they attained Issues, Roles, and Faith to approximately the same level they believed they were attainable. Transformation and Attitude, however, showed a higher perception of attainment than attainability. These are highly motive-directed goals, so it is possible that respondents gave normal or cautious responses for attainability, but believed they had achieved these goals more fully than they had expected to. 
Nature of IWM goals attainment

The last page of the questionnaire asked four questions to describe the nature of perceived attainment. Table 19 shows the results of the first question, which asked respondents what level of mission service effectiveness (MSE), on a scale of 1-10, they believe they had reached in the field; and the last which asked "On a scale of 1-100\%, what \% do you feel Missions Institute training contribured overall to the effectiveness of your mission service?" The range among groups for MSE level is 6.88 to 7.70 . The responses of both current and returned missionaries showed they thought they reached about the same level of MSE. Leaders, males, and marrieds average a half point higher than missionaries, females, and singles. For the average percentage of IWM's contribution to MSE, all groups believed IWM was responsible for around two thirds of their effectiveness. The greatest percentage difference among the groups was between current and retumed missionaries, with current $2 \%$ higher than those returned.

TABLE 19

PERCEIVED LEVEL OF MISSION SERVICE EFFECTIVENESS (MSE) REACHED AND IWM CONTRIBUTION TO MSE

\begin{tabular}{lcccccccc} 
& \multicolumn{2}{c}{ Population } & \multicolumn{2}{c}{ Missionaries } & \multicolumn{2}{c}{ Gender } & \multicolumn{2}{c}{ Stanus } \\
\cline { 2 - 9 } N=330 & Leaders & Miss & Current & Ret'd & Male & Female & Single & Married \\
\hline $\begin{array}{c}\text { MSE } \\
\text { Level }\end{array}$ & 7.70 & 7.23 & 7.35 & 7.12 & 7.49 & 6.90 & 6.88 & 7.50 \\
$\begin{array}{c}\text { IWM } \\
\text { Contri- } \\
\text { bution }\end{array}$ & 66.97 & 67.66 & 66.57 & 68.68 & 67.32 & 67.85 & 67.66 & 67.42 \\
\hline
\end{tabular}

Note. MSE $=$ Mission Service Effectiveness, $T=10 ;$ IWM Contribution, $T=100 \%$. 
If the IWM contribution percentage is studied for all missionaries, more than half the respondents believe the Institute's orientation contributed over $75 \%$ to their mission service effectiveness. Eighty-two percent believe the orientation was responsible for at least half their effectiveness. If all missionaries who attended IWM are divided into quartiles, the division of the $\mathbf{3 3 0}$ missionaries into each would be $37,48,105$, and 141 individuals (1st, 2nd, 3rd, 4th respectively). Although these responses are very positive, there is evidence the overall average would have been higher had everyone attended IWM before going to the field. It appears that the degree of perceived contribution reflects perceptions of how well the Institute met individual need more than how valuable persons felt the Institute was. One evidence for this is that most respondents who put percentages around 50\% and lower volunteered that they had been in the field several years before they had had the opportunity to attend IWM, and thus had to leam the concepts on their own. Another common reason given for IWM not playing the primary role in service effectiveness was that concepts had been learned as a missionary child or student missionary.

The remaining two questions sought to qualify what respondents believed contributed most to mission service and Institute effectiveness. One asked respondents to rate how valuable each of 15 factors was for service effectiveness, on a scale of $1-10$, only 3 of which related to IWM orientation. Table 20 shows that respondents recognize that many factors besides preparation contribute to mission service effectiveness. 


\section{TABLE 20}

FACTORS CONTRIBUTING TO MISSION SERVICE EFPECTIVENESS (MSE) LEVEL

\begin{tabular}{|c|c|c|c|c|c|c|c|c|c|c|c|c|c|}
\hline \multirow{2}{*}{ Factors } & \multirow{2}{*}{$\mathbf{N}$} & \multicolumn{10}{|c|}{ Frequencies by $\%$} & \multirow{2}{*}{$\mathbf{x}$} & \multirow{2}{*}{ Rank } \\
\hline & & 1 & 2 & 3 & 4 & $\mathbf{5}$ & 6 & 7 & 8 & 9 & 10 & & \\
\hline Personality/lemperament & 332 & 2 & $\mathbf{0}$ & 1 & 3 & 5 & 8 & 14 & 34 & 28 & 5 & 7.63 & 5.5 \\
\hline Background/experience & 328 & 1 & 1 & 2 & 4 & 6 & 7 & 11 & 27 & 33 & 8 & 7.63 & 5.5 \\
\hline Desire to be effective & 300 & 1 & $\mathbf{0}$ & $\mathbf{0}$ & 1 & 3 & 8 & 10 & 27 & 38 & 12 & 8.20 & 2 \\
\hline Commitment/perseverance & 294 & $\mathbf{0}$ & $\mathbf{0}$ & $\mathbf{0}$ & $\mathbf{0}$ & 5 & 4 & 13 & 23 & 43 & 12 & 8.24 & 1 \\
\hline Spirituality/sense of calling & 300 & 1 & $\mathbf{0}$ & 1 & 2 & 4 & 6 & 16 & 21 & 38 & 11 & 8.02 & 3 \\
\hline Flexibility/openness & 310 & o & o & $\mathbf{0}$ & 2 & 6 & 6 & 12 & 30 & 34 & 10 & 8.01 & 4 \\
\hline Living/working conditions & 359 & 2 & 3 & 5 & 9 & 20 & 15 & 14 & 19 & 10 & 3 & 6.21 & 12 \\
\hline Family situation/support & 312 & 1 & 1 & 3 & 2 & 13 & 11 & 13 & 19 & 27 & 10 & 7.37 & 7 \\
\hline Political/economic aspects & 366 & 8 & 9 & 16 & 11 & 24 & 12 & 11 & 6 & 2 & 1 & 4.65 & 15 \\
\hline Administration & 362 & 7 & 9 & 12 & 12 & 16 & 11 & 12 & 13 & 6 & 2 & 5.17 & 14 \\
\hline Nationals & 346 & 2 & 3 & 5 & 11 & 17 & 16 & 16 & 19 & 10 & 1 & 6.12 & 13 \\
\hline Health/well being & 317 & 2 & 1 & 2 & 3 & 9 & 10 & 16 & 29 & 22 & 6 & 7.28 & 8 \\
\hline Mission Institute experience & 333 & 4 & 2 & 3 & 2 & 9 & 11 & 22 & 23 & 19 & 5 & 6.96 & 9 \\
\hline Mission Institute information & 334 & 4 & 2 & 3 & 4 & 7 & 14 & 24 & 20 & 18 & 4 & 6.80 & 10 \\
\hline Mission Institute fellowship & 334 & 5 & 3 & 5 & 5 & 11 & 13 & 20 & 21 & 11 & 6 & 6.43 & 11 \\
\hline
\end{tabular}

Note. $1=$ none, $5=$ average, $10=$ most. 
All 15 factors are perceived to make an average or better contribution to effectiveness, but four themes emerge from the clustering of means: affective, personal/environmental, preparation, and contextual. The greatest contribution is believed to come from the affective dimension. As a group, participants believe commitment/perseverance, desire to be effective, spirituality/sense of calling, and flexibility/openness make the greatest contribution. After the affective theme comes personal, environmental, and social factors in two clusters: First are the two factors of personality/temperament and background/experience; next is the cluster of social (family support) and psychological/physical concerns (health). A third theme follows: The three IWM factors, Institute experience, information, and fellowship, cluster and contribute in that order; experience is rated higher than information which is rated higher than fellowship. Finally, respondents believe that the four situational factors listed, although important, made the least difference in their level of effectiveness. With the exception of political/economic aspects $(X=4.65)$, these factors are about 5 (average) on the scale. It is noteworthy that the means tend to cluster around themes that illustrate types of factors.

The other question asked how much each of 13 different aspects of the Institute contributed to effective orientation. Respondents were asked to rate particular aspects of the Institute on a scale of $1-10$, depending on how much each contributed to the effectiveness of their training. Table 21 shows that all aspects were believed to have contributed better than average. (The mean for dorm living 
TABLE 21

IWM ASPECTS CONTRIBUTING TO TRAINING EFFECTIVENESS

\begin{tabular}{|c|c|c|c|c|c|c|c|c|c|c|c|c|c|}
\hline & \multirow{2}{*}{$\mathbf{N}$} & \multicolumn{10}{|c|}{ Frequencies by $\%$} & \multirow{2}{*}{$\mathbf{x}$} & \multirow{2}{*}{ Rank } \\
\hline & & $\mathbf{I}$ & 2 & 3 & 4 & 5 & 6 & 7 & 8 & 9 & 10 & & \\
\hline \multicolumn{14}{|l|}{ Loctures and discussions in: } \\
\hline Missions anthropology & 329 & 3 & 2 & 3 & 5 & 9 & 13 & 18 & 22 & 20 & 5 & 6.92 & 4 \\
\hline Mission principles, practices, issues & 329 & 1 & 1 & 3 & 6 & 8 & 13 & 20 & 26 & 18 & 4 & 7.03 & 3 \\
\hline Physical and mental health & 344 & 2 & 3 & 5 & 5 & 16 & 16 & 20 & 20 & 11 & 2 & 6.39 & 6 \\
\hline Policies & 351 & 5 & 4 & 8 & 8 & 24 & 18 & 14 & 12 & 6 & 1 & 5.55 & 10 \\
\hline Area studies & 337 & 4 & 2 & 4 & 6 & 13 & 10 & 20 & 18 & 19 & 4 & 6.66 & 5 \\
\hline Worships and other spiritual activities & 332 & 1 & 2 & 3 & 5 & 10 & 12 & 13 & 24 & 25 & 5 & 7.15 & 1 \\
\hline Dedication service, communion & 327 & 2 & 3 & 3 & 4 & 11 & 9 & 13 & 25 & 22 & 8 & 7.13 & 2 \\
\hline Simulation games & 325 & 9 & 9 & 8 & 10 & 19 & 13 & 13 & 10 & 7 & 2 & 5.16 & 12 \\
\hline Panel discussion & 341 & 4 & 5 & 6 & 7 & 20 & 16 & 19 & 15 & 6 & 2 & 5.76 & 9 \\
\hline Films & 335 & 4 & 3 & 3 & 7 & 16 & 15 & 21 & 19 & 11 & 1 & 6.28 & 7 \\
\hline Work on committoes & 324 & 10 & 5 & 5 & 10 & 23 & 16 & 16 & 9 & 5 & 1 & 5.31 & 11 \\
\hline Living together in dorms & 314 & 18 & 7 & 7 & 5 & 17 & 11 & 12 & 12 & 9 & 2 & 5.00 & 13 \\
\hline Social fellowship (parties, program, etc.) & 337 & 6 & 5 & 4 & 8 & 20 & 14 & 15 & 14 & 12 & 2 & 5.92 & 8 \\
\hline
\end{tabular}

Note. $1=$ none, $5=$ average, $10=$ most. 
was 5.00 , but because it was not the only living arrangement offered, an average rating would be expected.)

Participants affirm that the affective/spiritual dimensions are the most important. These include the spiritual and attitudinal goals. To illustrate, they believe the spiritual events of IWM (worships, devotionals, dedication service, communion) were the most meaningful and made the greatest contribution to their training. These events were activities for the implementation of the goals of Faith, Attitudes, and Call/Commitment.

The main core of the Institute ranks next in perceived importance; the lectures and discussions in mission anthropology, mission principles and practices, and issues. (Note that Policies is excluded.) These make the major contribution to those goals most directly connected to cross-cultural aspects of preparation: Issues, Awareness, Attitudes, and Competencies. The remaining aspects relate to social fellowship and methods (films, panel discussion, committees, and simulation), with films being most appreciated. Although Fellowship was not rated highly as a goal, part of the reason the spiritual and affective aspects were as meaningful as they were is because of their fellowship dimensions.

Validation Category Number 4: Are the 12 Goals Comprehensive Enough to Achieve the Aim?

Another dimension of validity is gained if the 12 goals of IWM as a group were perceived to be comprehensive enough to meet the overall aim of the training 
program. I assumed IWM was comprehensive if all 12 goals were expected, recognized as appropriate, with no other expected/appropriate goals missing.

\section{IWM goals are expected}

On page 2 of the questionnaire, respondents were asked to circle the number in front of every goal they did not or would not have expected for an orientation program. (See Table 22.) For the 595 questionnaires, $11 \%$ (68 persons) indicated they did not or would not have expected one or more of IWM's goals. Of the 7,140 times goals could have been indicated unexpected, there were only 112 selections. Voluntary comments by these individuals offered the following reasons for not expecting the goals. Transformation was not understood. Several respondents believed Faith and Call/Commitment were either present or absent in participants before they attended IWM, and therefore they believed these goals could not be improved by IWM orientation. Policies were not seen as necessarily appropriate for presentation at the Institute; and Health issues were expected to be achieved in some other way.

TABLE 22

IWM GOALS THAT RESPONDENTS DID NOT EXPECT OR WOULD NOT HAVE EXPECTED

\begin{tabular}{|c|c|c|c|c|c|c|c|c|c|c|c|c|c|}
\hline $\mathrm{N}=68^{\text {Goal \# }}$ & 1 & 2 & 3 & 4 & 5 & 6 & 7 & 8 & 9 & 10 & 11 & 12 & $\mathbf{T}$ \\
\hline$f$ & 15 & 2 & 19 & 1 & 2 & 2 & 9 & 6 & 8 & 15 & 2 & 31 & 112 \\
\hline
\end{tabular}


IWM goals are perceived to be comprehensive

Eighty-one percent of the respondents believe that IWM goals are comprehensive enough to achieve the aim of preparing missionary appointees to be effective in their cross-cultural service. Only $7 \%$ disagree. Most of the $12 \%$ who are undecided about the adequacy of meeting the aim, and gave reasons, indicated that perhaps the length of time for training was too short to cover all the goals. A few wondered whether there were other factors that might enhance effectiveness. Table 23 shows the distribution and mean for respondent perceptions.

TABLE 23

PERCEPTIONS OF HOW COMPREHENSIVE IWM GOALS ARE

\begin{tabular}{lcccccccc}
\hline \hline & & \multicolumn{6}{c}{ Frequencies by $\%$} & \\
\cline { 3 - 6 } & & SD & D & U & A & SA & \\
\hline Is IWM Comprehensive Enough? & 477 & 1 & 6 & 12 & 70 & 11 & 3.84 \\
\hline
\end{tabular}

Note. $S D=$ strongly disagree, $\mathrm{D}=$ disagree, $\mathrm{U}=$ undecided, $\mathrm{A}=$ agree, $\mathrm{SA}=$ strongly agree.

\section{Respondent Comments}

There was no request or provision made for additional comments. The questionnaire was lengthy and complex. This did not stop respondents from adding comments, however. Some 142 respondents made comments of varying lengths, not counting written information in the questionnaire response lines marked "other." Another 22 wrote letters, making a total of $28 \%$ who contributed perceptions in addition to those requested. 
The majority of the comments affirmed the value of the Institute, although many said they could not remember many details. Such phrases as "an absolute must," "everyone should go," "should go twice," "100\% worthwhile," and "wonderful" were repeated frequently. There were only five negative comments, one of which is:

MI pumped me up with an overblown idealism. MI is like pre-marital counseling. It can help you start better. It helps for a year or two. But after that your success has very little to do with it. You grow quickly beyond the elementary instruction you needed to start. Longterm missionaries need the support and guidance of MI through a joumal.

Perhaps this comment best expresses the real purpose of pre-departure orientation by showing a distinction between the preparation necessary for the transition into another culture and the continuing preparation needed while in the field.

There were numerous suggestions and much constructive advice. Table 24 provides a sample of the suggestions made to the Institute. A few respondents gave reasons for some of the failures experienced by missionaries who had attended the Institute. Rather than holding the Institute responsible, most stated that the fault lies with recruitment/selection, or inability of participants to make necessary changes (i.e., attitude), inability to "get into" the learning process during the Institute, inability to transfer the leaming into life in the field, or inability to get along with administrators or other expatriates. Two suggested that IWM may have been negligent by not providing enough Area Studies, or not requiring communal living in dorms during the Institute. 
TABLE 24

\section{REPRESENTATIVE RESPONDENT SUGGESTIONS FOR IMPROVING IWM MISSIONARY PREPARATION}

\begin{tabular}{lll}
\hline \multicolumn{1}{c}{ IWM Goal-related } & \multicolumn{1}{c}{ IWM Method-related } & \multicolumn{1}{c}{ Preparation Cycle } \\
\hline $\begin{array}{l}\text { Stronger emphasis and more } \\
\text { details for Area Studies }\end{array}$ & $\begin{array}{l}\text { Have more nationals involved } \\
\text { in orientation }\end{array}$ & $\begin{array}{l}\text { Use better screening processes } \\
\text { before and after IWM }\end{array}$ \\
$\begin{array}{l}\text { Include professional admin. } \\
\text { skills such as committee work }\end{array}$ & $\begin{array}{l}\text { More frequent family times } \\
\text { during orientution }\end{array}$ & $\begin{array}{l}\text { Continue nurturing and } \\
\text { training in field }\end{array}$ \\
$\begin{array}{l}\text { More specific study of other } \\
\text { religions and gospel planting }\end{array}$ & $\begin{array}{l}\text { Provision for reading prior to } \\
\text { orientation program }\end{array}$ & $\begin{array}{l}\text { Provide re-orientation for re- } \\
\text { entry into own culture }\end{array}$ \\
$\begin{array}{l}\text { Include skills to express needs } \\
\text { and confront problems }\end{array}$ & $\begin{array}{l}\text { Make learning more practical } \\
\text { by practice opportunities }\end{array}$ & $\begin{array}{l}\text { Provide realistic info for } \\
\text { homeland needs (house/car) }\end{array}$ \\
$\begin{array}{l}\text { Include practical skills in } \\
\text { giving Bible studies/sharing }\end{array}$ & $\begin{array}{l}\text { Spare nothing to close the gap } \\
\text { between expectations \& reality }\end{array}$ & $\begin{array}{l}\text { Inform of realistic role } \\
\text { expectations in the field }\end{array}$ \\
$\begin{array}{l}\text { Add information and practice } \\
\text { in stress management }\end{array}$ & $\begin{array}{l}\text { Stronger emphasis on future } \\
\text { trends and realities }\end{array}$ & $\begin{array}{l}\text { Provide orientation for } \\
\text { children, especially teens }\end{array}$ \\
$\begin{array}{l}\text { Much stronger emphasis on } \\
\text { women's needs and roles }\end{array}$ & $\begin{array}{l}\text { More practical dissemination } \\
\text { of policies information }\end{array}$ & $\begin{array}{l}\text { Provide language learning in } \\
\text { field for whole family }\end{array}$ \\
$\begin{array}{l}\text { More opportunities for prayer } \\
\text { and personal reflection }\end{array}$ & $\begin{array}{l}\text { Elimination of overlap and } \\
\text { repetition in presentations }\end{array}$ & $\begin{array}{l}\text { Conduct cross-cultural sessions } \\
\text { in field for hosts/missionaries }\end{array}$ \\
$\begin{array}{l}\text { Include info to understand } \\
\text { children's cross-cultural needs }\end{array}$ & $\begin{array}{l}\text { Provide some of IWM's } \\
\text { orientution in the field }\end{array}$ & $\begin{array}{l}\text { Continue communication by } \\
\text { newsletter/journal/visits }\end{array}$ \\
\hline
\end{tabular}

One respondent summed up how the majority felt about the Institute when he said: "I am as convinced as ever that no one and I mean no one should be allowed to leave his homeland without IWM."

What factors determine or encourage missionary success? Respondents mentioned spiritual reasons, such as God, faith, commitment, and modeling the incarnational ministry of Christ. In fact, many respondents were adamant about the need for missionaries to have a strong faith, sense of call, and commitment prior to 
going to IWM or not be appointed to mission service. Other reasons were psychological, such as attitudes, role models/mentors, spouse feelings and a sense of being needed, balancing life with coping levels, the right motivation, flexibility, and common sense. Social relationship and support reasons were common, such as the dorm experience and staff interest at the Institute, fellowship (with family, resident or other missionaries, and nationals), visits from leaders, networking, a functioning family that integrates with the new culture, spouse's commitment and support, and rapport with leadership. Respondents frequently commented that the fellowship at IWM was one of its greatest benefits. Some environmental reasons were mentioned, such as weather, having previously lived in a cross-cultural context, multicultural experience, multiple moves that encourage adaptability, and a growing indigenous lifestyle. Finally, participants mentioned several transition characteristics that they felt contributed to missionary success, such as getting appointees into the field quickly after the Institute; becoming familiar with policies governing the particular field; finding that the organization had made preparation prior to arrival (housing, finances, moving needs, and details); and finally, being nurtured in the field. Respondents believed these factors contribute to missionary success.

Missionaries emphasized that much more care should be taken in the selection process. It was stated that a successful Institute experience should be a sort of "final test" that must be passed before appointment. Ineffectiveness and premature return were believed to be caused by fear, poor social relations, inability to handle stress, unstable sense of identity, and dysfunctional personality. There 
was the common sense advice to check out how well the individuals functioned in the U. S. before appointing them to cross-cultural ministry.

\section{Response Consistency}

Only a few group means, such as those relative to role preferences, were significantly different. Nevertheless, it is interesting and helpful to note response pattems by comparing the means of all validation responses for four pairs of groups: leaders vs. missionaries, current vs. retumed missionaries, males vs. females, and those with no training vs. those with IWM training. Three group pairs are discussed here; the fourth, differences between leaders (Source 2) and missionaries (Source 3), is discussed in the last section of the summary of Sources 2 and 3, which follows.

A comparison of current/retumed groups found that current missionaries rated all goals slightly higher in importance except two, Policies and Transformation. They also rated all goals more clear than retumed missionaries, except for Issues. Reasons for these findings probably relate to the greater number of current missionaries having IWM preparation, the increasing sophistication of IWM presentations, as well as improved general educational excellence and expectations. In addition, IWM goals have become more clearly articulated over time. Returned missionaries rated all goals more feasible, except Area Studies, and more relevant, except Roles and Health. They also rated five of six validation characteristics higher for Policies and Area Studies, but current missionaries rated five of six validation characteristics higher for health. 
Returned missionaries observed more implementation of goals except for Attitudes. They appreciated IWM more strongly, and believed they achieved goals during the Institute, and better applied the goals in the field (except for Health) better than did current missionaries. Current missionaries as a group rated their level of mission service effectiveness higher, but returned missionaries rated IWM as making a larger contribution to their mission service effectiveness.

Gender comparisons show that females rated all IWM goals higher in importance than males, except for Issues and Roles. Females rated most or all validation characteristics higher for Faith, Attitudes, Roles, Fellowship, Call/Commitment, and Area Studies, but men rated Issues and Competencies higher. Females observed the implementation of every goal more often than males, except for Policies. Males rated most factors contributing to mission service effectiveness higher except for IWM experience, information, and fellowship. Females rated achievement higher during IWM, but males rated application in the field higher. Males rated their mission service effectiveness higher, but females reported IWM's contribution to mission service effectiveness higher than males. Overall, females appear to appreciate (and perhaps benefit from) IWM preparation more than males do.

Institute training impacts the perceptions of its attendees, and in many cases, is responsible for a paradigm shift that enables them to view the world, orientation, and cross-cultural functioning differently. Except for Fellowship, missionaries with IWM orientation rated goals more appropriate (important, 
relevant, and essential) than those with no training. They also rated all or most validation characteristics higher for seven goals: Issues, Faith, Awareness, Call/Commitment, Health, Area Studies, and Transformation. Those with training also indicated they observed more implementation of all goals. Missionaries with no training rated Fellowship and Policies higher than those IWM-trained. They likely felt a stronger need for these goals because they did not have the opportunity to experience attainment of other goals.

\section{Summary of Findings From Sources 2-3}

\section{Leaders and Missionaries}

Leaders and missionaries responded to a questionnaire that elicited evaluations about whether IWM goals are perceived to be appropriate (important, essential, relevant), possible (clear, measurable, feasible, attainable), and whether they were attained (observed, achieved at IWM, and applied in the field) by those who attended it. The goals as a group were then evaluated to determine whether they were comprehensive enough to provide effective preparation for cross-cultural ministry (expected, comprehensive).

Findings from the questionnaire responses are summarized and analyzed in four ways: (1) validation categories, (2) individual goal validity based on nine validation characteristics, (3) the relative contribution of each goal to IWM orientation based on a ranking of goals, and (4) a comparison of the perceptions of leaders and missionaries. 


\section{Validation Categories}

The first category, Are these goals appropriate? examines whether the goals are perceived to be important, essential, and relevant. All goals were believed important by $96-100 \%$ of the respondents. From $61-81 \%$ of the responses were in the very/extremely important categories for 10 of the goals. Four goals had almost half (from 40-47\%) of their responses in the "strongly agree" category and rank 1-4: Awareness, Attitudes, Competencies, and Call/Commitment. The two goals ranked 11th and 12th, Transformation and Policies, still had $41 \%$ and 54\% (respectively) of their responses in the very/extremely important categories.

All goals were considered essential. Again, Policies and Transformation ranked last. Percentage of agreement for the other 10 goals ranged from 83-92\%. In fact, 3 goals had $42-49 \%$ in the "strongly agree" category. The top 5 goals seen as essential are the same as the top 5 seen as important, although not in the same order.

All goals were perceived relevant. Seven goals had $90-95 \%$ agreement in their responses. Policies and Transformation were again ranked 11th and 12th, although $85 \%$ agree that policies are relevant for cross-cultural preparation. The average responses for all goals were even higher for the characteristic of relevant than for important and essential.

Thus, all goais were found to be appropriate for a cross-cultural training program. Because primary validity is decided by whether the goals are considered important, essential, and relevant (appropriate), all goals were found to be valid by 
this study (even though participants questioned whether Transformation was possible).

The second category, Are these goals possible? examined whether goals are clear, measurable, feasible, and attainable. Eleven goals were perceived clear. Fifty-six percent of the respondents, however, questioned or disagreed with the clarity of Transformation. Call/Commitment, Area Studies, and Health each had between $90 \%$ and $92 \%$ of the respondents agreeing that they were clear.

No goal was considered fully measurable, although responses for Health and Area Studies were closer to agreement than indecision. Only $19 \%$ agreed that Faith is measurable, with $42 \%$ in disagreement and $39 \%$ undecided. Only $19 \%$ agreed that Transformation is measurable, but $53 \%$ were undecided, and $28 \%$ were in disagreement, reflecting the perceived lack of clarity. I do not believe measurability is essential for considering a goal valid, however.

Eleven goals were perceived feasible and attainable, and all goals were ranked similarly for both characteristics. For the 12th goal, about half the respondents are undecided about Transformation, although $41 \%$ believed it feasible and $40 \%$ attainable, with only $12 \%$ who disagreed. The range of response for these characteristics is smallest, except for relevant.

Thus, all goals were considered possible except for Transformation; participants were undecided for all four characteristics (clear, measurable, feasible, and attainable). 
The third category, Were these goals attained? explored whether the responding population observed these goals applied by others, and whether they believed they had achieved the goals during training and applied them in the field of service. Thirty-six percent of respondents indicated they had observed the attainment of one or more goals by IWM participants. Over three fourths of these believed they had observed Awareness.

Eight goals were thought to be achieved during IWM, and nine were believed applied in the field. Respondents questioned how well they achieved Area Studies, Awareness, Policies, and Roles during IWM, and how well they applied Fellowship, Policies, and Area Studies in the field.

Issues, Roles, and Faith were perceived as attainable as they were attained, but half the goals were believed more attainable than attained. Transformation and Attitudes were perceived to have been achieved and applied more strongly by respondents than they could be attained.

Comparisons between goal achievement during IWM and application in the field provide interesting insights. Participants believed seven of the goals were both achieved during IWM and applied in the field (8 achieved and 9 applied). Participants agreed they became more aware of current issues in world mission during IWM and worked more successfully because of it. They experienced growth in faith during IWM, but only mildly agreed that this growth helped them during tough times in the field. They believed they made progress in developing vital cross-cultural attitudes while at IWM, which enabled them to see from the local 
people's viewpoint. They also believed they developed a stronger sense of call/commitment to mission service during IWM, which increased their courage and satisfaction in the field. Participants increased their resolve to grow in skills and understanding for effective service during IWM and believed they are more effective today because IWM taught them to continue learning and growing.

Participants differ substantially in their perceptions of achievement at IWM and application in the field on two goals, Awareness and Roles. For each goal, participants questioned whether they achieved the goal at IWM, but believed they had applied it in the field. For Awareness, participants questioned whether they realized how important understanding culture in mission is while at IWM, but agreed they made a conscious effort to apply what they had learned at IWM. For Roles, participants were unsure whether IWM helped them know how to fill the various roles they had in the field, but felt they functioned reasonably well in those roles. The incongruities are not puzzling. Because Awareness expands substantially when one experiences the real situation, it is easy to understand how Awareness during IWM might be underrated. With Roles, it is not realistic to expect IWM to prepare participants for the variety of individually localized roles, a fact that would be more recognized after arrival in the field.

Participants questioned their achievement and application in two areas. They wondered whether they became well-informed of policies relevant to their life and work in the field, and whether they found their work easier because they were able to apply them $(3.31,3.17)$. Participants also were not sure whether they were 
170

provided adequate orientation to their new country and its culture and living conditions, or whether their effectiveness was greatly improved by the orientation they had.

Participants tentatively agreed that the teachers and participants became like family to them during IWM (3.75), but questioned whether that fellowship enabled them to better relate and identify with the local people (3.48). Participants only mildly agreed that IWM provided essential information regarding appropriate mental/physical practices, or that they found most of that information practical for their daily life overseas.

Eighty-one percent of all respondents said "yes" to the question for the final category, Are the 12 goals comprehensive enough to achieve the aim? A study of the comments showed that those who disagreed or were undecided did not indicate a need for more goals but questioned whether the program length was sufficient to meet all of them. This dimension of validity is also supported by the fact that all 12 goals were perceived expected and appropriate, and no other expected or appropriate goal was thought to have been left out. From the majority of the questionnaire responses, none of IWM's 12 goals were unexpected. A mere $11 \%$ of the respondents did not or would not have expected 1 or more of the 12 IWM goals and for reasons that do not challenge their value. Transformation, the goal least understood, was the goal most selected as unexpected, but only 31 of 595 questionnaire respondents selected it. 
To summarize, data from the questionnaire showed all goals are appropriate, that is, important, essential, and relevant. This validity is strengthened for 11 goals by respondent perceptions that they are possible, meaning they are clear, feasible, and attainable. (The clarity, feasibility, and attainability of Transformation is unclear.) Indecision regarding the measurability of most goals (only Area Studies was believed measurable) may weaken the strength of validity, but does not invalidate them. Goals that require experiential techniques are known to be very difficult to measure, yet are necessary and qualitatively known to be attainable. For instance, it was not clear to the respondents if Transformation could be measured, but they believe they attained it.

Attainment occurred; 9 goals were perceived to be achieved by respondents during IWM and 10 were applied in the field. Respondents questioned whether Area Studies and Policies were attained at all, and whether Awareness was achieved during the Institute. Perhaps the growth in awareness while in the field was so large that respondents questioned how much they had achieved during the Institute. Thus, there is consensus that $\mathbf{1 0}$ goals are very suitable for orientation because they are believed clear, feasible, attainable, and were attained. There is anecdotal evidence that some goals, such as Policies, would not have to be met by formal orientation, however.

Finally, Institute goals are perceived to be comprehensive; none are unexpected, nor are any others thought to be missing. Testing for differences indicated that the very few significant variations found between and among 
subgroups appeared limited to the felt needs of participants relative to age, role, gender, or degree of preparation.

\section{Validation of Individual IWM Goals}

Table 25 shows the means for all 12 IWM goals on nine validation characteristics, and thus provides a summary of population perceptions for all goals according to the nine characteristics examined. Because the discussion of goals classified according to validation categories and characteristics in the previous section apply here as well, there is no further discussion. The table provides the reader a view of the same information from the perspective of individual goals.

Goals ranked least contributory were Policies and Transformation for all three characteristics. Transformation was seen as least, or next to least, important, essential, relevant, clear, measurable, feasible, and attainable, yet was perceived as second-most achieved at IWM and sixth-most applied in the field. Why? Although many participants seemed not to have understood the concept in other parts of the questionnaire, they were quite able to answer (and affirmatively) the questions relating to goal attainment because it was described in the questionnaire by a stated behavior. Area Studies was perceived to be very clear, relevant, essential, and quite important. It was believed to be the most feasible and attainable, and the only measurable one. Yet, it was thought to be the least achieved and next-to-least applied goal of the 12 . 
TABLE 25

MEANS OF VALIDATION CHARACTERISTICS FOR IWM GOALS

\begin{tabular}{|c|c|c|c|c|c|c|c|c|c|c|}
\hline & \multirow[b]{2}{*}{ Goals } & \multicolumn{3}{|c|}{ Appropriate } & \multicolumn{4}{|c|}{ Poacible } & \multicolumn{2}{|c|}{ Attrined } \\
\hline & & Impt & Ea & Rel & Clear & Meas & Fear & Att & Ach'd & App'd \\
\hline 1. & Policies & 3.34 & 3.92 & 3.96 & 3.81 & $x$ & 3.77 & 3.78 & $x$ & $x$ \\
\hline 2. & Iroves & 3.91 & 4.15 & 4.19 & 4.00 & $x$ & 3.90 & 3.89 & 4.01 & 3.79 \\
\hline 3. & Fuith & 3.84 & 4.20 & 4.16 & 3.86 & $x$ & 3.75 & 3.73 & 3.75 & 3.58 \\
\hline 4. & Awareness & 4.24 & 4.38 & 4.37 & 4.10 & $x$ & 3.93 & 3.95 & $x$ & 3.92 \\
\hline 5. & Attitudes & 4.22 & 4.21 & 4.16 & 3.83 & $x$ & 3.72 & 3.67 & 3.93 & 3.80 \\
\hline 6. & Competencies & 4.17 & 4.25 & 4.21 & 3.89 & $x$ & 3.77 & 3.71 & 3.67 & 3.62 \\
\hline 7. & Roles & 3.84 & 4.05 & 4.09 & 3.81 & $x$ & 3.71 & 3.69 & $x$ & 3.98 \\
\hline 8. & Fellowship & 3.81 & 4.11 & 4.11 & 3.95 & $x$ & 3.79 & 3.78 & 3.75 & 3.48 \\
\hline 9. & Call/Commitment & 4.05 & 4.36 & 4.32 & 4.29 & $x$ & 3.93 & 3.93 & 3.81 & 3.85 \\
\hline 10. & Health & 3.71 & 4.20 & 4.20 & 4.13 & 3.59 & 3.94 & 3.97 & 3.66 & 3.66 \\
\hline 11. & Area Studiea & 4.02 & 4.30 & 4.34 & 4.21 & 3.70 & 3.99 & 4.02 & $x$ & $x$ \\
\hline 12. & Transformation & 3.56 & 3.62 & 3.66 & $x$ & $x$ & $x$ & $x$ & 3.95 & 3.71 \\
\hline
\end{tabular}

Note. $x=$ undecided; the means for this symbol lie below $3.5(3=$ undecided, $4=$ agree $)$.

The means for imp is an exception to the above note: $3=$ important, $4=$ very important. 


\section{Relative Contribution of IWM Goals to Orientation}

Although every goal was believed appropriate, some were considered more critical or contributory to effective cross-cultural preparation than others. To discover which were believed most or least contributing, the group means of the responses were ranked for each validation characteristic. Awareness is ranked as most important, essential, and relevant (appropriate). Table 26 shows all goals ranked on the basis of means, from highest to lowest, for each characteristic.

The five goals seen as most important and most essential are the same (Awareness, Attitudes, Competencies, Call/Commitment, Area Studies), although in slightly different order for each characteristic. Four of them are also seen as the most relevant. One can say that these goals are perceived to be the most appropriate, a finding well supported by literature and practice.

Fellowship was seen as ninth in the list of 12 goals in importance, essentiality, and relevance. Goals such as Issues and Health were ranked higher. IWM participants also questioned whether they applied their leaming of this goal in the field, an opinion confirmed by respondent comments in the questionnaire. Roles, although still perceived valid, was ranked 8th, 10th, and 10th in importance, essentiality, and relevance, respectively.

It is interesting to note that the ranking of goals for feasibility (whether training for the goal can be carried out by IWM) and attainability (whether goal can 


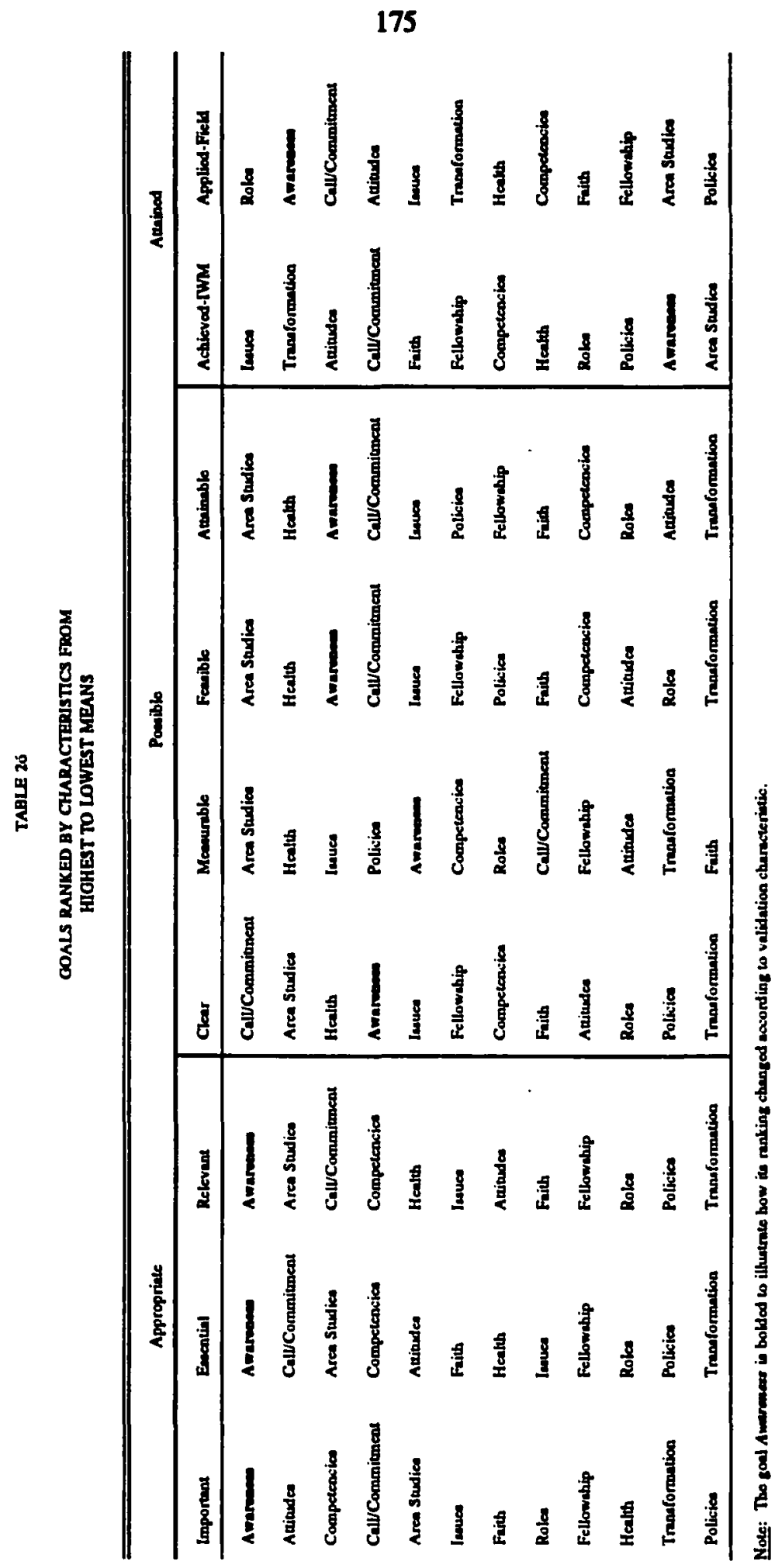

Reproduced with permission of the copyright owner. Further reproduction prohibited without permission. 
be accomplished by participants) was almost identical. It is possible that there was a lack of clarity in meaning (even though terms were defined), or that respondents did not bother to differentiate the terms carefully when marking the questionnaire. There is, however, a contrast between whether participants viewed a goal as attainable and the extent to which it was achieved at IWM or applied in the field.

\section{Comparison of Leaders' and Missionaries' Views}

Two major groups were combined and sent the same questionnaire: (1) church leaders at the General Conference, overseas Divisions/Unions, and overseas Institutions (administrative stakeholders); and (2) missionaries, both current and returned (criterion population). These two groups represent the populations who were deemed in a position to make valid perceptions conceming the Institute's goals, and make up Sources 2 and 3 . Although leaders and missionaries were sent the same questionnaire, the response rate for missionaries was greater than that for leaders.

The examination and discussion of findings for Sources 2 and 3 (administrative stakeholders and criterion population) has been based on combined group means partly because both leaders and missionaries responded to the same questionnaire. Even more importantly, it was discovered that there were very few statistical differences between the responses of each group (out of 153 validation comparisons of group means). One reason for so little difference between stakeholder and missionary views may be that $81 \%$ of the leaders were either 
current or former missionaries. Thus, there is considerable overlap between leadership and missionaries in terms of experience if not position, because only 19 leaders had never been in overseas service.

The five significant differences $(p=<.05)$ between leaders and missionaries are: (1) missionaries rated Area Studies more measurable, and (2) observed more implementation of Awareness and (3) Cross-cultural Competencies than leaders did; (4) leaders believed they reached a higher level of missionary service effectiveness (MSE), and (5) rated background/experience more important in their missionary service effectiveness than missionaries did.

There are interesting and informative differences in the patterns of responses between leaders and missionaries, although they are not statistically significant. Leaders rated the goals of Issues, Roles, and Transformation higher in importance, but missionaries rated responses for Health, Awareness, Fellowship, and Area Studies higher. Leaders also had higher means when rating six validation characteristics for Transformation and Policies. They rated 11 of the 13 aspects of IWM higher. Missionaries observed more goal implementation of all goals except Policies, and believed they achieved goals during IWM and applied them in the field more strongly than leaders.

To summarize Sources 1-3, there is a strong consensus among the perceptions of the case study populations: staff/attendees, leaders, and missionaries. 


\section{CHAPTER IV}

\section{PRESENTATION AND ANALYSIS OF FINDINGS FROM VALIDATION SOURCES 4 TO 6: LITERATURE, PRACTICE, AND TRENDS}

The final three data sources provide data that give an external perspective to the validation of IWM's goals. Source 4 seeks to identify orientation goals by a review of missionary literature and practice. Source 5 summarizes goals stated and implied from general cross-cultural preparation literature. The final source gathers information from world trends and preparation issues that impact goal determination for mission. Data from these sources are used to further validate the goals of the case in order to achieve this study's purpose--identification and determination of predeparture orientation goals needed by cross-cultural missionaries.

\section{Source 4: Review of Missionary Preparation}

The fourth source provides a brief overview of missionary preparation goals identified in the literature and program practice. The first subtopic looks at historical highlights of missionary preparation development; a second reviews missionary preparation literature and practice; and a third presents goal data from missionary orientation programs. 


\section{Historical Development of Missionary Preparation Goals}

Christianity was bom in an intercultural event, Pentecost (Peters, 1990). Prior to this event, Jesus Christ had asked His followers to "go into all the world" with the good news of the "arrival" of God's kingdom on earth. Cross-cultural mission began as the early church sought to share the gospel "to every creature under heaven" after Pentecost, a goal that Paul stated was achieved in his time (Col 1:23). Dowd (1978) noted that "the history of religious people reaching across cultural and national borders is long. . . . Thousands of people have been involved in spreading religious thought on the Earth for centuries," and, although Christians were not the first religious group to move across cultural boundaries, they have been among the most energetic and pervasive (p. 127).

\section{Paul and Pre-Modern Preparation}

Preparation for the earliest Christian missionaries actually began before Pentecost when Christ selected and prepared His followers before sending them on their first assignments. Although many of these early missions were only partially cross-cultural, the aim was not different-effective ministry. After Pentecost, Paul became the most recognized cross-cultural missionary of the early Christian movement and illustrated many of the principles that cross-cultural ministry practices today. His preparation began with a sense of call, identity as God's servant, and formal education eariy in his life. His calling was affirmed but redirected by the Damascus rad encounter when Christ revealed Himself as the Messiah. The 
encounter was followed by a 3-day seminar from Ananias, reflection and soul searching during his temporary blindness, discussions with church leadership, and a few years spent in personal study and communion with God in the desert.

Paul's encounter with Jesus Christ and his pre-service preparation resulted in a "mindset transformation" that directed him in his lifelong work to build up the kingdom of God on earth. His preparation continued throughout his life from his study of the Scriptures, communion with God, development of cross-cultural skills (i.e., Athens), and the actual experience and practice of ministry. Even though we would not consider Paul's mission preparation formal, his informal preparation accomplished the same outcomes for which orientation is designed.

By studying Paul's preparation and advice, we can deduce that preparation should include a call to ministry accompanied by a commitment necessary to accomplish the task, a strong identity as one "sent" to minister, a change in attitudes, a spiritual preparation of growth in faith dependence on God, an understanding of the task and issues relevant to it, the skills and strategies for understanding and communicating in the foreign culture, a social support system including the establishment of relationships with foreigners, a recognition of the need for dependable practices (policies), and a transformed mind to enable continuing learning and maturity for successful ministry.

For more than 15 centuries, preparation for cross-cultural ministry was largely similar to Paul's, although not always as complete. Missionaries were largely mentored and self-prepared. Formal preparation was generally non-existent 
outside of the theological training some had obtained. The sense of God's call to service, earnest commitment, dogged determination, and practical ingenuity were qualities that brought success for the pre-modern missionary. Many missionaries combined mission with other goals they had, such as conquest. Most were also powerful in their knowledge of the Scriptures and empowerment by the Holy Spirit. By today's standards, ministry was limited by the monocultural and often ethnocentric perspectives of missionaries.

\section{Rise of Planned Missionary Preparation}

In America's modern missionary movement, early preparation was in the form of fellowship, church meetings, social meetings, Sunday activities, special programs, and missionary speakers. Orientation was relegated to letters of instruction or advice to encourage the appointee to remember the importance of living the Christian lifestyle. Some of the earliest content of preparation focused on the transition itself. For instance, a 1833 mission society believed it had a duty to help the missionary with instructions for voyage preparation and lists of what to take (Peters, 1990). In some instances, a person would accompany the missionary overseas and prepare him during the several-month journey by ship. Early methods sometimes included mentoring in the field by established missionaries. Language learning usually took place on location, out of necessity.

Even as planned preparation began, selection of missionaries was believed to be a major key to success. Early requirements underscored deep understanding of 
the Bible and evidence of Christian commitment. Gradually, an emphasis on theological education was assumed a necessary pre-requisite for effective mission. The emphasis was on the "Word." By the early 1900s, requirements were expanded. For example, desirable candidates were those described as healthy, sociable, adaptable, with common sense and positive attitudes (Peters, 1990). Some missionaries themselves recognized the importance of high qualifications for successful ministry. The illustrious David Livingston was one of those who recognized that education and personality and character were important qualifications.

Among "modern" methods of preparation were missions conferences and the development of missionary manuals, first published by the mission society or sending board. They offered inspiration and information about the role of the missionary's spirituality and character as well as practical details. Conferences have continued to proliferate and are currently held even by local churches and in many parts of the world. Over the years, some of the manuals became generic, more sophisticated, comprehensive, and today are still practical sources of information to guide the missionary.

The Bible institute/Bible college movement, which began to provide the "lion's share" of trained missionary force, added to or replaced some of the early orientation procedures. Its curricula emphasized Bible knowledge, spiritual growth (although much was in a classroom setting), mission principles and practices, and some practical courses. At first, there were not many opportunities to develop the 
cross-cultural skills and understanding that were recognized as essential by the 1960s-1980s. For those with Bible college education, orientations were conducted by the sending agency, and became more concerned with details and policies specific to agency concems.

The orientation process became recognized as "one of the key factors in determining the effectiveness of a missionary" (Peters, 1990, p. 102). It was distinguished from theological and Bible college education by focussing on meeting the pre-departure needs of candidates. The orientation was not necessarily a group interaction opportunity. Often, the candidate met with the mission board for a few hours or days of instructions to add to what was provided by correspondence, conferences, or manuals. The early emphasis in more formal orientation, which appears to have started with the provision of policy and procedures information of the sending organization, later included growth in spirituality, Bible knowledge, healthcare, and practical opportunities to leam basic practical life skills such as accounting and phonetics; agriculture, animal husbandry, and building construction were aiso valuable.

\section{Post-World War II}

World War II changed the landscape of the North American missionary movement and perceived preparation needs. More opportunities for broader training were inaugurated. The impetus came not only from a global awareness resulting 
from international exposure brought on by the war, but also by a growing sense of American responsibility for helping other peoples.

At the same time, the changing character of American culture and people became evident. In 1957, the "Committee on Missionary Personnel of the Division of Foreign Missions" (National Council of Churches Committee or NCCC), published New Trends in Missionary Training in the United States. It was one of several publications of the 1950 s stressing the need for a new type of missionary preparation for several urgent reasons. Missionaries' needs had changed, even by the time of war. Although missionary candidates at that time were considered to be sincere, many were "religiously illiterate," generally not accustomed to or prepared for discipline or hardship, and easily influenced by "advertising" (p. 1). The Committee believed that the American candidate had been molded as a youth by an environment of materialism and technological achievements. The results were a weakened character and an ignorance of the Bible, and missionary and church history.

But even more important, the NCCC viewed the changes World War II itself had brought in the role of the American missionary as compounding the necessity of "new" training. The American was no longer welcome in a "revolutionary world." There was seen an emerging need of "preparing the young American missionary for life in a revolutionary world" where the American would likely face rejection (NCCC, p. 5) Furthermore, the missionary training in the 1940s, which had emphasized transition information and methods of evangelism, 
was no longer adequate. By the end of the 1950s, the primacy of attitudes in mission effectiveness was beginning to be recognized. The young American candidate needed to be prepared for what we today call "culture shock." As the booklet pointed out,

Less than 10 years ago, it is fair to say that the concem was to provide the missionary with useful information and techniques. Today, knowledge and technical skill are not discounted, but right attitudes and preparation for the strains of missionary living are singled out for primary emphasis. (p. 4)

After the war, orientation became conceptualized as supplementary to the candidate's general and professional education. The aim was "building a bridge between the situation out of which the candidate comes, and that to which he goes" (NCCC, p. 4). Such an aim contributed to the diversity of depth and breadth of missionary preparation programs, blurring the definitional lines between training and orientation and partially accounting for the wide variety of approaches. Authorities began to advise the inclusion of nationals in the orientation process, and stressed disseminating knowledge in an atmosphere of missionary fellowship and group living. The new challenge was to strengthen the motivation for the task, call, and commitment. The new model included: attitude/motivation training, mission principles and practices, area studies, relationships, cultural anthropology, language acquisition methods, psychological testing, and living/working together during orientation. A growing trend was to appoint the missionary after successful completion of orientation. A common demand was to make orientation a mandatory step in the selection process. 
Orientation programs that emerged were designed to complete the selection or appointment process. They had three components they related directly to the missionary task: academic, professional, and working experience. Curricula generally included Bible study, missionary task, mission issues, other religions, missionary role and responsibilities, practical living issues (health, relationship to government, standard of living), area studies, world issues, and language introduction. There was a very strong emphasis on corporate living, although not so much to meet the fellowship goal as to test the ability of the missionary family to endure the difficulties of "mission compound" living. Other curricular elements included psychological testing, perhaps again more to make sure the family was able to cope than to prepare for adjustment, particularly coping with uncertainty. In the last decade, there has been a stronger emphasis in using psychological testing to identify candidate strengths and weaknesses to facilitate preparation and effective cross-cultural functioning.

\section{Post-war Trends Affecting Preparation}

During the post-war era, changing orientation needs and the multiplication of training programs prompted several trends. One trend led planners to utilize relevant knowledge from related disciplines to enable orientation to meet the new "goals." But this move was not without resistance. Fear of replacing the ministry

of the Holy Spirit with behavioral science insights was strong (Reed, 1985). Several missionaries, like Kraft and Hiebert, published useful volumes that incorporated 
relevant principles from the social sciences (i.e., anthropology) and communication to illuminate the practice of making mission relevant to the context, at times risking their acceptance and value within the mission community.

A second trend was a new sensitivity to the view non-Christians (and many Christians) had of Westemers and missionaries. It grew out of changes brought by the World War, the explosion of scientific knowledge especially in the behavioral sciences, and the interaction among diverse peoples through advances in communication and transportation. There developed a global sense of selfdetermination and resistance toward domination, and a demand for religious autonomy. Unfortunately, missionary involvement across cultures has not always been constructive. As Dowd (1978) lamented: "In the 17th, 18th, and 19th centuries, the solution to basic cultural differences between missionary and host populations was often an imperialistic transfer of political and economic values rather than a culturally adaptive transfer of a message" (p. 127).

As anthropology and other social sciences enlarged the world's understanding of culture, there have been backlashes both in the secular world and among North American Christians against the "imposition of Westem values" (p. 127). The ensuing identity crisis for missionaries prompted an inflexible, conservative approach on the one hand, or a disavowal of the traditional mission message on the other. The post-war world milieu may have been more responsible for change in the types of mission, missionaries, message, and appointments than any other set of factors. 
A third trend was a shift toward interdenominational cooperation to provide for orientation needs. Although there are major differences in the length of service, commitment, and preparation of Protestant and Catholic missionaries, and minor differences among Protestant groups (Cleveland et al., 1960, pp. 266-267), ecumenical cooperation has played an important part in resource availability and conservation (Peters, 1990). The ecumenical consciousness grew out of a renewed sense of unity that may have been a partial response to the criticism of mission and missionaries. By some, commonalities were stressed and many differences overlooked; by others distinctions and separation were maintained.

Some of the most long-term and well-recognized orientation programs in mission history began during the post-war period. Part of the impetus came as mission recognized the usefulness of GI's who longed to help meet the needs of a world they had not known before the war. Many veterans were eager to return to carry the gospel to those who had suffered the horrors of war. In addition, ecumenism and proliferating training opportunities encouraged the combining of several different organizations into the preparation process, such as the mission board, orientation program, staff, local church or congregation, denomination, and overseas counterpart. The time spent for any or all of the components of the orientation process lengthened from a few days to over a month, and some for as long as 1 year or more.

What lies in the future? World trends and preparation issues are discussed in more detail in Source 6. However, most planners appear optimistic about the 
quality of preparation possible today, even if they are less positive about how mission structures will respond to the tremendous needs. In 1978, Dowd forecasted a bright future for cross-cultural training because there was a felt need to improve missionary preparation, and research and development were being conducted and shared. In addition, churches cooperation began to increase, and the rising level of expertise began to enable local congregations to contribute to the preparation of mission personnel (p. 132).

In summary, advice from NCCC is still relevant almost 40 years later. It recognized a need to integrate new training programs with institutional training already achieved by missionaries $(1957$, p. 14$)$. It mentioned that training should be adapted to the needs of the individual and meet common needs, yet be flexible enough to provide for unique and individual needs (p. 15). "Those responsible for planning programs of missionary training must never forget that the end in view is to prepare persons" (p. 15).

\section{Missionary Preparation Literature}

Research about mission is limited. Cleveland et al. (1960) spoke of this when they stated that the "mountains of lore about the history and theological presuppositions of missionary work contrast strangely with the paucity of hard facts and solid professional analysis about how religious missions actually operate in the face of the secular revolution all around them" (p. 269). Research that directly relates to missionary preparation is also very limited (Cleveland et al., 1960; Dowd, 
1976; Williams, 1973), particularly research that examines preparation needs and determines goals. The lack of sound research can be partially explained by the burden to "get the work done," and the diversity of approaches to message and method. Thus, non-research oriented literature is also included in this review. This subtopic on missionary preparation literature is divided into five sections: literature publication overview, preparation and personnel retention, effective orientation program practices and goals, characteristics of missionary effectiveness and success, and personnel assessment.

\section{Literature Publication Overview}

Non-joumal publications in the field of missionary preparation are limited in number, largely non-scientific, often localized, and somewhat difficult to secure for examination. A literature search through the world catalogue online via CDRom facilities generated over 100 sources. Many of these were 5-to-25-page reports of early mission board conferences, consultations, training institutes, or addresses presented at these events. Topics included specific types of missionaries, such as women, wives, and medical personnel; or appointments to particular target populations, such as Jews and Moslems; or contexts, such as China, Middle East, Africa, Latin America, Japan, India, and North America. Others sources were book reprints or updated editions, and missionary manuals published for the general missionary readership or candidates for particular organizations. There are many 
theses, some projects, and a few dissertations. Finally, there is a core of books dealing directly with various aspects of missionary preparation.

Chronologically, the literature reflected the concerns and development of missionary preparation. Prior to 1910 , most publications were reports of training and mission board issues such as the call for theological training to include missions courses, manuals (even self-preparation types), and a monograph for student volunteers (SVMs) on their call, qualifications, and preparation. The Edinburgh World Mission Conference (1910) prompted an increase in missions focus and published reports as well as more localized mission conferences. Out of it grew an emphasis on cooperation among those responsible for preparation, the representatives from theology departments and seminaries, and mission board secretaries working together to prepare personnel. Several trends generated by Edinburgh have continued until the present time; from it came a series on preparation for specific world areas and then non-Christian religions. One report included a bibliography on qualifications, preparation, and a list of institutions and facilities for missionary preparation. Issues discussed included keeping up to date, and the preparation of women, wives, nurses, and other medical personnel.

Between the 1920s and World War II, conferences and their reports continued to be a popular form of discussion on preparation. Literature continued to focus on specialized preparation, as for those going overseas as educators, and those attempting to reach the Moslem world. Mormons published books on the successful 
missionary. Other topics included biblical foundations for preparation (particularly as illustrated by Paul) and mission education in Christian liberal-arts colleges.

The changes brought by World War II and its aftermath were reflected in the literature and preparation: use of conferences as a preparation tool; increased emphasis on academic requirements and accreditation; proliferation of research theses and studies of programs and personnel (i.e., studies by K. Moyer, and Bailey and Jackson, on missionary motivation and retention qualifications); and an examination of missions history which showed the necessity of taking a "fresh look" to fit "new missionaries" and "changing world pattems." This latter trend developed into the drive for excellence, "breeding the best."

Literature of the 1960 s included more preparation manuals, a correspondence course in training, and awareness of cross-cultural issues and preparing for culture shock. It was during this decade that preparation began to recognize the need for "new training dimensions" that would begin to integrate the preparation and allow for flexible planning. During the 1970s, more manuals and handbooks were published, especially for the rising student missionary population.

In the 1980s, literature multiplied. The numbers of manuals and handbooks, theses, dissertations, and case studies escalated. Literature included knowledge of the orientation process and missiological dimensions in theological education. A new emphasis on leadership dimensions of missionary preparation gained prominence, and there was more study in the biblical basis of mission, principles and practices, the missionary role, and preparation. Historical analysis 
continued. But the most noteworthy development was a stronger discussion on the interpersonal, inter-cultural communication, and cross-cultural skills essential for effective mission. The four years of this decade so far have created preparation literature that is more diverse, scientific, international, specialized, and useful for establishing preparation programs on valid principles.

Numerous journals on aspects of mission add to the available sources, although most of them have only an occasional article on missionary training. One of the most useful journals for articles specific or related to preparation is Evangelical Missions Quarerly which began publication in 1964. The incidence of articles on missionary preparation has increased especially during the last 10-15 years; the first decade had only a handful, the number doubled in the 1970s, and doubled again during the 80 s. So far, in this decade prior to the third millennium, the number of articles on personnel preparation appear to have declined sharply and have been replaced with issues relative to global evangelization and re-evangelization in a context of change so rapid and challenges so enormous that they take precedence. Intemational Bulletin of Missionary Research and Missiology do not publish many articles directed specifically toward missionary preparation. Examples of other joumals that occasionally include articles relevant to American missionary preparation are Joumal of Psychology and Christianity, and Journal of Psychology and Theology. Their topics include matters relating to the psychology of missionary preparation issues, such as missionary assessment, selection, qualifications, and 
success, and are presented from a variety of theological and psychological perspectives.

\section{Preparation and Personnel Retention}

Missionary preparation, especially prior to service, promotes longer overseas careers and reduces premature retums. There is a "clear relationship between failure rate and lack of training" (Sutlive, Altshuler, Zamora, \& Kerns, Eds., 1986, p. 38), and a positive correlation between training and effective retention for missionaries (Brislin \& Pedersen, 1976, p. 149). Those who have had orientation are more likely to complete their term and work more effectively (p. 39). Besides, the cost of failure is substantial. For instance, Sutlive et al. (1986) stated that premature return of a business employee and his/her family could cost over $\$ 200,000$ in addition to the cost of lost contracts, reduced productivity, and other intangibles (p. 38).

A few studies point to the key role of pre-departure preparation to increase retention and reduce premature withdrawal rates. One of the earliest wellknown retention studies was conducted by Kenyon E. Moyer (1957): A Study of Missionary Motivation, Training, and Withdrawal, 1932-1952. His study established an apparent correlation between success of missionary selection, training, and turnover rates. By surveying 915 former missionaries, he found that $83 \%$ of the quitters lacked any cultural orientation, and he believed that half of the $25 \%$ who returned early were avoidable. 
Bailey and Jackson (1965) also studied missionary motivation, training, and withdrawal. In this frequently cited study, $75 \%$ of the 345 respondents stated they did not believe they had had any pre-departure preparation in mission principles, history, or methods. The $25 \%$ who did obtained the informal preparation by attending programs, conferences, or by experience. It is interesting that $80 \%$ of mission board leadership said they provided appointees with training or orientation, but only one-third of the appointees believed they had received any cultural orientation, and more than half of these found it inadequate (p. 34). For some missionaries, the inadequacies were made up by in-field cultural orientation and language study, and learning during furlough.

Johnston's study (1980) found that, in addition to poor interpersonal relationships, particularly with mission administration, inadequate preparation was also a cause of early withdrawal for missionaries between 1955 and 1974, especially inadequate orientation, area studies, and language training.

Thompson's dissertation (1982) examined tumover literature, agency research, and withdrawn missionaries to discover those factors important for retention. He found that the primary causes for withdrawal were incompatibility with other missionaries and disagreement with field and foreign mission board policies. Kyne's study (1992) supported previous research and showed that early returns are caused mainly by ineffective handling of interpersonal conflict, although his study was not able to establish a significant correlation between conflict management and poor field performance. Missionary preparation must seek to 
196

modify/eliminate negative factors while building positive attitudes and skills through their goals.

\section{Effective Orientation Program}

Practices and Goals

In the 1973 Mission Handbook, Muenstermann identified eight elements he believed necessary for adequate missionary qualification and preparation. Five related to the spiritual dimension (Bible literacy, steadfast commitment, and a knowledge of "what time it is," "where the world is at," who the Lord is," for the right attitude and humility) (p. 30). He also stressed adequate physical and emotional health, interpersonal relations skills, and professional competence. Muenstermann emphasized that "no missionary is ever a finished product and growth through preparation . . . is elemental Christian discipleship" (p. 31). In the same Handbook, Edward Pentecost stated in his article that "preparation for missionary service . . . must be goal-oriented" (p. 32). Ideal preparation for him would include commitment, Bible knowledge, mature theology, a broad understanding of mission task, and practical experience. These could be achieved through varied means, such as Bible institutes and colleges, Christian liberal-arts colleges, seminary internship programs, and mission training courses.

Magor (1987) developed a pre-departure orientation model for the South Sea Evangelical Mission. Her model took into consideration the diversities caused by time of training in relation to appointment in the country of training, the content and length/timing of training, the types of trainees (short-term, long-term, 
tentmakers, etc.), and the type of training delivery. Her 13 goals included: the biblical basis of mission, community/relationships, area studies, role of change agent/servant-leader, development ministries, cross-cultural communication, inservice teaching methods, relations with agency-church-supporters-nationals, cultural adjustment.

Preparation approaches may have contrasting organizational centers. For instance, Maltby (1980) and Masten (1988), in comparable studies, emphasize the cross-cultural core by focussing on an intercultural communication perspective. Because most functioning within a culture involves some form of verbal or nonverbal communication, there are orientation experts who believe that intercultural communication should be the core of cross-cultural preparation. Some authorities point out that the essence of the missionary task resides in communication. The thesis of Maltby's and Masten's approaches is that the major deterrent to successful mission is a missionary who is not culturally sensitive, and the best way to become such is through intercultural communication training. Maltby expresses his feelings strongly:

The combined record of missionary training by mission organizations, para-church agencies, and evangelical institutions is not impressive. Given the importance of intercultural communication in the formula for cross-cultural effectiveness the efforts are pathetic. . . . For hundreds of years the North American evangelical missionary enterprise seems to have been running in the wrong direction, from the perspective of making missionaries culturally sensitive. . . . There can be no doubt that North America has an ethical responsibility to send only the most highly qualified, and best trained missionary change-agents to other countries. (1980, pp. 116-117, 144) 
Whereas those responsible for missionary preparation may argue the strength of Maltby's perceptions of mission history, they would not argue the importance of effective intercultural communication preparation. Ensuring it for missionaries facing unique and seemingly insurmountable cross-cultural mountains is a challenge. The achievement of intercultural sensitivity, however, is a task that goes even beyond educational parameters.

Among the more than 10 theses/dissertations studying missionary preparation programs consulted, missionary needs and preparation concerns are common. Burt (1989) designed an intercultural orientation program for Salvation Army workers in Canada (emphasis on re-entry training) with the aim "To keep missionaries 'whole' throughout the international cycle" (p. 128). In fact, she stated this aim as one of her goals because she saw that "the key to determining the methodology for re-entry training lay in the setting of the goals" (p. 95). (She appeared to use the terms "aim," "goal," "objective" interchangeably.) Her seven goals are a list of participant processes she found important for the holistic approach: (1) describing steps in sequencing orientation, (2) facilitating the negotiation process with positive attitudes, (3) applying these steps to personal life, (4) accepting change as vital, (5) designing a personal strategy for handling crosscultural stress, (6) valuing and integrating cross-cultural experiences, and (7) planning specific steps towards becoming multicultural. Three points for orientation programs stand out. First, the leamer shares the responsibility for the whole process; second, the leamer's involvement should be conscious and 
third, the learning must include personal growth, cross-cultural development, and positive attitudes. She also believed a training model should include the physical, social, emotional, mental, and spiritual dimensions (p. 75). Burt (1989) stated that missionary effectiveness depended on "bonding, bilinguality, biculturality, and a commitment to them" (p. 74).

Peters (1990) did a study on orientation program effectiveness of the Board of International Missions (BMM), an organization whose forerunner began in 1814. When he studied the descriptions of orientation programs offered by several organizations, he identified several orientation challenges: attempting to meet the needs of individuals whose backgrounds and experience vary widely, adequate area studies, information overlap from previous leaming, personal/work-related aspects of preparation, and making pre-departure and in-field training complementary so that preparation gaps are eliminated (p. 3).

The combined curriculum represented by the orientations Peters described was: History, structure, and policies of the sending mission society; personal development of the missionary (psychology, stress management, collegial relationships, family and lifestyle issues, cultural adjustment, children's schooling), area studies, coping, personal evangelism, language acquisition skills, Bible knowledge/theology, medical care, wilderness survival skills. Peters saw predeparture orientation as general preparation that included area studies and mission policy/mission issues; and in-field preparation for in-depth area studies, and learning the procedures and practices of the local in-field organization. 
Peters found that pre-departure orientation programs had difficulty accommodating the needs of both the majority and minorities and usually had an unequal balance between personal and task-related preparation. There were also problems such as a lack of coordination, overlapping content, and differing expectations and requirements of mission boards.

Missionary preparation programs vary in their comprehensiveness. Some include only information about the sending agency and transition details conceming the move. Others provide comprehensive preparation in several phases of the preparation cycle--before and after departure and for re-entry. Institute of World Mission provides a fairly comprehensive pre-departure preparation in one orientation program.

Characteristics of Missionary Effectiveness and Success

One research focus has been an attempt to identify factors relating to missionary effectiveness and success. Bailey and Jackson (1965) asked mission board leaders to identify and prioritize characteristics they believed were most important for effective mission service. They found that dedication, commitment, and a desire to win souls to Christ were the three most emphasized. Preparation was seen as next in perceived importance. Qualities mentioned frequently were emotional stability from a sense of security and confidence, love and tolerance for people, vision, and an awareness of God's leading (p. 29). 
Britt (1981) conducted a study in which he sought to find a way to predict missionary success overseas. He ended up with 72 independent variables which produced 12 variable clusters that explained 56\% of the variance. Among those relevant for training were self-control, moodiness, forthright-astute, social relations, social poise, perseverance-discipline, and flexibility (p. 99).

Several studies point out categories for characteristics of successful missionaries. Cureton (1983) measured three categories: job, values, and personality. Smith (1983) studied the selection and orientation of missionaries for the Navigators mission agency because of high attrition rates. He conducted six surveys to discover those key factors that predict missionary success and are thus suitable for guiding selection procedures. He found 10 qualities for successful cross-cultural adjustment, and six qualifications for successful job performance. Psychological testing and counseling have been an important part of the selection process since post-World War II years because of their potential to help predict missionary success. In time, the selection rationale became modified. As the human potential movement and the trend toward personal responsibility have become American values, there has been a shift is using assessment to meet missionary needs and guide them toward effectiveness. In fact, one organization called Link Care grew from a "hole in the wall office to $81 / 2$ acres with a community center, offices, and 105 apartments, serving hundreds of missionaries and others." (See introduction to a special issue of Joumal of Psychology and Christianity on assessment of missionary effectiveness, volume 2(4), 1983. Most 
joumals combining theology, psychology, and Christianity have one or more special issues on missionaries.) Link Care's missionary preparation program was developed from a strongly psychological perspective.

The assessment literature includes studies of factors to identify or predict missionary overseas adjustment or ministry success (Lindquist, 1983). Discussions in the literature include psychological causes of premature return, assessment/counseling strategies, psychological testing methods and uses, and criteria for selection. Although there is no single pattern of personal characteristics to describe the ideal missionary (Diekhoff, Holder, Colee, Wigginton, \& Rees, 1991), there are factors that are commonly present in successful missionaries.

Among several more unusual assessment factors from several studies and authors that relate to missionary preparation goals are: leadership affirmation of God's call, degree of information about personal strengths and weaknesses, adjustment in family of origin, number of years as an active Christian, previous academic and vocational adjustment, degree of extracurricular activities in college and leadership in such activities, mental flex and breadth of interests, physical stamina, willingness to work with others without rewards, employer and peer adaptation, future expectations, skills for classification of information, and lack of concem for money/possessions. Finally, research shows that missionaries need a knowledge of biblical principles for more than an understanding of mission. They need the knowledge to provide the personal resources important to making decisions, resolving conflicts, responding to correction and authority, and meeting emotional 
and spiritual needs. (Gardner, 1987; Johnston, 1983; Kliewer, 1983; Lindquist, 1983; Williams, 1983)

\section{Goals of Missionary Orientation Programs}

Brislin and Pedersen (1976) stated that "American religious organizations have been sending personnel abroad for over 150 years and probably constitute the largest and oldest cross-cultural agency in our society" (p. 149). They believe missionary preparation programs are among the most varied, and range from some of the best to worst. Cleveland et al. (1960) also stated that missionaries have carried out orientation programs longer than any other group, and believe they have among the best training courses (p. 264).

This final section of Source 4 reviews (1) data relevant to the goals of one prominent and successful missionary orientation program, Missionary Internship; and (2) the views of 22 mission agency directors toward suitable orientation goals, particularly the goals of the Institute of World Mission. These directors were responsible for providing orientation for their missionary appointees, although in two cases, other organizations provided the orientation.

\section{Missionary Internship Orientation}

Missionary Internship, one of the few significant general missionary orientations still in operation, began to provide orientation for missionaries in 1954. For approximately 20 years, the training lasted for 8-9 months and was "internship" in its style; trainees were associated with a veteran worker and church congregation. 
In 1975, the organization began a shorter, more orientation-style program that has since been held 3-4 times per year. A combination program of orientation and training for language-acquisition skills began in 1984 and is held twice a year in addition to the other orientations. Over 9,000 missionaries have been prepared for mission service over the last $\mathbf{4 0}$ years, with the average number of participants per orientation around 30. Today, Missionary Internship services over 50 missionarysending organizations.

During its span of service, Missionary Internship has tried to "fit the changing times" with "new patterns of training," including a response to evolving trends (2-page program document on history, 1994). In January 1994, Missionary Internship evaluated its program in light of the trends in missionary preparation needs, and began a reconceptualization process. Because most of the recent participants have had some formal missiological education, the purpose of the orientation was able to shift more toward integrating that background and challenging participants more at the affective and reflective levels. A major aim was to encourage personal responsibility for continuing change and growth. The reformulation and reorganization have been in emphases rather than basics.

Missionary Internship's purpose statement reads: "to train Christians for effective, intercultural life and service with special emphasis on the spiritual and functional [practical] dimensions of personal, interpersonal, and intercultural issues" believed by the staff to be most critical to effective "intercultural life and service" (Cocks, program document, 1994). Missionary Internship organizes its four 
dimensions around the theme "Knowing God and Expressing His Love" because leaders believe that the "spiritual dimension of personal, interpersonal, and intercultural issues is at the core" of their orientation program. All four are integrated throughout the 3-week orientation. Apart from overviews, each day emphasizes one dimension (beginning with the spiritual) and the cycle is repeated three times. Mission topics include leadership and church-related issues.

A few principles mentioned in Missionary Internship's working document that are emphasized in their program are representative of missionary orientation concerns. For example, "the entire family is to be prepared for missionary life and service, not just the husband." The program design focuses on "the participants' growth, not just on the acquisition of knowledge and skills." One method used confirms this emphasis and encourages internal motivation for learning: "Guided reflection is essential. . . Participants reflect on how they respond both emotionally and cognitively to their experiences and instruction, on what they need to change or affirm, on how they leam, and on how they can integrate their working knowledge into appropriate life patterns."

Because Missionary Internship is a service organization that provides orientation for numerous denominations and organizations, it does not deal with specifics relative to mission appointment, such as policies, area studies, psychological advisement, language learning, and theological or doctrinal particulars. These are provided for by the sending organization in some other way. Nor does this orientation program have any requirements for its participants; these 
are determined by the mission organization who has appointed them. Those who attend Missionary Internship will serve in any part of the world, and in any type of mission role. Missionary Internship uses all types of teaching materials and almost every possible cross-cultural learning method except technical exercises, such as the culture assimilator. Built into the orientation program are times for devotional activities including prayer and testimony, group Bible studies, personal counseling opportunities with the assigned advisor, fellowship events, suggested readings, family time, and time for informal fellowship. Ten of the 12 Institute of World Mission's goal statements are considered essential by Missionary Internship. Two do not apply: clarifying church/agency policies, and providing orientation to specific areas of service. As already mentioned, these, along with language learning, are the responsibility of the sending agency.. Of the 10 IWM goals that Missionary Internship considers essential, all are stated, except those that are assumed, and therefore intended.

\section{Mission Agency Director Responses}

Twenty-two of 65 mission agencies retumed a questionnaire prepared by the researcher. The purpose was to discover what goals were used and/or believed important for cross-cultural missionary orientation. In the questionnaire, directors were asked which of 14 goals related to their orientation program by indicating if each was expected, stated, implied, or not applicable. The list of 14 included IWM's 12 plus 2 others that could apply to other orientation programs: (13) To 
reinforce, refresh or integrate previous preparation for mission service," and (14) To teach a language for the cross-cultural appointment."

Of the 22 mission agencies who returned the "Missionary Pre-departure Training Programs" questionnaire, 20 conduct their own cross-cultural pre-departure orientation programs from 1-5 weeks in length and 2 send their appointees to other orientation programs. Several provided other types of missionary training or education as well. Table 27 numbers the responding 22 agency programs, describes their length, and the IWM goals they selected as the 5 most important of the 12 . These orientations appear similar to IWM's orientation. First of all, they provide similar information using similar methods and materials as IWM. The average number of participants is comparable ( 35 vs. 42 ), and the average number of times orientations are held per year (2 $1 / 2$ vs $2-3)$. Although participants of both will serve in similar parts of the world and in similar appointments, there are some variations. Persons who have gone through the average mission agency orientation are more likely to go to the Middle East, Europe, North Africa, urban areas, and to unreached people groups than those attending IWM. Besides the usual types of mission, these agencies also assign people a wider range of roles than IWM does, partially because of differences in methods of financial support: orphan/child care, literacy training, translation/linguistics, youth ministry, health/lifestyle training, frontier mission, and "tent-making." 
TABLE 27

RESPONDING MISSION AGENCIES: ORIENTATION LENGTH AND GOALS PERCEIVED MOST IMPORTANT

\begin{tabular}{|c|c|c|c|c|c|c|c|c|c|c|c|c|c|}
\hline \multirow[b]{2}{*}{ Prognam } & \multirow[b]{2}{*}{ Orientation Length } & \multicolumn{12}{|c|}{5 Goals Selected as Most Important } \\
\hline & & 1 & 2 & 3 & 4 & 5 & 6 & 7 & 8 & 9 & 10 & 11 & 12 \\
\hline 1 & $\begin{array}{l}4 \text { weeks, 3-6 } \\
\text { months }\end{array}$ & & & & & & & & & & & & \\
\hline 2 & 3-6 months & $x$ & & & & $x$ & & $x$ & & & & $x$ & \\
\hline 3 & 7 days & & & & & & & & & & & & \\
\hline 4 & (varied) & & & & & & & & & & & & \\
\hline 5 & 4 days & $x$ & $x$ & $x$ & & & & & $x$ & & & $\mathbf{x}$ & \\
\hline 6 & 10 days, 3 weeks & $x$ & & $\mathbf{x}$ & & $x$ & & $x$ & & & & $x$ & \\
\hline 7 & 1 week, 1 year & $x$ & & $x$ & & & $x$ & $x$ & & & & & \\
\hline 8 & 3-14 days & & & $x$ & $x$ & $x$ & $x$ & & & $\mathbf{x}$ & & & \\
\hline 9 & 3 weeks, 1 year & $x$ & & & & & $x$ & $x$ & $x$ & & & & $x$ \\
\hline 10 & $\begin{array}{l}\text { 4-13 weeks. } \\
\text { 3-12 monthss }\end{array}$ & & & $x$ & $x$ & $x$ & $x$ & & $x$ & & & & \\
\hline 11 & 4 weeks & $x$ & & & & $\mathbf{x}$ & $x$ & & $x$ & $x$ & & & \\
\hline 12 & 4 weeks & & & & & $x$ & $x$ & & $x$ & $x$ & & & $\mathbf{x}$ \\
\hline 13 & 4-5 weeks & & & & $x$ & $x$ & $x$ & $x$ & & $x$ & & & \\
\hline 14 & (varied) & & & $x$ & $x$ & $x$ & $x$ & & & & & & \\
\hline 15 & 2 weeks, 1 year & & & & & & & & & & & & \\
\hline 16 & 4-8 weeks & & & $x$ & $x$ & $x$ & $x$ & & $x$ & & & & \\
\hline 17 & 2 weeks & $x$ & & & $x$ & $x$ & & $x$ & $x$ & & & & \\
\hline 18 & 3 weeks & $x$ & & & & $x$ & $x$ & & & & & $x$ & $x$ \\
\hline 19 & 3 weeks & & & & & & & & & & & & \\
\hline 20 & 2 weeks & $x$ & $x$ & $x$ & $x$ & $x$ & & & & & & & \\
\hline 21 & 10 days & $x$ & & & $x$ & & $x$ & & $x$ & & $x$ & & \\
\hline 22 & 3 weeks & $x$ & & $x$ & & $x$ & & & & & $x$ & $x$ & \\
\hline Totals & & 52 & 9 & 44 & 35 & 61 & 48 & 26 & 35 & 17 & 13 & 26 & 13 \\
\hline
\end{tabular}

These agencies also offer additional training: diploma, undergraduate, and/or graduate work/degree. 
Pre-training requirements/expectations are one difference between IWM participants and persons who attend other agency orientations. According to the responses, half of the other programs require language acquisition, half require field appointment prior to orientation, $30 \%$ require cross-cultural coursework, and $17 \%$ require cross-cultural experience; IWM has no such requirements. The contrasts reflect variations in the nature of mission, expectation of what constitutes crosscultural preparation, and type of appointments to be filled. Background differences impact type/emphases of goals, and demonstrate why IWM is so comprehensive.

Two additional goals were added to the IWM's list of 12 to be evaluated: (13) is "To reinforce, refresh or integrate previous preparation for mission service" (Integration), and (14) is "To teach a language for the cross-cultural appointment" (Language). Ten agencies believe goal 13 is essential, seven state it, nine intend the goal to be reached, and two believe it does not apply. As expected, 15 agencies believe goal 14 does not apply to pre-departure orientation. Of the five agencies who believe goal 14 is essential, all provide several other forms of education, including graduate education, and most indicated that language training may be best after arrival in the foreign context. These may have viewed orientation as continuing in the field and assumed language-leaming skills important to predeparture orientation. Eleven of 12 Institute goals are considered essential by the majority of mission agency respondents, and Transformation is considered intended. Three goals are stated by the majority of the programs: Health, Area Studies, and Policies; the rest of the goals are stated by a third or more of the programs. The 
goals most intended besides Transformation are Call/Commitment, Fellowship, Issues, Faith, and cross-cultural Competencies. Language learning, one of the two additional goals listed for this questionnaire, was considered not applicable to predeparture orientation by $73 \%$ of the agencies, and those that said it was essential or stated were organizations that provided more than orientation. The second, Integration with previous learning, was considered essential or intended by 10 agency respondents, and stated by a third of them.

The content of the agency orientation curricula is close to that of the Institute. As a group, the two most important components in their curriculums are policies of mission board (100\%), and attitude/psychological preparation (91\%). The next three tie at $83 \%$ each: Spiritual formation and growth, cross-cultural communications/relations, and principles and practices of mission. Area studies and mental/physical health (both 78\%), and culture learming of both ones' own and the other culture (65\%) follow. Those areas covered by around half the orientations include several mission topics such as theology, history, anthropology, growth, and issues, as well as practical skills. In general, mission agency directors were satisfied with their orientation programs--only two said they needed improvement.

\section{Source 5: Summary of Cross-cultural Literature}

A validation of IWM's goals is more complete if findings are supported by theorists and practitioners in the general cross-cultural training field. This verification was sought by reviewing relevant literature for two purposes: 
(1) briefly exploring the historical development of cross-cultural training programs and goals, and (2) making a list of stated and implied needs and goals, synthesizing these into goal clusters, creating goal categories from the clusters, and organizing them into a framework as an aid to the validation and reconceptualization of missionary orientation goals.

The literature examined for stated or implied needs and goals for crosscultural training included relevant research studies, dissertations, several seminal books in the field, articles from joumals such as Intemational Jownal of Intercultural Relations, and syllabi from seminars designed for students and crosscultural trainers. Several sub-areas were reviewed: (1) cross-cultural adjustment and adaptation; (2) traits, attitudes, and skills for intercultural communication effectiveness and intercultural competence; (3) orientation needs; and (4) training, orientation program development, and evaluation. It is assumed that even if goals are not stated, it is possible to extrapolate them by the context or reference to needs. For instance, a study of theories relating to cross-cultural issues such as adjustment, adaptation, and competence will disclose those needs that help shape the goals to meet them.

The search for training goals ignored the distinctions made between "intercultural" and "cross-cultural," as well as "orientation," "training," and "education" in cross-cultural literature because these terms are often used interchangeably, the connotations are similar, or goals are relevant to the parameters of this study (J. Bennett, 1986; Paige, 1986b). The variance is not important for 
determining which goals are necessary to adequately prepare individuals for crosscultural experience.

\section{Historical Overview of Cross-cultural Training Programs and Goals}

Because the development of cross-cultural training goals "are analogous to its historical development" (Nunes, 1987, p. 15), this second part of chapter 4 begins with a brief overview of the history of cross-cultural training. The search for factors contributing to cross-cultural adaptation and effectiveness in general began in the United States during the 1940s. Global changes in mobility patterns, transportation, and communication technology prompted by World War II provided an impetus to formation of cross-cultural awareness. Within this field, pre-departure orientation programs are "among the best known of all cross-cultural training programs" (Paige \& Martin, 1983, p. 49).

"The need for improved selection and training of cross-cultural sojoumers became apparent" during the 1950s (Ruben, Askling, \& Kealey, 1977, p. 89). Preparation for prospective sojoumers was instituted by numerous organizations for their personnel (p. 89). As the need for improved cross-cultural preparation became apparent, briefing and orientation programs multiplied (pp. 89-102). In fact, it was estimated that around 20,000 programs had been held between 1951 and 1981 . Just when cross-cultural training became formalized and research-based is debated:

Ruben et al. (1977) prefer a 1950s date, Paige and Martin (1983) point to the early Peace Corps years (1960-61), and Smith (1977) argues that the field was 
underdeveloped during these decades because much of the research, literature, and theory had not been shared. Findings were not well shared or easily accessible because most of the academics were also the training practitioners (p. 3 ).

During the late 1950s and early 1960s, interest in what patterns of interpersonal, group, or situational factors contributed to success or failure grew. Those who had had cross-cultural experience were among the first studied, and early preparation programs were also surveyed (Smith \& Otero, 1977, p. 90). It was during this time that men such as Hall and Oberg made powerful contributions to the field. The study of the "clarification of the nature of effectiveness remains a most important component in clarifying and solidifying the assumptions which undergird many training efforts" even at this present time (IIR). The academic discipline of cross-cultural communication became one of the core areas of study.

The 1960s saw expansion in the fields of cross-cultural literature, research, training, and the development of agencies and resources (Ruben et al., 1977 , p. 90). Three populations that have been especially popular for research are Peace Corps volunteers, military, and international students (Gudykunst \& Hammer, 1983, p. 118; Hannigan, 1990, p. 90). "Literature concerned with interpersonal effectiveness was dominated by Peace Corps studies" during the 1960s (Ruben et al., 1977). Although the United States govemment had sent personnel across cultures for 2 centuries, it had not provided much preparation for them prior to corps training that started around 4 decades ago. The Peace Corps has perhaps provided the greatest impetus to the field because it provided a 3-month preparation 
for the youthful thousands sent by the government of the United States as ambassadors throughout the world. The government recognized the need to evaluate the effectiveness of that preparation. By the end of the 1970 s, the trends of selfselection and in-country training for Peace Corps personnel opened the door to interest in and research of other groups, especially those in business and industry (Ruben et al., 1977).

Intemational students make up another group that grew out of international exchange programs after World War II. Early research focussed on preparation program effectiveness, but later studied the process of adjustment and adaptation. Much of the research studied the sojoumer over time, so the direction of the research was long-term and developmental, such as adaptation and adjustment.

The initial practice of disseminating information about the target country to which the sojourner would go (area studies) was rapidly expanded to include study and hypotheses about what determined success in cross-cultural functioning. The field attempted to predict cross-cultural success. The interest in and commitment to intercultural training stimulated thought, conceptualization, research, and training practices that gave rise to experimental programs, audio-visual resources, and methodologies (Brislin \& Charles, 1977, pp. 103-149).

During the 1970s and 1980s, commitment to training continued. The decade raised questions that aimed at "clarifying the goals, methods, and outcomes," culture-specific vs. culture-general issues, and increased theoretical refinement of the concept of adaptation (Ruben et al., 1977, pp. 89-91). Studies revealed changing 
perceptions of the nature of cross-cultural leaming in relation to cognitive information, strategies for personal growth, cross-cultural awareness, and crosscultural relativism. Assumptions were altered to recognize that cross-cultural effectiveness was best learned on the affective level rather than cognitive. In many orientation programs, the emphasis was on personal growth and cross-cultural awareness in order to impact trainees on the affective level (Brislin \& Charles, 1977, p. 104). As a result, training programs developed unique styles of providing learning opportunities, such as simulations of cross-cultural experience, and shortterm living in foreign villages.

By the end of these decades, there was an abundance of literature related to intercultural training (Gudykunst \& Hammer, 1983, p. 118). Examples of major works are Brislin and Pedersen's Cross-cultural Oriensation Programs (1976), the "early and seminal work" in the field of cross-cultural orientation (Paige, 1986b, p. v); the three-volume Overview of Intercultural Education, Training and Research (Hoopes, Pedersen, \& Renwick, 1977-1978), the three-volume Handbook for Intercultural Training and Research (Landis \& Brislin, 1983); and 10 years after Brislin and Pedersen's seminal work, M. Paige (1986b) edited a volume entitled Cross-cultural Orientation: New Conceptualizations and Applications to "articulate those advances in our thinking and practice." Section I of this book that deals with cross-cultural conceptualizations and orientation training clarified five necessary elements for cross-cultural programs that summed the range of program development: experiential learning activities, culture-general content, culture- 
specific content, integration of several content areas and methods, and instructional allowances for individual differences (p. 13).

Cross-cultural training program goals have changed with shifts in methodologies. In the early decades of cross-cultural training, the primarily cognitive "university" model stressed area studies of the target country and culture, but this was deficient in providing the skills required for effective functioning in the new context. This lack prompted a dramatic swing to the experiential emphasis of the human relations sensitivity model, which centered on personal growth instead of information. Because the approach is confrontational, stress-producing, and demands sophisticated trainer expertise, an integrated model seemed to be the answer. By 1967 , there was a recognized need to provide skill training in problemsolving, making sense out of confusion and ambiguity, and strategy development for guiding one's adjustment process (Paige \& Martin, 1983, p. 41). The new model was named the "alternative leaming" model. Years later, Martin (1986) along with several others called for an expanded multi-dimensional model. Brislin's latest book (1994) suggests a balanced and sequenced model: awareness, knowledge, emotions, and skills.

Most areas of human life today function on a level of complexity previously unknown; research in the 1980s explored complex sets of variables. The early years of the 1990s have seen a dramatic increase in cross-cultural literature. Issues in the field are becoming more defined. 


\section{Cross-cultural Training Goals}

As noted, there is wide diversity in what constitutes cross-cultural orientation today. The range of programs are undoubtedly enabling a larger number of individuals to serve more effectively in cross-cultural contexts today than would have been able to survive before such orientation opportunities. There has been little formal discussion about what goals are important for cross-cultural training. When mentioned, goals may be in reference to implications for research findings, theory development, or sojourner needs. Or they may be related to learning domains (cognitive/affective/behavioral), or a methodological approach. Stated goals are often very general (as in purpose) or very specific (as for objectives) (J. Bennett, 1986; Paige, 1983). The importance of goals (and their determination from needs assessment) is receiving more attention. Brislin and Yoshida (1994) devoted their first chapter in a book just off the press to needs assessment, aims, and goals.

\section{Cross-cultural Training Goal Categories}

The result of the literature review was a several-page list of factors, qualities, skills, and considerations that make a necessary and unique contribution to cross-cultural effectiveness and that are necessary to or enhanced by some form of preparation. Authorities vary in their conceptualization and categorization of the factors, qualities, and skills important for cross-cultural effectiveness, and no particular model was used to categorize goals for this study. Instead, the pages of stated and implied goals were organized into five categories with sub-categories 
based on the pattems and clusters found. The list of goal categories and subcategories that emerged from the stated and implied goals is presented here, and is useful for a synthesis of data. Although it is unlikely that any set of categories would be entirely discrete, an attempt was made to minimize conceptual overlap.

1. Personal factors: individual learning, prompting new or modified behavior

a. cultural self-awareness and understanding

b. paradigm shift

c. adjustment, adaptation, and integration skills

d. personal qualities development

e. personal growth

2. Culture-sensitive factors: information about other cultures and countries

a. general other-culture awareness and understanding

b. target culture information and understanding

c. cross-cultural skills

3. Interpersonal factors: understanding/skills for communication/relationship

a. verbal, non-verbal, and linguistic communication skills

b. social interaction/relationship skills

c. social support systems

4. Role-related factors: factors related to purpose for being in other culture

a. career/professional expertise

b. technical understanding and skills

5. Transition factors: factors related to move/early survival in new culture

a. logistic information for the move

b. survival information and skills for daily life. 
The above list is also intended to construct a framework that would accommodate any need or goal. It is unlikely that any two planners would develop identical goal/sub-goal lists, or organize them in precisely the same way. The goal categories presented here are intended to be broad and representative enough to be useful both conceptually and practically. A description of each category and its subcategories follows.

1. Personal Factors include individual learning that prompts change to new or modified behavior. This category is divided into five sub-categories, and each is illustrated by sample sub-goals. "Cultural Self-awareness and Understanding" includes learning about one's own cultural identity, values, beliefs, worldview, and personal expectations. "Paradigm Shift" includes gaining a new mindset, a move from ethnocentrism to ethnorelativism, and the stabilization of beliefs and values. A paradigm shift enables and/or enhances the likelihood that the whole cross-cultural preparation program will achieve optimum results. "Adjustment, Adaptation, and Integration Skills" include dealing with culture shock and the development of coping strategies, leaming how to make decisions and solve problems amidst stress, learning to learn including the development of observation skills. "Personal Qualities Development" includes the understanding of personality and temperament characteristics, particularly one's own, and the enhancement of such qualities and traits as openness, flexibility, ambiguity, tolerance, humor, patience, enthusiasm, empathy, humility, and respect. "Personal Growth" includes those aspects that contribute to stable identity formation and emotions, flexible personal boundaries, 
cognitive complexity, motivation, commitment to continuing growth in training goals and role expertise, and developing intemal consistency amidst change. Personal change is the most critical category because all others are to some degree dependent upon it. In most cases, sub-goal development in the personal category is essential.

2. Culture-sensitive factors are those that relate to the other culture. One of the three sub-categories is "General Other-culture Awareness and Understanding" which includes learning how other cultures contrast with one's own culture and other major cultural issues that enable realistic expectations. "Target Culture Information and Understanding" provides information and understanding of the particular cultural context and situation for effective functioning, the expected role of foreigner in that society, and other contextual factors. "Cross-cultural Skills" are those personal skills that are necessary to function and continue learning effectively in a foreign culture, such as attributions, perceptual acuity, learning-to-leam skills, and others.

3. Interpersonal Factors are those understandings and skills necessary for effective cross-cultural communication and social relationships. "Verbal, Nonverbal, and Linguistic Communication Skills" are the communication skills that are necessary for the profession and daily life functioning. These skills include such skills as confrontation/conflict management and resolution. Effective communication is also dependent on general "Social Interaction/Relationship Skills" relating to social adjustment and other relational skills, and team building/leadership skills. The development of "Social Support Systems" is critical, including family, rolerelated, and local supporn networks as well as multicultural peer group identification. 
4. Role-related Factors are those that are dictated by the purpose for going in the foreign culture. The relevance of these factors depends on the type and purpose of the sojourn. "Career/Professional Expertise" includes role clarity and responsibilities, understanding lines of authority, issues and policies relative to the organizational and its management, and in some cases the dynamics and ethics of change--all of which are required to maintain effective job functioning. "Technical Understanding and Skills" are an important part of living in a world on the brink of a new millennium when the limits of technology and information expansion seem infinite.

5. Transition Factors guide specific family considerations regarding "Logistic Information for the Move," such as resources/travel information, lifestyle decisions, and basic "Survival Information and Skills for Daily Life" in the new context.

In summary, the field of cross-cultural preparation is rich in insights for those who plan missionary preparation and who will take the time and effort to keep up with the literature.

\section{Source 6: A Discussion of World Trends and Preparation Issues}

A revolution in missionary preparation is inevitable. Trends such as globalization, accelerating change, and international expectations are creating and transforming the milieu in which mission and missionaries are shaped and operate. These forces help direct and determine who the missionary is and what message, 
motivation, method, and means will best carry out the task of personnel preparation and world evangelization, all of which impact the goals for missionary preparation. Siewert and Kenyon (1993) remind us that "understanding the context of world mission in the 1990s [is] a challenging task" (p. 1). Ward (1987) speculates that "the situations with which missionaries deal today are apt to be child's play compared to what seems likely to unfold" (p. 399). Mayers (1986) asks if we will "be ready for the challenge of 21 st century missions" (p. 306).

Fascination with futurism has become an expected part of existence in our rapidly changing environment. More than 15 years ago, Wight and Boyle (1978, p. 1) listed several major trends that were then changing our view of life on Earth. In 1982, Naisbitt published Megatrends to help forecast life in the 1980s. His projections, now largely present realities, have been updated by their sequel (1990) which faces the new millennium. Megarrends 2000 was an attempt to provide a structure or frame of reference to help make sense of the "vast amount of data" that demands our attention as we prepare to enter the 21st century (1990, p. 13). The authors believe this decade offers a "new world view" (p. 14).

Curriculum planners were among the earliest to recognize the necessity of making education responsive to the future. Human resource development experts are attempting to keep personnel prepared for changing workforce needs. It is not surprising, then, that mission leaders also recognize the importance of milieu and trends in shaping mission and missionary. One evidence is the direction taken by several authors of articles in Mission Handbook and Evangelical Missions Quarerty 
in the last 2 to 3 decades. Focussing their attention on what appears most urgent, many note how today's global revolution is changing the face of daily life throughout the world. Their articles prompt the question: Are missionary preparation enterprises ready to adapt to the increasing diversity and complexity that is required of today's multi-national organizations?

Ward (1987) warns the mission community that current preparation practices cannot be assumed to be "adequate for the future," so we must plan even if the future is "beyond our knowledge" (p. 398). Because planning "makes an unmistakable assumption about some particular future" (p. 398), we are responsible for discerning the times by continually becoming informed about world trends and preparation issues. These considerations, together with being "sensitive to the Spirit's leading in dealing with them" (Mayers, 1986, p. 306), should not only alert us to the challenges, but contribute insights for those who plan or direct the preparation essential for cross-cultural ministry.

\section{World Trends and Preparation}

\section{A New Millennium}

A new millennium is about to dawn. Naisbitt and Aburdene (1990) believe that we are living in "the most important decade in the history of civilization" (p. 11), and we "cannot understand the megatrends of the 1990's without acknowledging the metaphorical and spiritual significance of the millennium" (pp. 13-14). The "powerful magnet" of the year 2000 is "reaching 
down into the 1990's and intensifying the decade," and "is amplifying emotions, accelerating change, heightening awareness, and compelling us to reexamine ourselves, our values, and our institutions" (p. 11).

The approaching millennium has strengthened mission initiatives for optimum advance. In his 1986 article "Taking Aim on 2000 AD," Coote stated that "the turn of a millennium offers a tempting target" for renewing mission aims. He listed a sampling of North American aims, from "presenting the gospel to every person in the world by century's end," to dramatic expansion of training persons to do the work (p. 35), which represent the two organizational purposes of the Christian church (Newman, 1985). The first--world evangelization--is largely dependent upon the second--effectively trained personnel.

Despite hope, projections, and a lively discussion of just what is possible by the end of the 20th century, world evangelization is not keeping pace with the dream, either in numbers and coverage, or missionary preparation. (See Coote, 1991; Jaffarien, 1994; McQuilkin, 1994.) By the year 2000, the world Christian population is expected to reach 2 billion, a number far short of the projections by those with an eye on a turn-of-the-century completion of the gospel task. The gradual increase in the growth of Christianity has not kept up with population growth in many localities. The overall net per hour increase of people who hear the gospel compared with those who are borm is only 500 , a ratio of $1: 300$ in the net reduction of the unevangelized. At this rate, reaching the world would take another 
400-500 years if the pace of population growth remained the same. Besides, much of any net gain is "eroded" by factors such as secularism and nominalism.

Although we must keep in mind that a transcendent God is directing the expansion of His kingdom on earth, and His ways are often beyond our understanding, history tells us that unless we come very near reaching millennial goals, passing beyond 1999 will bring disappointment and likely a deflation of motivational energies currently propelling the world evangelization movement. And, if dreams fall far short of expectations, the thrust empowered by millennial motivation and mobilization should at least put in place structures that are comprehensive and flexible enough to support, direct, and maintain the momentum until the task is completed, whenever and however that time arrives.

As the new millennium approaches, diverse evangelization needs demand a dramatic increase in personnel numbers, requiring recruitment of large numbers of personnel. McQuilkin (1994) admonishes "we must not send out unprepared harvesters in an effort to hit the target date" (p. 132), and points out that even "if we had the recruits right now, which we do not, it would take more than the remaining six years to get them prepared, into the target areas, and usable" (p. 132). Notwithstanding the 285,000 missionaries deployed worldwide, the total number of North American missionaries decreased between 1988 and 1992 for the first time in 40 years (Myers, 1993, p. 26; Siewert, 1993, p. 55). A further problem is the limited "spiritual dynamic necessary to mobilize the resources 
needed" because American Christians tend to have self-oriented agendas, and "without a spiritual revival strong enough to tum our values right side up, we, at least, will not be able to accomplish the task" (McQuilkin, 1994, p. 134). A powerful evangelization offensive demands recruiting large numbers of missionaries and, of course, training them (Myers, 1993). With 2000 A.D. so near, there is a growing pessimism about reaching the world by then. An important question arises: Is the North American mission community prepared to meet the challenge of preparing large numbers should there be a sudden increase in those deployed through recruitment and renewal? Some think not.

But the approaching millennium challenges mission in ways other than goal-setting evangelism. One example is the wide diversity in Christian and nonChristian eschatological views that presents a challenge to mission's message, method, and motivation for which missionaries must be prepared. Naisbitt and Aburdene (1990) discuss the issue from both secular and fundamentalist positions. The secular view of the new millennium refers to a "golden age in human history, a time to close the door on the past and embark upon a new era" (p. 14), but Christianity has historically interpreted the "new age" as being inaugurated by the second coming of Christ after everyone has had an opportunity to have decided for or against the gospel option (p. 14). Both views project that during this decade, "the end-of-the-world . . . apocalyptic themes will emerge and reemerge with stunning regularity" (pp. 284, 14). (See McQuilkin.) Naisbitt and Aburdene (1990) 
see a "concurrence of new age, fundamentalist, and ancient prophecies" (p. 284). Many will look to Christianity for answers.

\section{Changing Values}

The world has shifted from the Industrial Age and the values it embodied to "new age" values. Many of these values are positive and have the potential to empower missionary preparation. For example, a new basic concern for the future promotes proactive planning rather than reactive planning, cooperation instead of competition. Rather than hierarchical organization and centralization, problemsolving networks and participatory consensus are utilizing the gifts and expertise of more than the few who used to direct decision-making. Information, technology, and growth are becoming selected and used in a more balanced manner. Because of rapid change and diversity, specialists are finding it necessary to take on generalist roles. Holism is modifying our dependence on science and calling for a balanced approach that takes input from the arts, perception, philosophy, and intuition as well. A growing interdependence is replacing individual isolation; even our thinking pattems are moving from linear to systemic modes. Despite growing optimism, the rapid transitions required present challenges that are complex and perplexing.

\section{Technology, Transportation, and Communication}

Based on the most recent developments, one has difficulty imagining where technology will take us in the future. Transportation styles are making the 
world a global village as much as other factors are. Many traditional communication modes are becoming antiquated as technology opens up new vistas. The computer age with its information networks and diverse applications is truly bringing to us phenomenal opportunities. These will not only influence how we live, but also how we think.

The technology explosion is very encouraging for missionary preparation trends. Efficient and effective expansion and diffusion of the gospel seem more possible than at any previous time in history. Furthermore, technology can provide more comprehensive, flexible, and versatile delivery systems, methodologies, and materials to meet diverse preparation needs. One example is the high technology that has provided computers and other means to enable publishing capabilities which in tum have opened infinite windows of opportunity. For instance, in 1988 alone, the publication of 10,000 new books and articles in 70 languages on missions were expected (Dymess, 1989).

Leaming opportunities abound through audio/video production, the computer, radio, and television. Many of these high quality, highly sophisticated modes of learning are available at marginal cost. Whereas group interaction in a pre-departure orientation program should not be replaced, significant portions of what is necessary for effective preparation can be delivered and leamed before and outside of it. Mission's search for more economical strategies must include a utilization of these technologies; planners must keep up with technological advance. 
Is missionary preparation taking advantage of today's technological resources in its effort to practice responsible stewardship?

\section{Globalization}

Increased technology, knowledge/information, communication, transportation, and international marketing are creating a global village in which cultures and groups are interdependent. Globalization challenges traditional approaches to spreading the gospel. Fortunately, these trends are breaking down many logistic barriers to world evangelization, and it is responsible stewardship for missionary preparation to take advantage of today's technological resources. But human tensions are increasing, because the very trends that create a global village worldview also promote individualism, cultural nationalism, pluralism, relativism, materialism, and secularism, all of which present immense difficulties for mission. Individualism, for instance, makes it easy for persons to become "a law unto themselves." This independence inhibits the ability for many to submit to any authority higher than or outside of themselves, or to believe that anyone else's way is any better than their own. Nationalism is increasing anti-missionary and/or antiChristian attitudes. In fact, the world is seeing the greatest ethnic and religious violence ever (Siewert \& Kenyon, 1993). Furthermore, large numbers of people are becoming inaccessible in "closed" areas; national barriers are rising against the entrance and movement of Christianity (Dymess, 1989, p. 22). In 1988, 44 countries did not allow professional missionaries, and another 52 permitted only 
limited access (Staples, 1990). The growing number of Christian professionals who enter as non-missionaries are able to make a contribution to world evangelization as individual representatives if prepared to do so.

\section{Religion and Renewal}

Part of the reason for anti-Christian policies can be explained by the spiritual renewal occurring in both the religious and non-religious alike. The world's socio-cultural climate is creating an environment that drives humankind to recognize unmet spiritual needs. Globalization and nationalism, perhaps in interaction with millennial consciousness, are helping to create this environment-isolation, fluctuating social support systems, rapid change, and uncertain provision for the basic necessities of life.

Renewal in the non-Christian religions is illustrated by Islam's fourfold increase between 1900 and 1988 (Dymess, 1989). Religious fanaticism and militancy is also rising, whether against groups like Muslims or by them. Meanwhile, numerous secular and non- or quasi-religious movements are gaining influence, and the number of non-religious persons has tripled since 1900 (Dyrmess, 1989). Even amongst Christians, a growing nominalism and secularism makes reevangelization an important need even in the Third World.

Diversity at a time of relativism and pluralism is another example of how the apparently contradictory consequences of globalization are affecting mission. Pluralism challenges the "only one way" paradigm of Christianity and projects it as 
"only one among many." Competition and confusion have compelled some sectors of Christianity itself to embrace pluralistic views, which have blurred its boundaries of belief and questioned its essence. Secularism presents yet another option, life without God. So, as the Christian message runs into competition with proliferating ideologies, it is met with strong resistance, ignored, accommodated as one among many, or outlawed. An obvious challenge is to prepare personnel to understand the implications of these changes so they can contextualize the message and method as they operate within these contexts.

\section{Population and Poverty}

Population growth and political responses are shifting world balance. World population figures are continuing to rise beyond our planet's resources and abilities to cope. For example, the trend toward urbanization forecasts that more than half the world will live in cities by 2000 A.D. (Coote, 1986, see pp. 54-62). Even though urbanization brings many benefits, it also contributes to the widening gap between the rich and poor. Poverty is at its highest level ever and is increasing in intensity and scope while consumerism and materialism are also increasing and the distribution of wealth becomes more imbalanced. One in five are so poor that "their survival is at stake daily," and another two are malnourished (Myers, 1993, p. 18). More than 1.5 billions of people have no access to health care.

Furthermore, numerous social and cultural challenges are added to the strain of urbanization and poverty: illiteracy, the changing role of women, a loss of 
traditional values, and non-traditional and/or dysfunctional family structures. From the non-Christian perspective, human morality and destiny are becoming altered. So many of these problems are in response to the global political, economic, social, and ecological challenges we face, and the rapidity with which change is taking place. Prominent today are problems of drug trafficking, prostitution, mafia-type operations, Satanism, ecological destruction, and epidemics such as AIDS. Crime is a way of life for people at every socio-economic level. Human rights abuses are being ignored. The age of science is giving way to spiritual revivalism of a godless nature and daunting us with ethical dilemmas for which there are few answers. Moral decline defies solution.

\section{Political Stability}

Political along with social instability, terrorism, and human and natural disasters are creating and multiplying migrant and refugee populations, enormous devastation, hopelessness, and death. While some nations are experiencing emerging democracy and/or a market economy, others are moving towards disintegration. No part of the world is exempt from these afflictions. Tied into political power plays are the issues of human and national rights. One of the net consequences of these trends is a world population of people groups who are becoming more difficult to identify and contact, or increasingly more interested in political solutions to life problems and human rights. 
What impact are the above trends having? For many, these conditions in our world are creating a spiritual longing and moral concern that are bound to arise from the depths of apparent hopelessness and meaninglessness in which millions find themselves. Perhaps these very conditions are creating a greater openness to and readiness for the good news about Jesus Christ. History has shown that "in turbulent times, in times of great change, people head for the two extremes: fundamentalism and personal, spiritual experience" (Naisbitt \& Aburdene, 1990, p. 277). For others, these conditions are hastening the hardening of hearts against the gospel. In any event, missionary preparation cannot continue as it has and still be responsible to God and those who need preparation or to be reached.

\section{Missionary Preparation Issues}

\section{Meeting Preparation Needs}

The need to make missionary preparation relevant and responsive to the milieu challenges content, methods, and deliveries. One useful source for monitoring trends is the Mission Handbook. Twenty years after initial publication (1953), the Handbook began to include articles addressing current mission issues. The first of these (1973) discussed 20 years of trends and included: dominance of change; emergence of non-Western missionaries; decline of single women and career missionaries; "fantastic" rise of short-termers; rise of missiological scholarship; and accelerating world change seen in independence, nationalism, urban industrialization, blind faith in science and technology, and secularism (Beaver, 1973). 
Complex cold-war realities further complicated the recognition of preparation needs. Because "the upheaval of perception of mission in the United States has had a profound influence on the intercultural training among the churches" (Dowd, 1978, p. 127), the whole picture of North American mission was altered. Dowd mentioned six trends that were set in motion. First, the total number of missionaries declined rapidly beginning in the 1960 s bringing on a rapid decline in training activities; some churches "began sending persons overseas without any formal orientation" (p. 128). Also, a cross-cultural emphasis evolved, from area studies, to area studies plus language, then to sensitivity training, and finally training that included "intercultural communication concepts in some form" (p. 128).

By 1975, short-term mission and "functional specialization" were replacing the traditional pioneering view of the career missionary (Dowd, 1978, p. 128). As overseas mission was scaling down, North American Christians channeled their mission energies into "making churches responsive to the needs of U. S. cultural minorities" (p. 128). Finally churches became willing to "prepare people carefully for domestic and overseas intercultural assignments" as a result of "the development of human relations training methodologies, communications training, and the articulate response of third world people to the old assumptions of the U. S. based churches" (p. 128). Training designs included experimentation with domestic and foreign missions participating in each other's training programs. For example, urban or multicultural ministries in the U. S. have been used to prepare overseas candidates for cross-cultural work. 
Even though Dowd (1978) spoke of training that placed a new significance on cross-cultural needs, it was not until the early 1980 s when this practice became widespread. Out of the post-war trends came a growing understanding of how important a knowledge of the mission context was. As Reed (1984) showed, what had started as preparation in the Word, grew to include a larger preparation for the work; then came the addition of preparing the worker, and finally, an understanding

of the world context. Most career missionaries sent out today have probably had training or formal education in all these areas important for cross-cultural ministry in addition to their pre-departure orientation.

Whereas in practice there may have been a de-emphasis in pre-departure orientation in some sectors, preparation itself expanded as the concept of preparation cycle revealed the need for extended training to meet in-field and re-entry needs more formally. Orientation, first seen as necessary only prior to arrival in the new context, was continued for the first 3-6 months in the field to "boost morale" (Dowd, 1978, p. 130). This practice was first implemented by the Peace Corps in the 1960 s and was found effective for them. According to the general literature, some of the most appreciated and valuable preparation occurs during this active, infield, on-the-job phase of mission orientation.

\section{Structures and Support}

Mission structures and support are moving to the grassroots level. Today, Christian outreach springs from a variety of Christian organizations such as local 
churches, Christian colleges, student fellowships, and privately funded missions (Siewert, 1993). Moffett (1989) links the trend to mission when he states that "the tides of history are running in favor of greater freedom in mission and a loosening of ecclesiastically institutionalized ties" (p. 24). This move away from institutionalism toward individualism, from ecclesiastical or clerical mission to a lay movement, helps explain the rise in short-term, volunteer, and specialist missionaries, and helps express the West's anti-institutional posture. Some Christian leaders feel threatened although there are obvious benefits to mission. As Siewert (1993) noted, Christian mission is undergoing a "paradigm shift" perhaps equal to the changes that took place 200 years ago during the time of William Carey (p. 56).

Authority and responsibility for mission have shifted between denominational structures and independent individuals or organizations throughout mission history. But today's reality is an "unexpected reversal" of a North American trend of the past 100 years. Building on the 1960s shift in the "center of gravity," 90\% of North America's full-time missionary force was the responsibility of independent and parachurch organizations outside of mainline denominational control by 1988 (Moffett, 1989, pp. 23-30).

Mission sending and preparing structures are becoming more flexible and diverse. Despite the dangers as well as stress and strain of shifting organizational structures, this trend is enabling more rapid missionary expansion. One mainline denomination is working with the trend for maximum effectiveness. It has encouraged a networking relationship among the groups within its constituency. As 
a result, the Council for Global Mission was organized, a 29-member organization that includes national denominations, schoois, publications, and unofficial mission programs. The common purpose is "for information sharing, planning cooperative ventures and other activities" (Siewert, 1993, p. 57).

Today, Christians give more money to non-denominational ministries than the institutional church (Myers, 1993). "Increasingly the method of choice for working on common tasks" is informal networks (p. 35). Mission leaders need to evaluate whether they are enabling and encouraging mobilization of the energy and resources from the grassroots level for mission and missionary preparation. How preparation adequacy, stability, and continuity will be ensured must be determined. Other preparation concerns include cross-cultural workers' identities and the focus of their loyalties.

\section{North American Personnel}

The role of the North American missionary is changing. The fastest growing sector of the Christian community is non-Western, whose proportion in that community has increased tenfold since 1900 (Myers, 1993). Consequently, there is a well-recognized "mushrooming" of non-Westem missionaries and sending agencies (Dyrness, 1989, p. 14). For instance, there were an estimated 1,094 Protestant nonWestem mission agencies with 35,900 missionaries in 1988, around half of the number from North America and Europe at that time $(85,000)$. If the trend continues at the present rate, by the year 2000 there will be 150,000 missionaries 
from the non-Westem world. By 2010 , the numbers of cross-cultural missionaries sent from non-Western countries are expected to surpass those from the West (Myers, 1993), unless mission fervor in the West becomes renewed. A recent book (1990) edited by Taylor reveals the dynamic progress being made in creative and needs-oriented international missionary preparation programs.

There is a debate that questions the need for Westem missionaries. Some think "the cost of sending Westem missionaries is increasingly prohibitive and scandalous" (Myers, 1993, p. 35), and, of course, effective preparation is a substantial part of that cost. Yohannan calls for a restructuring of the North American effort to shift from sending North Americans to financing and praying for national evangelists (cited in Poston, 1992). Can North Americans, many of whom cannot even imagine the marginal life accommodated by significant groups in many of these countries, who have not known struggle without basic necessities being taken for granted, be effectively and economically prepared for ministry in crosscultural settings? Is the cost justified, especially for those Americans who tend to be more ethnocentric than many of their co-workers in the Third World?

Others, such as Poston (1992), argue that Western missionaries still have much to offer cross-cultural mission. He points out what he perceives as their advantages, such as a history of preparation opportunities, no ancient enemies, rigid social structures, an international urban culture, and technological expertise. "We need each other. Let us join hands" (p. 62). Should Americans continue to be missionaries in an age when missionary training is becoming internationalized? 
Does their cost, ethnocentrism, and lack of hardiness mean that they should be eliminated? No. The Christian mandate includes "everyone to everywhere." Needs are great enough to use all who are willing to go. An encouraging trend is the growing multiculturally literate population from which potential North American personnel pool will recruit and select.

Although there are signs of Westem renewal in the growth of short-term and "intentional layperson" workers, Americans will be working side by side with indigenous workers to share the load, rather than direct the joumey. The rising number of non-Western missionaries summons North Americans to serve in "partnership" without "domination or manipulation" (Adeyemo, 1993, p. 42). This fact remains true whether partnership is with non-American indigenous or among Americans, for even within Western cultures populations are "becoming inescapably multi-cultural. The culturally myopic are going to be ineffective and irrelevant" (Myers, 1993, p. 35). Americans need to understand that "only those who can accept and adjust to minority status and see cultural diversity as a resource provided by a gracious God to be used for the kingdom will make a difference" (p. 35).

\section{Complex Preparation Needs}

Preparation is challenged to match the needs of both the missionary and appointment/context. Types of missions and missionaries are becoming more diverse. An evidence of North Americans' changing missionary role and identity is seen in the sense of mission among those who are not "appointed." There is a 
decline in the numbers of career personnel, yet an increase in short-term and layperson volunteers. One source estimated there were 120,000 American lay missionaries in short-term mission in 1989 (Siewert, 1993, p. 57). Laity in every walk of life are accepting a personal challenge to practice their vocation in a needy context for the sake of expanding God's kingdom.

A comparison of two Urbana conventions (mission conferences for youth) demonstrates this exploding interest in "intentional layperson" ministry. (Such persons are also called "tentmakers" or missionaries to the "creative access windows. ") In 1984, there was one seminar in intentional lay ministry offered and 2800 persons signed up. At the next Urbana Convention in 1987, 14 seminars were offered and 28 others dealt with the subject. For one seminar alone, 500 were packed into a room for 350 even 20 minutes before time to start (Wilson \& Siewert, 1989, pp. 31-32). Although professionally or technically well qualified, most of these persons have limited training in the "task" of mission, and may never receive cross-cultural preparation. The preparation needs of such a diverse missionary population are a challenge that needs to be addressed.

With expanding personnel needs but declining career missionary task force, strategists are calling for the preparation of diverse groups. Short-term and "tentmaker" volunteers are an important personnel source for the flexibility required by a rapidly changing world. Generally speaking, however, the intermixing of cultural groups within North America and around the world point to the fact that all Christians need "missionary preparation," and the growing number of Christians 
who are sojouming across cultures need special preparation for cross-cultural ministry. Besides volunteers and tentmakers, cross-cultural workers that fit the classification of unofficial missionaries include the $\mathbf{3 0 0}$ million Christians around the world who are travelers, exchange students, and "associates" (see Coote, 1986, pp. 69-71; see also Barrett, 1982). Yet, world evangelization plans still need longterm and career personnel to pioneer in difficult regions, and these groups justify comprehensive preparation more than most others.

Given the divergent cultural backgrounds of North Americans, the typical North American missionary is no longer typical. The monocultural background of mission candidates of the past likely included a foundation of Bible knowledge, spiritual strength, as well as a sense of God's calling and commitment to His service. Today, this background cannot be assumed. The "multicultural" backgrounds of personnel require that those responsible for planning preparation individualize sufficiently to provide for meeting the needs of each person and family, regardless of background, personality, motivations, and experience. For instance, traditional views toward call and commitment have all but disappeared among large numbers of Christians through the pervasive impact of secularism, and limited Christian enculturation.

Selecting and preparing personnel for some regions of the world demand very thorough and disceming consideration. While the number of short-term volunteers with different backgrounds but limited preparation needs are escalating, and career missionaries declining, there is still an urgency to reach out to those in 
the least evangelized part of the world, which requires vastly different cross-cultural preparation. In fact, only incarnational approaches will make the gospel a viable option in these regions. For example, the least-evangelized region comprises 1.3 billions of persons still largely inaccessible to Christian mission. In addition, these countries tend to have the most severe starvation, poverty, devastation, inequalities, illiteracy, as well as governments that are very resistant to freedom and/or traditional Christian approaches. Only $1.2 \%$ of all mission funds are being used for this region, and fewer than $6 \%$ of all full-time Christian workers. But there is growing evidence that such limited activity will not long remain (Myers, 1993).

\section{Selection vs. Preparation}

The decision about which orientation goals are needed will be influenced by the types of candidates who will be prepared. The type of candidate is determined by selection requirements. From the beginning of Christian mission until the 1700 s when the modern missionary movement began, the key to effective mission was believed to be selection. Although Christ practiced the first selection process, many became missionaries through self-selection based on personal conviction of a call either from God Himself or the recommendation by another missionary who recognized the potential and personal qualities for success. In either event, selection was usually based on the person's qualities and/or experience rather than training or preparation. Paul was probably selected by God not so much 
because he had theological training, but because of his faith, perseverance, abilities, potential to grow, and willingness to be "trained on-the-job."

Gradually, as mission boards and candidates multiplied, self-selection was replaced by board recommendation, approval, or the fulfillment of qualifications, which became the norm and is still stressed (Britt, 1981; Peters, 1990). As selection moved to committees or mission boards, the process became more rigorous even though not necessarily more objective. The many "desirable" characteristics of prospective missionaries became requirements, and the differences between characteristics that were a part of the person and those that could be developed through preparation were not clearly delineated. Even today, the distinctions between goals represented by personal characteristics and training requirements are not clearly separable. The long-time debate that has revolved around psychological testing helps illustrate the search for balance between selection and preparation.

The relationship and balance between selection and preparation are important issues. Unfortunately, a post-war emphasis on training and other forms of preparation began to take precedence over the perceived importance of selection at a time when the "quality" of missionary was deteriorating. Motivations for mission moved from a sense of call and Christ's love for the world toward travel and the excitement of discovering the world and its peoples. Ministry roles and practices were viewed as standard regardless of cultural differences found in the particular foreign context, which masked the need for cultural sensitivity and contextualizing the gospel. 
Choosing which goals are required to meet the preparation needs of candidates depends on several factors. A new enthusiasm for science and education encouraged the belief that an average person could become an effective missionary through quality preparation which tended to de-emphasize selection requirements. Dependence on psychological screening rather than evaluating the candidates and families holistically illustrated the new direction. Other factors affecting the goals of preparation included the changing views of human potential, human dignity and equal rights, and a renewed conviction that all Christians are to be "witnesses." Less prudent selection procedures were also driven by the enormous challenge of evangelizing a godless world that required massive numbers of missionaries.

During the last 2 decades, selection criteria have become modified in order to accommodate the needs of mission facing a declining personnel force. Many agencies receive many applications from candidates whose desire for travel and cross-cultural experience are stronger than their Christian commitment and identity. Success in mission may have been thought to come from selection processes that are more sophisticated than ever before (Britt, 1981, p. 99), but the emphasis has been strongly shared by training. In our modern world, we do not wait for a Paul to come along, or take the risk of letting people leam by experience over decades. Instead, those responsible for preparation try to meet individual and family needs for each of the phases of the preparation cycle. They usually want candidates to have mission education, intensive training, and orientation. 
Perhaps the aims of mission in the 1990 s and the trend towards diversification of evangelization and personnel needs should prompt us to re-evaluate the importance of sound selection procedures, especially for critical appointments, while continuing to search for ways to increase the effectiveness of orientation. When all the needs for effective functioning of cross-cultural missionaries are identified, they should be divided according to how feasible they are to meet. Those difficult to fulfill could be achieved through selection procedures, and those more easily met would be designated for preparation.

Thus, the distinctions between selection characteristics and preparation needs have not been clearly defined in practice. At first, selection was made on the basis of personal character and qualities that are fairly stable in addition to many requirements now routinely included in training or orientation. As preparation was expanded to include a wider range of offerings, facets of the process and criteria of selection were modified or eliminated. In fact, many forms of orientation attempt to develop or strengthen even such personality qualities as flexibility and adaptability.

For some educators there is an underlying belief and attitude that human potential is "limitless," and given the right "training" opportunities learners can achieve any desired goal with motivation and time. For the Christian, the concept that "I can do all things through Christ" tempts some to pay less attention to the present state of the appointee than others consider responsible and wise. There are no easy answers in the debate, but, as time becomes compacted by the accelerating 
pace of change, selection based on present capabilities that correspond to appointment needs would make preparation easier, more relevant, and accountable.

In light of the current evangelization challenge, both selection and preparation need strengthening. Selection becomes more critical than ever for mission appointments that require strongly incamational ministry, but less so for short-term volunteers who will not have the time to identify so closely with the people nor the same degree of responsibility to plant the gospel. A part of selection should include careful marching of the appointment with personnel qualifications and potential. Preparation, also, should be suited to the appointment as well as its context and the person selected to fill it.

World trends demand changes in missionaries, whether these are achieved through selection procedures or preparation. "The mental process skill most needed for tomorrow is the capacity for, expectation toward, and openness to new information and insights ... the capacity to think" (Ward, 1987, p. 400). Missionaries will need generalized culture information plus the strategies to learn about the particular cultural context needs. Finally, future career missionaries will need to be more spiritual, have a stronger sense of call/commitment, and attitudes that will build successful relationships with both mission partners and target peoples.

\section{Missionary Role}

As we face the future in light of recent trends, several issues demand attention. First of all, what is the role of the missionary? The "greatest and oldest 
challenge is to define ways in which a religious person can be one with another people and still an agent of spiritual change" (Dowd, 1978, p. 130). Missionaries are unlike other American cross-cultural workers because they generally go more as Christians than Americans (Cleveland et al., 1960, p. 265), and their desired purpose is to be change agents without destroying the culture of a people (Dowd, 1978). It is extremely difficult, however, to separate the "universal seeking for God from the cultural conditioning that influences the missionary's perception of faith, worship and community" (p. 130). "Separating the message from the cultural role of the missionary and the culture of the transferring church or organization is still a vital question for people" in every overseas endeavor (Dowd, 1978, p. 127). These problems have become more complex in the 1990 s because globalization and secularization promote "equal" rights and accommodation for every diversity which makes change an unwelcome imposition.

Dowd (1978) drew attention to the contrasting assumptions among "faiths and organizations" (p. 129). He stated: "The central issue seems to be how much the sender of the mission message and the message itself is to be affected by the local culture" (p. 129). Is the missionary role/method to "convert to the truth," or demonstrate the message through personal example, or contribute to the "spirituality of a community" by being a leamer and becoming part of it (p. 129). The assumption that underlies each concept of role directs the purpose and goals of the training. For instance, the "conversion" model mentioned first would prepare the missionary to "lower host national resistance to 'truth'"; training would center in a 
study of the particular culture to find "ways of penetrating the host culture" without becoming very different as a result. Dowd calls this a "sales technique" (p. 129).

\section{Design Issues}

Several trends will impact how preparation goals will be met. Harris and Moran (1987) discussed 12 trends in human resource development, most of which relate to missionary preparation. For example, personnel training will become more integrated with life--holistic, interdependent, more dynamic and mobile, and less compartmentalized or institutionalized. It will be continued over the span of service rather than concentrated in pre-service preparation. Its content will be more global, exploratory, international, and less dogmatic and elitist/ethnocentric. Training will be structured in ways that are more individualized, customized, and non-formal. Methodologies will be more affective and intuitive rather than cognitive, and more innovative instead of maintenance oriented. Technology will continue to play a larger role, with an increase in the use of home communication services. Missionary personnel preparation should utilize those trends that will make it more effective and efficient.

Another design issue is the difficulty but necessity of integration in training. Human leaming dimensions (cognitive, affective, and behavioral), diverse personal and appointment needs. coordination of preparation, and other curricular concerns challenge effective preparation. For instance, Dowd (1978) states that 
language and intercultural communication skills should never be separated because human relations aspects become lost or isolated (p. 130).

Finally, to what extent should missionary preparation be provided for the different types of missionaries, particularly volunteers, and who is responsible for it? There is a vast difference in the type, extent, and coordination of missionary preparation, although most agencies provide at least some form of orientation to the organization and foreign context.

In summary, the most recent trends in missionary preparation include a diversification of learning opportunities, orientation program options, and topic seminars. There is a new sense of responsibility by the local congregation to mission with a move away from structures/agencies outside local congregations (Millham, 1988). Mission organizations have established preparation programs and seminars for most people-group targets and types of outreach. With the changing missionary force and its changing preparation needs has come a re-emphasis on meeting the spiritual needs of missionaries, as well as a stronger emphasis on encouraging attitudinal change and developing cross-cultural skills. It is recognized that the felt needs of missionaries vary according to the phase of missionary cycle, and preparation should correspond to those differing needs. Preparation needs do not end with departure, but must be continued during service in the field and into the re-entry phase.

Observers recognize the enormous challenge to world evangelization presented by the pace of world change (Dymess, 1989; Myers, 1993; Siewert \& 
Kenyon, 1993). It demands great creativity to prepare missionaries who can cross cultural boundaries with "good news" to the suffering, or those too hardened to hear about the sufferers. Success in enlarging the personnel force could come from such strategies as innovative recruitment practices, but without adequate preparation, the new recruits would be limited in their evangelistic effectiveness. Preparation should begin with an awareness that comes from a realistic portrayal of the challenge, continue with honest recruitment practices, advance through responsible selection procedures, proceed with quality training and orientation, and extend with nurture and support throughout the mission experience, including re-entry.

There are heretofore unknown challenges catapulting the world into a new millennium. As a growing secular optimism reaches for hope, and a diverse Christianity with irreconcilable views of salvation attempts to provide hope, there is an urgency for a stronger-than-ever push to evangelize the world. There is a sense of responsibility at the grassroots level but with increasingly diverse responses. There are expanding technological opportunities. These and other trends are both exciting and challenging. Missionary preparation must understand the trends and set in motion plans that will take the greatest advantage possible. We may presume that the next decade will write a new chapter in missionary preparation.

\section{Comparison of External Sources Sources 4 to 6}

There are several contrasts between missionary preparation and other forms of cross-cultural preparation. Missionary preparation needs (goals) are 
broader and more numerous than those for other types of cross-cultural orientation. One goal that is seen as critical is conviction of a personal "call" to service, a reality that projects a unique sense of identity and strongly motivates to commitment. Depth of commitment to God, the organization, and the appointed task are assumed non-negotiable for effective cross-cultural ministry. Another is termed "faith," also a motivating factor, and one which refers to a particular worldview and approach to service. Although cross-cultural training literature did not deal expressly with goal areas unique to missionary preparation (spiritual dimensions of faith, sense of call, and commitment), it would support the rationale undergirding this dimension of missionary preparation if it is viewed as psychological and motivational.

Other contrasts occur between missionary and other cross-cultural preparation. One is a belief in the supernatural dimension in mission. Another is the stronger emphasis placed on the history and issues related to the missionary "profession," and information about the sending organization. Physical health considerations and practices are more frequently mentioned as needs for missionary preparation.

It should be noted that the particular approach to cross-cultural preparation, whether for business, government, or mission, is a reflection of the assumptions undergirding those who plan or practice it. The purpose for the sojoum influences the selection and priority of goals. The object of the mission task is not to market as for business, or mediation as for representing governments, or learning/teaching as in educational exchange. Missionaries are change agents. The 
challenge is to change the culture without destroying it, without use of undue pressure or non-ethical means, and without denigrating human rights, autonomy, and dignity.

Missionary literature emphasizes community building, fellowship, and interpersonal relationships, which are an integral part of mission's purpose and incarnational method. Relations seen as particularly crucial are those with the nationals of the country, and within the mission organization and community, particularly with administrative personnel. This need becomes more significant because leaders and workers (whether foreign or national) work together so closely they find interpersonal relations challenging yet essential to their ministry.

World trends that impact all modes of cross-cultural preparation also impact missionary preparation. In most cases, however, understanding and responding to these trends and milieu factors become more critical for missionary preparation because of the nature of mission service. Taken together, these factors point to the need for daring and dramatic new designs for missionary preparation. 


\section{CHAPTER V}

\section{CROSS-VALIDATION AND RECONCEPTUALIZATION OF GOALS}

This study used a four-phase validation process to determine what goals are suitable for missionaries. The goals of the case studied, Institute of World Mission, were first clarified, then validated by the data gathered from six sources and presented in the previous two chapters. This chapter discusses the final two phases of the validation process. Phase Three involves a cross-validation of the goals by a synthesis and analysis of the data from the 6 sources compared with the set of IWM's clarified goal statements. In Phase Four, a reconceptualization of suitable orientation goals emerged from the entire research process.

\section{Phase Three: Cross-Validation of Goals From a Synthesis of Six Sources}

Six sources provided information about what goals missionary orientation programs should include. The first derived information from an observation of the IWM orientation program in operation throughout its history. Data came from the director/staff reports to the Secretariat of the General Conference, my experience as a participant-observer in a summer session, and from participant evaluations from 
that particular Institute as well as 17 other Institutes covering a 7 -year period. Data for the second and third sources were secured from a questionnaire administered to a large group of church leaders and missionaries. The perceptions of these two groups formed the major empirical portion of this study. The fourth source was a review of missionary preparation. Data for the fifth validation source came from a summary of cross-cultural preparation literature. Finally, Source 6 provided data to identify the goals that would be responsive to future needs.

This section presents the synthesis/analysis of findings: an overview of findings, discussion of individual goals, and a validated list of IWM goal statements.

\section{Overview of Findings}

The purpose for using several sources to validate IWM goals was to provide a wide but relevant base from which to make judgments, and ultimately to draw conclusions and make recommendations. Table 28 presents a general statement of the findings from each of the six sources in order to relate the broad themes that emerged from chapters 3 and 4 . A look at the findings in the table shows that IWM goals were by and large supported.

The goals of the Institute were favorably rated by all survey populations, and by extension, program activities derived from those goals were favorably received by attendees. Furthermore, IWM goals were favorably endorsed by reviews of literature and missionary orientation programs, and appear to be appropriate for the future needs of missionary preparation. When IWM's goals are 
TABLE 28

OVERVIEW OF FINDINGS FROM SDX VALIDATION SOURCES PERTINENT TO GOALS DETERMINATION

\begin{tabular}{|c|c|}
\hline Source & Overview of Findings \\
\hline $\begin{array}{l}\text { I Staff } \\
\quad \text { Attendees }\end{array}$ & $\begin{array}{l}\text { IWM orientation provides a socially warm, nurturing environment for } \\
\text { contributing necessary assistance to prepare missionaries for service and to } \\
\text { meet their transition supportsecurity needs. Although all goals are } \\
\text { appreciated and believed appropriate, spiritual, attitudinal, and cross-cultural } \\
\text { ministry preparation goals are seen to be the most neceasary. Fellowship is } \\
\text { critical to meet the orientation purpose of support and readiness. }\end{array}$ \\
\hline $2 \& 3$ & $\begin{array}{l}\text { Questionnaire respondents rated Awareness, Call/Commitment (spiritual), } \\
\text { Attitudes (psychological), cross-cultural Competencies, and Area Studies } \\
\text { higher than all other goals in seven analyses. Their views of Policies varied, } \\
\text { and a sizeable proportion appeared not to understand Transformation. } \\
\text { Fellowship was highly appreciated for IWM orientation, but skills were not } \\
\text { necessarily transferred to the field. Unmet concerns were indicative of } \\
\text { individual personal/session needs rather than missing goals. }\end{array}$ \\
\hline 2 Leaders & $\begin{array}{l}\text { Leaders believe all goals are necessary, but tended to see Policies, Issues, } \\
\text { Roles, and Transformation goals more relevant than missionaries did. } \\
\text { Leaders also believed IWM made a greater contribution to their mission } \\
\text { service effectiveness (MSE) than did missionaries. }\end{array}$ \\
\hline 3 Missionaries & $\begin{array}{l}\text { Missionaries believe all goals are necessary, but valued Awareneas, Area } \\
\text { Studies. Health, and Fellowship more highly than leaders. Missionaries } \\
\text { believed they achieved and applied IWM goals more, and tended to observe } \\
\text { more goal implementation by other IWM attendees in the field (except for } \\
\text { Policies) than leaders. }\end{array}$ \\
\hline $4 \begin{array}{c}\text { Missionary } \\
\text { Training }\end{array}$ & $\begin{array}{l}\text { IWM represents recommended missionary preparation goals well. Most other } \\
\text { organization patterns comprise a variety of preparation/orientation } \\
\text { opportunities rather than a single orientation program such as IWM's. } \\
\text { however. }\end{array}$ \\
\hline $\begin{array}{l}5 \text { Cross- } \\
\text { culturd } \\
\text { Training }\end{array}$ & $\begin{array}{l}\text { Multi-dimensional orientation is essential for effective cross-cultural } \\
\text { preparation, and should prepare sojourners for successful adjustment, } \\
\text { adaptation, and integration into the foreign context by providing coping, } \\
\text { communication, and interpersonal skills. Sojourners must also develop skills } \\
\text { to continue the learning process in the field and in a rapidly changing world. }\end{array}$ \\
\hline 6 Trends/lssues & $\begin{array}{l}\text { Trends demand that goals/determination be increasingly flexible, needs- } \\
\text { oriented, and individualized. Planning should be holistic to meet } \\
\text { complex/diverse needs as missionary preparation faces globalization, a rapidly } \\
\text { changing world, and new millennium. }\end{array}$ \\
\hline
\end{tabular}


compared with the goals practiced by other missionary preparation programs, there are strong similarities. Other programs and/or orientations may contrast in purpose, scope, depth, length, and emphasis, but not the core.

A more detailed look at the findings from Sources 2 and 3 reveals strong agreement in perceptions of the value and usefulness of the goals. One of the most interesting themes is the correspondence of the five highest-ranking goals in several analyses. (See Table 29. Although the goals/areas are listed in reference order, which in some cases is not the rank order, the variation in rank probably results from contrasting individual needs and/or leaming levels.)

The five goal or goal categories ranked highest by mean responses of the population in seven analyses include three that relate to cross-cultural preparation for ministry and two that relate to the motivation (spiritual/psychological dimensions). Awareness of the essential role of culture in ministry is consistently ranked highest by the population. (Two analyses did not include Awareness as a possible choice.) It appears that respondents believe Awareness is the most basic need for missionary preparation. Logic would suggest the same; awareness is readiness for whatever follows. Two more goals receiving high mean responses that are part of crosscultural preparation are Area Studies and Competencies. These three categories appear to suggest a kind of preparation needs hierarchy for the goal category of cross-cultural ministry. One fact appears clear, awareness of the cross-cultural dimension, attention to and motivation for the necessary leaming, as well as specific preparation for cross-cultural ministry are all ranked among the most necessary. 
TABLE 29

COMPARISON OF THE FIVE HIGHEST GOAL OR GOAL CATEGORY RESPONSES IN SEVEN QUESTIONNAIRE ANALYSES

\begin{tabular}{|c|c|c|c|c|c|c|}
\hline $\begin{array}{l}\text { Most Important } \\
\text { Goals }\end{array}$ & $\begin{array}{l}\text { Most Essential } \\
\text { Goals }\end{array}$ & $\begin{array}{l}\text { Most Relevant } \\
\text { Goals }\end{array}$ & $\begin{array}{l}\text { Goals Observed to } \\
\text { Be Most Practiced }\end{array}$ & $\begin{array}{l}\text { Least Unexpected } \\
\text { Goals }\end{array}$ & $\begin{array}{l}\text { Most Important } \\
\text { Factors in MSE" } \\
\text { Level }\end{array}$ & $\begin{array}{l}\text { Most Important } \\
\text { Aspects of IWM } \\
\text { Program }\end{array}$ \\
\hline Awareness & Awareness & Awareness & Awareness & Awareness & n.a. & n.a. \\
\hline Call/Commitment & Call/Commitment & Call/Commitment & Call/Commitment & & Call/Commitment & $\begin{array}{l}\text { Spiritual/ } \\
\text { Psychological }\end{array}$ \\
\hline Altitudes & Altitudes & & & Altitudes & Attitudes & $\begin{array}{l}\text { Spiritual/ } \\
\text { Psychological }\end{array}$ \\
\hline $\begin{array}{l}\text { Cross-cultural } \\
\text { Competencies }\end{array}$ & $\begin{array}{l}\text { Cross-cultural } \\
\text { Competencies }\end{array}$ & $\begin{array}{l}\text { Cross-cultural } \\
\text { Competencies }\end{array}$ & $\begin{array}{l}\text { Cross-cultural } \\
\text { Competencies }\end{array}$ & $\begin{array}{l}\text { Cross-cultural } \\
\text { Competencies }\end{array}$ & $\begin{array}{l}\text { (flexibility, } \\
\text { openness) }\end{array}$ & $\begin{array}{l}\text { Cross-cultural } \\
\text { aspects }\end{array}$ \\
\hline Area Studies & Arca Studies & Area Studies & Area Studies & Area Studies & n.a. & Area Studies \\
\hline
\end{tabular}

Note. The goals or categories are not necessarily in highest to lowest order, except for Awareness. MSE = Mission Service Effectiveness 
Missionary preparation literature and practice confirm the importance of these five goal areas: Awareness, Attitudes, Competencies, Area Studies (culturespecific information), and Call/Commitment. The spiritual dimension, particularly Call/Commitment which is so highly ranked in missionary preparation, is not commonly recognized per se by general cross-cultural literature (although there is occasional reference to commitment). But cross-cultural orientation literature/practice would not deny its importance, especially when seen as enhancing psychological readiness and motivation. Comparable needs mentioned in crosscultural literature would include qualities such as stable identity, perseverance, and humility.

I believe it is significant that when IWM-prepared missionaries were asked to rate 15 factors that contributed to their MSE level (mission service effectiveness), they rated psychological and spiritual factors as those that contributed most, followed by family situation/support factors, health/well being, and then IWM orientation experience, information, and fellowship. A person may ask why IWM did not rate higher. Although respondents consider orientation extremely desirable, they recognized that missionaries can be effective without orientation, even if more so and more quickly with it. Many IWM-prepared missionaries had served several years overseas before having an opportunity to attend IWM; and in fact, $38 \%$ of SDA missionaries had never attended IWM orientation. Missionaries, however, recognize that they cannot succeed without the psychological/spiritual dimension, even if they have been prepared. This fact does not deny that preparation helps 
protect against premature withdrawal from mission service. The fact that contextual factors-living/working conditions, nationals, administration, and political/economic aspects-were considered least important in determining MSE shows that missionaries believe that internal factors (spirituality, attitudes, and preparation) are more critical to MSE than extemal conditions.

Both missionary and cross-cultural preparation literature support the primacy of the affective/spiritual/psychological domain, along with the importance of social support and health/weil-being. I believe that cross-cultural literature would place more importance on orientation preparation than IWM populations did, however.

All data sources recognize the importance of cross-cultural skills and affective goals, although in different order of priorities. Table 30 presents a general view of these core goals for each source in descending order of importance. The order was determined by both analytical and empirical means.

Similarities among all case study population groups are seen first of all in the recognition of the core needs: awareness, cross-cultural preparation, spiritual and/or attitudinal. Different groups vary in how they order these, however. Both attendees and missionaries place cross-cultural ministry preparation goals first (Awareness, cross-cultural Competencies, Roles, Area Studies), followed by attitudes and then spiritual needs. According to the emphasis in staff reports, both spiritual and attitudinal goals are more important than cross-cultural preparation goals, especially as the background and previous experience of attendees changed. 
Because of the uniqueness of the teacher and leamer perspectives, it is logical that the staff would recognize the importance of the affective dimension in preparing attendees to learn the knowledge and skills necessary for the cross-cultural ministry task, whereas the attendees would not recognize their readiness need and see crosscultural preparation as most important. Missionaries also view the three categories in the same priority order as attendees, but their rating is much closer.

TABLE 30

\section{RELATTVE IMPORTANCE OF GOAL CATEGORIES PRIORITIZED FROM MOST/LEAST IMPORTANT ACCORDING TO FIVE DATA SOURCES}

\begin{tabular}{|c|c|c|c|c|}
\hline Staff & Attendees & $\begin{array}{l}\text { Leaders, } \\
\text { Missionaries }\end{array}$ & $\begin{array}{l}\text { Missionary } \\
\text { Orientation }\end{array}$ & $\begin{array}{l}\text { Cross-cultural } \\
\text { Orientation }\end{array}$ \\
\hline Spiritual & $\begin{array}{l}\text { Cross-cultural } \\
\text { Ministry Prep }\end{array}$ & $\begin{array}{l}\text { Cross-cultural } \\
\text { Ministry Prep }\end{array}$ & $\begin{array}{l}\text { Agency } \\
\text { Information }\end{array}$ & $\begin{array}{l}\text { Awareness \& } \\
\text { Information }\end{array}$ \\
\hline Attitudes & Attitudes & Attitudes & Spiritual & $\begin{array}{l}\text { Adjustment \& } \\
\text { Adaptation }\end{array}$ \\
\hline $\begin{array}{l}\text { Cross-cultural } \\
\text { Ministry Prep }\end{array}$ & Spiritual & Spiritual & Attitudes & Attitudes \\
\hline Fellowship & Issues & Issues & $\begin{array}{l}\text { Cross-cultural } \\
\text { Ministry Prep }\end{array}$ & $\begin{array}{l}\text { Communication } \\
\text { Skills (includes } \\
\text { interpersonal) }\end{array}$ \\
\hline Transformation & Fellowship & Lifestyle & Issues & $\begin{array}{l}\text { Learning Stills } \\
\text { (Transformation) }\end{array}$ \\
\hline Lifestyle & Lifestyle & Fellowship & Fellowship & Social Support \\
\hline Issues & Policies & Policies & Lifestyle & Area Studies \\
\hline Policies & Transformation & Transformation & Transformation & Logistic \\
\hline
\end{tabular}

Note. Spiritual goals are: Faith and Call/Commitment. Cross-cultural Ministry Prep goals are: Awareness, Competencies, Roles, Area Studies. Lifestyle includes Health. 
From my study of missionary training literature, I believe that the cluster of spiritual, attitudinal, and cross-cultural ministry goals would also be ranked in this order. Awareness as a goal is not often explicitly mentioned in missionary preparation literature because most candidates in orientation have already been made very aware through previous education opportunities. Cross-cultural orientation programs, however, underscore the role of awareness (Brislin \& Yoshida, 1994). They also emphasize personal affective goals before cross-cultural skills. It is axiomatic that participant readiness to integrate learning into his/her cognition, values, and experience requires involvement of the affective dimension.

One of the unique and beneficial strengths of missionary preparation is found in its emphasis on the spiritual, attitudinal, commitment, and motivational dimensions, all of which include affective elements. As a whole, other missionary orientations place the goal of familiarizing their candidates with the sending agency, its philosophy, history, task, mission principles, and policies as primary. This is not a denial of the importance of spiritual, attitudinal, and cross-cultural goals, however, but a reflection of their missionary sending and preparation structures. Because most appointees attending IWM are not involved in deputation nor operate by selfsupport, and because IWM serves all missionaries who are members of the denomination that appointed them, participants do not need the extensive information other missionaries require. For IWM attendees, the diversity of interest in the Policies goal shows that appointees generally feel secure that the resources necessary to function in the new environment will be met. 
It was shown that one of the outcomes of orientation training is that it creates in its participants a greater awareness, more observation, and recognition of the importance of cross-cultural learning needs. Missionaries who had attended IWM orientation believed it played a more crucial role than those who had not attended, even though those who commented that they had no opportunity to attend IWM also stated they wished they had. Missionaries with IWM orientation rated the value of IWM's goals more strongly; they rated most goals more appropriate (important, relevant, and essential) than those without IWM orientation. They also rated Faith, Call/Commitment, Awareness, Health, Issues, and Area Studies more possible and attainable than non-IWM prepared missionaries. Institute-oriented missionaries observed more goal implementation than non-oriented missionaries. These facts show that the Institute appears to sensitize its participants to how important preparation for ministry is and to what is important for effective service, which shows the importance of preparation in developing cross-cultural effectiveness. A sensitivity to these attitudes and behaviors lays a foundation on which to continue learning and developing. Cross-cultural training literature stresses the importance of preparation in stimulating the developmental processes of crosscultural adjustment, adaptation, and movement from ethnocentric to ethnorelative behavior. The continued development of this skill could easily be encouraged by providing continuing communication in reference to cross-cultural issues while missionaries are serving in the field. 
How comprehensive was the Institute's orientation perceived to be? In general, the number of goals as well as the amount of time spent implementing them would be affected by the length of the orientation, as well as the philosophy, scope, and aim of the particular orientation. Current pre-departure orientation programs vary from a few hours to several months. The average range for general missionary orientation is around 2 to 4 weeks. General cross-cultural orientation programs, such as for business organizations, are much shorter, usually ranging from a few hours to a few days. Programs for business, for instance, see the primary aim as preparing for culture shock, and/or providing specific information to ease the transition to living in a foreign country. They may provide a focus on adjustment/adaptation, communication and interpersonal relations skills, and culture specific information (Area Studies). It is amazing that even a few well-planned program hours can make a measurable and critical difference.

IWM participants are appointees who generally have not had a background in missionary or cross-cultural studies, except for Bible knowledge. Thus, IWM attempts to provide an overview of what would be achieved in a diploma or degree program in missions, including cross-cultural aspects. Compared to the missionary and cross-cultural orientations evaluated, few other orientation programs need to accomplish as many goals as broadly as IWM in a 4-week period of time.

Sources 1 to 3 indicated that the Institute should not be shortened, although a few felt it could be lengthened. In fact, IWM was a 6-week orientation between 1973 and 1985. Missionaries believed IWM was comprehensive enough, 
but still made suggestions to emphasize certain goals or to include more content in them. These individuals, however, made few suggestions as to what should be left out to provide time for additions, because they saw every goal as necessary. When comparing data from all six sources, it becomes clear that an overall preparation could include many forms of training and education prior to or including orientation, but should make sure the most critical needs are met first. Participants should be willing (and even eager) to learn, have basic information about the new context, understand themselves sufficiently and know how to cope and adjust/adapt in a new environment, know how to function effectively in their assigned roles/tasks which include cross-cultural communication and interpersonal skills, and know how/what to continue learning.

Case study populations consistently identified the main "unmet concems" as those of persons with particular needs, such as wives, children, and singles. Although some provision was made in the curriculum, this research identified this as an area of weakness in the Institute's orientation. Women, children, and singles are significant minorities whose needs were not sufficiently addressed. Their satisfaction and effectiveness in the cross-cultural context could be improved by addressing their unique needs. Recommendations and practices from data sources 4 to 6 also point out the necessity of spouse preparation.

It is interesting to note that women tended to be more responsive to IWM orientation. They evaluate their goal achievement during IWM higher than men even though they made few direct or vocal requests toward the inclusion of gender 
issues. Do women feel more needy and not really require more time spent on their concerns? Why did case study women not appeal more strongly than they did? I believe there are at least two reasons women were not more demanding. The female population in general had fewer opportunities for such experiences as orientation and appeared to gain more from the experience than men. Their responsiveness gave them a stronger feeling of satisfaction overall, masking the sense of need that becomes more recognized in the field. In addition, Christian women in general may not be as assertive as the general female population.

Both missionary and cross-cultural literature underscore the importance of preparing the whole family for the new experience. Literature indicates that the female contribution to the well-being of the entire family is larger than the male's. If both are employed, the task is even more challenging because the female spouse has several complex roles and responsibilities, and her contribution to enabling her husband and family to experience satisfaction and success in the foreign context is significant. Literature also recognizes that pre-departure preparation essential for the wife may be neglected, which is frequently the underlying cause for diminished success or ultimate failure of the sojourn.

The need to prepare women for their multiple roles and tasks goes far beyond what the usual pre-departure preparation provides, or is able to provide. I believe, however, adequate preparation for the whole family is a moral responsibility for organizations sending missionaries. A stronger family approach 
throughout the orientation curriculum would make a valuable contribution to the success of cross-cultural mission.

The only other unmet concerns mentioned consistently by IWM participants were more Area Studies information, continued preparation opportunities in the field, and individual needs, all of which are well recognized in cross-cultural literature and practice. These are also needs of emphasis rather than absence. Individualization is a theme in topics of training programs, curriculum development, and cross-cultural preparation. IWM has responded to individual needs by examining information from psychological assessment and participant registration forms, and maintaining a functioning evaluation committee composed of participants. During some orientation programs, attendee diversity makes it difficult for IWM to meet all minor needs because the breadth of preparation leaves little time for it. Individual counseling opportunities help, but these are usually restricted to the most pressing needs due to time constraints. If prospective missionaries' needs were identified and some were met prior to IWM, the Institute would have more time to accomplish its goals.

Other program planning principles help determine what goals should be selected for orientation programs. One is the relation of the program to the time of departure. Most IWM attendees leave for their appointed fields within a few weeks after IWM orientation. According to research, from 6 months before departure until shortly after arrival in the field, participants are most interested in survival information rather than general preparation. Unfortunately, much of what IWM 
must accomplish during its orientation is general rather than survival in nature because it is a comprehensive program. The fact that it appears so successful is testimony to its orientation purpose, effective methodology, and motivation of participants who have not had other pre-departure preparation. If several general IWM goals could be achieved by missionaries prior to appointment, or at least prior to IWM, the program could spend more time re-emphasizing and integrating important knowledge and skills while enhancing spiritual, attitudinal, and missionary formation. Missionary Internship Orientation includes time for integration through reflection to make its leaming experiential. With fewer goals, IWM could also provide time for reflection, and reap the benefits that come from the reflection.

General findings in the cross-validation from five sources are as follows.

1. There is strong affirmation for the necessity, effectiveness, and satisfaction of pre-departure cross-cultural orientation.

2. The need to orient the whole family is recognized.

3. Three general categories emerged into which most goals may be accommodated $($ Personal $=$ spiritual-psychological, Professional $=$ work or careerrelated role/task, and Practical $=$ transition/daily life aspects).

4.Variation in goals and their emphases depends on the program's underlying assumptions and perceived orientation purpose, in addition to availability of resources.

5. The importance of cross-culturally appropriate attitudes, awareness, competencies, and role expectations is recognized by all sources. 
6. The importance of developing motivation and skills for continuing growth in the cross-cultural context is recognized by theorists and trainers, even though this may not be strongly implemented in missionary orientation programs.

7. Most authorities, especially theorists and trainers, realize that effective cross-cultural functioning requires cognitive/affective/behavioral leaming, and is a lifetime process.

\section{Synthesis and Analysis for Individual Goals}

There is a wide range of practice and perception for goal number 1, To clarify church and agency policies and their application. Organizational policies that describe working conditions such as remuneration are unquestionably necessary for anyone going overseas. Logic indicates that the person's success in a foreign context requires security in the knowledge and dependability of expectations and policies of the organization that is responsible for his/her being there. General literature assumes that the conditions of the appointment are delineated prior to departure, so this goal is essential to the preparation process.

The question is whether or not Policies should be a part of the orientation program, and the answer depends on the purpose of the program. For instance, most general cross-cultural training programs would not address the issue because it is considered the domain of the sending organization. But mission boards and agencies have always stressed the importance of policies, and implement the goal themselves if their appointees attend an orientation that trains persons from more 
than one agency. Mission agency directors ranked Policies as the second most important goal. One reason for the strong emphasis may be because each mission agency has its own specific purposes, aims, and philosophies that are to be understood by the missionaries it sends. In addition, many missionaries need to "shop" for an agency that fits their philosophy, goals, mission style, financial needs, and other policy expectations. There is a range of involvement by sending agencies, however. For instance, non-SDA missionaries are likely to be responsible for the task of raising their own financial support after appointment and before departure can take place (deputation).

IWM includes Policies because it is a comprehensive program. Those who responded to the questionnaire differed in their perception of the importance of Policies. One reason for the variation of responses, and apparent ambivalence of some, is the employment security Seventh-day Adventist missionaries tend to feel because the denomination is responsible for their appointment as well as logistical and financial support. Some respondents questioned whether "teaching" Policies during the orientation program was the best use of time. There was a feeling that more time should be spent after arrival in the field where the policies are in effect. Perhaps there are more practical ways of communicating policy information outside of the Institute schedule.

The second goal, To enlange the undentanding of current issues in world mission, plays an important part in making mission service effective. As a goal, it is a part of the professional or work/related category that contributes to the role and 
task of the missionary. For IWM, Issues topics changed according to participant needs, and tended to generate lively and sometimes heated discussions. Most participants did not see this goal as critical as other goals. Some participants saw it as part of the professional preparation that is more useful for particular missionary roles, such as administration.

No missionary or preparation director would question the necessity of Faith for successful mission service. Some questioned the importance of the third goal, To facilitate growth in the experience of faith, for orientation programs, however. These explained that Faith should be a living reality in the person even before appointment. Therefore, nurturing Faith was not believed as important as other program goals. Even mission agency directors rated it as fourth in importance on a list of five most important, after Attitudes, Policies, and Competencies. It is unclear why anyone would question the goal as worded in the goal statement, especially when for the Christian every activity of life should facilitate growth in faith. Furthermore, all four sources relating to missionary preparation see faith as the core of successful mission experience. Perhaps faith is seen so integral to Christian life that goals which are more critical to the cross-cultural aspects of training are rated higher for programs.

Before any significant leaming for cross-cultural functioning can take place, a readiness should be created, as expressed in goal 4, To create an awareness of the essential role of culture in ministry. Institute participants ranked this goal most important, relevant, and essential. The necessity of awareness has logical 
support. In their latest book, Brislin and Yoshida (1994) place awareness first in the developmental process of preparation, followed by knowledge, emotions, and skills.

Goal 5, To further the development of attitudes vital to effective ministry, was seen by all sources to be axiomatic. It is one of the core goals, and was recognized as important for both program and cross-cultural effectiveness. Without appropriate attitudes, there would be little positive leaming or intercultural communication, nor could healthy human relationships be established or maintained.

The goal perceived as the essence of general cross-cultural training is comparable to the sixth IWM goal, To identify and foster essential cross-cultural competencies. Missionary preparation is stronger in the affective dimensions than general cross-cultural training, but tends to place less emphasis on the practical development of cross-cultural skills. Both aspects are necessary. Just as general cross-cultural training would be well served by including more of a "spiritual" dimension, including identity and commitment factors, so would missionaries benefit from the inclusion of more practical skills development techniques in their preparation. These skills should include communication, interpersonal interaction, and others. (Some may wish to include learning-to-leam skills, such as observation, here instead of in goal 12.)

Technical or professional expertise is more critical in a cross-cultural setting. A higher level of competence is demanded because functioning on the job is more complex. To increase knowledge and understanding of role expectations, goal 7, addresses this important area. This goal should be broad enough to include 
roles expected by society and important to the family in the cross-cultural context as well. IWM needs to include more time for non-professional role considerations, such as spousal, parental, and community membership roles. This is where the urgent need for preparing women for their unique roles and responsibilities should be recognized. Cross-cultural research particularly points to this need. It is not because the concept of gender equality is denied that this need exists, but because in reality (practice) the female is expected to provide more than an "equal" share of work and support.

Goal 8 meets participants' readiness, psychological, and social needs more than it contributes to the development and application of relational skills in the cross-cuitural context: To nurture community, fellowship, and relational stills. Case study populations seemed to recognize the difference between the goals more directly related to ministry effectiveness and those necessary for personal orientation needs. As a result, this goal was ranked 9th in importance, essentiality, and relevance, and between 6 th and 10 th for the other characteristics. Although attendees recognized the goal was essential, they ranked it least important of the five goals listed on the attendee evaluation forms. Questionnaire respondents consistently placed it 9th out of 12 goals. Yet, fellowship was stated as the most meaningful activity by a large number of respondents. Comments by current and former missionaries frequently mentioned with fondness the memory of that fellowship. Institute participants did not feel their ultimate effectiveness in cross-cultural 
ministry was necessarily impacted by this goal, but it is clear that the goal was indispensable in assisting their search for support and security for the transition. Another contrast is seen when comparing the views of the goal of Fellowship. Staff emphasized Fellowship strongly, and although attendees were generous in their appreciation of Fellowship they ranked it last in the five "stated objectives" listed in the evaluation questionnaire. Missionaries rated Fellowship important, relevant, and essential, but ranked it ninth in the list of 12 and were not very sure they were able to better relate and identify with the local people because of IWM fellowship. It appears that fellowship at the Institute was indispensable in creating an environment conducive to orientation and preparation to enter the foreign field; but the necessity and benefit of establishing and maintaining a social support system in the host country was not well learned. Missionary orientation in general has encouraged fellowship and stressed establishing a social support system overseas. Some cross-cultural orientation programs recognize the importance of a sense of community during the program, but very strongly urge developing a social support system in the new context and cross-cultural interpersonal skills to enable it to occur.

Missionary and cross-cultural literature identify relational/interpersonal skills as non-negotiables. Why do the case study populations not rank Fellowship among the primary goals? Perhaps they viewed it as a goal more for the orientation program itself than as a skill necessary for effective cross-cultural service. In fact, it appears that the Institute emphasized the fellowship aspect more as a program goal 
than actively seeking the development of relational/interpersonal skills. The goal statement itself may be at fault. The goal as stated serves two purposes: It combines IWM's program goal (fellowship for learning readiness and effectiveness) with that of skill development (establishing social support systems, and enhancing interpersonal skills). The program goal aspect may need to be separate from the participant skill aspect because experiencing and building social support (whether at the Institute or in the field) is not equivalent with the development of interpersonal skills.

Participants strongly felt the need for fellowship during the transition period in which IWM preparation usually took place, and appeared not to recognize the need to actively seek fellowship after arrival in the field or to establish a social support system among the nationals. Perhaps the lack of differentiation among the particular competencies in goal statement 6 had the effect of moderating the importance of both cross-cuitural communication and interpersonal skills development.

IWM filled an important role in providing support and security for its participants as they faced critical changes ahead. They attempted to learn as much about the unknown as possible, and to create a support system, a "family," to begin replacement for those they were about to leave behind. Examples of participant responses that illustrated their drive for support and security are: Interest in and importance placed on the spiritual, psychological, and cross-cultural preparation goals and aspects of the Institute; expressed need for more attendee involvement in 
the Institute; requests for opportunities to interact with more missionaries and nationals; recognition that fellowship was the most meaningful activity; call for more emphasis on Area Studies and women's issues; felt need for counseling opportunities with various IWM and General Conference staff; and desire for children to also have some form of cross-cultural preparation.

The potential of this goal could be expanded. If more intentional instruction were added to the practical emphasis on group fellowship, and if implementation of this goal were extended into the field context, as several requested, I am confident there would be a greater long-term difference in interpersonal relations. IWM could implement this if time were created by enabling appropriate goal aspects to be met prior to the Institute. This goal should be implemented in interaction with interpersonal skill development that would come within goal 6, Competencies.

Goal 9, To strengthen the sense of call and commitment to mission, is strongly supported and emphasized by the first four validation sources. In these emphases, missionary preparation is unique. There has been, however, a trend in mission away from a strong sense of calling. It has paralleled the shift from career to short-term missionaries. Today, there appears to be a stronger sense of commitment to God rather than a specific mission, a generalized agreement to do whatever God wants rather than a translation of that willingness into a particular mission role. The practical effects of this trend so far indicate a decrease in recognition of Christian responsibility to long-term foreign service. Commitment 
tends to decrease as a sense of calling decreases. Prospective missionaries who accept the challenge of frontier work in the least evangelized areas of the world must reverse the trend. With that call must come commitment.

A goal whose validity for orientation is recognized more by missionary than other programs is goal 10, To teach and encourage appropriate mental/physical health practices. This goal is also axiomatic. It is emphasized in missionary preparation in a practical way, including assessment by psychological testing and counseling, and learning to cope with stress. IWM likely emphasizes physical Health more strongly than the average orientation, which corresponds to the health emphasis that is characteristic of Seventh-day Adventists. Health as a goal was rated higher in importance by individual concerns of certain groups, such as older missionaries.

Area Studies (goal 11, To provide orientation to respective world areas of service) is the goal that was mentioned most often as in need of more emphasis and information by all groups familiar with IWM. It forms the core of culture-specific preparation for orientation programs, whether formally or informally. Further support for increasing its emphasis is found in Table 26 (ranks respondent ratings of IWM's goals according to validation characteristics) where it was viewed by respondents as very important, essential, relevant, clear, feasible, attainable, observed, and next to least unexpected; but ranked 11th or 12th of goals achieved during IWM or applied in the field. This fact supports previous evidence that participants felt the need to leam more before moving into the foreign context. 
IWM-prepared persons believed the purpose of Area Studies was more to provide living arrangement details than is usually meant by cross-cultural literature. In fact, some participants were decidedly disinterested in leaming about the culture, history, and government of their prospective country. This is explainable largely by the timing of the orientation program, a time when sojoumers want transition, logistic, and survival information. IWM is not equipped to provide the kind of details most wanted. When we understand what the populations mean by Area Studies, the expressed desire for more implementation it is not as critical. It would be enlightening to evaluate the achievement and application responses of trainees if orientation participants felt they had had enough Area Studies during orientation.

The continuing debate between culture-general and culture-specific training in the general cross-cultural training field is not a denial of the importance of specific culture understanding. It is a belief by many that the trainee changes that take place in culture-general leaming are more important because they can be transferred to learning the specific culture during service there. One suggested solution from literature is to train participants in the skills of learning how to learn, such as observation and resource identification skills.

To equip for continuing growth by mindset transformation (goal 12) is a goal that confused respondents, but whose importance is confirmed by training literature. The term "mindset transformation" appears to be responsible for a large part of the confusion. The mean responses ranked this goal last or next to last on every validation characteristic except attainment. It is interesting to note that the 
questions on page 4 that spelled out evidence of perceived attainment appeared to be understood even if elsewhere the concept appeared to be misunderstood. For example, when asked if Institute orientation increased their "resolve to grow in skills and understanding for effective service," missionary agreement ranked this goal next to highest in achievement. When asked if they were "more effective today" because IWM taught them "how to continue learning and growing," missionaries' agreement ranked the application of this goal in sixth place of the 12 .

Four sub-groups found the concept clearer than their counterparts, although leaders more so than missionaries, returned missionaries more than current, IWM-oriented missionaries as opposed to those with no orientation, and females more than males. Logic could support this finding and render acceptable explanations for the pair differences, but the study provides descriptive evidence.

Both missionary and cross-cultural training literature emphasize the need to teach skills for continuing growth in the field and throughout life. Some stress the importance of the "aha" experience, a paradigm shift. Hopefully this occurs early enough in the preparation before departure to provide a fertile personal climate for effective cultural learning. Others stress the growth of Transformation resulting from observation, experience, and application of cultural leaming. Evidence for both can be found in the responses. The "aha" experience appears to be a part of achieving the Awareness goal. Transformation as a gradual process of service and experience is demonstrated partly by comparing the stronger responses from leaders than missionaries. Their mean responses were higher for Transformation's 
importance as well as all other validation characteristics for it, including perceived attainment and application. It is probable that if this goal were implemented in a more deliberate and verbal way, attendees would not only be more clear about its meaning, but would also make a more conscious effort to develop and practice these skills earlier and more consistently in their service.

Transformation appears to be a goal statement that needs modification also because it joins two different concepts: paradigm shift (or mindset transformation) that makes the prospective cross-cultural worker ready to learn new information, attitudes, and skills necessary for being effective; and leaming how to learn. In one sense, the goal statement reflects this paradigm shift for readiness when implying that mindset transformation is necessary for continuing growth; and it is. But, according to cross-cultural literature, equipping for continuing growth is largely achieved by participants developing skills for leaming how to leam. Whether the paradigm shift comes at the Awareness level, or towards the end of pre-departure preparation, it should come. It should not only make the participant ready to learn or to continue learning, but to take an active part in continuing to leam throughout the sojourn by implementing the learning-to-learn skills the preparation has taught.

\section{Validated List of Goals}

The original list of 12 goals to be validated and an overview of findings for each of them is shown in Table 31. 
TABLE 31

ORIGINAL GOAL STATEMENTS AND FINDINGS FROM RESEARCH

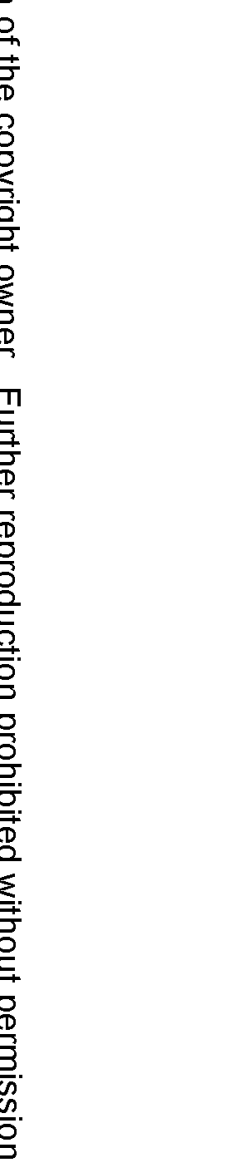

\section{Original Goal Shatements (Clarified)}

AlM: To help missionary appointees be affective in cross-cultural ministry in general, and in their respective fields in particular.

1. To clarify church and agency policies and their application

2. To ealarge the understending of current issues in world mission

3. To facilitate growth in the experience of faith

4. To create an awareness of the easential role of culture in ministry

5. To further the development of attitudes vital to effoctive ministry

6. To identify and foster essential cross-cultural competencies

7. To increase knowlodge and underatanding of role expectalions

8. To nurture community, fellowship, and relational skills

9. To strengthen the sense of call and commitment to mission

10. To teach and encourage appropriate mental/physical bealth practices

11. To provide orientation to respective world areas of service

12. To equip for continuing growth by mindset transformation
Validation Findings From Research

IWM should emphasize the missionary family unit rather than appointee, and provide more preparation for respective fields.

Appropriate for preparation, but general policies could be implemented prior to IWM, relevant policies during IWM, and others in the field

Appropriate and useful for creating flexibility and individualization

Critical; can be fecilituted by IWM, but an adequate level of faith should be reached before appointment and participation in IWM

Most basic and approprinte of goals; contributes to leaming readiness

Among 5 most appropriate; helps determine quality of other learning

Amoag 5 most appropriate; emphesize communication/interpersonal

Appropriate; should expand to include relevant non-professional roles

Appropriate; most meaningful for encourngement during pre-departure transition experieace; should guido wocial-aupport-system building

Critical; among 5 most appropriate, clearest, socond-most essential; contributes to identity, persevernece, spiritual strength, satisfaction

Appropriate; psychological espocially indispensable for adjustment

Among 5 most appropritte, easiest to implement and achieve but believed least achieved, almost least applied; acods more emphasis

Moat confusing, believod least appropriate, but soen more necesany as prepartion, time, and experience continue; should create readineas, motivation, a paradigm aift, and include learning-to-leam skills 
Three more tables complete the description of findings. Table 32 presents the list of original goal statements along with suggested changes from the research findings. Some changes are to improve the statements themselves so they better represent the goal content; others indicate a modification of content or emphasis.

I suggest that the aim should refer to the family unit rather than individual appointee only, even if appointee is single. For singles, the concept of family could include the dimension of "extended" family.

The goal statement for Policies should make reference to more than only policy information because most missionary sending organizations (IWM as well) include information about their history, philosophy, goals, methods, and expectations. This information is very important for building the "identity" and commitment of appointed persons/families.

The rewording for Issues better reflects the goal content, and for Area Studies indicates that the intention is not to provide all the necessary information but only what the orientation considers it should be responsible for.

The reworded goal statement for Roles includes preparation for nonprofessional individual roles in order to accommodate for the unmet needs of women, children, and singles.

For the Area Studies, I suggest that the word minimum be added to suggest that some of the information must be gained outside the IWM program. Finally, the goal statement for Transformation should be modified by including leaming-to-leam skill development. 
TABLE 32

ORIGINAL AND MODIFIED AIM AND GOAL STATEMENTS

Original and Validated Aim and Goal Statements

AlM: To help missionary appointees be effective in cross-cultural ministry in general, and in their respective fields in particular.

AlM: To help the appointed missionary family members be effective in cross-cultural ministry in general, and in their respective fields in particular.

1. To clarify church and agency policies and their application

To clarify church/agency policies/application and other necessary information

2. To enlarge the understanding of current issues in world mission

To enlarge the understanding of current issues in mission and missionary preparation

3. To facilitate growth in the experience of faith

4. To create an awareness of the essential role of culture in ministry

5. To further the development of attitudes vital to effective ministry

6. To identify and foster essential cross-cultural competencies

7. To increase knowledge and understanding of role expectations

To prepare for individual and professional roles in another culture

8. To nurture community, fellowship, and relational skills

9. To strengthen the sense of call and commitment to mission

10. To teach and encourage appropriate mental/physical health practices

11. To provide orientation to respective world areas of service

To provide minimum orientation to respective world areas of service

12. To equip for continuing growth by mindset transformation

To equip for continuing growth by mindse transformation and leaming shills

Note: Italicized-bolded aim and goal statements are changes suggested for IWM by research. 
Some models categorize goals according to leaming dimension: cognitive, affective, and behavioral or skills. One of the premises of this research is that a goals approach to designing missionary orientation programs must also provide for multidimensional learning. One difference in this study's goals approach is the assumption that every goal has all three dimensions, although obviously not to the same degree. Identifying cognitive, affective, and behavioral aspects of each goal would come at the sub-goal or objective level of specificity.

Table 33 illustrates this principle. It lists IWM's goal categories and suggests for each goal a sample skill that was identified in the research as important for making a contribution to meeting missionary needs for that goal. Identifying knowledge (cognitive) and attitude (affective) aspects would be just as possible and useful.

This study suggests that IWM's participant preparation should begin prior to the orientation program. Identifying and organizing this learning at the subgoal/objective level would be easier than at the goal level. For purposes of exploration, however, Table 34 illustrates a possible scenario for recommended primary delivery modes for IWM goals. The individual and group options are not specified but could include numerous creative possibilities. If some preparation learning did take place prior to IWM, the program would have more time to concentrate on integrating prior learning and implementing its orientation purpose rather than having to provide basic education and training that could be obtained earlier. Repeated exposure to preparation aspects makes learning more permanent. 
TABLE 33

ILLUSTRATION OF IWM GOALS EXPANSION TO SUB-GOAL LEVEL: IMPORTANT SKILLS IDENTIFIED IN RESEARCH

\begin{tabular}{ll}
\hline \multicolumn{1}{c}{ IWM Goal Categories } & \multicolumn{1}{c}{ Sample Skills for Cross-cultural Context } \\
\hline Policies & Resource/financial management in other cultures \\
Issues & Recognizing and planning for trends/future \\
Faith & Spiritual formation \\
Awnreness & Observation in/of other cultures \\
Attitudes & Attributions, seeing from cross-cultural others' perspectives \\
Cross-cultural Competencies & Intercultural communication and interpersonal relations \\
Roles & Spouse relationships, parenting in other cultures \\
Fellowship & Building social support systems in other cultures \\
Call/Commitment & Decision-making \\
Mental/Physical Health & Coping skills development and stress management \\
Area Studies & Locating information and resources in other cultures \\
Transformation & Learning-to-learn \\
\hline
\end{tabular}


TABLE 34

SAMPLE SCENARIO: SUGGESTED PRIMARY DELIVERY

OPTIONS FOR IWM GOALS

Individual and/or Family Unit $\begin{gathered}\text { Polential Non-IWM Group } \\ \text { Opportunities }\end{gathered}$
$\begin{aligned} & \text { Policies } \\ & \text { Faith }\end{aligned}$
Awren Orientation Program
Competencies
Roles
Relationships


Phase Four: Reconceptualization of Program Goals

I expanded the study to include a fourth step in the case study approach because I desired to make a practical contribution to missionary training research, a reconceptualization of the validated goals. This second section of chapter 5 presents the reconceptualization that emerged from the research.

As several missionary preparation principles became evident from the study, principles that impact the identification and selection of goals, it appeared to me they would require consideration as a part of the goal determination process. Goals are not created in a vacuum but within the preparation context. To suggest suitable goals requires flexibility. These facts shaped the nature of the reconceptualization that emerged. Consequently, it is in the form of a framework designed for planners of missionary preparation to use as a conceptual planning tool leading to the determination of suitable goals for pre-departure cross-cultural orientation programs. A discussion of 10 preparation principles/concepts derived from the research process follows.

1. Goal-directed: In order for preparation to be comprehensive, relevant, and without gaps, overlaps, or unnecessary repetition, goals should be carefully designed to represent and meet participant needs.

2. Comprehensive: Gaps, overlaps, and repetitions will also result if there is no single entity responsible for planning and guiding the entire preparation process. Every organization has its own unique philosophy and preparation style. Without careful planning, preparation may be delivered in piecemeal fashion. For 
instance, Peters (1990) found that one reason missionaries felt inadequately prepared was because different organizations were responsible for pre-departure and in-field preparation and gaps occurred. Accountability for preparation may not be vested in a single entity because sending organizations are structured differently; some are denominational, some independent, some agency-based, and others are a combination of these. When several entities are responsible for the preparation cycle, the specific purpose and preparation needed may be unclear, making the goals ill-defined or haphazard.

3. Continuous: Most missionary needs continue to some degree throughout the entire mission service (or the missionary's life), so preparation should be an on-going process. The mission service cycle has at least three distinct phases: Pre-departure (including awareness, recruitment, selection, appointment, and preparation that includes orientation), in-service (including continuing education in the foreign context as well as during furloughs), and re-entry (which should occur prior to leaving the field at the close of active service and be maintained for a period following).

4. Unit-organized: The pre-departure phase of the preparation process includes several segments: Awareness, mission education/training, recruitment, selection, assessment, appointment, deputation for many, and orientation preparation. What occurs during each of these segments dictates the goals for predeparture orientation. If all necessary learning is organized into units according to appropriate unit purpose and suitable goals, preparing missionaries could be more 
flexible and comprehensive. The Institute of World Mission has been responsible for awareness, assessment, and a comprehensive preparation that includes mission education/training and orientation. If prospective appointees had "leamed" preparation units prior to appointment, IWM would have had more time to integrate the previous preparation and bring the appointed family into a stronger readiness and eagerness to begin service just before going to the field.

5. Needs-based and participant-centered: Missionary preparation should be centered on preparing appointees by meeting their needs. These needs are discovered by information gathered about the person/family, sending organization, foreign context, appointment roles/tasks, and purpose of each particular preparation unit.

6. Individual-responsive and family-oriented: The needs of each individual should be met as far as possible. This is not always easy in a group setting, such as an orientation program. Some programs may find they have such a varied group that the program cannot prepare everyone for effective service. Besides, trends in mission, evangelization, and personnel are changing the criteria for preparation. To illustrate, a person planting a church in the least evangelized part of the world would need a different preparation than one spending a year as a medical assistant in Guam. Although there are many commonalities for general cross-cultural preparation, the specific preparation needed depends on: (1) the length of the appointment, whether long-term or short-term; (2) the type of appointment--frontier or maintenance, professional or tentmaker, career or 
volunteer; (3) the foreign locality and its degree of contrast with the home lifestyle and culture; (4) the nature and size of the family unit, whether single, couple, or single/couple with children; and (5) what each individual brings into the program in regard to personal qualities, capacities, background, and experience. The whole plan should be responsive to individual needs within the family system so the family unit can share the vision and enthusiasm as well as preparation before service begins. If a preparation plan is designed for and by individuals and families who are interested in cross-cultural mission service, many preparation needs that make individualization difficult for orientation programs could be addressed in other ways and before the program begins.

7. Developmental: The preparation cycle includes several goals that reflect the developmental process of cross-cultural effectiveness. One example is the preparation for personal adjustment, which continues into adaptation, and finally integration into a foreign culture. The point is that people who cross cultures go through a general developmental process that essentially never ends since integration never fully takes place. If the preparation is designed and organized to accompany the developmental process natural to cross-cultural learning, it will be more efficient and effective. Part of this concem also relates to the felt needs of the participants depending on where they are in the preparation cycle. For example, the closer appointees are to departure, the more they feel the need for survival information and social support for the transition. 
8. Multi-dimensionl: Erfective and interaned learning perthins to the whole person, including the spiritud, menthl, poschological, emotional, social, physical, behavioral, and culbural chareteristios. Lenruing dimensions/domains involved in the leaming proceas include cogmition, pereeption, reflection, affect, experience, and still developmeat. Laning will be more effective to the extent that the methodology is more bolistic, including all apsoprinte dimensions for goal implemention.

9. Participam-guided: Both cross-cultonal and curriculum development litereture dealing with adult leaming principles stress the importunce of participant involvement in designing and coatrolling the learning process. The prospective missionary should share the reaponsibility for his or ber preparation, and contribute to decision-making with the organizational entity responsible for the preparation process. This process will make the prepanation more responsive to individual need.

10. Future-directed: Relevance requires a forward look, especially in a world changing so rapidly. What is the future of missionary prepantion? One observes from the literature that a growing number of Christians believe that evangelizing the world and training for ministry across cultural barriers are now more urgent but possible than ever before. They cite several reasons, such as a growing awareness, globalization, increasing cross-culturl experience, motivation prompted by an approaching millennium, exploding knowledge and expanding technology, transportation, and communications. 
To summarize, the answer to ther goals are subbole for preparing crassculnural missionaries? requires a process as well as contert answer. The answer depends on bow the quextioner views preparation, and the particulur sezmeat he or she is reaponsible for planming; it depends on how minsionery preparation principlea are incorporned and executed; it depeads on the puppose of the segment and how it fits into the rest of the preparation cycle; and it depends on what the preparation requirements of individual miscionaries, their appointments, and contexts are. Finally, it also depends on bow the prepantion is delivered to those who need it.

The reconceptualization reflects this emerging reality. The fromewort in Figure 3 guides the answer to the question: What goals are suricable for a missionary cross-cultural orientation program? It is a process framework comprised of five steps to guide a director/planner of tho prepantion process or orientation program to identify the aim and gaals of the orientation program to be planned. At the beginning of this study, I delimited the research question to pre-deparure preparation. I viewed preparation broadly, however, because the IWM program is a comprebensive program that covers "all" pre-departure prepantion neods. As the research progressed, the complexity of the answer prompted viewing the research question more narrowly, as represented by Step 5 in the frumework, and also more flexibly, which required the first four reps to clarify one's understanding of the challenge. The discussion of the framework that follows alens the planner to issues involved in this reconceptualization. A matrix is presented for each step to make the conceprualization visual and understandable. 


\section{Framework to Determine Suitable Orientation Program Goals}

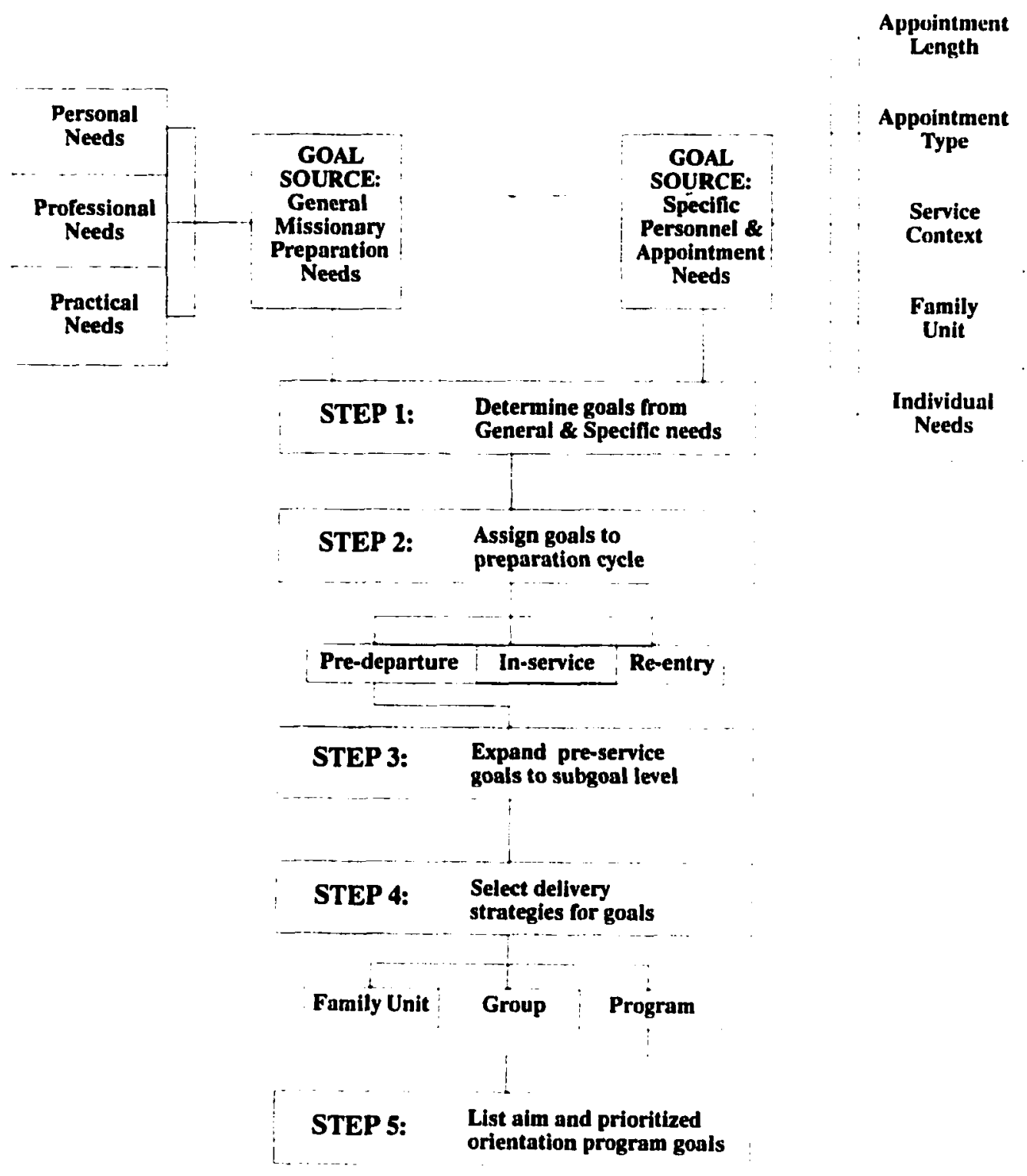

Figure 3. Steps to guide the determination of orientation program goals. 
Before beginning the first sep of goul determinntion, the plamer should seek to discover when participan needs should be mee. Input should come from two sources: gecenal mixsionary prepantion needs, and specific personnel and appointement needs. This andy provides a valideted set of prodeparme mivioniry pepantion goals thet conld be used as the first source. During the validetion process, these needs were charified into three caregories: Personal (spirimal, psychological), Profescional (individunl and family cross-cultural anst, roles, expertise), and Prectical (transition and cross-cultural dily life).

My resenreh could buve ended with the idemifiention of validited predeparture orientation goals. Through the literature review and validation process, however, I was alerted to a mumber of factors that require consideration for selecting suibable goals besides identification of needs and valid goals. (See Figure 4.) Fint are specific personnel and appointment factors that would modify these general preparation needs and answer the question more clearly. Factors included the length of appointment, type of appointment, context of service, type of family unit, and individual needs. This observation forced the additional consideration of these specific needs along with the goals arising from general needs.

Step I calls for integrating the needs/goals from both sources into a compreheasive set of goals at either the corporate or individual level. These goals should serve at least one of four functions: to provide readiness, growth, crosscultural leaming, and support. 


\section{4}

\begin{tabular}{|c|c|c|c|c|c|}
\hline & \multicolumn{5}{|c|}{ 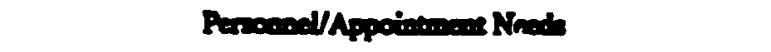 } \\
\hline & 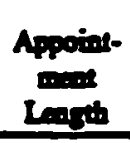 & $\begin{array}{c}A p i n \\
x y\end{array}$ & $\begin{array}{l}\text { Servioes } \\
\text { Connes }\end{array}$ & $\begin{array}{l}\text { Pruily } \\
\text { Unil } \\
\text { Dye }\end{array}$ & $\begin{array}{l}\text { Individual } \\
\text { Neade }\end{array}$ \\
\hline Pendend & & & & & \\
\hline Proferion & & & & & \\
\hline Pretiol & & & & & \\
\hline
\end{tabular}

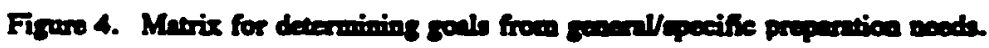

The oext part of the answer to the "what gonls" question requires Step 2, deciding when in the preparation cycle the goals should be implemented and assigning each to one or more phases of the cycle. Langunge trining is a good example. Most ageacy directors setted thet language learing does not apply to predeparture orientation, although a few indicated they believe it does. It is obvious that a short-term orientation of 4 w 6 weeks cannor teach a language and achieve its other goals, but it is also very strongly believed that laming the language is essential for effective service. The apparent conflict is solved by understanding what is meant by "orientation." For example, if orientation is delimited to the meaning used by this study, a common and appropriate goal for orientation programs would be longuage leaming skills. Learning the language itself can occur prior to or after orientation.

All goals sbould be assigned to at least one part of the preparation cycle (Figure 5). In a broad sense, pre-departure preparation can include general awareness, education, recruitment, selection, as well as orientation prior to leaving 
for the field. In-service includes oriention or training thet contivenes while in the

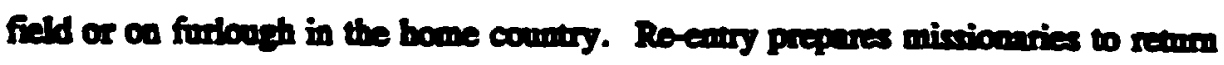
to the homelnod and helpe mimuin readiness for new appintmeors. It shoold be noted then most goals for effective cross-culturel service are opeo-ended by nome, and not all achievement is accomplistred by formal preparation. Some gonls should be implemented in more than one part of the cycle to correspond to the developonemt process of sojoumers. In fect, most gonls could heve some appect suinble for each phase in the cycle. The primary concern for this sudy is to determine which goils oeed pre-departure implementrion, and to provide flexibility in plaming for then comprebeasively. If pre-deparure orientition is broader than one progrnm, this step eliminates gaps by providing for the toel prodeparme proparation seeded.

\begin{tabular}{|c|c|c|c|}
\hline & \multicolumn{3}{|c|}{ Preves of Prepantion Cyele } \\
\hline & Prodeperane & In-menvice & Roeatry \\
\hline \multicolumn{4}{|l|}{ Perronal } \\
\hline \multicolumn{4}{|c|}{ Profemional } \\
\hline Prnetical & & & \\
\hline
\end{tabular}

Figure 5. Matrix for ascigning soals to preparation phese.

Afte: assigamem to the "ideal" preparation phase, only those goals which fall into the pre-deparure category need to be considered for pre-departure orientation programs. Yet, 2s Steps 4 and 5 indicate, not all of those goals may be suitable for a short orientation program, the final focus of this study. Step 3 takes 
goals in all three needs categories (personal, professional, practical) that are assigned to the pre-departure phase of missionary preparation and expands them. It allows for flexibility in planning philosophy and assumptions, and enables planners to provide for specific sub-goals arising out of perceived needs of specific groups and individuals.

The sample expansion is based on five leaming dimensions essential for cross-cultural functioning, and therefore preparation. The five learning dimensions indicated are: spiritual (human-divine), intra-personal, inter-personal, inter-cultural, and inter-communicational. Each of these dimensions represents an interaction between the individual and some other important reality. The spiritual is between the individual and God, portraying the dynamic of faith and spiritual growth, and includes a sense of call from God and commitment to Him in service. The intrapersonal includes those psychological factors centered in motivation, attitude, and personal growth. Inter-personal refers to the social and relational dimension of interaction so essential to cross-cultural life and ministry effectiveness. Intercultural includes all those aspects of knowledge, understanding, and skills that enable basic functioning in the foreign context. Finally, inter-communicational defines the most pervasive skill for cross-cultural workers, and even more basic for missionary service, the ability to communicate effectively. These learning dimensions are dynamic interactions that are especially critical for cross-cultural missionaries to effectively adjust, adapt, and function in the missionary task/role and daily life. 
Each of these learning dimensions "fleshes out" the basic goals that are identified as personal, professional, and practical. The scheme in Figure 6 demonstrates only one possible way to visualize the task of expanding goals into corresponding sub-goals. It is not the only way. Learning dimensions could utilize many other organizational schemes or models, such as Brislin's categories: awareness, knowledge, emotions, and skills; or J. Bennett's cognitive, affective, and behavioral categories. The point is to find some scheme for enabling the major goals categories to be broken down into goals, sub-goals, and objectives.

Cross-cultural Learning Dimensions

\begin{tabular}{|c|c|c|c|c|c|}
\hline & Spiritual & $\begin{array}{c}\text { Intra- } \\
\text { Personal }\end{array}$ & $\begin{array}{c}\text { Inter- } \\
\text { Personal }\end{array}$ & $\begin{array}{c}\text { Inter- } \\
\text { Cultural }\end{array}$ & $\begin{array}{c}\text { Inter- } \\
\text { Communi- } \\
\text { cational }\end{array}$ \\
\hline \multicolumn{6}{|l|}{ Personal } \\
\hline \multicolumn{6}{|c|}{ Professional } \\
\hline Practical & & & & & \\
\hline
\end{tabular}

Figure 6. Matrix for expanding goals to sub-goal/objective levels.

Step 4 of the process is necessary to further identify only those goals suitable for the orientation program being planned or evaluated. This step requires selecting delivery strategies for each goal so that only those that are most appropriate for program treatment are allowed to take program time. There are at least three category options: family unit, whether single, married, with or without children; group, meaning delivery to more than one person or family unit; and 
orientation program, the focus of this study. The next matrix (Figure 7) shows this scheme.

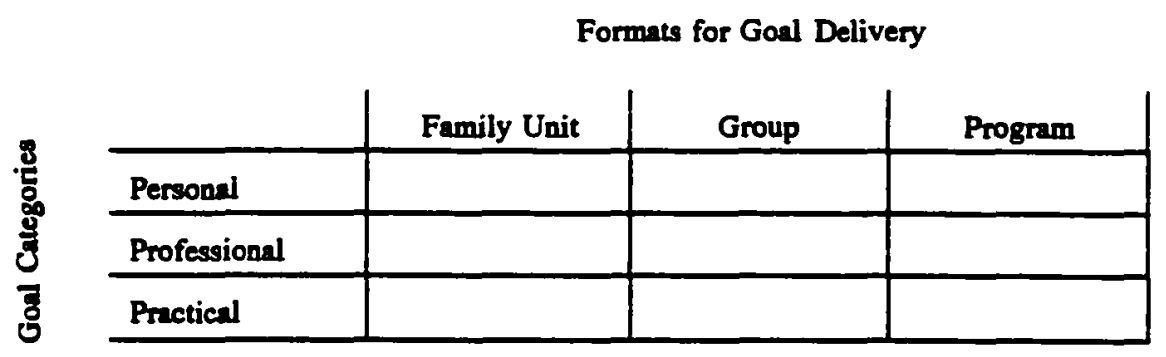

Figure 7. Matrix for determining goal/sub-goal delivery strategies.

Twenty-first-century technology allows goal implementation to take a number of alternative forms for the three categories above. With financial resource concerns, preparation efficiency without compromising effectiveness is appealing. It provides maximum flexibility for time expenditure and also learning style preference. To illustrate, there may be some goals that could be delivered to the individual family unit through reading lists, materials, audio or video cassettes, or programs offered within easy access range of the family unit. It is possible that regional training seminar modules or college/university class opportunities may be available. There may be mission conferences, get-togethers of former missionaries, or other opportunities in which the family unit (or multiple family units) may participate. A group format may be useful for special training opportunities that can be offered just prior to the beginning of the orientation program, or after it, for those who are scheduled for orientation and need the additional training. 
Step 5, the final step and focus of this study, provides an aim and prioritized goals for the missionary orientation program. After the elimination of goals by sending them through various conceptual "sieves," the goals that remain are those that should be incorporated into the orientation program. The first task is to state the aim so it can provide the center around which to help keep the goals' emphases channelled and guide the methodologies used to attain them. The final task is to prioritize the goals to ensure the best possible coverage should there be unexpected constraints, such as a scheduling problem.

One scheme to prioritize goals considers the difficulty of the goal task compared to the level of its importance. Figure 8 presents a conceptual device to prioritize each goal by crossing these two dimensions. A goal could first be evaluated by how difficult it is to achieve during training: low, moderate, or high. The next activity would determine the relative level of goal importance: low, moderate, or high. Each box at the intersection of these two considerations identifies the priority level for that goal; the lower the number, the higher the priority. For example, the goal identified in box $\# 1$ would be the goal of highest priority. Goals that share the same rank are of equivalent priority. There may be extremely important goals that are very difficult to achieve, goals that participants have little hope of achieving during orientation. However, these goals should have been eliminated prior to this step, as they are likely ones that require some other form of preparation in addition to or instead of the orientation program. 


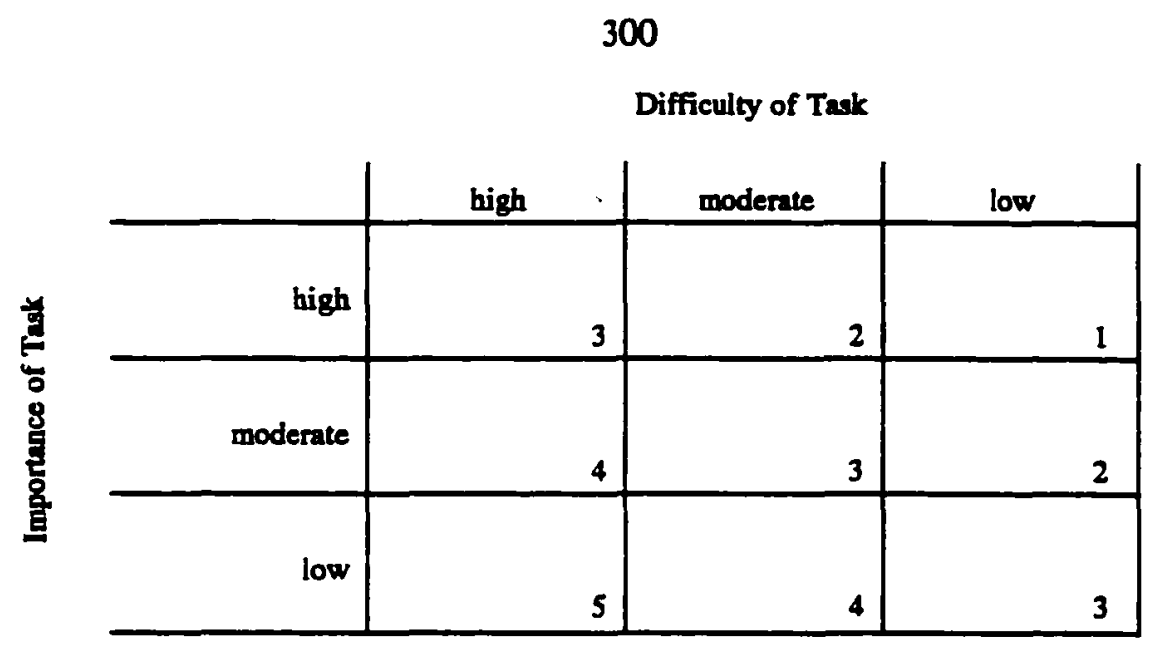

Figure 8. Matrix for prioritization of goals/sub-goals.

After going through this reconceptualization process, the planner will have a prioritized list of suitable goals with which to plan an orientation program for missionaries offered just prior to departure for the field. These goals provide one answer to the planner's question, What goals are suitable for our pre-departure missionary orientation program? 


\section{CHAPTER VI}

\section{SUMMARY, CONCLUSIONS, AND RECOMMENDATIONS}

\section{Summary}

\section{Background and Problem}

Today's global interaction challenges every dimension of human existence, but effective human functioning across cultures is not considered a natural predisposition. It requires changes in thinking and behaving that must be learned. As a result, there is a growing consensus that planned preparation for cross-cultural service is necessary for efficient and productive cross-cultural leaming and effective service.

Much of this preparation is delegated to some form of pre-departure orientation. Although orientation programs differ widely, they seek to prepare individuals to enter and function successfully in another culture. Although the backgrounds and abilities of persons about to enter cross-cultural service also differ, they all share some common needs. The recognition of these needs enables responsible planning that is systematic, comprehensive, and accountable to both the organization, persons to be prepared, and the field that receives them. 
Accountability requires the determination of suitable goals before the selection of strategies to reach them. Missionaries have a longer history than any other type of overseas service, and preparation grew out of attempts to meet perceived needs. Orientation traditionally began with logistic advice, to which spiritual preparation was added, followed by the assumption that theological understanding and appropriate personal traits were necessary. However, preparation goals and emphases changed as additional needs were recognized. During and following World War II orientation gradually became more focussed on attitudinal and cross-cultural communication aspects. Current missionary orientation emphases now recognize the importance of trends and issues to plan for a rapidly changing future. The field of general cross-cultural orientation received its greatest impetus from the needs of military personnel, Peace Corps workers, and international students in the 1940s to 1960 s. Extensive research in areas such as program effectiveness, personnel assessment, prediction of success, intercultural effectiveness, and cross-cultural adjustment/adaptation have contributed much to the general understanding needed to design preparation programs and develop theory.

The purpose of this study was to verify goals necessary to prepare persons for effective cross-cultural service by validating the goals of an 4-6-week predeparture orientation program for missionaries. The research question was: What goals are suitable for missionary pre-departure cross-cultural orientation programs? In order to answer this question, I was compelled by the research process to ask also, How can these goals be determined? 


\section{Research Procedures}

The case selected for this study was the Seventh-day Adventist (SDA) Institute of World Mission (IWM or Institute), an orientation program that began in 1966 to prepare Seventh-day Adventist missionaries for cross-cultural ministry. There were several reasons for this choice. I was familiar with the orientation because I attended the Institute once as a missionary after 6 years of cross-cultural service, and again 8 years later as a researcher. This representative program was aiso selected because it is comprehensive, effective, and had conducted more than 66 sessions to date since it began in 1966.

The goals validation methodology was comprised of a four-phase process developed for this study. The first phase was the identification and clarification of the orientation goals of the case under study. Phase 2 was a collection of validation data from six relevant sources: observation of the program in operation (staff/attendees), administrative stakeholders (church leaders), criterion populations (current and retumed missionaries), a review of missionary preparation, a summary of goals from cross-cultural literature, and discussion of trends and issues.

Data from the first three sources were from case study populations. Source 1 included information from IWM documents and observation. Data from Sources 2 and 3 came from a questionnaire constructed for this research and returned from 595 church leaders and missionaries (current and returned) who evaluated the suitability of IWM goals. Treatment of questionnaire data formed the 
empirical portion of the study. Goals were evaluated by 12 characteristics (important, essential, relevant, clear, measurable, feasible, attainable, observed, achieved during IWM, applied in the field, expected, and comprehensive). These were organized into four validation categories represented by four questions: Are the goals perceived appropriate? Are the goals perceived possible? Were the goals attained? Are all the goals together comprehensive enough to achieve the aim? The first three categories were confirmed by factor analysis. The returns were analyzed with descriptive statistics.

The last three sources were external to the case populations. Missionary preparation data (Source 4) came from an overview of how goals developed over time, a brief view of missionary preparation literature, and program practice as explored by an examination of another current missionary orientation program and responses from 22 mission agency directors who evaluated IWM's goals. Data for Source 5 was gleaned from a brief search of stated/implied goals from cross-cultural preparation literature. Finally, a discussion of trends and issues involving the milieu for mission and missionary preparation provided data for Source 6.

The third phase involved a synthesis of data from these six sources to cross-validate the findings. Information derived from the synthesis resulted in a slight modification of the original Institute goal statements. Finally, Phase 4 reconceptualized the goal findings that emerged from the research into a framework to make goal determination easier for planners and evaluators. 


\section{Research Findings}

Findings from the six sources directly or indirectly confirmed the validity of the original set of clarified Institute goals for the purpose of preparing missionaries for cross-cultural ministry. All Institute goals were validated by church leaders and current/former missionaries as well as favorably endorsed by reviews of missionary and general cross-cultural preparation literature and an examination of other training programs. Goals were considered appropriate (important, essential, and relevant) by $96 \%$ or more of the enthusiastic case populations, and no essential goals were believed to be missing. These goal areas are: Policies, Issues, Faith, Awareness, Attitudes, Competencies, Roles, Fellowship, Call/Commitment, Health, Area Studies, Transformation. Institute participants believed that spiritual and affective factors make the greatest contribution to their mission service effectiveness, and believed that spiritual activities and fellowship contributed most to the effectiveness of their Institute training.

The case study populations, Sources $1-3$, were fairly consistent in their perceptions of the goals and/or their characteristics. Although all goals were perceived to be appropriate, five were consistently seen as more important, essential, and relevant than the others: Awareness, Attitudes, cross-cultural Competencies, Call/Commitment, and Area Studies. Those that were ranked least contributory, yet confirmed as appropriate, were Policies and Transformation. None of IWM's 12 goals could be considered unexpected. 
Sources 2 and 3 provided the empirical validation of IWM's goals. For this study, all goals found appropriate (important, essential, and relevant) were considered valid and suitable for a missionary training program. The other three validation categories, possible, attained, and comprehensive, were to contribute to this foundational validity. Thus, validity for 11 goals was strengthened because they were also perceived to be possible; but respondents were unsure about whether the 12th, Transformation, was possible. Respondents were not clear on the concept or meaning of the term. Validity was further strengthened for eight goals because they were also perceived to have been attained. Institute participants did not question the appropriateness, possibleness, or attainment of Institute goals even though they questioned the measurability of most goals.

According to the case study populations, IWM achieves 10 of its clarified goals very satisfactorily, but Area Studies and continuing growth by mindset Transformation were achieved marginally.

When asked whether IWM goals were comprehensive enough for crosscultural preparation, $81 \%$ of the respondents answered in the affirmative. A study of the comments showed that those who disagreed or were undecided did not indicate a need for more goals but questioned whether the program length was sufficient to accomplish all 12. The evaluation questionnaires given by IWM at the close of its training program indicated that, whereas participants might have "unmet concerns," these related to the degree of goal emphases given by the staff and/or individual needs rather than a missing goal. A possible exception is the recognition 
of unmet orientation needs specific to women, children, and singles. These needs could easily be met in IWM's goal statements by (1) expanding the present goal statement for Roles to include the needs/concerns of these groups, then implementing the goal in its expanded form; and (2) modifying the aim to include a stronger family emphasis.

There was some variance in the range of perceptions among the case study population groups. Staff and attendees believed IWM's orientation is important for effective cross-cultural ministry, and all IWM's goals contribute necessary assistance in preparing missionaries for service and meeting their transition supportsecurity needs. However, although both groups agree that fellowship in a nurturing environment is an essential ingredient for successful cross-cultural leaming, the staff tended to see the affective dimensions as more important than attendees did; attendees believed specific cross-cultural preparation aspects should be primary. Another contrast showed that Administrative stakeholders (leaders) believed all goals are necessary, but they rated higher those more relevant to them (Policies, Issues, Roles, and Transformation). Leaders also rated IWM orientation validation characteristics generally higher than missionaries did. Missionaries believed all goals are necessary, but rated Awareness, Area Studies, Health, and Relationships higher. Missionaries also rated their goal achievement and application higher than leaders did, and observed a greater percentage of fellow missionaries who implemented IWM goals (except for Policies) than leaders did. 
Sources $4-6$, the external sources of validation, corroborated the general findings of the case study populations. Based on comparisons with other missionary orientation programs, IWM goals well represent missionary preparation while covering a broader spectrum of preparation than most other single orientation programs. Furthermore, even though the necessity and essence of missionary preparation has evolved over time, the general pattern of essential goals is favorably reflected in IWM's goals. General cross-cultural training literature supports the validity of IWM goals for preparation although its focus is more narrow and specific than IWM or missionary orientation. The key purpose of cross-cultural orientation is to prepare the sojoumer for successful adjustment, adaptation, and integration into the foreign context so he/she can function effectively. The purpose can be attained by raising awareness, providing knowledge, eliciting positive emotions, and teaching skills-in a manner and to the level appropriate for the sojoum. Missionary preparation will require more flexibility and diversity in orientation goal selection, individualization, and delivery as it examines world trends, seeks to meet current challenges, and plans for the future.

There is both an empirical and a theoretical basis for acknowledging the effectiveness of IWM's preparation. IWM is strongly appreciated by nearly all of its participants not only during the training, but also during and after mission service. As a group, missionaries who have attended the Institute believe they are above average in their mission service effectiveness, and believe the Institute contributed around $75 \%$ of their effectiveness. Based on comments and 
demographics, it is reasonable to assume that the percentage would have been substantially higher if all missionaries had attended IWM prior to going overseas. Most of the unmet concerns reported by IWM participants reflected a deficiency in emphases determined by the particular session and/or presenters, or an expression of individual needs and preferences based on background/experience, expectations, and personality.

\section{Conclusions}

The conclusions of this research are based on all four phases of the validation process, and are intended to reflect the descriptive and analytical nature of this case study. They are divided into two sections: conclusions relating to the case, IWM orientation; and those relating to general orientation preparation, with particular reference to making preparation more effective in the future.

\section{IWM Orientation}

\section{Conclusions Related to IWM Effectiveness}

Factors in IWM effectiveness

Based on the findings of this study, IWM appears to be more successful in its missionary orientation than would normally be expected, given its attendees have had little or no previous missionary education or training. IWM is able to prepare its attendees for effective cross-cultural service in only 4-6 weeks. I believe two major factors that contribute to this effectiveness are IWM's goals and its orientation 
purpose. The goals are valid, comprehensive, needs-based, and responsive to both individual/group needs. In addition, they are organized around an orientation purpose that builds on the expectant motivation of its attendees. Through its goals and purpose, IWM attempts to provide optimum readiness for its attendees to learn during the program and to enter the foreign context. IWM also seeks to initiate or continue the cross-cultural adjustment process of its attendees during its program. An important factor in attendee readiness and adjustment is IWM's deliberate creation of a "family" because it provides support and security at a critical time in the cross-cultural transition of its attendees.

Orientation goals and readiness

Every IWM goal makes a contribution to participants' readiness for crosscultural leaming and eagemess to enter the new experience because they have been organized around an orientation purpose. Aspects of each of the 12 goal areas increase cross-cultural learning readiness by creating awareness, impacting the emotions, or helping to meet the survival needs of participants. For instance, the strongly appreciated nurturing climate is created by the goal of Fellowship, the program goal that "glues" the others together into a unity. The earliest and most noticeable learning is a result of implementing the goal Awareness. Attitudes, Transformation, and spiritual goals of Faith and Call/Commitment impact readiness/eagerness directly; and the felt needs of participants are most expressed in the desire for survival-type information, such as are met by goal areas of Health, 
Area Studies, Roles, and even Policies. Participants consistently point to the need to learn cross-cultural Competencies and to understand Issues because they recognize these as the core of cross-cultural learning, "the real thing." Thus, all IWM goals worked together to achieve the readiness essential for and distinctive of orientation.

Improvement through goal expansion

Although the Institute's orientation program is comprehensive enough to prepare for effective cross-cultural ministry, some changes could increase its effectiveness, and consequently the effectiveness of missionary service. IWM could enhance its preparation for women, children, and singles by addressing their particular needs in greater depth within the goal areas, and by approaching the orientation aim from a stronger family basis. Furthermore, missionary service effectiveness would improve if prospective SDA missionaries attained some aspects of the goals before the Institute, and if there was provision for continued learning during service in the field. To the extent that IWM can encourage/implement these opportunities, or other learning provisions are made, IWM will be able to modify its orientation goals and goal emphases, and thus strengthen its impact on preparation.

\section{Conclusions Related to}

Suitability of Goals

Area Studies

Participants consistently requested more Area Studies. Literature indicates that a demand for more Area Studies is a common problem for pre-departure 
programs because those preparing to depart typically feel they never know enough about the new place. For IWM, there is an additional explanation, however. The intended meaning of the goal Area Studies and the meaning participants perceive differs. When IWM participants demand more Area Studies, they usually hope to discover such context details as window size and shopping opportunities; when literature and practice refer to Area Studies, they usually connote information about the country's geography, politics, economy, history, culture, and other related details. The disparity illustrates the theory that sojoumers feel a stronger need for survival information as they approach departure during the 6 months prior to it. The timing of IWM (usually 1 to 2 months before departure) helps explain the contrast.

IWM staff are happy to provide what information they may have about such living arrangements in a particular locality, but this is not the responsibility of the Institute nor intended content for the Area Studies goal. It is neither possible nor advisable to spend already-packed program time providing such logistic details. An orientation program for persons who had already learned culture specific knowledge would not have the same struggle as IWM in this area. One two-fold solution for relieving the tension is to provide adequate living arrangement details prior to IWM, or in some other way provide opportunities for missionaries to continue learning Area Studies information after they are settled in the cross-cultural context. 


\section{Fellowship}

The experience of orientation fellowship in which to prepare for departure appears to make such a beneficial contribution to the transition adjustment of missionaries that it should definitely be a part of pre-departure preparation. One of the best ways to provide this opportunity is through orientation programs. Although missionary pre-departure preparation can (and should) be delivered by several leaming modalities, the orientation program must not be eliminated. The distinctive qualities of orientation programs to meet sojoumer adjustment needs assure its necessity.

Conclusions Related to the Research Study

Population groups

The responding church leaders and current/retumed missionaries for the empirical part of the study appear to be a representative cross-section of the total possible population.

Implementation variation

The perceptions of attendees concerning the validity of goals were influenced by the staff/participant interpersonal dynamics and the content/methods of presentation, a fact observed and reflected in their end-of-session evaluation forms. Interpersonal/content variation did not appear to alter the validation findings significantly, however. 
General research support

One of my research goals was to build on the findings of previous research. Many of the case study populations' perceptions confirm and support missionary and general cross-cultural research.

IWM as model

IWM's finalized goals can serve as a useful model to guide planning for pre-departure missionary preparation, as well as for orientation programs, because it is comprehensive.

Goal categories

The categorization of goals based on participant needs into a personal/professionai/practical schema is useful.

Program goal selection

Goal selection and degree of program goal emphasis is contingent upon the needs of the particular program purpose, staff, and individual participants of a given orientation session.

\section{Missionary Orientation Preparation}

Despite the widespread diversity in missionary preparation models, there are several conclusions from this goals study that contribute to a greater understanding of the commonalities in the orientation process, missionary needs, and future directions. 


\section{Conclusions Related to \\ Orientation Programs}

Even if participants have not received cross-cultural missionary preparation before attending an orientation program, a single comprehensive orientation program can provide satisfactory preparation for missionaries about to go overseas if two factors (besides effective methodologies) exist. The first relates to the recruitment and appointment of prospective attendees. Candidates should not have abnormal needs; they should be professionally equipped for their appointment, and must have spiritual strength and a sense of call/commitment, or attain it during the orientation program. It is also generally true that the more traits important for effective cross-cultural service a candidate possesses, the more effective the preparation and service will be.

The second relates directly to orientation programs. Programs should possess both breadth and an orientation purpose in order to meet missionaries' real/felt needs. Breadth means attendees should have an overall, integrated view of their needs and future challenges before departing, in addition to a minimum attainment of the goais deemed suitable and/or necessary. Orientation purpose means that the program should create in its participants a learning readiness and an eagerness for the appointment, besides providing support/security and transition/survival information.

Such a single program will face some basic limitations, however. Concluding from IWM's program, these will likely include inadequate cross-cultural 
skills development, a measure of program inefficiency due to content overload and limited time for participant reflection, and a difficulty in meeting unique individual participant/family unit needs. Additional preparation prior to the orientation program and during service in the field would help remove limitations and enhance the effectiveness of such a single program considerably.

\section{Conclusions Related to Suitable Preparation Goal Areas}

\section{Twelve goal areas}

Based on this research, pre-departure orientation preparation for crosscultural missionaries should contribute to the readiness of the appointed family unit in twelve areas critical to their service effectiveness. These $\mathbf{1 2}$ goal areas are: cross-cultural Awareness and Skills/Competencies, a sense of Call/Commitment, Spiritual formation and growth, essential emotional growth and Attitudes development, cultural understanding from Area Studies and mission Issues, knowledge and practices important for new Roles and psychological/physical Health, familiarity with the sending organization's Philosophy/Practices/Policies, a paradigm shift for continuing growth through the Transformation of the mind/worldview, and Fellowship which is a critical program goal for achieving an "orientation" purpose. The four major cross-cultural skill areas needed are: adjustment/adaptation, communication, interpersonal relationships, and leaming-to-learn. It is ideal for an orientation program to prepare participants to meet those goals in which they still have needs. 


\section{Trait goals}

Missionaries need certain traits and qualities as well as knowledge, motivations, and skills to be successful in cross-cultural service. There are no clear lines separating traits and leaming for designing preparation. This study shows the importance of including orientation goals that seek to strengthen the participant qualities that are important for candidate selection. These may include spiritual and psychological aspects in addition to Christian beliefs and values.

\section{Providing program flexibility}

Provision for meeting the needs of particular session groups as well as individual needs within those groups requires a flexibility that should be reflected in the goals. When needs assessment brings these to the staff's attention, plans should be made to meet them. A generic goal, such as IWM's goal addressing crosscultural missionary Issues, is useful for enabling the program to respond to the needs of the particular group and each individual.

\section{Learning-to-learn skills}

It is essential to equip candidates for continuing growth in cross-cultural leaming throughout life. This skill is becoming one of the most critical for the future. Two elements are required for learning-to-learn: (1) a change of mindset/worldview, or paradigm shift as it is sometimes referred to, which provides 
the indispensable motivation; and (2) the development of basic skills for continuing to leam, such as observation and resource management.

\section{Conclusions Related to Planning Principles for the Future}

How to plan for future pre-departure orientation is an important question at a time of rapid change and growing diversity. In addition, orientation preparation will need to provide for much larger numbers of missionaries with more diverse needs than it previously has if the pace and complexity of world evangelization continues to accelerate. Trends demand that preparation for each participant/family unit be as relevant and complete as can be provided.

Several conclusions arising from the findings of this study provide insights that address trends and issues for the flexibility pre-departure orientation will require in the future. The findings highlighted several planning principles that relate to the determination of goals. Implementing these principles will contribute to providing more effective orientation in the future. They include:

\section{Participant/family-centered}

People are the key for cross-cultural preparation because the missionary task is communicating a message clearly to others in the context of trust built on interpersonal relationship. Effective preparation attempts to meet the particular needs of its candidates to enable this clear communication. As people, contexts, and appointments become more diverse and complex, the necessity of focussing on the 
participants to be prepared will become more critical. In addition, responsible planning should be flexible enough to respond to the preparation needs of the family unit whether within or outside of the orientation program.

\section{Neeck-based goal determination}

Rapid change and diversity makes holistic preparation more difficult because needs are harder to recognize. All pertinent sources for determining needs/goals should be utilized. Thus, goals will be more relevant if they have been determined by examining the needs of the persons, appointment, context, and preparation purpose. They will also be more valid if both research and theory are also explored and incorporated. It is true that general cross-cultural theory and methods could make an invaluable contribution if applied to the missionary model. (Missionary orientation principles could also make a greater contribution than has been made to general cross-cultural training literature.) The strategy of using all pertinent sources has the advantage of combining all needs into an integrated approach for comprehensive, continuous, and individualized preparation that is more responsive to the future than most others. Needs assessment procedures are well defined and easy to use.

\section{Preparation context planning}

The determination of pre-departure orientation and program goals should be made within the parameters of the larger preparation context. Preparation begins with recruitment and ends with re-entry into the home country. Only when 
orientation is planned with the entire preparation cycle in mind will preparation be comprehensive enough to eliminate gaps. Even though it is true that goals are essential for every stage of preparation, goal selection will vary according to the purpose, design, delivery format, resources, and participant needs of any given stage. Thus, planning should begin on the macro-level (to determine what goal/need areas should be met during which part of the preparation cycle) and end on the micro-level (to determine the goals/needs of specific persons in a particular stage, such as pre-departure orientation).

\section{Appropriate goal sequencing}

Several factors influence which goals to select on the basis of sequence considerations. Cross-cultural learning is developmental, so goal sequence should correspond to the multidimensional and developmental aspects of cross-cultural learning. Sequence should also be influenced by the stage of preparation cycle and how it impacts participants' real and felt needs. Even the degree of diversity in participants' previous preparation and experience history means that leaming entry levels and integration needs will vary. Trends in our world indicate the range of needs will continue to widen. Preparation that is sequenced will be more effective than that which is not.

\section{Shared responsibility for learning}

Adult education theory and cross-cultural training literature emphasize the need for adult leamers to be a part of the decision-making process for learning. 
Aduits who leam best assume a large share of the responsibility for leaming. Sending organizations should study how to motivate and enable candidates to meet all their pertinent needs as well as assume a larger role in their own readiness. This principle will continue to be more important for missionary preparation as trends indicate effective preparation will require increasing flexibility, individualization, and resource management.

Flexible learning modalities and delivery systems

Because the participant group may vary dramatically from session to session, and the primary focus of the orientation program is on group needs, a provision for individualizing opportunities outside the orientation program itself becomes more important. Participants also have different learning styles and preferences. Flexible goal organization, learning modalities, and delivery systems will contribute to more adequate preparation that is more suited to the person/family unit's ability to attain it.

\section{Single-entity guidance}

The above principles and characteristics have prompted me to conclude that, for maximum effectiveness, one entity (organization, group, or individual) should oversee a particular participant/family's preparation. If the participant/family preparation is guided after assessing their needs based on data from all relevant needs sources, a plan suitable for them could be devised. Decisions could be made about sequencing, leaming modalities, delivery systems, and participant-shared 
responsibility that would strengthen the preparation. If this entity were also involved with or responsible for recruitment, selection, and appointment, the preparation would be even more comprehensive, more responsive to individualization, and better integrated.

In summary, preparation demands of the future will require utilization of the basic characteristics of effective holistic learning as identified by curriculum theory and practice and missionary needs. Characteristics that have been mentioned in this study include those from the aforementioned planning principles, as well as others: a provision for goal-directed continuous leaming opportunities throughout the preparation cycle, integration with previous experience/preparation, individualization as far as possible, and relevance for the future. Implementation of these characteristics, together with appropriate multi-dimensional methodologies, will improve missionary orientation preparation.

\section{Recommendations}

\section{For Research}

This research is an exploratory study that is designed to stimulate more indepth investigation of most aspects examined. Understanding what is essential for cross-cultural pre-departure missionary orientation would be enhanced by more research in each of the 6 sources used here as well as those sources mentioned as important contributors but not included in this study. 
A formal in-depth study of selected aspects of the literature and research available in missionary and general cross-cultural preparation, and trends/issues for both (Sources 4, 5, or 6), would be particularly helpful for missionary preparation planners. For example, a research study could be designed to establish essential needs and goals by examining cross-cultural adjustment/adaptation, or intercultural competence/effectiveness.

Another important source of information for the setting of goals for missionary orientation that was not included in this study is the biblical/theological source. As mentioned, the foundation of all Christian missionary endeavor--most of which is in some way cross-cultural--is determined and guided by the Bible. If studied and applied to today's world, principles from the Scriptures used as a basis for goal-setting may open new lines of research, may identify faulty presuppositions, and may stimulate new insights for mission in the 21 st Century. A study of the whole process of preparation for cross-cultural experience would be useful to develop altemative orientation approaches, or possible ways to achieve goals outside of orientation programs, and to determine which goals are best achieved within a formal program. Another study could examine alternative methods of delivering preparation, especially those utilizing today's technologies.

Finally, the perceptions of the indigenous rank-and-file of the host culture (along with a larger number of national leaders than examined in this study) should be explored. Host views of what constitutes an effective missionary would undoubtedly make a contribution to understanding the elements/goals of effective 
missionary orientation, especially if compared with how hosts perceive the nature and level of current missionary effectiveness.

\section{For Missionary Cross-Cultural Preparation}

In light of missionary trends both within the Seventh-day Adventist organization and the larger missionary context, study should be given to the future needs of missionary preparation in order to make better long-range plans for meeting them. Of primary importance is provision for greater flexibility in meeting the unique needs of individuals, organizations, and mission frontiers, within the parameters of resource constraints while taking full advantage of today's technological opportunities.

It would be beneficial if organizations established or delegated responsibility for cross-cultural preparation, and required accountability, from a single entity for guiding the overall preparation process of every person/family unit's needs. The entity should share the responsibility for planning and implementation with the participant/family. The planning should be based on the purpose for the cross-cultural assignment, organizational constraints, and individual/family needs. Since the planning would cover the entire missionary cycle, coordination of preparation would be more possible, which would help to eliminate gaps in the preparation and make it responsive to the future needs of the participant/family. As an extension of the above recommendation, it would be useful if mission sending-organizations would study how to organize their goals into units 
based on the preparation cycle needs of their missionaries (including sequence considerations), and potential unique needs of individual/family units. They could then plan for each appointee family's needs based on type of mission, expected length of service, specific contextual needs, personal needs, appointees' background and experience, and logistic/transition concerns. An individualized plan could be structured and modified according to available resources (time, funding, materials), and implemented by creative strategies.

Numerous approaches could be taken. One scenario could be to begin the preparation of individual/family units who are interested in future service by making them aware of their needs, such as a sense of call, and by appealing to them to begin (or continue) their preparation process. This could lead to an extensive needs assessment of those individual/family units who wish to begin preparing themselves for prospective mission service. The assessment could include an examination of backgrounds/experiences, personal/mission goals, and assessment of the spiritual, psychological, social, and educational readiness, as well as leaming style preferences. From the needs assessment would come an individualized goal plan based on needs and available resources. This plan could be organized around any of several different units. For instance, because the pre-departure orientation program is essential, it could be the initial unit selected for consideration around which the rest of the preparation plan would be organized and developed. Or it could be selected as the final unit after which all needs able to be met outside orientation have 
been taken care of. The plan could take advantage of the multifarious learning opportunities available today.

\section{For Institute of World Mission}

It would be helpful to the Institute staff if some forms of pre-departure preparation could be developed and delivered prior to the orientation program to ease the amount of preparation it is required to provide to complete the predeparture phase of preparation. One benefit would allow IWM to have more time to integrate the previous preparation. Another benefit would be a greater time allowance within the program itself to provide participants practice in critical crosscultural skill development. Ways to provide stronger cross-cultural, interpersonal, and communication skills development could be explored and developed if time permitted, particularly in areas such as attribution training, interpersonal skills development especially for building relationships with nationals. and stress/conflict management.

In cooperation with the General Conference, IWM should to do more to provide additional resources for understanding the specific foreign context to which each participant is appointed if resources are available and IWM is notified early enough.

The Institute should emphasize more strongly the need for participants to continue active growth in leaming after entering their field of service. Participants 
could be shown how to recognize goal achievement in their leaming and service, and how to continue learning skills development.

Although the Institute should study ways to enhance a family-centered orientation during the Institute, the General Conference Secretariat should take steps to provide the resources to meet the special preparation needs of women, children, singles, and other specific groups. The General Conference should also study how the preparation needs of all classes of unprepared volunteers can be met, whether short-termers or tentmakers. Serious consideration should also be given to providing overseas communication in the form of a journal and/or newsletters to continue encouraging the sense of community, and to provide additional opportunities for continued leaming.

Preparing missionaries through cross-cultural orientation training is only one of the organizational responsibilities of the Institute of World Mission . Two others are conducting research and building constituent awareness by "marketing" missions. In this day of vast needs and growing interest, the General Conference should consider providing additional resources to meet these responsibilities more fully. An awareness campaign could include opportunities for meeting some aspects of the preparation that prospective missionaries will eventually need, which would improve preparation prior to recruitment and appointment. 
APPENDIX

Reproduced with permission of the copyright owner. Further reproduction prohibited without permission. 


\section{APPENDIX A. QUESTIONNAIRES}

Institute of World Mission: Missionary Orientation Session Evaluation . . . 330

Research Study Questionnaire: Institute of World Mission . . . . . . . . . 334

Research Study Questionnaire: Mission Agency Directors . . . . . . . . 338 
Institute of World Mssion

\title{
Missionary Orientation Session Evaluation
}

\begin{abstract}
Directione: In the Interoet of making tho next Inetitute wore offlelent and zelevent. we zequect that you reepond to the following guevelone. The noze epecille your anowers exe. the more helplul they becowe.

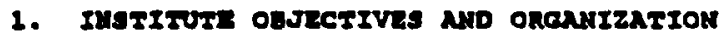

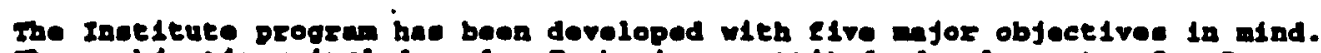

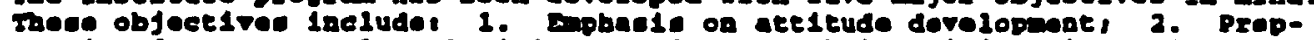

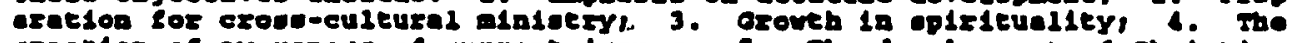

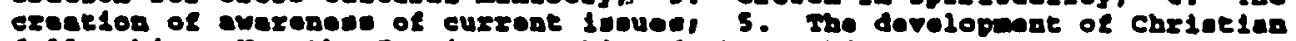
eallowablp. Hee tho Inatitute achlored those objectiver?
\end{abstract}

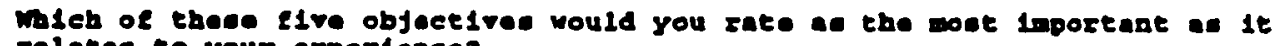
zedated to your experience?

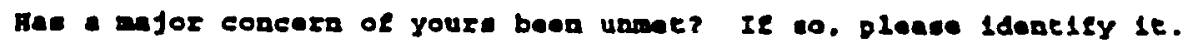

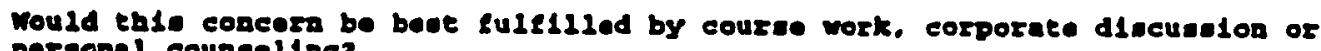
perseasl councellng?

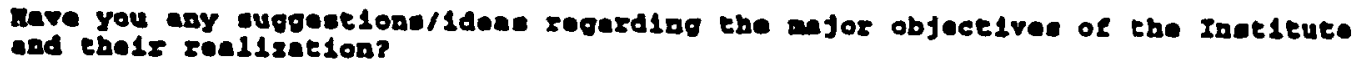

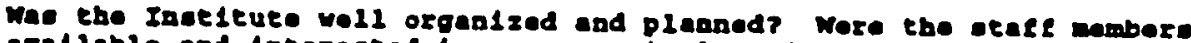
arallable and Interented in your part cular astuation?
} 


\section{INSTRUCTION}

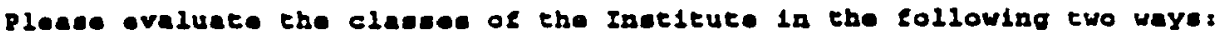

A: Check the number which bast Ejes your evaluacion

1. Excellent: These classes provided a diversitied yet comprehensive and balanced approach; the presentations were stimulating, persuasive, wall organized. and relavant to our preparation.

2. Cood: These classes were dbly presented, covering important material for our preparation, but were not of the caliber of organtzacion. presentation. and relevancy as the category above.

3. Pele: While this class material was important, it was poorly organized and presented.

4. Delece: These elasses wero poorly preșented and the material was not necessary for our mission preparacion.

B. In the space to the eight of the numerical avaluation. add spacific coments chat will heip us make our Insticute sessions more efficient and rolovant.

Classes taught by Jon Dybdahl:

1.

2.

3.

4.

Classes taughe by Reinder Bruingma

1.

2.

3.

4.

Classes Eaughe by Tony Brandon

1.

2 .

3.

4.

Personal Counseling

1.

2 .

3 .

s.

Classes eavahe by Albert Whit ing

1.

2.

3.

4.

Clasege taughe by Rowena Rick (CC Treasury)

1.

2.

3.

4. 
Classes eaught by Athal Tolhurse

1.

3.

4.

Class raughe by Charles Warson

1.

2.

3.

4.

Classes taught by Nancy Vyhmeister

1 .

2.

3.

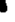

Class eaught by Gail Ormsby (ADRA)

1.

2.

3.

4.

Ilass taughe by Ken Flemmer (ADRA)

1.

2.

3.

4.

Madol Female Meetings

Male

Female

1.

2.

3.

1.

2.

3.

4. Films: Were the films of such a nature that they enhanced cross-cultural
ministry, sensitivity, and understanding?

1.

2.

4.

Worahip Falks: Did the worship talks engender a spiritual actitude and promote idas about the maintenance of missionary spirituality?

1.

2.

3. 
Special Issues in Mission Classes

1 .

2.

4.

hae the Inetitute left you with important questione unanawered or needa unmet? It so, pleave utate them.

Do you conelder come of the uubjecte covered unimportant? If so, what could beat be lete out?

III. SOCIAL ACTIVITIES

Were the goclal ectulties of the neture that they foetered a cenes of fellowblp and compunity?

1.

2.

3.

4.

What were the mose meaninglul soclal activitlon?

What were tho leat mentingtul woclal activitlea?

suggestlone for luture noclal activities?

IV. ACCOMadodison

Were the eccomodations sat1utactory? Yes No

Do you beve any couneel on how to 1mprove your bome-away-tron-bome tor this noneh?

4 


\section{BACKGROUND INFORMATION}

PLEASE CIRCLE ONE LETTER for each question (except *7) that answers it mast accurately.

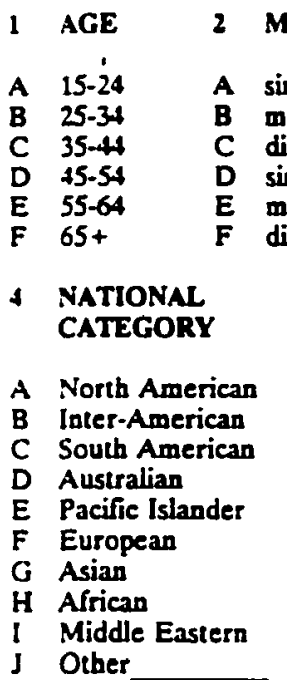

MARTAL STATUS

single male

married male

C divoreed male

single female

married female

divorced female

\section{CURRENT OCCUPATION}

A church administration USA G medital/hualth

B administration outside USA II publishing/media

C clerical/secretarial i pastural/evangelistic

D construction/maintenance J develonnent/relite

E tcchnical/aviation $K$ educational

F homemaker

\section{PRE-ADULT} BACKGROUND

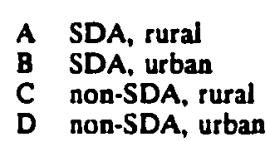

D non-SDA, urban

\section{Highest Level}

Completed

A secondary

B vocational training

C some collcge work

D associate degrec

E bachulor's degree

$F$ graduate work

$G$ master's degree

$H$ doctoral degrec

I wther

\section{EDUCATION}

Circle All Areus You Have Taken College-level Wark in

A Bible, religion

B missiuns

C church growth

D communications

E anthropology

F cross-cultural studics

(i world history

H current world alfairs

Questions \&-14 RELATE TO MISSION SERVCE, and should be fllled oul by thase who hove been missionaries. or are aurenly in the field of under appointment PLEASE CIRCLE ONE LETTER per question (except \#/A).

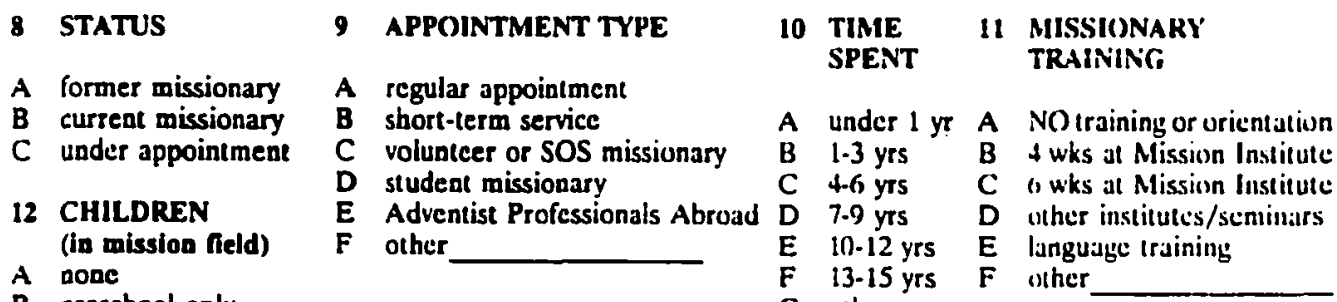

B preschool only

C schoolage only

D boch preschool/schoolage

13 TYPE OF SERVICE

A church administration
B clerical/secretarial
C construction/maintenance
D iechnical/aviation
E homemalker
F medical/health
G publishing/media
H pastora/evangelistic
I development/relief
J educationa
K other

\section{REASONS FOR RETURN (circle ull that apply)}

A assignment accomplished
B new appointment/opportunity
C govt/political factors
D leadcrship/administration
E physical health
F emotional health
G spouse needs
H aeeds of relatives
I resignation
J adjustment difficultics
K exernal circumstances

$L$ education nceds--sell/spousc $M$ education needs--chiluren $N$ family crisis O dissalisfaction/disappointment P nationalization

Q other

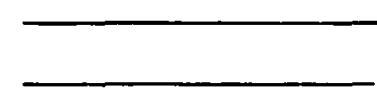




\section{GOALS VALIDATION}

MISSION INSTITUTE GOAL STATEMENTS: Mission Institutc is a 4-6 wcek predcparture training program. Its AIM is: TO HELP MISSIONARY APPOINTEES BE EFFECTIVE IN CROSS-CULTURAL MINISTRY IN GENERAL. AND IN THEIR RESPECTIVE FIELDS IN PARTICULAR.

PLEASE RANR the following 12 gaal statements (desigred to meet th: above AIM) according to the importance you mech wo each in preporing misrionaries for crass-aultural ministy. CIRCLE according to the following: $1=$ not important $2=$ somewhat important $3=$ important $\quad+=$ very importunt $5=$ extremely importint

1 To clarify church and agency policies and their application

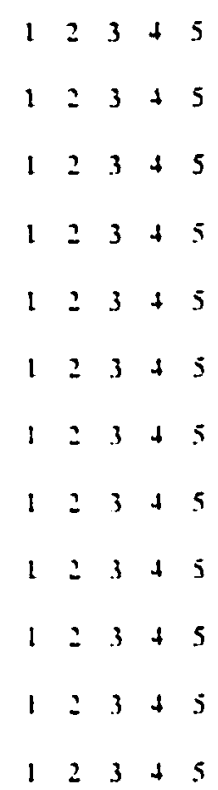

2 To enlarge the understanding of current issues in world mission

3 To facilitate growth in the experience of faith

4 To create an awareness of the essential role of culture in ministry

5 To further the development of attitudes vital to effective ministry

6 To identify and foster essential cross-cultural competencies

7 To increase knowledge and understanding of role expectations

8 To nurture community, fellowship and relational skills

9 To strengthen the sense of call and cummitment to mission

12 To equip for continuing growth by mindset transformation

PLEASE CIRCLE the numerd in front of any of the goals listed above that you did not or would not expect for a micrionary orining progem.

PLEASE CIRCLE the appropriate choices below 10 express your opinions regarding the 12 gow stotements. Use the following comogovies:

FOR EXAMPLE:

$$
\begin{aligned}
& \text { SD }=\text { Strongly Disagrce } \\
& \mathbf{D}=\text { Disagrec } \\
& \mathbf{U}=\text { Undecided } \\
& \mathbf{A}=\text { Agrec } \\
& \mathbf{S A}=\text { Strongly Agrce }
\end{aligned}
$$

If you agree that the goal is CLEAR and ATTAINABLE, and you disgorec that it is FEASIBLE, and you are undecided if it is MEASURABLE, and strongly aprec that it is RELEVANT, but stronely disigurcec that it is ESSENTIAL, your answer would look like this:

CLEAR
ATTAINABLE
FEASIBLE
MEASURABLE
RELEVANT
ESSENTIAL

(goal is easily understood)

(goal can be accomplished by participants) (training for goal can be carried out by MI)

(achicvement of goal discernable)

(goal is appropriate and timely)

(goal is necessary for effective preparation)

$\begin{array}{lllll}\text { SD } & D & U & A & \text { SA } \\ \text { SD } & D & U & A & S A \\ \text { SD } & \text { D } & U & A & S A \\ \text { SD } & D & \bigcup & A & S A \\ \text { SD } & D & U & A & \text { SA } \\ \text { SD } & D & U & A & S A\end{array}$


1 To charify church and agency policies and their application.

This goal is:

$\begin{array}{llllll}\text { CLEAR } & \text { SD } & \text { D } & \text { U } & \text { A } & \text { SA } \\ \text { ATTAINABLE } & \text { SD } & \text { D } & \text { U } & \text { A } & \text { SA } \\ \text { FEASIBLE } & \text { SD } & \text { D } & \text { U } & \text { A } & \text { SA } \\ \text { MEASURABLE } & \text { SD } & \text { D } & \text { U } & \text { A } & \text { SA } \\ \text { RELEVANT } & \text { SD } & \text { D } & \text { U } & \text { A } & \text { SA } \\ \text { ESSENTIAL } & \text { SD } & \text { D } & \text { U } & \text { A } & \text { SA }\end{array}$

2 To enlnge the understanding of current lsoues in world mission.

This goal is:

$\begin{array}{llllll}\text { CLEAR. } & \text { SD } & \text { D } & \text { U } & \text { A } & \text { SA } \\ \text { ATTANABLE } & \text { SD } & \text { D } & \text { U } & \text { A } & \text { SA } \\ \text { FEASIBLE } & \text { SD } & \text { D } & \text { U } & \text { A } & \text { SA } \\ \text { MEASURABLE } & \text { SD } & D & U & \text { A } & \text { SA } \\ \text { RELEVANT } & \text { SD } & \text { D } & \text { U } & \text { A } & \text { SA } \\ \text { ESSENTIAL } & \text { SD } & \text { D } & \text { U } & \text { A } & \text { SA }\end{array}$

3 To folliente growth in the expertence of faith.

This goal is:

$\begin{array}{llllll}\text { CLEAR } & \text { SD } & \text { D } & \text { U } & \text { A } & \text { SA } \\ \text { ATTAINABLE } & \text { SD } & \text { D } & \text { U } & \text { A } & \text { SA } \\ \text { FEASIBLE } & \text { SD } & \text { D } & \text { U } & \text { A } & \text { SA } \\ \text { MEASURABLE } & \text { SD } & \text { D } & \text { U } & \text { A } & \text { SA } \\ \text { RELEVANT } & \text { SD } & \text { D } & \text { U } & \text { A } & \text { SA } \\ \text { ESSENTIAL } & \text { SD } & \text { D } & \text { U } & \text { A } & \text { SA }\end{array}$

4 To create an awareness of the essentivl role of culture in ministry.

This goal is:

CLEAR

ATTANABLE

U A SA

SD $D$ U A SA

MEASURABLE SD D U A SA

RELEVANT SD D U A SA

ESSENTIAL SD D U A SA

5 To further the development of

attludes vital to effective ministry.

This goal is:

CLFAR

SD D U A SA

SD $D$ U $A$ A

MEASURABle SD D U A SA

RELEVANT SD D $U$ A SA

ESSENTIAL SD D U A SA

6 To ldentify and foster

essentivl cross-cultural competencies.

This goal is:

$\begin{array}{llllll}\text { CLEAR } & \text { SD } & \text { D } & \text { U } & \text { A } & \text { SA } \\ \text { ATTANABLE } & \text { SD } & \text { D } & U & \text { A } & \text { SA } \\ \text { FEASIBLE } & \text { SD } & \text { D } & \text { U } & \text { A } & \text { SA } \\ \text { MEASURABLE } & \text { SD } & \text { D } & \text { U } & \text { A } & \text { SA } \\ \text { RELEVANT } & \text { SD } & \text { D } & \text { U } & \text { A } & \text { SA } \\ \text { ESSENTIAL } & \text { SD } & \text { D } & \text { U } & \text { A } & \text { SA }\end{array}$

7 To increase knowiedge and understanding of role expectations.

This goal is:

$\begin{array}{llllll}\text { CLEAR } & \text { SD } & \text { D } & \text { U } & \text { A } & \text { SA } \\ \text { ATTAINABLE } & \text { SD } & \text { D } & \text { U } & \text { A } & \text { SA } \\ \text { FEASIBLE } & \text { SD } & \text { D } & \text { U } & \text { A } & \text { SA } \\ \text { MEASURABLE } & \text { SD } & \text { D } & \text { U } & \text { A } & \text { SA } \\ \text { RELEVANT } & \text { SD } & \text { D } & \text { U } & \text { A } & \text { SA } \\ \text { ESSENTIAL } & \text { SD } & \text { D } & \text { U } & \text { A } & \text { SA }\end{array}$

8 To nurture community, fellowship, and relational skills.

This goal is:

CLEAR $\quad$ SD D $U$ A SA

ATTAINABLE SD D U A SA

FEASIBLE SD D $U$ A SA

MEASURABLE SD D U A SA

RELEVANT SD D U A SA

ESSENTIAL SD D U A SA

9 To strengthen the sense of call and commitment to mission.

This goal is:

CLEAR

SD $D$ U $A$ SA $\begin{array}{llllll}\text { FEASIBLE } & \text { SD } & D & U & A & \text { SA }\end{array}$ MEASURABLE SD D U A SA RELEVANT SD D U A SA ESSENTLAL SD D U A SA

10 To teach and encourage appropriate mental/physical health practices.

This goal is:

- ClEAR SD D U A SA ATTAINABLE SD D U A SA FEASIBLE SD D U A SA MEASURABLE SD D U A SA RELEVANT SD D U A SA ESSENTLAL SD D U A SA

11 To provide orientution to

respective world areas of service.

This gool is:

$\begin{array}{llllll}\text { CLEAR } & \text { SD } & \text { D } & \text { U } & \text { A } & \text { SA } \\ \text { ATTAINABLE } & \text { SD } & \text { D } & \text { U } & \text { A } & \text { SA } \\ \text { FEASIBLE } & \text { SD } & \text { D } & \text { U } & \text { A } & \text { SA } \\ \text { MEASURABLE } & \text { SD } & \text { D } & \text { U } & \text { A } & \text { SA } \\ \text { RELEVANT } & \text { SD } & \text { D } & \text { U } & \text { A } & \text { SA } \\ \text { ESSENTIAL } & \text { SD } & \text { D } & \text { U } & \text { A } & \text { SA. }\end{array}$

12 To equip for continuing growh by mindset transformation.

This goal is:

$\begin{array}{llllll}\text { CLEAR } & \text { SD } & \text { D } & \text { U } & \text { A } & \text { SA } \\ \text { ATTAINABLE } & \text { SD } & \text { D } & \text { U } & \text { A } & \text { SA } \\ \text { FEASIBLE } & \text { SD } & \text { D } & U & \text { A } & \text { SA } \\ \text { MEASURABLE } & \text { SD } & \text { D } & \text { U } & \text { A } & \text { SA } \\ \text { RELEVANT } & \text { SD } & \text { D } & \text { U } & \text { A } & \text { SA } \\ \text { ESSENTIAL } & \text { SD } & \text { D } & \text { U } & \text { A } & \text { SA }\end{array}$

AS A GROUP these goals are COMPREHENSIVE enough for preparation: $\quad$ SD D U A SA

CRCTE THE NUMERAL in frone of EACH of the 12 goals above for which you believe you have evidence that it is effectivets anained by thase who have arrended Mission Instinuce. 


\title{
GOALS ATTAINMENT
}

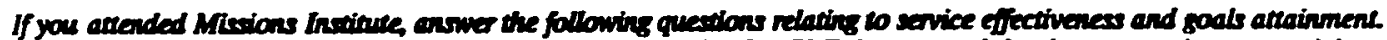

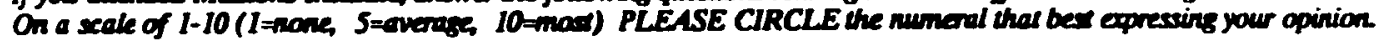

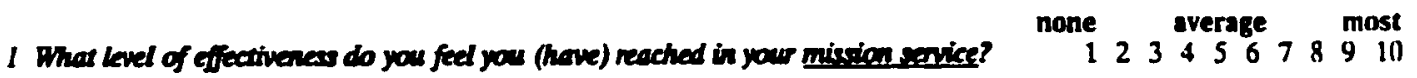

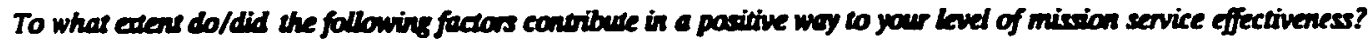

2 personality/temperament $122344567789910 \mid 10$ political/economic aspects 12234456789910

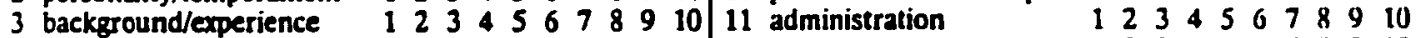

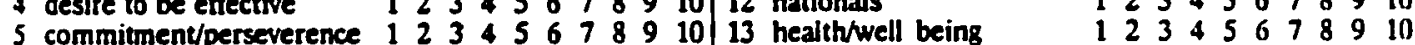
6 spirituality/sense of call $\quad 12534556789910 \mid 14$ M. Institute experience $\quad \begin{array}{lllllllllll}2 & 3 & 4 & 5 & 6 & 7 & 8 & 9 & 10\end{array}$ 7 fiexibility/openness $\quad 12345678910$ 15 M. Institute information 1233456789 lil

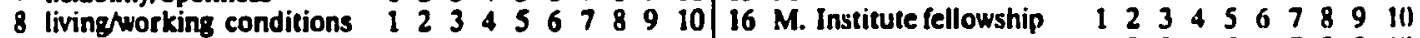

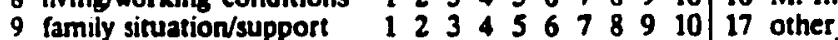
1253445667889111
\end{abstract}

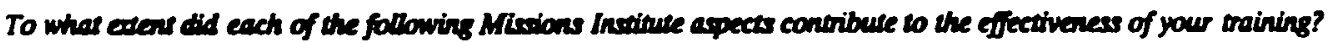

lecrures/discussions in:

18 -missions anthropology $12234567789910 \mid 25$ simulation games

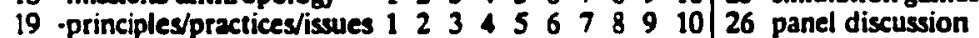

20 -physical \& mental health 12234456778991027 films

21 -policies $\quad$. $\quad 12334567891028$ work on committees

22 -area studies $\quad 1234567891029$ living together in dorms

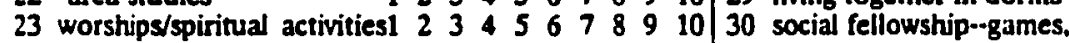

24 dedication/communion 12345678910 parties, trip, program
12345678910

$\begin{array}{llllllllll}1 & 2 & 3 & 4 & 5 & 6 & 7 & 8 & 9 & 10\end{array}$

12344567789910

12345678910

12334566789910 12345678910

PLEASE CRCLE the chaice that eppresees your opiniones:

SD (stongt' disagree), D (disagee), U (undecided), A (agreeh SA (strongh) agree).

31 At MI. I became well-informed of policies relevant to my mission life and work. 32 In the field. I found my work easier because I was able to apply necessary policies. 33 I became more aware of current issues in world mission while attending MI. 34 In the field, my work was more successful because of my understanding of these issues. 35 I experienced growth in my faith and dependence on God during MI.

36 My grown in faith at MI helped me when times were tough in the field.

37 Before MI, I didn't realize how important understanding culture is in mission. 38 My effectiveness improved because I made a conscious effort to apply what I learned. 39 During MI. I made progress in developing attitudes vital to cross-cultural ministry. 40 In the field, my attitude change enabled me to see from the local people's viewpoint. 41 I was able to identify and learn several essential cross-cuitural skilis during MI. 12 My service was more effective because I applied many cross-cultural skills I learned. $43 \mathrm{MI}$ helped me understand how to fill the various roles I had in the mission field. 44 I functioned reasonably well in the different roles expected of me in the field. 45 During MI, the group of teachers and participants became like a family to me. 46 I was more able to relate and identify with the local people because of MI fellowship. 47 At MI. I developed a stronger sense of call and commitment to mission service. 48 The sense of call and commitment increased my courage and satisfaction in the field. $49 \mathrm{M}$ l provided escential information regarding appropriate mental/physical practices. SO I found most of the information on mental/physical health practical for daily life. $51 \mathrm{MI}$ provided adequate orientation to my new country, culture, and, living conditions. 52 My effectiveness was greatly improved by the orientation toany region of service. $53 \mathrm{MI}$ increased my resolve to grow in skills and understanding for effective service. 54 I am more effective today because MI taught me how to contine learning and growing.
SI) D U A SA

SI) D U A SA

SI) D U A SA

SI) D U A SA

SI) D U A SA

SD D U A SA

SD D U A SA

SD D U A SA

SD D U A SA

SI) D U A SA

SU D U A SA

SI) D U A SA

SD D U A SA

SI) I) U A SA

SI) D U A SA

SD D U A SA

SD D U A SA

SD D U A SA

SD D U A SA

SI D U A SA

SI) D U A SA

SI) D U A SA

SD D U A SA

SI) D U A SA

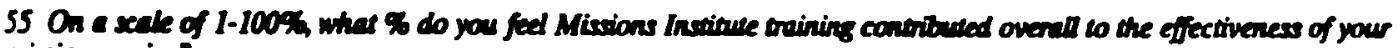
mivion service? 


\section{MISSIONARY PRE-DEPARTURE TRAINING PROGRAMS QUESTIONNAIRE}

Nane of Mrsion Agency

None of Thining Progon/Instimtion/Opmizmion
Cherh Alfitiation

Do you wish 10 recaive a summory of the findings of this quationnainet NOS NO

PLEASE CRCLE the LETTER in from of each hpe of miesionery owining proguen you offer.

\author{
A graduate degree in missions \\ B graduate coursework in missions \\ C undergraduate degree in missions \\ D undergraduate coursework \\ E diplomas in missions
}
$F$ one-year training in missions
G 3-6 month missionary training
H $\quad 1.2$ month missionary training
I pre-departure orientation/training programs no. of weeks? no. of days?

\section{PRE-DEPARTURE TRAINING PROGRAM GOALS AND OBJECTIVES}

If you conduce PRE-DEPARTURE ORIENTATION/TRANING progoms, please eromine cach goal/objective listed and CRCLE each LETTER to the rith chat is ante for your progon. If you dont have this kind of vaining progen, arswer this question acconding 10 what you think SHOULD be ture of one Use this code:

$E=$ Essentlal $S=$ Stated (written gaal) $\quad I=$ Intended (not formally expressed) $\quad D=$ Doesn't apply

1 To clarify church and agency policies and their application

2 To enlarge the understanding of current issues in world mission

3 To facilitate growth in the experience of faith

+ To create an awarencss of the essential role of culture in ministry

5 To further the development of altitudes vital to effective ministry

6 To identify and foster essential cross-cultural competencies

7 To increase knowledge and understanding of role expectations

8 To nurture community, fellowship and relational skills

9 To strengthen the sense of call and commitment to mission

10 To teach and encourage appropriate mental/physical health practices

11 To provide orientation to respecdtive world areas of service

12 To equip for continuing growh by mindset transformation

13 To reinforce, refresh or integrate previous preparation for mission service E S I D

14 To teach a language for the cross-cultural appointment

15 OTHER

COMMENTS are mekame

\begin{tabular}{|c|c|c|c|c|}
\hline $\mathbf{E}$ & $\mathbf{S}$ & 1 & D & COMMENTS \\
\hline $\mathbf{E}$ & $\mathbf{S}$ & I & D & \\
\hline $\boldsymbol{E}$ & $\mathbf{S}$ & I & D & \\
\hline$E$ & $\mathbf{S}$ & I & D & \\
\hline $\mathbf{E}$ & $\mathbf{S}$ & I & D & \\
\hline $\mathbf{E}$ & $\mathbf{S}$ & l & D & \\
\hline$E$ & $\mathbf{S}$ & I & D & \\
\hline $\mathbf{E}$ & $\mathbf{S}$ & I & D & \\
\hline $\boldsymbol{E}$ & $\mathbf{S}$ & I & D & \\
\hline $\mathbf{E}$ & $\mathbf{S}$ & I & D & \\
\hline $\mathbf{E}$ & $\mathbf{S}$ & I & D & \\
\hline $\mathbf{E}$ & $\mathbf{S}$ & I & D & \\
\hline & $\mathbf{S}$ & 1 & D & \\
\hline $\mathbf{E}$ & $\mathbf{S}$ & I & $\mathbf{D}$ & \\
\hline $\mathbf{E}$ & $\mathbf{S}$ & 1 & D & \\
\hline
\end{tabular}

PLEASE select 5 of the above gods you feel we the mart importans and CRRCLE the numeral in front of each. 
PLEASE CRCLE the Leter of EVERY ITEM which ceanuely answes the following questions. If you do not

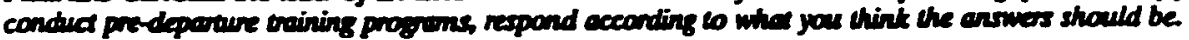

What leads of INFORMATION do you provide?

A policies of mission board or organization

B principles and practices of mission

C missions theology

D missions history

E anthropology for missions

F cross-cultural communications/relations

G comparative religions

H church growh principles

1 area sudies

$J$ language learning

$K$ global awareness and issues affecting mission

L spiritual formation and growh

$M$ culture of both missionary and host people

N psychological topics, such as attitudes

O practical skills

P healib,physical/mental

$O$ Bible doctrines

$\mathbf{R}$ how 10 give Bible studies

$S$ OTHER

What kinds of METHODS do you use?

A lectures

B discussions

C question and answer sessions

D panel presentations

E language learning opportunities

F individual reading programs/opportunities

G group reading programs/opportunitics

H exposure to a different culture

I experiences in a cross-cultural context similar to context of appointment

I experiences in a cross-cultural context different from context of appointment

$K$ simulation games

L culture-general assimilator excreises

$M$ culture-specific assimilator exercises

$N$ prayer bands

O devotional or celebration worships

P Bible study groups

Q dramas

R social activities, as parties, dinners, programs, games, tours

$S$ OTHER

What kinds of MATERIALS do you use?
A visual aids, such as films, videos, slides
B overheads
C maps, diagrams, charts, ete.
D audio tapes, records
E pencil and paper exercises, tests
F texabooks, readings
G. handouts
H OTHER

What is the average number of trainees/session? A 1.9 B $10-24$ C $25-49$ D $50-99$ E $100+$

How often do yow hold training sessions per year? A 1 time B 2 times C 3 times D $4+$ times

Where will the participants serve?

A Latin America $H$ North Africa

B North America I Subsaharan Africa

C Middle East J urban arcas

D Carribean $K$ established institutions

E Occania L unreached pcople groups

F Asia M OTHER

G Europe

What kids of appointments will they nill?

A pastoral $L$ translation/linguistics

B administrative $M$ community development

C medical $N$ literacy training

D agricultural $O$ health/lifestyle training

E cducational $\quad \mathbf{P}$ business cnterprises

F "tent-making" Q Bible/litcraturc distribution

$\mathbf{G}$ youth ministry $\mathbf{R}$ humanitarian/rclicf

$H$ fronticr work $S$ orphan/child care

I media/cassette $T$ technical assistance

$J$ aviation $U$ correspondance courses

$K$ publishing $V$ evangelism/church gromh

W OTHER

What educational background do you require?

A language acquisition

B Bible training

C high school education

D undergraduate degree

E graduate work

F theological coursework

G cross-cultural courscwork

H cross-cultural experience

I OTHER

$J$ none of the above required

What other requirements do you have for those who attend a predeparture training progrum?

A previous experience in appointed work

B psychological assessment

C health clearance

D miscion board acceptance

E ficld appointment

F OTHER

What level of effectiveness do you think you reach?

A greater than expected D average

$B$ fully satisfactory $\quad E$ needs improvement

C mildly satisfactory $F$ unsatisfactory

THANK YOU for your observations. Plense seal this questionsaine and any comments you may wish to make on additional papes, in the asuelope provided and mail immediatefy. 
APPENDIX B. IWM SESSION SCHEDULE, SUMMER 1989

Reproduced with permission of the copyright owner. Further reproduction prohibited without permission. 


\begin{tabular}{|c|c|c|c|c|c|}
\hline & & Institut & $\begin{array}{l}\text { ef world } \\
\text { Sumer. } 1989 \\
\text { schedule }\end{array}$ & Mission & \\
\hline & Monday, June 12 & Tuesday. June 13 & Wed. June 14 & Thurs. June 15 & Friday, June 16 \\
\hline $\begin{array}{r}8: 15- \\
8: 30\end{array}$ & & & Praise and Prayer & Praise and Prayer & Praise and Prayer \\
\hline $\begin{array}{r}8: 30- \\
9: 20\end{array}$ & & & $\begin{array}{l}\text { Opening } \\
\text { Introductions }\end{array}$ & $\begin{array}{l}\text { Missionary } \\
\text { Anthropology }\end{array}$ & $\begin{array}{l}\text { Missionary } \\
\text { Anthropology }\end{array}$ \\
\hline $\begin{array}{l}9: 30- \\
10: 20\end{array}$ & & & Announcements & $\begin{array}{l}\text { Missionary } \\
\text { Anthropology }\end{array}$ & $\begin{array}{l}\text { Hissionary } \\
\text { Anthropology }\end{array}$ \\
\hline $\begin{aligned} & 10: 30- \\
& 11: 20\end{aligned}$ & & & Registration & Area Studies & Area Studies \\
\hline $\begin{array}{l}: 1: 30- \\
12: 00\end{array}$ & & & $\begin{array}{l}\text { Horship } \\
\text { (W. Amundson) }\end{array}$ & $\begin{array}{l}\text { Worship } \\
\text { (G. Oosterwal) }\end{array}$ & $\begin{array}{l}\text { Worship } \\
\text { (G. Oosterwal) }\end{array}$ \\
\hline $\begin{array}{r}1: 45- \\
3: 15\end{array}$ & & & $\begin{array}{l}\text { Library Tour } \\
\text { EGW Estate Tour }\end{array}$ & $\begin{array}{l}\text { Films and } \\
\text { Discussion }\end{array}$ & \\
\hline $\begin{array}{r}6: 45- \\
8: 30\end{array}$ & & $\begin{array}{c}7: 30 \\
\text { Parents' Meeting }\end{array}$ & & $\begin{array}{l}\text { Getting } \\
\text { Acquainted }\end{array}$ & \\
\hline
\end{tabular}

Please sign up for one of the following cumittees: Spiritual Life. Social Activities, Dedication/Lord's Supper, Evaluation 


\begin{tabular}{|c|c|c|c|c|c|}
\hline & Monday, June 19 & Tuesday, June 20 & Wed. June 21 & Thurs. June 22 & Eriday. June 23 \\
\hline $\begin{array}{r}8: 15- \\
8: 30\end{array}$ & Praise and Prayer & Praise and Prayer & Praise and Prayer & Praise and Prayer & Praise and Prayer \\
\hline $\begin{array}{l}8: 30- \\
9: 20\end{array}$ & $\begin{array}{l}\text { Health and } \\
\text { Aygiene } \\
\text { (A. Whiting) }\end{array}$ & $\begin{array}{l}\text { Professional } \\
\text { Meetings }\end{array}$ & ADRA & $\begin{array}{l}\text { Principles and } \\
\text { Practice of } \\
\text { Horld Mission }\end{array}$ & $\begin{array}{l}\text { Principles and } \\
\text { Practice of } \\
\text { Horld Hission }\end{array}$ \\
\hline $\begin{array}{l}9: 30- \\
10: 20\end{array}$ & $\begin{array}{l}\text { Health and } \\
\text { Bvriene } \\
\text { (A. Whiting) }\end{array}$ & $\begin{array}{l}\text { Professiunal } \\
\text { Meetings }\end{array}$ & ADRA & $\begin{array}{l}\text { Principles and } \\
\text { Practice of } \\
\text { Horld Hission }\end{array}$ & $\begin{array}{l}\text { Principles and } \\
\text { Practice of } \\
\text { Horld Mission }\end{array}$ \\
\hline $\begin{array}{c}10: 30- \\
11: 20\end{array}$ & Area Studies & $\begin{array}{l}\text { Professional } \\
\text { Meetings }\end{array}$ & ADRA & Area Studies & Area Studies \\
\hline $\begin{array}{l}11: 30- \\
12: \infty\end{array}$ & $\begin{array}{l}\text { Worship } \\
\text { (A. Whiting) }\end{array}$ & $\begin{array}{l}\text { Horship } \\
\text { (G. Oosterwal) }\end{array}$ & $\begin{array}{l}\text { Norship } \\
\text { (K. Plemer) }\end{array}$ & $\begin{array}{l}\text { Worship } \\
\text { (R. Staples) }\end{array}$ & $\begin{array}{l}\text { Horship } \\
\text { (Instituce) }\end{array}$ \\
\hline $\begin{array}{r}1: 45- \\
3: 15\end{array}$ & $\begin{array}{l}\text { Health and } \\
\text { Hygiene } \\
\text { (A. Whiting) }\end{array}$ & $\begin{array}{l}\text { Bealth and } \\
\text { Bygiene } \\
\text { (A. Whiting) }\end{array}$ & $\begin{array}{l}\text { Pilm and } \\
\text { Discussion }\end{array}$ & $\begin{array}{c}\text { Personality } \\
\text { Profles }\end{array}$ & \\
\hline $\begin{array}{r}6: 45- \\
8: 30\end{array}$ & $\begin{array}{l}\text { Personal } \\
\text { Appointments }\end{array}$ & Recreation & & Recreation & \\
\hline
\end{tabular}




\begin{tabular}{|c|c|c|c|c|c|}
\hline & Monday, June 26 & Tuesday, June 27 & Wed. June 28 & Thurs. June 29 & Friday, June 30 \\
\hline $\begin{array}{l}8: 15- \\
8: 30\end{array}$ & Praise and Prayer & Praise and Prayer & Praise and Prayer & Praise and Prayer & Praise and Prayer \\
\hline $\begin{array}{r}8: 30- \\
9: 20\end{array}$ & $\begin{array}{l}\text { Mental Bealth } \\
\text { (T. Brandon) }\end{array}$ & $\begin{array}{l}\text { Mental Health } \\
\text { (T. Brandon) }\end{array}$ & $\begin{array}{l}\text { Missionary } \\
\text { Anthropology }\end{array}$ & $\begin{array}{l}\text { The Church } \\
\text { in Mission } \\
\text { (H. Battle) }\end{array}$ & $\begin{array}{l}\text { The Church } \\
\text { in Mission } \\
\text { (H. Batele) }\end{array}$ \\
\hline $\begin{array}{l}5 \cdot 30- \\
-0: 20\end{array}$ & $\begin{array}{l}\text { Hental Health } \\
\text { (T. Brandon) }\end{array}$ & $\begin{array}{l}\text { Mental Eealth } \\
\text { (T. Brandon) }\end{array}$ & $\begin{array}{l}\text { Missionary } \\
\text { Anthropology }\end{array}$ & $\begin{array}{l}\text { Missionary } \\
\text { Anthropology }\end{array}$ & $\begin{array}{l}\text { Misstonary } \\
\text { Anthropology }\end{array}$ \\
\hline $\begin{array}{r}10: 30- \\
11: 20\end{array}$ & $\begin{array}{l}\text { Mental Bealth } \\
\text { (T. Brandon) }\end{array}$ & Area Studies & Area Studies & Area Studies & Area Studies \\
\hline $\begin{array}{l}11: 30- \\
12: c 0\end{array}$ & $\begin{array}{l}\text { Worship } \\
\text { (T. Brandon) }\end{array}$ & $\begin{array}{l}\text { Worship } \\
\text { (T. Brandon) }\end{array}$ & $\begin{array}{l}\text { Horship } \\
\text { (R. Staples) }\end{array}$ & $\begin{array}{l}\text { Horship } \\
\text { (M. Battle) }\end{array}$ & $\begin{array}{l}\text { Horship } \\
\text { (H. Battle) }\end{array}$ \\
\hline $\begin{array}{r}1: 45- \\
3: 15\end{array}$ & $\begin{array}{l}\text { Film and } \\
\text { Discussion }\end{array}$ & $\begin{array}{l}\text { Personal } \\
\text { Appointments }\end{array}$ & $\begin{array}{l}\text { Personal } \\
\text { Appointments }\end{array}$ & $\begin{array}{l}\text { Film and } \\
\text { Discussion }\end{array}$ & \\
\hline $\begin{array}{r}6: 45- \\
8: 30\end{array}$ & Recreation & $\begin{array}{l}\text { Personal } \\
\text { Appointments }\end{array}$ & & Bafa-Bafa & \\
\hline
\end{tabular}

- Evaluation Comittee 


\begin{tabular}{|c|c|c|c|c|c|}
\hline & Monday, July 3 & Tuesday, July 4 & Wed. July 5 & Thurs. July 6 & Friday, July 7 \\
\hline $\begin{array}{r}8: 15- \\
8: 30\end{array}$ & Praise and Prayer & $\mathbf{H}$ & Praise and Prayer & Praise and Prayer & Praise and Prayer \\
\hline $\begin{array}{l}8: 30- \\
9: 20\end{array}$ & $\begin{array}{l}\text { Missionary } \\
\text { Anthropology }\end{array}$ & $\mathbf{o}$ & $\begin{array}{l}\text { Principles and } \\
\text { Practice of } \\
\text { Horld Hission }\end{array}$ & $\begin{array}{c}\text { Missionary } \\
\text { Finance }\end{array}$ & AWPS \\
\hline $\begin{array}{l}9: 30- \\
10: 20\end{array}$ & $\begin{array}{l}\text { Missionary } \\
\text { Anthropology }\end{array}$ & $\mathbf{L}$ & $\begin{array}{l}\text { Principles and } \\
\text { Practice of } \\
\text { Morld Mission }\end{array}$ & $\begin{array}{l}\text { Missionary } \\
\text { Finance }\end{array}$ & Insurance \\
\hline $\begin{array}{l}10: 30- \\
11: 20\end{array}$ & Area Studies & $I$ & Area Studies & $\begin{array}{l}\text { Missionary } \\
\text { Finance }\end{array}$ & $\begin{array}{l}\text { Issuas in } \\
\text { Mission }\end{array}$ \\
\hline $\begin{array}{l}11: 30- \\
12: 02\end{array}$ & $\begin{array}{l}\text { Worship } \\
\text { (R. Staples) }\end{array}$ & $\mathbf{D}$ & $\begin{array}{l}\text { Morship } \\
\text { (J. Boyson) }\end{array}$ & $\begin{array}{l}\text { Worshlp } \\
\text { (D. Rogers) }\end{array}$ & $\begin{array}{l}\text { Horship } \\
\text { (Insurance) }\end{array}$ \\
\hline $\begin{array}{r}1: 45- \\
3: 15\end{array}$ & $\begin{array}{l}\text { Language } \\
\text { Learning }\end{array}$ & $\mathbf{A}$ & & $\begin{array}{l}\text { Porsonal } \\
\text { Appointwents }\end{array}$ & $\begin{array}{l}\text { Personal } \\
\text { Appointments }\end{array}$ \\
\hline $\begin{array}{r}6: 45- \\
8: 30\end{array}$ & & $\boldsymbol{Y}$ & Recreation & $\begin{array}{l}\text { Personal } \\
\text { Appointments }\end{array}$ & \\
\hline
\end{tabular}

- Evaluation Committee 


\begin{tabular}{|c|c|c|c|c|c|}
\hline & Monday, July 10 & Tuesday, July 11 & Wed. July 12 & Thurs. July 13 & Friday, July 14 \\
\hline $\begin{array}{r}8: 15- \\
8: 30\end{array}$ & Praise and Prayer & Praise and Prayer & Praise and Prayer & Praige and Prayer & Praise and Prayer \\
\hline $\begin{array}{r}8: 30- \\
9: 20\end{array}$ & $\begin{array}{l}\text { Principles and } \\
\text { Practice of } \\
\text { World Mission }\end{array}$ & $\begin{array}{l}\text { Principles and } \\
\text { Practice of } \\
\text { World Mission }\end{array}$ & $\begin{array}{l}\text { Principles and } \\
\text { Practice of } \\
\text { Morld Mission }\end{array}$ & $\begin{array}{l}\text { The Church } \\
\text { in Mission } \\
\text { (c. Hatson) }\end{array}$ & $\begin{array}{l}\text { The Church } \\
\text { in Mission } \\
\text { (c. Hatson) }\end{array}$ \\
\hline $\begin{array}{l}9: 30- \\
10: 20\end{array}$ & $\begin{array}{l}\text { Principles and } \\
\text { Practice of } \\
\text { Horld Mission }\end{array}$ & $\begin{array}{l}\text { Principles and } \\
\text { Practice of } \\
\text { Horld Mission }\end{array}$ & $\begin{array}{l}\text { Missionary } \\
\text { Anthropology }\end{array}$ & $\begin{array}{l}\text { Case Study } \\
\text { (Exam) }\end{array}$ & $\begin{array}{l}\text { Evaluation of } \\
\text { the Institute }\end{array}$ \\
\hline $\begin{array}{l}20: 30- \\
11: 20\end{array}$ & $\begin{array}{l}\text { Issues in } \\
\text { Mission }\end{array}$ & $\begin{array}{l}\text { Issues in } \\
\text { Mission }\end{array}$ & $\begin{array}{l}\text { Issues in } \\
\text { Mission }\end{array}$ & $\begin{array}{l}\text { Issues in } \\
\text { Mission }\end{array}$ & $\begin{array}{l}\text { Closing of } \\
\text { the Institute }\end{array}$ \\
\hline $\begin{array}{l}11: 30- \\
12: 00\end{array}$ & $\begin{array}{l}\text { Norship } \\
\text { (Institute) }\end{array}$ & $\begin{array}{l}\text { Worship } \\
\text { (B. Baller) }\end{array}$ & $\begin{array}{l}\text { Horship } \\
\text { (c. Hatson) }\end{array}$ & $\begin{array}{l}\text { Horship * } \\
\text { (c. Hatson) }\end{array}$ & $\begin{array}{l}\text { Practice for } \\
\text { Dedication } \\
\text { Service }\end{array}$ \\
\hline $\begin{array}{r}1: 45- \\
3: 15\end{array}$ & $\begin{array}{l}\text { Panel: As } \\
\text { Others See Us }\end{array}$ & $\begin{array}{l}\text { Language } \\
\text { Learning }\end{array}$ & $\begin{array}{l}\text { Special Interest } \\
\text { Groups }\end{array}$ & $\begin{array}{l}\text { Film and } \\
\text { Discussion }\end{array}$ & \\
\hline $\begin{array}{r}6: 45- \\
8: 30\end{array}$ & & Recreation & & $\begin{array}{l}\text { Dinner and } \\
\text { Talent Night }\end{array}$ & Lord's Supper \\
\hline
\end{tabular}




\section{APPENDIX C. ADDITIONAL TABLES}

Table 36: Population Groups by Age $\ldots \ldots \ldots \ldots \ldots \ldots \ldots \ldots \ldots$

Table 37: Population Groups by Gender $\ldots \ldots \ldots \ldots \ldots \ldots \ldots \ldots$

Table 38: Population Groups by Marital Status . . . . . . . . 349

Table 39: Population Groups by National Category . . . . . . . . . . 350

Table 40: Population by Current Occupation $\ldots \ldots \ldots \ldots \ldots \ldots \ldots$

Table 41: Population by Educational Level $\ldots \ldots \ldots \ldots \ldots \ldots \ldots \ldots$

Table 42: Population by Educational Background $\ldots \ldots \ldots \ldots \ldots 35$

Table 43: Missionaries: Type of Assignment . . . . . . . . 354

Table 44: Missionaries: Time Spent in the Field $\ldots \ldots \ldots \ldots \ldots \ldots$

Table 45: Missionaries: Type of Training $\ldots \ldots \ldots \ldots \ldots \ldots \ldots \ldots$

Table 46: Missionaries: Type of Service . . . . . . . . . 357

Table 47: Missionaries: Reasons for Return by Frequencies $\ldots \ldots \ldots \ldots 358$ 
TABLE 36

POPULATION GROUPS BY AGE

\begin{tabular}{lcccccc}
\hline & \multicolumn{7}{c}{ Age Spans by Years } & \\
\cline { 2 - 7 } & $25-34$ & $35-44$ & $45-54$ & $55-64$ & $65+$ & N \\
\hline Leaders & 5 & 21 & 29 & 46 & 9 & 110 \\
Cur. Miss & 5 & 12 & 19 & 20 & 2 & 58 \\
Ret. Miss & 0 & 3 & 7 & 17 & 4 & 31 \\
Non-Miss & 0 & 6 & 3 & 9 & 3 & 21 \\
\hline Missionaries & 29 & 131 & 151 & 116 & 55 & 482 \\
Current & 29 & 75 & 48 & 46 & 12 & 210 \\
Returned & 0 & 56 & 103 & 70 & 43 & 272 \\
\hline Male & 24 & 103 & 113 & 110 & 44 & 394 \\
Female & 10 & 49 & 67 & 51 & 20 & 197 \\
\hline Single & 2 & 2 & 7 & 6 & 2 & 19 \\
Married & 32 & 149 & 172 & 154 & 62 & 569 \\
Divorced & 0 & 1 & 1 & 1 & 0 & 3 \\
\hline North American & 29 & 131 & 153 & 130 & 58 & 501 \\
Non-N.American & 4 & 21 & 26 & 31 & 5 & 87 \\
\hline Age Totals & 34 & 152 & 180 & 162 & 64 & 592 \\
\hline
\end{tabular}

Reproduced with permission of the copyright owner. Further reproduction prohibited without permission. 
TABLE 37

POPULATION GROUPS BY GENDER

\begin{tabular}{lcccc}
\hline & Male & Female & N & H-W Respond \\
\hline Leaders & 104 & 5 & 109 & 0 \\
\hline Missionaries & 290 & 193 & 483 & 328 \\
Current & 134 & 77 & 211 & 113 \\
Returaed & 156 & 116 & 272 & 215 \\
\hline Single & 3 & 16 & 19 & 0 \\
Married & 389 & 181 & 570 & 328 \\
Divorced & 2 & 1 & 3 & 0 \\
\hline North American & 322 & 179 & 501 & 307 \\
Non-N.American & 69 & 18 & 87 & 18 \\
\hline Gender Totals & 394 & 198 & 592 & $164+164$ \\
\hline
\end{tabular}


TABLE 38

POPULATION GROUPS BY MARITAL STATUS

\begin{tabular}{lcccc}
\hline & Single & Married & Divorced & N \\
\hline Leaders & 2 & 107 & 0 & 109 \\
\hline Missionaries & 17 & 463 & 3 & 483 \\
Current & 8 & 201 & 2 & 211 \\
Returned & 9 & 262 & 1 & 272 \\
\hline North American & 16 & 483 & 2 & 501 \\
Non-N.American & 3 & 83 & 1 & 87 \\
\hline Status Totals & 19 & 570 & 3 & 592 \\
\hline
\end{tabular}

Reproduced with permission of the copyright owner. Further reproduction prohibited without permission. 
TABLE 39

POPULATION GROUPS BY NATIONAL CATEGORY

\begin{tabular}{lccccc}
\hline & & \multicolumn{4}{c}{ Missionaries } \\
\cline { 3 - 5 } & Leaders & Current & Returned & Total Miss. & N \\
\hline North American & 52 & 191 & 258 & 449 & 501 \\
Inter-American & 8 & 2 & 2 & 4 & 12 \\
Soutb American & 7 & 1 & 0 & 1 & 8 \\
Australian & 17 & 1 & 0 & 1 & 18 \\
European & 12 & 5 & 5 & 10 & 22 \\
Asian & 6 & 4 & 3 & 7 & 13 \\
African & 8 & 5 & 2 & 7 & 15 \\
Middle Eastern & 1 & 0 & 0 & 0 & 1 \\
\hline Group Totals & 111 & 209 & 270 & 479 & 590 \\
\hline
\end{tabular}


TABLE 40

POPULATION BY CURRENT OCCUPATION

\begin{tabular}{lccccc}
\hline & & \multicolumn{4}{c}{ Missionaries } \\
\cline { 3 - 5 } & Leaders & Current & Retumed & Total Miss. & N \\
\hline USA Admin & 25 & 2 & 27 & 29 & 54 \\
Overseas Admin & 36 & 23 & 2 & 25 & 61 \\
Clerica/secretarial & 1 & 19 & 28 & 47 & 48 \\
Construction/maint & 1 & 6 & 0 & 6 & 7 \\
Technical/aviation & 0 & 5 & 2 & 7 & 7 \\
Homemaking & 0 & 12 & 29 & 41 & 41 \\
Medical/health & 18 & 48 & 28 & 76 & 94 \\
Publishing/media & 6 & 5 & 7 & 12 & 18 \\
Pastoral/evangelistic & 2 & 12 & 39 & 51 & 53 \\
Development/relief & 1 & 12 & 1 & 13 & 14 \\
Educational & 18 & 64 & 72 & 136 & 154 \\
Other & 3 & 3 & 37 & 40 & 43 \\
\hline Group Totals & 111 & 211 & 272 & 483 & 594 \\
\hline
\end{tabular}

Reproduced with permission of the copyright owner. Further reproduction prohibited without permission. 
TABLE 41

POPULATION BY EDUCATIONAL LEVEL

\begin{tabular}{lcccccc}
\hline & & \multicolumn{4}{c}{ Missionaries } & \\
\cline { 3 - 5 } & Leaders & Current & Returned & Total Miss. & N \\
\hline Secondary & 0 & 0 & 3 & 3 & 3 \\
Vocational & 0 & 1 & 2 & 3 & 3 \\
Some College & 2 & 23 & 25 & 48 & 50 \\
Associate Degree & 3 & 5 & 13 & 18 & 21 \\
Bachelor's Degree & 15 & 35 & 50 & 85 & 100 \\
Graduate Work & 10 & 18 & 29 & 47 & 57 \\
Master's Degree & 40 & 67 & 117 & 184 & 224 \\
Doctoral Degree & 38 & 59 & 32 & 91 & 129 \\
Other & 2 & 2 & 1 & 3 & 5 \\
\hline Group Totals & 110 & 210 & 272 & 482 & 592 \\
\hline
\end{tabular}


TABLE 42

POPULATION BY EDUCATIONAL BACKGROUND

\begin{tabular}{lccccc}
\hline & & \multicolumn{4}{c}{ Missionaries } \\
\cline { 2 - 5 } & Leaders & Current & Returned & Total Miss. & N \\
\hline Bible, Religion & 101 & 185 & 252 & 437 & 538 \\
Missions & 45 & 81 & 111 & 192 & 237 \\
Church Growth & 37 & 37 & 41 & 78 & 115 \\
Communications & 49 & 105 & 121 & 226 & 275 \\
Anthropology & 26 & 60 & 70 & 130 & 156 \\
Cross-Cultures & 30 & 57 & 59 & 116 & 146 \\
World History & 73 & 129 & 174 & 303 & 376 \\
Current Affairs & 37 & 37 & 56 & 93 & 130 \\
\hline Avernge * Courses & 50 & 86 & 111 & 197 & 247 \\
\hline
\end{tabular}


TABLE 43

MISSIONARIES: TYPE OF ASSIGNMENT

\begin{tabular}{lcccc} 
& Regular & Short-term & Other & N \\
\hline Leader Missionaries & 88 & 1 & 0 & 89 \\
Missionaries & 475 & 4 & 2 & 481 \\
Current & 205 & 4 & 2 & 211 \\
Returned & 270 & 0 & 0 & 270 \\
\hline Group Totals & 563 & 5 & 2 & 570 \\
\hline
\end{tabular}


TABLE 44

MISSIONARIES: TIME SPENT IN FIELD

\begin{tabular}{lcccccccc}
\hline & $\begin{array}{c}1-11 \\
\text { mo }\end{array}$ & $\begin{array}{l}1-3 \\
\text { yrs }\end{array}$ & $\begin{array}{l}4-6 \\
\text { yrs }\end{array}$ & $\begin{array}{l}7-9 \\
\text { yrs }\end{array}$ & $\begin{array}{c}10-12 \\
\text { yrs }\end{array}$ & $\begin{array}{c}13-15 \\
\text { yrs }\end{array}$ & $\begin{array}{c}16+ \\
\text { yrs }\end{array}$ & N \\
\hline Leader Missionaries & 2 & 3 & 21 & 12 & 12 & 16 & 22 & 88 \\
Missionaries & 14 & 84 & 104 & 74 & 47 & 48 & 111 & 482 \\
Current & 12 & 44 & 44 & 35 & 17 & 15 & 43 & $210^{*}$ \\
Returned & 2 & 40 & 60 & 39 & 30 & 33 & 68 & $272 *$ \\
\hline $25-34$ yrs & 4 & 12 & 12 & 5 & 1 & 0 & 0 & 34 \\
$35-44$ yrs & 9 & 25 & 47 & 36 & 9 & 11 & 9 & 146 \\
$45-54$ yrs & 1 & 27 & 43 & 28 & 27 & 16 & 35 & 177 \\
$55-64$ yrs & 1 & 16 & 18 & 10 & 18 & 29 & 59 & 151 \\
$65+$ yrs & 1 & 7 & 4 & 7 & 4 & 8 & 30 & 61 \\
\hline SAale & 11 & 54 & 83 & 57 & 41 & 43 & 82 & 371 \\
Femule & 5 & 33 & 42 & 28 & 18 & 21 & 51 & 198 \\
H-W Respond & 2 & 56 & 72 & 49 & 35 & 36 & 78 & 328 \\
\hline Single, Divorced & 2 & 5 & 6 & 2 & 1 & 1 & 5 & 22 \\
Married & 14 & 82 & 119 & 83 & 58 & 63 & 128 & 547 \\
\hline Total Missionaries & 16 & 87 & 125 & 86 & 59 & 64 & 133 & 570 \\
\hline
\end{tabular}


TABLE 45

MUSSIONARIES: TYPE OF TRAINING

\begin{tabular}{|c|c|c|c|c|c|c|}
\hline & \multicolumn{3}{|c|}{ IWM Orientation } & \multirow[b]{2}{*}{ Language } & \multirow[b]{2}{*}{ Other } & \multirow[b]{2}{*}{ None } \\
\hline & 4 wks & 6 wks & Total & & & \\
\hline Leader Missionaries & 5 & 10 & 15 & 3 & 1 & 22 \\
\hline Non-Leader Mssys & 197 & 124 & 321 & 31 & 14 & 483 \\
\hline Current & 36 & 109 & 49 & 9 & 8 & 211 \\
\hline Returned & 81 & 88 & 75 & 22 & 6 & 272 \\
\hline Male & 140 & 82 & 222 & 25 & 23 & 103 \\
\hline Female & 78 & 54 & 132 & 10 & 5 & 51 \\
\hline H-W Respond & 124 & 97 & 221 & 18 & 8 & 81 \\
\hline Single, Divorced & 10 & 3 & 13 & 3 & 1 & 5 \\
\hline Married & 208 & 133 & 341 & 32 & 27 & 149 \\
\hline Total Missionaries & 218 & 136 & 354 & 35 & 28 & 155 \\
\hline
\end{tabular}

Reproduced with permission of the copyright owner. Further reproduction prohibited without permission. 
TABLE 46

MISSIONARIES: TYPE OF SERVICE

\begin{tabular}{lccccc}
\hline & & \multicolumn{3}{c}{ Missionaries } & \\
\cline { 3 - 5 } & Leaders & Current & Retumed & Total & N \\
\hline Church Administration & 51 & 27 & 62 & 89 & 140 \\
Clerical-secretarial & 1 & 19 & 25 & 44 & 45 \\
Construction-main & 1 & 3 & 0 & 3 & 4 \\
Technical-aviation & 0 & 3 & 3 & 6 & 6 \\
Homemaking & 0 & 9 & 29 & 38 & 38 \\
Medical-heaith & 15 & 45 & 22 & 67 & 82 \\
Publishing-media & 4 & 5 & 7 & 12 & 16 \\
Pastoral-evangelistic & 4 & 12 & 17 & 29 & 33 \\
Development-relief & 1 & 15 & 2 & 17 & 18 \\
Educational & 12 & 73 & 105 & 178 & 190 \\
\hline Group Totals & 89 & 211 & 272 & 483 & 572 \\
\hline
\end{tabular}

Reproduced with permission of the copyright owner. Further reproduction prohibited without permission. 


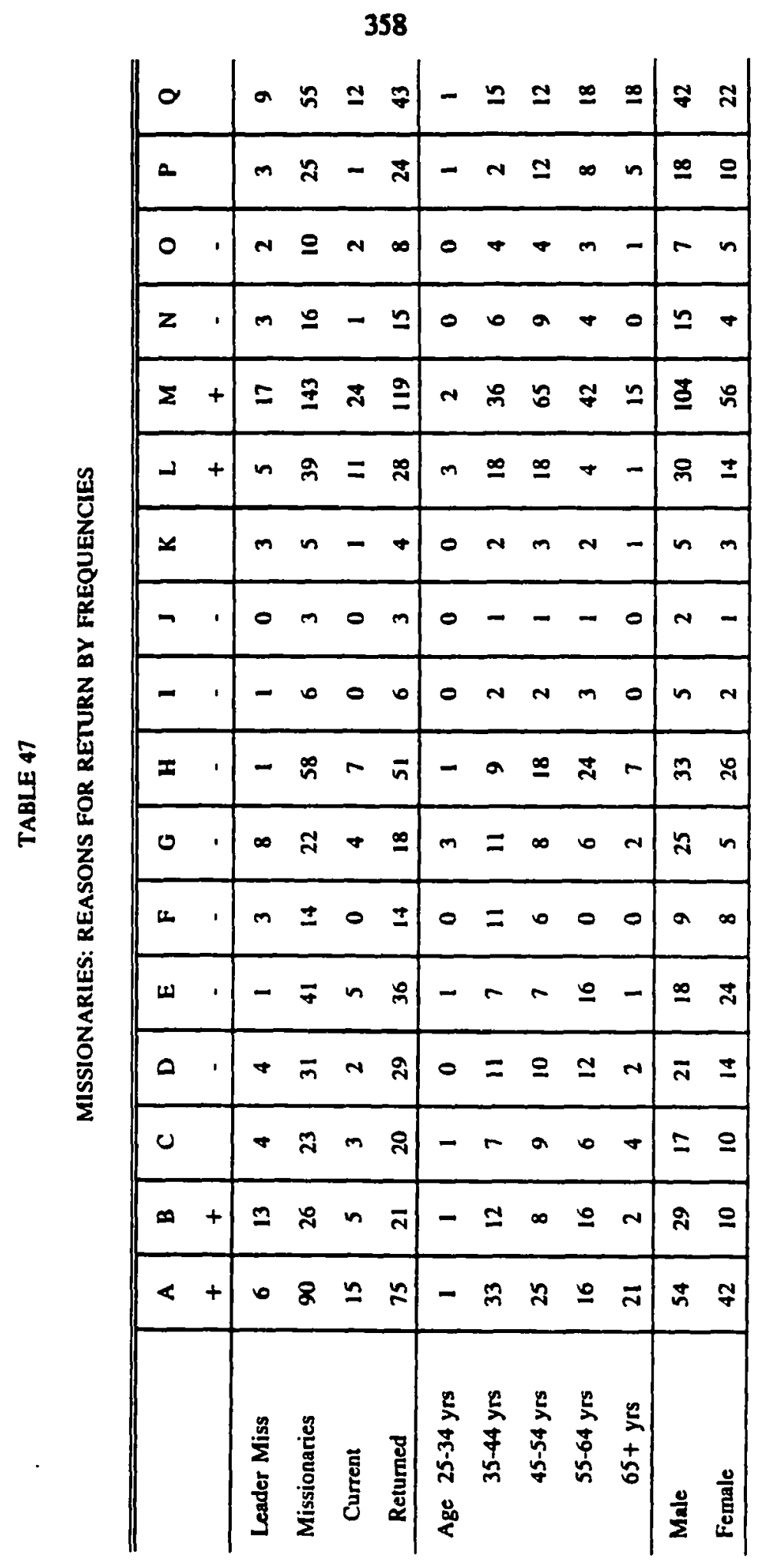

Reproduced with permission of the copyright owner. Further reproduction prohibited without permission. 


\begin{tabular}{c|c|c|c|c|c|c|c|c|c|c|c|c|c|c|c|c|c}
\hline Time 1-11 mo & 1 & 0 & 0 & 1 & 0 & 0 & 0 & 0 & 0 & 1 & 0 & 0 & 1 & 1 & 0 & 0 & 1 \\
$1-3$ yrs & 7 & 3 & 4 & 10 & 12 & 4 & 3 & 4 & 2 & 2 & 1 & 4 & 8 & 6 & 5 & 7 & 8 \\
$4-6$ yrs & 31 & 9 & 11 & 10 & 9 & 7 & 11 & 10 & 3 & 0 & 1 & 17 & 32 & 1 & 2 & 5 & 8 \\
7-9 yrs & 26 & 8 & 8 & 3 & 3 & 4 & 6 & 5 & 0 & 0 & 1 & 6 & 31 & 4 & 1 & 3 & 6 \\
$10-12$ yrs & 6 & 3 & 0 & 1 & 5 & 1 & 2 & 12 & 1 & 0 & 2 & 3 & 26 & 3 & 1 & 3 & 5 \\
$13-15$ yrs & 10 & 8 & 2 & 2 & 4 & 1 & 2 & 6 & 1 & 0 & 2 & 4 & 26 & 0 & 1 & 5 & 4 \\
$16+$ yrs & 15 & 7 & 2 & 7 & 9 & 0 & 6 & 22 & 0 & 0 & 1 & 10 & 36 & 4 & 2 & 5 & 32 \\
\hline IWM Orientation & 64 & 14 & 22 & 24 & 32 & 16 & 21 & 30 & 6 & 2 & 5 & 31 & 97 & 13 & 8 & 16 & 24 \\
IWM Miss \% & .67 & .36 & .81 & .69 & .76 & .94 & .70 & .51 & .86 & .67 & .63 & .70 & .61 & .68 & .67 & .57 & .38 \\
No Orientation & 24 & 17 & 5 & 10 & 7 & 0 & 6 & 19 & 0 & 1 & 2 & 5 & 42 & 4 & 3 & 8 & 31 \\
$\quad$ Non-IWM \% & .25 & .44 & .19 & .29 & .17 & .00 & .20 & .32 & .00 & .33 & .25 & .11 & .26 & .21 & .25 & .29 & .48 \\
\hline Total \# Selected & 96 & 39 & 27 & 35 & 42 & 17 & 30 & 59 & 7 & 3 & 8 & 44 & 160 & 19 & 12 & 28 & 64 \\
\% of All Miss's & .14 & .06 & .04 & .05 & .06 & .02 & .04 & .09 & .01 & .00 & .01 & .06 & .23 & .03 & .02 & .04 & .09 \\
\hline
\end{tabular}

Nole. Reasons for Return are:

$\begin{array}{ll}\text { A } & \text { Assignment accomplished } \\ \text { B } & \text { New appointment/opportunity } \\ \text { C } & \text { Government/political factors } \\ \text { D } & \text { Leadership/administration } \\ \text { E } & \text { Physical health } \\ \text { F } & \text { Emotional health } \\ \text { G } & \text { Spouse needs } \\ \text { H } & \text { Needs of relatives } \\ \text { I } & \text { Resignation } \\ \text { J } & \text { Adjustment difficulties } \\ \text { K } & \text { Exlemal circumstances } \\ \text { L } & \text { Education needs-self/spouse } \\ \text { M } & \text { Education needs--children }\end{array}$

N Family crisis

O Dissatisfaction/dissappointment

P Nationalization

Leadership/administration

Q
OTHER REASONS (sumples)
Retirement
Asked to resign
God calling elsewhere




\section{APPENDIX D. LETTERS}




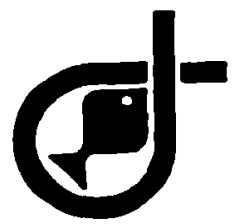

MAIN OFFICE Andrewe Univeralty Borrien Springe. MI 49104 (a16) $471-3540$

BRANCH OFFICE Lome unde Univeraly Lame unda. CA vesse (714) 024-4057

\section{Seventh-day Aduentist \\ Institute of World Mission}

Kay 11, 1998.

Deer Frlendal

Hext year it 111 be 25 yeare alnce the Seventh-day Adventiat Church eatobliehed apecild Inetitute of World Miasion vith the apeelfic olw of preparing lte alesionerlee for their croas-cultural eervice. Branchee of this Inatitute heve been extabilahed aince then in Europe and in Auctrolie, while opectal programa are aleo being conducted in each of the other continents. It ie high time nov for an objectlve reaencher to evaluate the progras as it hae developed over the yeara.

Hre. Donne Morley has undertaken thie agalgnment for her doctoril disertetion. She herself has participated In number of programe offered by the Institute, and opent aone trelve yearo in croas-cultural aervice for the Church in Africe. Her ecedente preparotion, oe vell en her experience and comaltment, wake her vell qualilied for this eveluative etudy, which concentratea in porticular on en eveluation of the goala of alesionery training and their effectiveneas in proctice.

Since your agency hee had a great deal of experience olth this kind of alealonary troining, and I'm aure has wrestled too with the ianue of goala and hov to attain then, your aoplatance in this reseorch 18 conaldered very easent1al. Any contribution on your pert to this atudy on goele in miselonary training is greatly apprecieted. Pleane complete the queetionnelre and return it in the enclosed envelope along olth any additionel commente you any have. Thank you very wuch for your participotion.

With vere Chrietien greetinge,

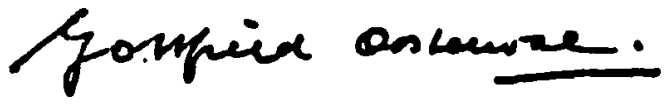

Dr. Gotelried Doetervil, Director Inetilute of Morld Migalon 


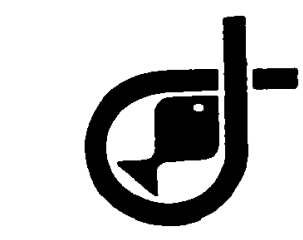

MAIN OFFICE

Andrewe University Sutheriend House Berrien Soringe. Mi 40104 $(616) 471-3540$

BRANCH OfFICE Loma Linds Universuty Nichot Hell 1313 Loma Linde. CA 02354 (714) 924.4057

\section{Seuenth-day Ofuentist Institute of World Mission}

Uclober $y, 19 y b$.

Dear Fellov Worker in Christ:

Mianion is the heartbegt of the Adventist Church. You are part of that heat. And, in order for that heartbeat to remain etrong and healthy, ve need to check up on hov ve are doling. and where ve are going. That is true for Adventist alasion as a vole: that is equally true for the vork here at the Ingtitute of Vorld Hiagion. It 18 fur that reagon that $I$ an so bold as to eollcst your help.

Next year it 111 be trenty-11ve yeara aince the Institute vag firat eatablished. Some three thousand missioneries like youraell have participated in ita programa. It la high tiae nov for an objectlve' researcher to evaluate that program, 1 ta gosis and 1 ta eflectiveneas. Hra. Donna Horley has undertaken this ageignment for her doctorel disgertation at Andrevo Univeralty. She heraell has particlpated in a number of prograna olfered by the Inatitute, and apent ane tvelve yeara in croas-cultural service for the Church in Africa. Her acedentc preparbtion, her experience and commitment, make her vell qualified for this evaluative study. which locuges in particular on an evaluation of the goala in missionary training and hov to attain them in practice.

Hany of you have qone through this tratning program; you are best qualified to judge these goala aet by the Inetilute and hov effective they heve been vith regard to miabionary itfe ant practjae in the fleld. It ia for thet reason that your Insighta and thoughts on this matter are so egaential to this atudy. Those of you who hove not attended a Hasions Instltute can proulde valuable insighta in abaegaing the gobla from your unique perspect 1 ve. Pleage be go kind, therefore, as to $\$ 111$ out theae questionneirea, and ahare your thoughta - Ith uB. Additional cnmmenta are velćome. Your contributiona are greatly appreclated. Thank you very much for your participation.

Hith varm Chriatian greetings,

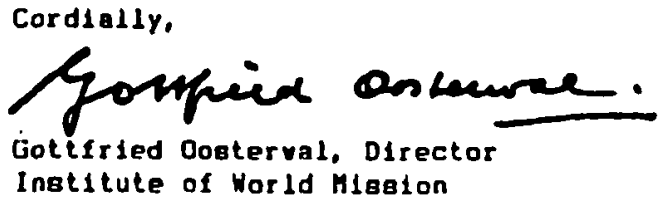




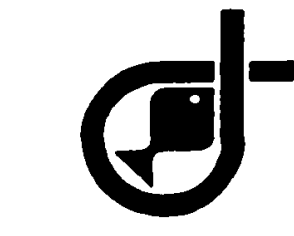

MAIN OFFICE

Androwe Untveraly

Suthertand Moune

Eerrien Bpringe. MI 10104

(ब16) 474-3840

ERANCH OFFIC: Lome Linde Univereiry Nichol Malt 1313 Lome Linde. CA 92384 (714) 824-4057

\section{Seventh-day Aduentist \\ Institute of World Mission}

March 18, 1992

Dear Friends:

Last year it was 25 years since the Church established its own Institute of World Mission with the specific aim of preparing Adventist missionaries for their life and work in cultural settings different from their own. It is high time now for an objective researcher to evaluate the program of the Institute as it has developed over the years.

Mrs. Donna Worley has undertaken this assignment for her doctoral dissertation at Andrews University. She herself has participated in a number of programs offered by the Institute, and spent some twelve years in service of the church in Africa. Her academic preparation, as well as her experience and commitment, make her well qualifled for this evaluative study, whlch concentrates in particular on an evaluation of the goals of missionary training and their effectiveness in practice.

It is at this point that you can make a powerful contribution. Your work constantly challenged you with the question: what really are the goals of our mission, and, therefore, what should be the goal of all missionary training? Your thoughts and insights on this matter are greatly needed, for the sake of the study, as well as for the Institute itself. Any assistance you can give Mrs. Worley, therefore, with regard to the issue of goals of missionary training and how to attain them, will be greatly appreciated. Please complete the questionnaire and return it in the enclosed envelope along with any comments you may wish to make. (The second questionnaire should be filled out by your spouse.) Thank you very much for your participation.

With warm Christian greetings,

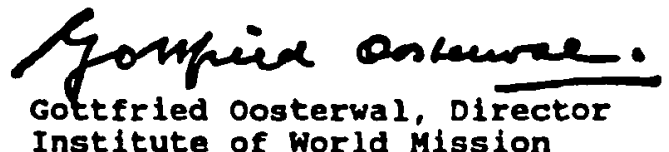

Institute of World Mission 
BIBLIOGRAPHY

Reproduced with permission of the copyright owner. Further reproduction prohibited without permission. 


\section{BIBLIOGRAPHY}

Abe, H., \& Wiseman, R. (1983). A cross-cultural confirmation of the dimensions of intercultural effectiveness. Intemational Joumal of Intercultural Relations, 7, 53-67.

Adelman, M. B. (1988). Cross-cultural adjustment: A theoretical perspective on social support. Intemational Joumal of Intercultural Relations, 12, 183-204.

Adeyemo, T. (1993). From Africa: An open letter to the North American mission community. In J. A. Siewert \& J. A. Kenyon (Eds.), Mission handbook: USA/Canada Christian ministries overseas 1993-95 (15th ed.), (pp. 39-42). Monrovia, CA: MARC, World Vision International.

Adler, L. L. (Ed.). (1977). Issues in cross-cultural research. New York: New York Academy of Sciences.

Adler, N. J., \& Kiggundu, M. N. (1983). Awareness at the crossroad: Designing translator-based training programs. In D. Landis \& R. W. Brislin (Eds.), Handbook of intercultural training: Vol. 2. Issues in training methodology (pp. 124-150). New York: Pergamon Press.

Albert, R. D. (1983). The intercultural sensitizer or culture assimilator: A cognitive approach. In D. Landis \& R. W. Brislin (Eds.), Handbook of intercultural training: Vol. 2. Issues in training methodology (pp. 186-217). New York: Pergamon Press.

Albert, R. D. (1986). Conceptual framework for the development and evaluation of cross-cultural training programs. International Journal of Intercultural Relations, 10, 2.

Allen, F. (1986). Why do they leave? Reflections on attrition. Evangelical Missions Quarerly, 22(2), 118-122.

Anderson, L. E. (1994). A new look at an old construct: Cross-cultural adaptation. International Joumal of Insercultural Relations, 18(3), 293-328. 
Araujo, A. (1993). Retooling for the future. Evangelical Missions Quarterly, 29(4), 362-370.

Amdt, J. R., \& Lindquist, S. (1976). Twenty to fifty percent fail to make it: Why? Evangelical Missions Quarterly, 12(3), 141-148.

Bailey, H. L., \& Jackson, H. C. (1965). A study of missionary motivation, training, and withdrawal. New York: Missionary Research Library.

Bandura, A. (1977). Social leaming theory. Englewood Cliffs, NJ: Prentice-Hall.

Bama, L. M. (1983). The stress factor in intercultural relations. In D. Landis \& $R$. W. Brislin (Eds.), Handbook of intercultural training: Vol. 2. Issues in training methodology (pp. 19-49). New York: Pergamon Press.

Bamey, G. L. (1969). Training the new breed: Jaffray's two-pronged approach. Evangelical Missions Quarterly, 5(4), 201-205.

Barns, S. (1992). The changing face of the missionary force. Evangelical Missions Quarterly, 28(4), 376-381.

Barnum, C., \& Wolniansky, N. (1989, October). Why Americans fail at overseas negotiations. Management Review, 78, 55-57.

Barrett, D. B. (Ed.). (1982). World Christian encyclopedia: A comparative study of churches and religions in the modern world, A.D. 1900-2000. Nairobi, Kenya: Oxford University Press.

Barrett, D. B. (1994). Annual statistical table on global mission: 1994. Intemational Bulletin of Missionary Research, 18(1).

Batchelder, D., \& Wamer, E. (1977). Beyond experience: The experiential approach to cross-cultural education. Brattleboro, VT: The Experiment Press.

Bauer, B. L. (1982). Congregational and mission structures and how the Seventhday Adventist church has related to them. (Doctoral dissertation, Fuller Theological Seminary, School of World Mission, 1982).

Bauer, B. L. (1993, December 23). Battling against the odds: The 10/40 window is the greatest challenge facing global mission. Adventist Review, pp. 12-14.

Beane, J. A., \& Toepfer, C. F., Jr., \& Alissi, S. J., Jr. (1986). Curriculum planning and development. Boston: Allyn and Bacon. 
Beane, J. A., \& Lipka, R. P. (1986). Self-concept, self-esteem, and the curriculum. New York: Teachers College Press.

Beauchamp, G. A. (1981). Curriculum theory (4th ed.). Itasca, IL: F. E. Peacock.

Beaver, R. P. (1973). Foreword. In E. R. Dayton (Ed.), Mission handbook: North American Protestant ministries overseas (10th ed.), (pp. ix-xii). Monrovia, CA: MARC, World Vision Intemational.

Befus, C. P. (1988). A multilevel treatment approach for culture shock experienced by sojoumers. Intemational Joumal of Intercultural Relations, 12, 381-400.

Bellah, R. N., Madsen, R., Sullivan, W. M., Swindler, A., \& Tipton, S. M. (1985). Habits of the hear: Individualism and commiment in American life. Berkeley: University of Califomia Press.

Bennett, J. M. (1986). Modes of cross-cultural training: Conceptualizing crosscultural training as education. Insernational Joumal of Intercultural Relations, 10, 117-134.

Bennett, M. J. (1986). A developmental approach to training for intercultural sensitivity. Intermational Joumal of Intercultural Relations, 10, 179-196.

Benson, P. G. (1978). Measuring cross-cultural adjustment: The problem of criteria. Insemational Journal of Insercultural Relations, 2, 21-37.

Blake, B. F., \& Heslin, R. (1983). Evaluating cross-cultural training. In D. Landis \& R. W. Brislin (Eds.), Handbook of intercultural training: Vol 1. Issues in theory and design (pp. 203-223). New York: Pergamon Press.

Bloom, B. S., et al. (Ed.). (1956). Taxonomy of educational objectives: Handbook I, cognitive domain. New York: David McKay Company.

Bochner, S. (Ed.). (1982). Cultures in contact: Studies in cross-cultural interaction. Oxford: Pergamon Press.

Brein, M., \& David, K. (1971). Intercultural communication and the adjustment of the sojourner. Psychological Bulletin, 76, 215-230. 
Brislin, R. W., \& Charles, J. (1977). Research on cross-cultural interaction. In D. S. Hoopes, P. B. Pedersen, G. W. Renwick (Eds.), Overview of interculnural education, training, and research, Vol. I: Theory, (pp. 103149). Washington, DC: Society for Intercultural Education, Training, and Research, Georgetown University.

Brislin, R. W., \& Pedersen, P. (1976). Cross-cultural orientation programs. New York: Gardner Press.

Brislin, R. W., \& Yoshida, T. (1994). Intercultural communication training: An introduction. Beverly Hills, CA: Sage Publications.

Britt, W. G. (1981). The prediction of missionary success overseas using pertaining variables. (Doctoral dissertation, Rosemead School of Psychology, Biola University, 1981).

Britt, W. G. (1983). Pre-training variables in the prediction of missionary success overseas. Joumal of Psychology and Theology, 11(3), 203-212.

Buckley, R., \& Caple, J. (1990). The theory and practice of training. San Diego, CA: University Associates.

Burke, S. E. (1992). Cross-cultural training and development. Unpublished master's thesis, State University of New York, Institute of Technology, NY.

Burt, M. R. (1989). Cross-cultural re-entry program for the Salvation Ammy (Canada). Unpublished master's thesis, Fuller Theological Seminary, School of World Mission, Pasadena, CA.

Burton, J. K., \& Merrill, P. P. (1991). Needs assessment: Goals, needs, and priorities. In L. J. Briggs, K. L. Gustafson, \& M. Tillman (Eds.), Instructional design: Principles and applicarions (pp. 17-43). New York: Merrill.

Bush, L., Ed. (1992). AD 2000 \& beyond: $A$ handbook. San Jose, CA: Intemational Office for $A D 2000 \&$ Beyond Movement.

Bushong, B. H. (1986). The world gospel mission (Studies of attrition by four mission agencies). Evangelical Missions Quarterly, 22(2), 129.

Cambum, D. (1986). The Conservative Baptist Foreign Mission Society (Studies of attrition by four mission agencies). Evangelical Missions Quarterty, 22(2), 127 128. 
Campbell, R. J. (1987). The program of pre-field orientation for appointees of Greater Europe Mission. DMiss., Trinity Evangelical Divinity School.

Candidate orientation handbook: Orientarion handbook for missionary personnel. (1978). Cherry Hill, NJ: Association of Baptists for World Evangelism.

Carpenter, H. C. (1986). Components of a model missions major from the perspective of a field missionary. Evangelical Missions Quarterly, 22(2), 186187.

Casino, E. S. (1983). Consultants and competence in the development of crosscultural programs. In D. Landis \& R. W. Brislin (Eds.), Handbook of interculural training: Vol. 2. Issues in training methodology (pp. 218-240). New York: Pergamon Press.

Casse, P. (1980). Training for the cross-cultural mind: A hand-book for crosscultural trainers and consulsants. Washington, DC: The Society for Intercultural Education, Training and Research.

Casse, P. (1982). Training for the multicultural manager: 1 practical and crosscultural approach to the management of people. Washington, DC: The Society for Intercultural Education, Training and Research.

Casse, P., \& Deol, S. (1985). Managing intercultural negotiations: Guidelines for trainers and negotiators. Washington, DC: SIETAR International.

Church, A. (1982). Sojoumer adjustment. Psychological Bulletin, 91, 540-572.

Cleveland, H. G., Mangone, G., \& Adams, J. (1960). The overseas American. New York: McGraw-Hill.

Clinton, J. R. (1984). Leadership training models. Altadena, CA: Bamabas.

Cocks, L. (1994). Personal correspondence, including brochures, working documents, and a personal note. Missionary Internship, Colorado Springs, Colorado.

Collier, M. J. (1989). Cultural and intercultural communication competence: Current approaches and directions for future research. Insernational Journal of Interculural Relations, 13, 287-302.

Collins, M. A. (1986). Manual for today's missionary: From recruitment to retirement. Pasadena, CA: William Carey Library. 
Committee on Missionary Personnel of the Division of Foreign Missions. (1957). New trends in missionary training in the United States. New York: National Committee of the Council of Churches.

Conn, H. M., \& Rowen, S. F. (Eds.). (1984). Missions and theological education in world perspective. Farmington, MI: Associates of Urbanus.

Conn, H. M. (1986). Missions and our present moment in history. Evangelical Missions Quavierly, 22(2), 178-183.

Coote, R. T. (1986). Taking aim on 2000 AD. In S. Wilson \& J. Siewert (Eds.), Mission handbook: North American ministries overseas (13th ed.), (pp. 35-76). Monrovia, CA: MARC, Worid Vision International.

Coote, R. T. (1991). The numbers game in Western evangelization. Evangelical Missions Quarterly, 27(2), 118-127.

Copeland, L., \& Griggs, L. (1985). Going intemational: How to make friends and deal effectively in the global marketplace. New York: New American Library, Random House.

Cummings, D. (1987). Programmed for failure-mission candidates at risk. Evangelical Missions Quarterly, 23(3), 240-246.

Cureton, C. B. (1983). Missionary fit: A criterion-related model. Joumal of Psychology and Theology, 11(3), 196-201.

Damers, A. H. (1955). Where should missionary recruits be trained? Intermational Review of Missions, 44, 185-186.

Damsteegt, P. G. (1988). Foundations of the Seventh-day Adventist message and mission. Berrien Springs, MI: Andrews University Press.

Davies, I. K. (1976). Objectives in curriculum design. London: McGraw-Hill.

Day, H. R. (1983). Race relations training in the U.S. military. In Handbook of inserculrural training: Vol. 2. Issues in training methodologies (pp. 241-289). New York: Pergamon Press.

Dayton, E. R., \& Needham, W. L. (1973). Changes and trends in mission today. In E. R. Dayton (Ed.), Missison handbook: North American Protestant ministries overseas, (10th ed.), pp. 66-79. Monrovia, CA: MARC, World Vision Intermational. 
de Souza, A. R. (1989). Developing, implementing, and evaluating a program of training selected volunteers for overcoming cross-culural barriers in communicating the gospel. DMin. Project, Golden Gate Baptist Theological Seminary.

Diekhoff, G. M., Holder, B. A., Colee, P., Wigginton, P., \& Rees, F. (1991). The ideal overseas missionary: A cross-cultural comparison. Joumal of Psychology and Theology, 19(2), 178-185.

Dillon, D. E. (1983). Personality characteristics of evangelical missionaries as measured by the MMPI. Joumal of Psychology and Theology, 11(3), 213-217.

Dinges, N. (1983). Intercultural Competence. In D. Landis \& R. W. Brislin (Eds.), Handbook of intercultural training: Vol. 1. Issues in theory and design (pp. 176-202). New York: Pergamon Press.

Dixon, J. (1990). Unrealistic expectations: The downfall of many missionaries. Evangelical Missions Quarterly, 26(4), 388-393.

Dowd, T. C. (1978). Intercultural communication training for people in mission. In D. S. Hoopes, P. B. Pedersen, \& G. W. Renwick (Eds.), Overview of intercultural education, training, and research, Vol. 2: Education and training (pp. 127-133). Washington, DC: Society for Intercultural Education, Training, and Research, Georgetown University.

Dubert, K. (1989). Ten steps to success: The major themes. Evangelical Missions Quarterly, 25(2), 161-163.

Dunton, H. I., Pfeiffer, B. E., \& Schantz, B., (Eds.) (1990). Adventist missions facing the 21st century: A reader. Frankfurt am Main, Germany: Peter Lang.

Dymess, W. A. (1989). A unique opportunity. In W. D. Roberts \& J. A. Siewert (Eds.), Mission handbook: USA/Canada Protestant ministries overseas (14th ed.), (pp. 8-22). Monrovia, CA: MARC, World Vision Intemational.

Dybdal, J. (1993, March 18). Our mission: We are sent to people. Adventist Review, pp. 8-11.

Dysinger, Y. M. (1992, April 23). Adventist tentmakers: Opening global doors where others cannot enter. Adventist Review, pp. 16-18. 
Elkins, P. (1981). Preparation: Pay the Price!. In R. D. Winter \& S. C. Hawthome (Eds.), Perspectives on the world Christian movemen: A reader (pp. 800-807). Pasadena, CA: William Carey Library.

Ferguson, L. N., Kliewer, D., Lindquist, S. E., Williams, D. E., \& Heinrich, R. P. (1983). Candidate selection criteria: A survey. Joumal of Psychology and Theology, I1(3), 243-250.

Firth, R. E., (Ed.) (1980). Servants for Christ: The Adventist church facing the '80s. Berrien Springs, MI: Andrews University Press.

Folkenberg, R. S. (1992, February 6). Four themes for the nineties. Adventist Review, p. 11.

Foyle, J. (1986). How to choose the right missionary. Evangelical Missions Quarterly, 22(2), 196-204.

Fumham, A., \& Bochner, S. (1982). Social difficulty in a foreign culture: An empirical analysis of culture shock. In S. Bochner (Ed.), Cultures in contact: Intemational series in experimental social psychology, volume I (pp. 161-198). New York: Pergamon.

Fumham, A., \& Bochner, S. (1986). Culture shock: Psychological reactions to unfamiliar environmens. London: Methuen.

Gardner, L. M. (1987). Proactive care of missionary personnel. Journal of Psychology and Theology, 15(4), 308-314.

Gardner, L. M. (1987). A practical approach to transitions in missionary living. Joumal of Psychology and Theology, 15(4), 342-349.

Gangel, K. O. (1989). Developing new leaders for the global task. Evangelical Missions Quarterly, 25(2), 166-171.

Gao, G., \& Gudykunst, W. B. (1990). Uncertainty, anxiety, and adaptation. Intemational Joumal of Intercultural Relations, 14, 301-317.

General Conference of Seventh-day Adventists. (1956). Annual Council Minutes.

Grove, C. L. (1985). A new conceptualization of intercultural adjustment and the goals of training. Intemational Joumal of Intercultural Relations, 9, 205-233. 
Grove, P. B. (1986). Webster's third new intermational dictionary of the English language, unabridged (3rd ed.). Springfield, MS: MerriamWebster.

Gudykunst, W. B., \& Hammer, M. R. (1983). Basic training design: Approaches to intercultural training. In D. Landis \& R. W. Brislin (Eds.), Handbook of intercultural training: Vol. 1. Issues in theory and design (pp. 118-154). New York: Pergamon Press.

Gudykunst, W. B., \& Hammer, M. R. (1984). Dimensions of intercultural effectiveness: Cultural specific or cultural general? Insernational Joumal of Intercultural Relations, 8, 1-10.

Gudykunst, W. B., \& Kim, Y. Y. (Eds.). (1984). Methods for cross-cultural research. Beverly Hills, CA: Sage Publications.

Gudykunst, W. B., \& Ting-Toomey, S. (1988). Culture and interpersonal communication. Newbury Park, CA: Sage Publications.

Guthrie, G. M., \& Zektick, I. (1967). Predicting performance in the Peace Corps. Joumal of Social Psychology, 71, 11-21.

Hall, P. H., \& Gudykunst, W. B. (1989). The relationship of perceived ethnocentrism in corporate cultures to the selection, training, and success of intemational employees. Insemational Joumal of Intercultural Relations, 13, 183-21.

Hammer, M. R. (1987). Behavioral dimensions of intercultural effectiveness: A replication and extension. International Joumal of Intercultural Relations, 11, 65-88.

Hammer, M. R., Gudykunst, W. B., \& Wiseman, R. L. (1978). Dimensions of intercultural effectiveness: An exploratory study. International Journal of Intercultural Relations, 2, 382-392.

Hannigan, T. P. (1990). Traits, attitudes, and skills that are related to intercultural effectiveness and their implications for cross-cultural training: A review of the literature. Insemational Joumal of Intercultural Relations, 14, 89-111.

Harris, P.R., \& Moran, R. T. (1987). Managing cultural differences. Houston: Gulf Publishing. 
Harrison, R., \& Hopkins, R. (1967). The design of cross-cultural training: An altemative to the university model. Joumal of Applied Behavioral Sciences III(4), 431-461.

Hass, G. (1983). Curriculum planning: A new approach (4th ed.). Boston: Allyn and Bacon.

Henerson, M. E., Morris, L. L., \& Fitz-Gibbon, C. T. (1978). How to measure amitudes. Beverly Hills, CA: Sage Publications.

Hesselgrave, D. (1987). Today's choices for tomorrow's mission: An evangelical perspective on trends and issues. Grand Rapids, MI: Zondervan.

Hesselgrave, D. J. (1973). Identification--key to effective communication. Evangelical Missions Quarterty, 9(4), 216-222.

Hesselgrave, D. J. (1987). Missions education: Major trends and issues in world missions today. Evangelical Missions Quarterty, 23(3), 298-305.

Higdon, E. K. (1956). New missionaries for new days. St. Louis: Bethany Press.

Hoke, S. T. (1985). The introduction to missions course--how to prepare "world" Christians. Evangelical Missions Quarterly, 21(1), 68-80.

Hoopes, D. S., Pedersen, P. B.. \& Renwick. G. W. (Eds.). (1977-1978). Overview of insercultural educarion, training and research, Vols. 1-3. LaGrange Park, IL: Intercultural Network.

Hughes-Wiener, G. (1986). The 'leaming how to learn' approach to cross-cultural orientation. Intermational Joumal of Interculsural Relations, 10, 485-505.

Imahori, T. T., \& Lanigan, M. L. (1989). Relational model of intercultural communication competence. Intemational Joumal of Intercultural Relarions, 13, 269-286.

Jaffarian, E. M. (1994). World evangelization by A.D. 2000: Will we make it? Evangelical Missions Quarerty, 30(1), 18-26.

Jennings, G. J. (1993). American missionary candidates-out of these worlds. Missiology, 21(2), 207-222. 
Johnston, L. N. (1983). Should I be a missionary? Joumal of Psychology and Christianity, 2(4), 5-9.

Johnston, M. S. (1980). A study of the reasons for early withdrawal of Seventhday Adventist missionaries between 1955 and 1974. A report of a study done for the department of world mission, Andrews University, Berrien Springs, MI, and the General Conference of Seventh-day Adventists, Washington D.C.

Jung, L. B. (1985). How cross-cultural social participation affects the international attitudes of U. S. students. Intermational Joumal of Intercultural Relations, 9, 377-387.

Kealey, D. J. (1989). A study of cross-cultural effectiveness: Theoretical issues, practical applications. Intemational Joumal of Intercultural Relations, 13, 387428.

Kealey, D. J., \& Ruben, B. D. (1983). Cross-cultural personnel selection criteria, issues, and methods. In D. Landis \& R. W. Brislin (Eds.), Handbook of intercultural training: Vol. 1. Issues in theory and design (pp. 155-175). New York: Pergamon Press.

Kim, Y. Y., \& Gudykunst, W. B. (Bds.), (1988). Cross-cultural adaptation: Current approaches. Newbury Park, CA: Sage Publications.

Kliewer, D. (1983). Missionary program evaluation: An assessment strategy. Joumal of Psychology and Christianity, 2(4), 38-44.

Klein, M. H. (1977). Adaptation to new cultural environments. In D. S. Hoopes, P. B. Pedersen, \& G. W. Renwick (Eds.). Overview of interculsural education, training and research: volume I: Theory (pp. 4955). Washington, DC: Society for Intercultural Education, Training and Research.

Knight, G. R. (1984, March 29). Spiritual revival and educational expansion. Adventist Review, pp. 8-11.

Koester, J., \& Olebe, M. (1988). The behavioral assessment scale for intercultural communication effectiveness. Insemational Joumal of Intercultural Relations, 12, 233-246. 
Kohls, L. R. (1987). Four traditional approaches to developing cross-cultural preparedness in adults: Education, training, orientation, and briefing. Intemational Joumal of Intercultural Relations, 11, 89-106.

Kolb, D. (1984). Experiential leaming. Englewood Cliffs, NJ: Prentice-Hall.

Komfield, D. (1979). What it costs to prepare. Evangelical Missions Quarterty, 15(4), 223-228.

Kraft, C. H. (1973a). God's model for cross-cultural communication--the incamation. Evangelical Missions Quarterly, (4), 205-216.

Kraft, C. H. (1973b). The incarnation, cross-cultural communication and communication theory. Evangelical Missions Quarterty, (5), 277-284.

Kruckeberg, J., \& Stafford, A. (1981). The missionary's need of family life training. Evangelical Missions Quarerly, 17(3), 163-171.

Kyle, J. W. (1980). Recruitment in the 1980s. In S. Wilson (Ed.), Mission handbook: North American ministries overseas (12th ed.), (pp. 15-18). Monrovia, CA: MARC, World Vision International.

Kyne, J. N. (1992). Conflict resolution overseas: MMPI scores and overseas perseverance among missionaries. (Doctoral dissertation, Fuller Theological Seminary, School of Psychology, 1992).

Landis, D., \& Brislin, R. W. (Eds.). (1983). Handbook of intercultural training, Vols. 1-3. New York: Pergamon Press.

Lindquist, S. E. (1983). A rationale for psychological assessment of missionary candidates. Joumal of Psychology and Christianity, 2(4), 10-17.

Long, M. (1973). The increasing role of short-term service in today's mission. In E. R. Dayton (Ed.), Mission handbook: North American Protestant ministries overseas, (10th ed.), pp. 16-23. Monrovia, CA: MARC, World Vision International.

Mager, R. F. (1972). Goal analysis. Belmont, CA: Lear Siegler (Fearon Publishers)

Magor, D. R. (1987). A preservice orientation model for the South Sea Evangelical Mission. Unpublished master's thesis, Fuller Theological Seminary, School of World Mission, Pasadena, CA. 
Maltby, D. A. (1980). A rationale for the intercultural communication training of North American Evangelical missionaries. Unpublished master's thesis, University of Virginia.

Margolis, F. H., \& Beil, C. R. (Eds.) (1989). Leam before you leap: An initial diagnosis. In F. H. Margolis \& C. R. Beil, Understanding training: Perspectives and practices (pp. 11-20). San Diego, CA: University Associates.

Martin, A. (Ed.). (1974). The means of world evangelizarion: Missiological education at the Fuller School of World Mission. South Pasadena, CA: William Carey Library.

Martin, J. N. (1986). Training issues in cross-cultural orientation. International Joumal of Interculural Relarions, 10, 103-116.

Martin, J. N. (1989). Behavioral categories of intercultural communication competence: Everyday communicators' perceptions. International Joumal of Intercultural Relations, 13, 303-332.

Masten, A. G. (1988). Intercultural communications training for the Evangelical Christian missionary abroad. Unpublished master's thesis, University of Virginia.

Mayers, M. K. (1986). Training missionaries for the 21st century. Evangelical Missions Quarterly, 22(3), 306-312.

Mayers, M. K. (1987). Christianity confronts culture: A strategy for crosscultural evangelism. Grand Rapids, MI: Zondervan.

Mayo, G. D., \& DuBois, P. H. (1987). The complete book of training: theory, principles, and techniques. San Diego, CA: University Associates.

McCaffery, J. A. (1986). Independent effectiveness: A reconsideration of crosscultural orientation and training. Intemational Joumal of Intercultural Relations, 10, 159-178.

McNeil, J. D. (1981). Curriculum: A comprehensive introduction. Boston: Little, Brown and Company.

McQuilkin, R. (1994). Six inflammatory questions. Evangelical Missions Quarterly, 30(2), 130-134. 
Mestenhauser, J. A. (1983). Leaming from sojoumers. In D. Landis \& R. W. Brislin (Eds.), Handbook of intercultural training: Vol. 2. Issues in training methodology (pp. 153-185). New York: Pergamon Press.

Millham, D. E. (1988). Short-term mission: A model for mobilizing the church. Fuller Theological Seminary, School of World Mission, DMiss.

Missionary pre-orientation manual. (1987). Foreign Mission Board of the Southern Baptist Convention (FMB).

Missions education: Missions professors talk about trends. (1987). Evangelical Missions Quarterly, 23(2), 178-182.

Moffett, S. H. (1989). Individualism in ascendancy. In W. D. Roberts \& J. A. Siewert (Eds.), Mission handbook: USA/Canada Protestant ministries overseas (14th ed.), (pp. 23-30). Monrovia, CA: MARC, World Vision International.

Moran, R. T., \& Harris, P. R. (1982). The intemational management productivity series: Vol. 2. Managing cultural synergy. Houston: Gulf Publishing.

Moyer, B. (1987). Seventh-day Adventist missions face the 21st century. (Doctoral dissertation, San Francisco Theological Seminary, 1987).

Moyer, K. E. (1957). A study of missionary motivation, training, and withdrawal, 1932-1952. New York: Missionary Research Library.

Muenstermann, H. O. (1973). Missionary preparation and qualification. In E. R. Dayton (Ed.), Mission handbook: North American ministries overseas (10th ed.), (pp. 30-33). Monrovia, CA: MARC, World Vision Intemational.

Mumford, S. J. (1983). The cross-cultural experience: The program manager's perspective. In D. Landis \& R. W. Brislin (Eds.), Handbook for intercultural training: Vol. 2. Issues in training methodology (pp. 83-99). New York: Pergamon Press.

Myers, B. L. (1993). The changing shape of world mission. In J. A. Siewert \& J. A. Kenyon (Eds.), Mission handbook: USA/Canada Christian ministries overseas 1993-95 (15th ed.), (pp. 1-37). Monrovia, CA: MARC, World Vision International.

Myklebust, O. G. (1951). An international instinute of scientific missionary research. (Occasional Paper No. 1). Oslo: Egede-Instituttet. 
Myklebust, O. G. (1955). The study of missions in theological education (vol. 1). Oslo: Forlaget Land Og Kirke.

NCCC (1957). New trends in missionary training in the United States. (1957). New York: Committee on Missionary Personnel of the Division of Foreign Missions, National Council of Churches (NCC).

Naisbitt, J. (1982). Megatrends: Ten new directions transforming our lives. New York: Wamer.

Naisbitt, J., \& Aburdene, P. (1990). Megatrends 2000: Ten new directions for the 1990. New York: William Morrow.

Newman, J. (1985). Is our church putting first things first? Ministry, 58(10), 24.

Nunes, S. A. (1987). Towand a theoretical framework for cross-cultural training programs. (Doctoral dissertation, Florida State University, 1987).

Odiome, G. S. (1980). The effective executive's guide to successful goal setting. A special management report from MBO, Inc.). [Brochure]. Westfield, MS: Management Publishers.

O'Donnell, K. S., \& O'Donnell, M. L. (1988). Helping missionaries grow: Readings in mental health and missions. Pasadena, CA: William Carey Library.

Olebe, M. (1989). Exploring the cross-cultural equivalence of the behavioral assessment scale for intercultural communication. International Joumal of Intercultural Relations, 13, 333-347.

Oosterwal, G. (1972). Mission: Possible: The challenge of mission today. Nashville: Southem Publishing Association.

Oosterwal, G. (1980). The Seventh-day Adventist Church in the world today. In R. E. Firth (Ed.), Servants for Christ: The Adventist Church facing the '80s. Berrien Springs, MI: Andrews University Press.

Oosterwal, G. (1988). Training for missions tomorrow. Unpublished document presented at first meeting of European missiologists held in August, 1988, at Newbold College, England. 
Oosterval, G. (1990). Training for missions tomorrow. In H. I. Dunton, B. E. Pfeiffer, \& B. Schantz (Eds.), Adventist missions facing the 21st century: $A$ reader, (pp. 78-91). Frankfurt am Main, Germany: Peter Lang.

Oosterwal, G. (1993, March 18). Continuing reassessment. Adventist Review, p. 10.

Oosterwal, G., \& Wallace, E. (1972). Student missionary orientation manual. Washington, DC: Youth Department, General Conference of Seventh-day Adventists.

Paige, R. M. (1986a). Trainer competencies: The missing conceptual link in orientation. Intemational Joumal of Insercultural Relations, 10, 135-158.

Paige, R. M., (Ed.), (1986b). Cross-cultural orientation. Lanham, MD: University Press of America.

Paige, R. M. \& Martin, J. N. (1983). Ethical issues and ethics in cross-cultural training. In D. Landis \& R. W. Brislin, Handbook of intercultural training: Vol. 1. Issues in theory and design (pp. 36-60). New York: Pergamon Press.

Palmer, N. N. (1987). Cross-cultural training and orientation for missionaries with special reference to the North American Baptist Conference. Unpublished master's thesis, Nazarene Theological Seminary.

Parshall, P. (1979). God's communicator in the 80's. Evangelical Missions Quarierly, 15(4), 215-221.

Parshall, P. (1987). How spiritual are missionaries? Euangelical Missions Quarterly, 23(1), $10-16$.

Parshall, P. (1994). Missionaries: Safe or expendable? Evangelical Missions Quarterly, 30(2), 162-166.

Pedersen, P. B., \& Brislin, R. W. (Eds.). (1986). A manual of structured experiences for cross-cultural leaming. Yarmouth, ME: Intercultural Press.

Pentecost, E. (1973). Missionary preparation and qualification. In E. R. Dayton (Ed.), Mission handbook: Norn American ministries overseas (10th ed.), (pp. 31-33). Monrovia, CA: MARC, World Vision International.

Pentecost, E. (1986). A new emphasis on partnership. Evangelical Missions Quarterty, 22(3), 314-315. 
Peters, M. (1965). Training missionaries for today's world. Evangelical Missions Quarterly, 1(4), 19-28.

Peters. M. (1990). A functional analysis of the missionary orientation process of the Board of Intemational Ministries of the American Baptist Churches, USA. DMin., Eastem Baptist Theological Seminary, 1990.

Pfeifïer, J. W. (1988). Using lecturettes, theory, and models in hwman resource development. San Diego, CA: University Associates.

Phillips, W. (1985). Your church can train and send missionaries. Evangelical Missions Quarterty, 21(2), 196-201.

Pichard, G. (1993). Making missions more marketable. Evangelical Missions Quarierty, 29(1), 68-70.

Pocock, M. (1985). A recruiter's view of missionary training. Evangelical Missions Quarterly, 21(4), 409-412.

Pont, T. (1991). Developing effective training skills. New York: McGraw-Hill.

Poston, L. (1992). Should the West stop sending missionaries? Evangelical Missions Quarerly, 28(1), 58-62.

Pusch, M. D., Patico, A., Renwick, G. W., \& Saltzman, C. (1981). Cross-cultural training. In G. Althen (Ed.), Leaming across cultures (pp. 72-102).

Washington, DC: NAFSA.

Pusch, M. D., Sulye, H. N., \& Wasilewski, J. H. (1979). Training for multicultural education competencies. In M. Pusch (Ed.), Mulricultural educarion: $A$ crosscultural training approach (pp. 86-103). Chicago: Intercultural Press.

Ratzloff, T. (1986). The Christian and Missionary Alliance (Studies of attrition by four mission agencies). Evangelical Missions Quarterly, 22(2), 125-127.

Recruiting, selection and training of missionaries. (1957). Paper prepared by the Secretary of the Committee on Missionary Personnel of the Division of Foreign Missions, NCC, New York.

Reddy, W. B., \& Henderson, C. C (1987). Training theory and practice. San Diego, CA: University Associates. 
Reed, L. E. (1985). Preparing missionaries for intercultural communication: A bicultural approach. Pasadena, CA: William Carey Library.

Renwick, G. W. Evaluation handbook: For cross-cultural training and multicultural education. LaGrange Park, II: Intercultural Network.

Roberts, W. D., \& Siewert, J. A. (Eds.) (1989). Mission handbook: USA/Canada Protestant ministries overseas (14th ed.). Monrovia, CA: MARC, World Vision International.

Roblyer, K. A. C. (1990). Development of a training program to prepare church workers for cross-cultural ministry (Field project report for DMin.). Colorado Springs, CO: Golden Gate Baptist Theological Seminary.

Ruben, B. D. (1989). The study of cross-cultural competence: Traditions and contemporary issues. Insemational Joumal of Intercultural Relations, 13, 229240.

Ruben, B. D., Askling, L. R., \& Kealey, D. K. (1977). Cross-cultural effectiveness. In D. S. Hoopes, P. B. Pedersen, \& G. W. Renwick (Eds.). Overview of intercultural education, training and research: volume I: Theory (pp. 92-105). Washington, DC: Society for Intercultural Education, Training and Research.

Ruben, B. D., \& Kealey, D. (1979). Behavioral assessment of communication competency and the prediction of cross-cultural adaptation. International Journal of Interculnural Relations, 3, 15-47.

Ryan, M. L. (1992, February 20). Global mission: To every people group. An interview by M. K. Widmer. Adventist Review, pp. 12-14.

Saylor, J. G., Alexander, W. M., \& Lewis, A. J. (1981). Curriculum planning for better teaching and learning (4th ed.) New York: Holt, Rinehart and Winston.

Schantz, B. (1983). The development of Seventh-day Adventist missionary thought: A contemporary apprisal. (Doctoral dissertation, Fuller Theological Seminary, School of World Mission, 1983).

Seventh-day Adventist Yearbook. (1990). Hagerstown, MD: Review and Herald Publishing Association.

Seventh-day Adventist Yearbook. (1992). Hagerstown, MD: Review and Herald Publishing Association. 
Severn, F. M. (1992). The critical context of today's world mission. Evangelical Missions Quarterty, 28(2), 176-179.

Shane, H. G. (1977). Curriculum change: Toward the 21st century. Washington, DC: National Education Association.

Shellrude, B. (1987). Quality control: Four ways to check it. Evangelical Missions Quarterly, 23(4), 372-377.

Siewert, J. A. (1993). Overview of the Mission Agency Survey. In J. A. Siewert \& J. A. Kenyon (Eds.), Mission handbook: USA/Canada Christian ministries overseas 1993-95 (15th ed.), (pp. 55-81). Monrovia, CA: MARC, World Vision International.

Sikkema, M., \& Niyekawa, A. (1987). Design for cross-cultural learning. Yarmouth, MN: Intercultural Press.

Silberman, M. L., \& Auerbach, C. (1990). Active training: A handbook of techniques, designs, case examples, and tips. New York: Lexington Books.

Singer, M. R. (1988). Intercultural communication: A perceptual approach. Englewood Cliffs, NJ: Prentice-Hall.

Smalley, W. A. (1993). Doctoral dissertations on mission: Ten-year update 19821991. Intemarional Bulletin of Missionary Research, 17(3), 97-98.

Smith, D. K. (1992). Creating understanding: A handbook for Christian communication across cultural landscapes. Grand Rapids, MI: Zondervan.

Smith, D. P. (1961). A new approach to missionary orientation. International Review of Missions, 50, 395-408.

Smith, M. A. (1983). Selection and orientation of missionaries for the Navigators. (Unpublished master's thesis, Fuller Theological Seminary, School of World Mission, Pasadena, CA.)

Smith, G. R., \& Otero, G. G. (1977). Teaching about cultural awareness. Denver, CO: Center for teaching international relations, University of Denver. 
Staples, R. L. (1990). Adventist missions facing the third millenium. In H. I. Dunton, B. E. Pfeiffer, \& B. Schantz (Eds.), Adventist missions facing the 21st century: A reader, (pp. 149-163). Frankfurt am Main, Germany: Peter Lang.

Steadham, S. V. (1989). Leaming to select a needs assessment strategy. In F. H. Margolis \& C. R. Beil, Understanding training: Perspectives and practices (pp. 21-33). San Diego, CA: University Associates.

Steffen, T. (1993). Missiological education for the 21st century. Evangelical Missions Quarterly, 29(2), 178-183.

Stowe, D. M. (1980). Mission in the '80s. In E. R. Dayton (Ed.), Mission handbook: North American Protestant ministries overseas, (10th ed.), (pp. 914). Monrovia, CA: MARC, World Vision International.

Sussman, N. M. (1986). Re-entry research and training: Methods and implications. Intemational Journal of Intercultural Relations, 10, 235-254.

Sutlive, V. H., Altshuler, N., Zamora, M. D., \& Kerns, V. (Eds.). (1986). Anthropology and intemational business, Publication no. 28, Studies in Third World Societies. Williamsburg, VA.

Taylor, W. D. (Ed.) (1991). Intemationalising missionary training: A global perspective. Exeter, U.K.: The Patemoster Press. (Grand Rapids: Baker Book House)

Taylor, W. D. (1993). How shall we equip the cross-cultural force? Evangelical Missions Quarterly, 29(3), 242-251.

Technical trainer's source book (1992). San Diego, CA: Pfeiffer.

Thompson, C. K. (1989). Japanese language and culture training for American professionals. (Doctoral dissertation, Arizona State University, 1989).

Thompson, J. G. (1982). Factors related to retention of teaching and missionary personnel in overseas work environments. (Doctoral dissertation, University of Houston, 1982). DAI-A 43/07, p. 2300, January 1983.

Tippett, A. R. (1987). Introduction to missiology. Pasadena, CA: William Carey Library. 
Triandis, H. (1977). Theoretical framework for evaluation of cross-cultural training effectiveness. Intemational Joumal of Intercultural Relations, 1, 19-45.

Vyhmeister, N. J., \& Johnston, M. S. (1984). Go! A student missionary manual. Berrien Springs, MI: Andrews University Press.

Ward, T. (1987). Educational preparation of missionaries-a look ahead. Evangelical Missions Quarterly, 23(4), 398-404.

Weaver, V. P. (1988). Education that is multicultural and global: An imperative for economic and political survival. The Social Studies, $79(3)$, 107-108.

Weeks, W. H., Pedersen, P. B., \& Brislin, R. W. (Eds.). (1975). A manual of structured experiences for cross-cultural learning. LaGrange Park, IL: Intercultural Network. The Society for Intercultural Education, Training and Research.

Widmer, M. K. (1992, February 20). Global mission: To every people group. An interview with M. L. Ryan. Adventist Review, pp. 12-14.

Wight, A. R., \& Boyle, N. E. (1978). Evaluation of intercultural courses and programs. In D. S. Hoopes, P. B. Pedersen, G. W. Renwick (Eds.), Overview of inserculural education, training, and research, Vol. 3: (pp. 1-27). Washington, DC: Society for Intercultural Education, Training, and Research, Georgetown University.

Williams, D. E. (1983). Assessment of cross-cultural adaptability in missionary candidates: Theoretical, biblical, and practical perspectives. Joumal of Psychology and Christianity, 2(4), 18-24.

Williams, K. L. (1973). Characteristics of more successful and less successful missionaries. 73-22, 697).

Wilson, S. (Ed.) (1980). Mission handbook: North American ministries overseas (12th ed.). Monrovia, CA: MARC, World Vision Intemational.

Wilson, S., \& Siewert, J. (1989). Tentmakers today, an update. In W. D. Roberts \& J. A. Siewert (Eds.), Mission handbook: North American ministries overseas, (13th ed.), (pp. 31-32). Monrovia, CA: MARC, World Vision International. 
Wiseman, R. L., Hammer, M. R., \& Nishida, H. (1989). Predictors of intercultural communication competence. International Joumal of Interculnural Relations, 13, 349-370.

Zais, R. S. (1976). Curriculum principles and foundations. New York: Thomas Y. Crowell.

Zemke, R. (1989). Finding out what people need to leam. In F. H. Margolis \& C. R. Beil, Understanding training: Perspectives and practices (pp. 34-42). San Diego, CA: University Associates.

Zemke, R., \& Zemke, S. (1981). 30 things we know for sure about adult leaming. Training/HRD, 115-117.

Zenger, W. F., \& Zenger, S. K. (1982). Curriculum planning: A ten step process. Palo Alto, CA: R \& E Research. 


\title{
VITA
}

\author{
Donna Maurine Monks Worley \\ 8797 College Avenue \\ Berrien Springs, MI 49103 \\ (616) 471-7168 \\ December, 1994
}

Personal

Born on February 7, 1942, in Vancouver, B. C., Canada. Married to Richard H. Worley, and have four daughtersAlicia, Darchelle, Clarissa, and Celina. Spent 13 years in Zambia and Zimbabwe.

Educational

B.A., 1964, from Walla Walla College, with a major in history, minors in sociology and English, and teaching certification.

M.Ed., 1971, from Walla Walla College, with an emphasis in counseling.

Ph.D., 1995, in curriculum, from Andrews University, with a cognate in administration.

Professional

1966-75, part-time teacher at Columbia Adventist Academy, Battle Ground, WA.

1975-80, teacher and head of English Department (1 year) at Rusangu Secondary School, Zambia.

1984-89, Assistant Professor of Education and English, Solusi College, Zimbabwe.

Affiliations National Honor Society, Who's Who in American Colleges and Universities, Phi Kappa Phi, Phi Delta Kappa, Society for Intercuitural Education, Training and Research (SIETAR). 